\title{
ASSESSMENT OF EAGLE FORD SHALE OIL AND GAS RESOURCES
}

\author{
A Dissertation \\ by \\ XINGLAI GONG
}

\begin{abstract}
Submitted to the Office of Graduate Studies of
Texas A\&M University

in partial fulfillment of the requirements for the degree of

DOCTOR OF PHILOSOPHY
\end{abstract}

$\begin{array}{ll}\text { Chair of Committee, } & \begin{array}{l}\text { Duane McVay } \\ \text { John Lee }\end{array} \\ & \begin{array}{l}\text { George Voneiff } \\ \text { Jeffrey Hart }\end{array} \\ \text { Head of Department, } & \text { Daniel Hill }\end{array}$

August 2013

Major Subject: Petroleum Engineering

Copyright 2013 Xinglai Gong 


\begin{abstract}
The Eagle Ford play in south Texas is currently one of the hottest plays in the United States. In 2012, the average Eagle Ford rig count (269 rigs) was $15 \%$ of the total US rig count. Assessment of the oil and gas resources and their associated uncertainties in the early stages is critical for optimal development. The objectives of my research were to develop a probabilistic methodology that can reliably quantify the reserves and resources uncertainties in unconventional oil and gas plays, and to assess Eagle Ford shale oil and gas reserves, contingent resources, and prospective resources.
\end{abstract}

I first developed a Bayesian methodology to generate probabilistic decline curves using Markov Chain Monte Carlo (MCMC) that can quantify the reserves and resources uncertainties in unconventional oil and gas plays. I then divided the Eagle Ford play from the Sligo Shelf Margin to the San Macros Arch into 8 different production regions based on fluid type, performance and geology. I used a combination of the Duong model switching to the Arps model with $b=0.3$ at the minimum decline rate to model the linear flow to boundary-dominated flow behavior often observed in shale plays. Cumulative production after 20 years predicted from Monte Carlo simulation combined with reservoir simulation was used as prior information in the Bayesian decline-curve methodology. Probabilistic type decline curves for oil and gas were then generated for all production regions. The wells were aggregated probabilistically within each production region and arithmetically between production regions. 
The total oil reserves and resources range from a $\mathrm{P}_{90}$ of 5.3 to $\mathrm{P}_{10}$ of 28.7 billion barrels of oil (BBO), with a $\mathrm{P}_{50}$ of $11.7 \mathrm{BBO}$; the total gas reserves and resources range from a $\mathrm{P}_{90}$ of 53.4 to $\mathrm{P}_{10}$ of 313.5 trillion cubic feet (TCF), with a $\mathrm{P}_{50}$ of 121.7 TCF. These reserves and resources estimates are much higher than the U.S. Energy Information Administration's 2011 recoverable resource estimates of 3.35 BBO and 21 TCF. The results of this study provide a critical update on the reserves and resources estimates and their associated uncertainties for the Eagle Ford shale formation of South Texas. 


\section{DEDICATION}

This dissertation is dedicated to the one and only living God, his only son Jesus Christ and the Holy Spirit who saved me from my deadly sins.

This dissertation is also dedicated to my lovely wife, Yihan, my daughter Ruth, my son Austin, my parents Manqi Gong and Yanli Chi. 


\section{ACKNOWLEDGEMENTS}

I would like to thank my committee chair, Dr. McVay, for his continuous guidance, extensive supervision, and generous support during my 4 years of stay at Texas A\&M University, without Dr. McVay, this research simply would not start and could not be finished. I also want to thank my committee members, Dr. Lee, Prof. Voneiff, and Dr. Hart, for their guidance and support throughout the course of this research.

Thanks also go to my friends and colleagues and the department faculty and staff for making my time at Texas A\&M University a great experience and unforgettable memory. Special thanks to Raul Gonzalez, Yao Tian, and Carlos Velasco who worked with me patiently on different topics of the project.

I also want to extend my gratitude to the Crisman Research Institute and its members for the generous support for this research.

Finally, thanks to my lovely wife Yihan for her wonderful support through the entire stay when I was pursuing my $\mathrm{PhD}$ degree, half of the degree and results belong to her. 


\section{TABLE OF CONTENTS}

Page

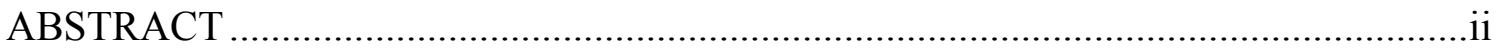

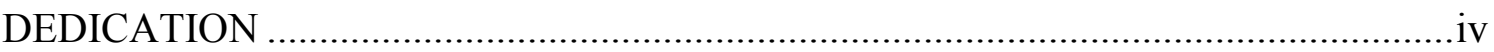

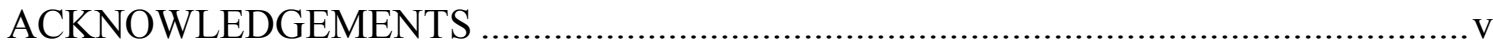

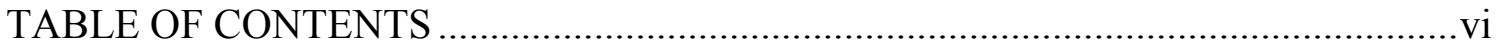

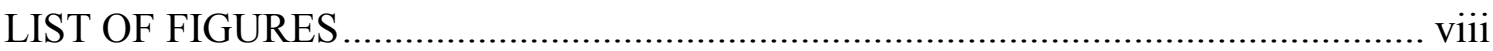

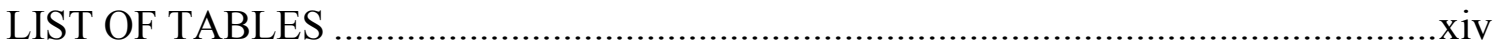

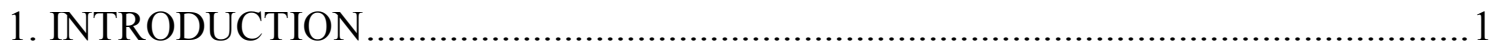

1.1. Introduction of Eagle Ford Shale Play ................................................................ 1

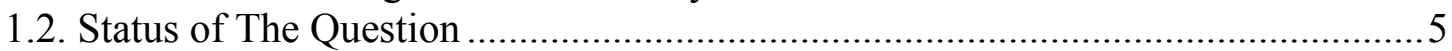

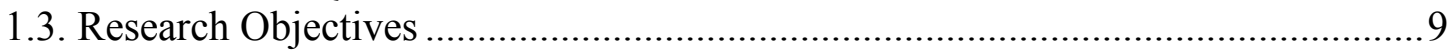

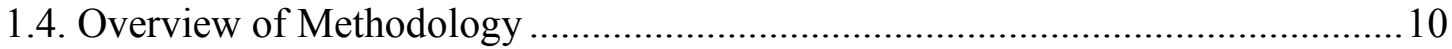

2. BAYESIAN PROBABILISTIC DECLINE CURVE ANALYSIS ..........................11

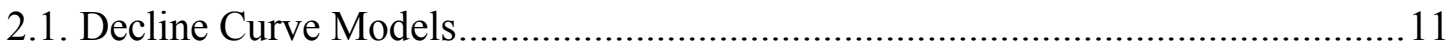

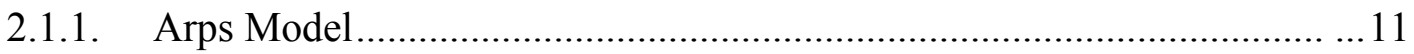

2.1.2. Power-Law Exponential .................................................................... 12

2.1.3. Stretched Exponential Production Decline Model (SEPD)...................... 13

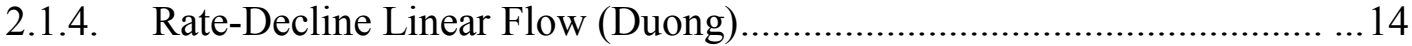

2.2. Previous Probabilistic Methodologies.............................................................. 14

2.3. Introduction to Bayes' Theorem ....................................................................... 15

2.4. Introduction to Markov Chain Monte Carlo (MCMC) ......................................... 17

2.5. Application of MCMC with Arps Model ........................................................ 19

2.6. Case Study: Barnett Shale Hydraulically Fractured Gas Wells ............................24

2.7. Comparison Between MCMC and Modified Bootstrap Method (MBM)............. 38

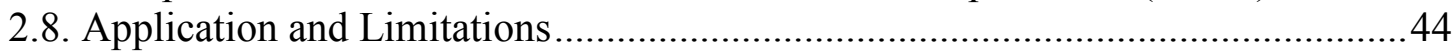

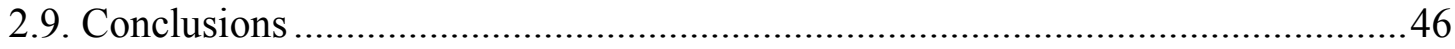

3. ASSESSMENT OF EAGLE FORD SHALE OIL AND GAS RESOURCES ...........47

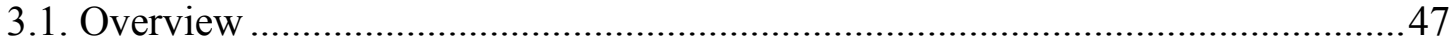

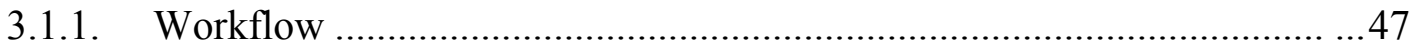

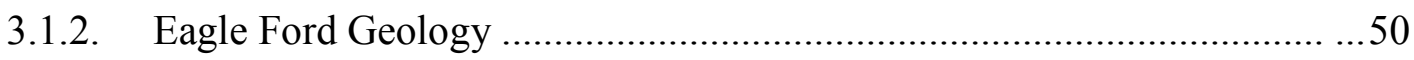


3.1.3. Eagle Ford Drilling and Completion ........................................................53

3.1.4. Reserves, Contingent Resources, and Prospective Resources ...................55

3.2. Data Acquisition......................................................................................56

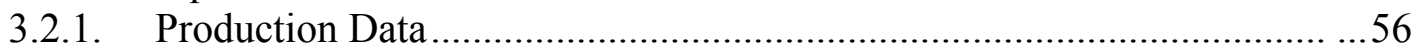

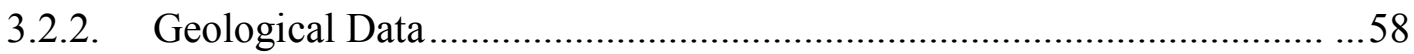

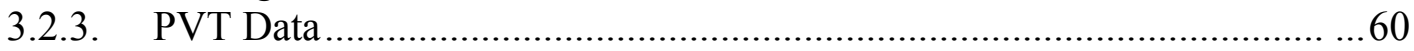

3.3. Partition of Eagle Ford Shale Play into Eight Production Regions .......................60

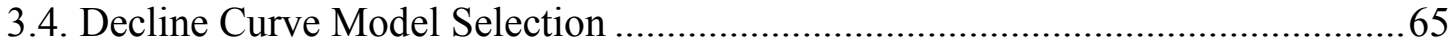

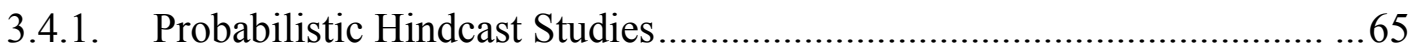

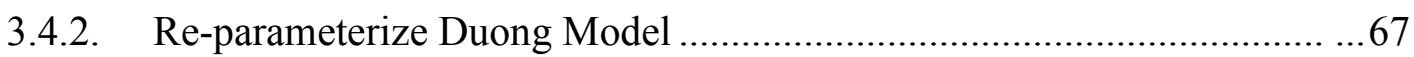

3.5. Integration of Geological and Engineering Data Through Reservoir Simulation.69

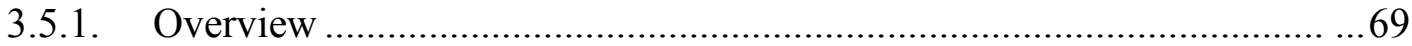

3.5.2. Initialization of Base Case Reservoir Simulation Models ..........................70

3.5.3. Monte Carlo Simulation with Reservoir Simulation..................................... 86

3.6. Generation of Type Probabilistic Decline Curves.................................................91

3.6.1. Estimation of Minimum Decline Rate ……….........................................

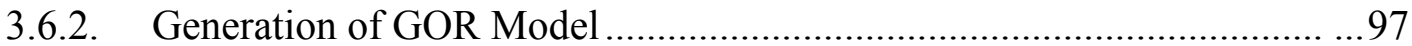

3.6.3. Generation of Type Probabilistic Decline Curves................................... . 103

3.7. Reservoir Area, Well Density and Well Count .................................................... 112

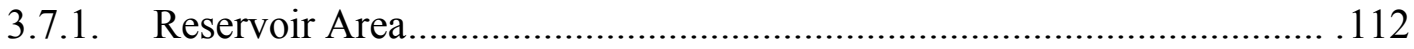

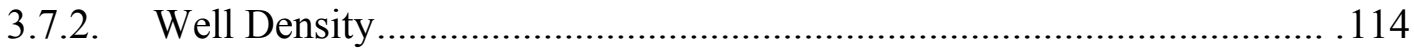

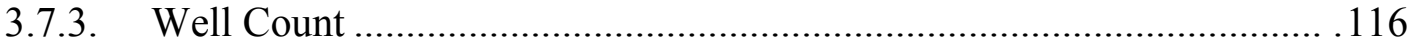

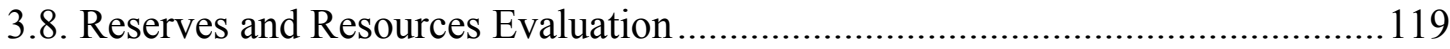

3.8.1. Aggregation within Production Regions ............................................ 119

3.8.2. Reserves and Resources Estimation ..................................................... 121

3.8.3. Comparison with 2011 EIA Estimates ................................................... 131

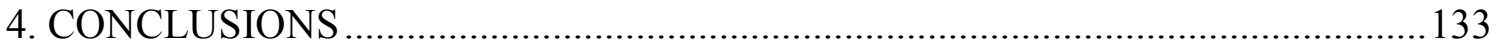

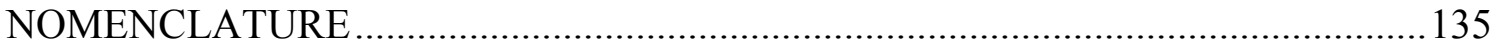

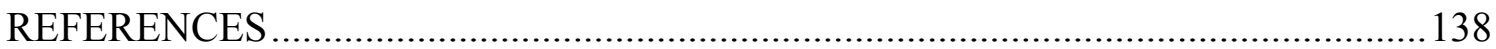




\section{LIST OF FIGURES}

Fig. 1.1- Railroad Commission of Texas (2013) reported Eagle Ford shale average daily oil production increases significantly from 2008 to 2013

Fig. 1.2 - The Eagle Ford play in the U.S. side is bracketed among the U.S. Mexico border, the Sligo Shelf Margin, and the San Macros Arch

Fig. 1.3- Geologic Column of south Texas shows the Eagle Ford formation is in upper Cretaceous age.

Fig. 2.1- The 1000-iteration Markov chain of one of the horizontal gas wells.......23

Fig. 2.2 - Example well. The longest time window (months 32 to 106) without any restimulation was chosen as the interval to be analyzed....................26

Fig. 2.3 - Relative error decreases as the number of MCMC iterations increases ....28

Fig. 2.4- Probabilistic hindcasts averaged over all wells narrow with time in the Barnett well set generated using a non-informative prior distribution.

Fig. 2.5- Probabilistic hindcasts underestimate CPEOH in the Barnett well set generated using a non-informative prior distribution.

Fig. 2.6- Histogram of $b$ values for the 197 wells and triangular distribution fit to the histogram.

Fig. 2.7- $g(t)$ decreases with increasing $t$ so the prior density has less effect when more production data are available for matching.

Fig. 2.8 - Probabilistic hindcasts averaged over all wells generated using an informative prior distribution yield better $\mathrm{P}_{50}$ estimates than the noninformative estimation in the Barnett well set.

Fig. 2.9- Probabilistic hindcasts generated using an informative prior distribution yield better calibrated $\mathrm{P}_{10}, \mathrm{P}_{50}$ and $\mathrm{P}_{90}$ estimates in the Barnett well set.

Fig. 2.10 - Uncertainty in PDTSP (future production) decreases with time and more production. 
Fig. 2.11- Relative uncertainty in PDTSP (future production) decreases slightly with time and more production.

Fig. 2.12 - Well matched production underestimate uncertainty when inherent

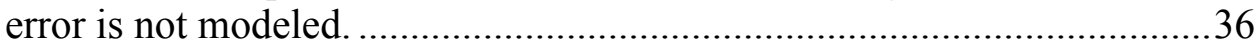

Fig. 2.13 - The range of probabilistic decline curves increases by adding an

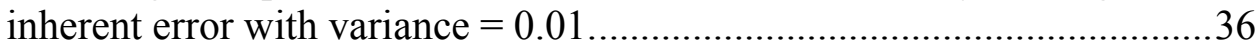

Fig. 2.14- Probabilistic hindcasts generated using an informative prior distribution and inherent error $=0.001$ yield further improved $\mathrm{P}_{10}, \mathrm{P}_{50}$ and $\mathrm{P}_{90}$ estimates in the Barnett well set.

Fig. 2.15- Comparison between probabilistic hindcasts generated using Bayesian and MBM methods for an example well in the Barnett set........40

Fig. 3.1- Workflow of assessment of Eagle Ford shale oil and gas resources, black boxes represent input data, blue boxes represent intermediate steps, and red boxes represent results

Fig. 3.2 - Peak month oil and peak month gas in black oil window is highly correlated, with $\mathrm{R}^{2}=0.53$

Fig. 3.3- The Eagle Ford play located in south Texas covers petroleum fluid types from black oil to condensate to dry gas (EIA 2010)

Fig. 3.4 Geology column and type log: (a) The Eagle Ford formation is in Turonian to Cenomian stage in Cretaceous (Edman and Pitman 2010). (b) Typical well log in Maverick County, Texas, USA shows different log characteristics for upper and lower Eagle Ford (Tian et al. 2013)

Fig. 3.5- Structural top of Eagle Ford deepens from northwest to southeast (Tian et al. 2013).

Fig. 3.6- Flow chart and generalized division of resource and reserve categories, from PRMS (SPE et al. 2007)

Fig. 3.7- An example well with increasing monthly production that was excluded from the study.....

Fig. 3.8 - An example well in which only the higher production period was analyzed and an outlier was excluded. 
Fig. 3.9- Gridblocks of $1000 \mathrm{ft}$ by $1000 \mathrm{ft}$ used to calculate distributions of reservoir properties.

Fig. 3.10 - Histogram of the top of the Eagle Ford formation ..................................59

Fig. 3.11- Fluid type changes from black oil to dry gas from north to south.............62

Fig. 3.12- Second-month oil production was used as the production indicator and it decreases from east to west..............................................................63

Fig. 3.13 - Upper Eagle Ford formation is only present in west and middle part of the Eagle Ford play...............................................................................63

Fig. 3.14- Areas that have depth below $3000 \mathrm{ft}$ were excluded from the study inside of Production Region 1 (PR1).

Fig. 3.15- Areas in the northwest corner of PR1 is excluded from the study because the depth is below $3000 \mathrm{ft}$.........................................................64

Fig. 3.16 - Production hindcasts show that the Arps model and the Duong model have the best coverage rate for oil production of condensate region PR2 (a), black oil region PR3 (b), and volatile oil region PR6(c), and gas production of dry gas region PR8 (d)

Fig. 3.17- Geometry for base case reservoir model for all production regions...........71

Fig. 3.18 - Fracture permeability decreases logarithmically from perforation to the boundary of reservoir in the fracture plane.

Fig. 3.19- Type log of production region 3 (PR3) that was used to build the static base case reservoir model.

Fig. 3.20 - Type logs for production regions 1 (a) to 8 (h) ……….............................75

Fig. 3.21- Comparison between EOS generated PVT curves and lab measurements from a full PVT report in PR4 (green: oil properties, red: gas properties): (a) to (d) constant composition expansion experiment and (e) to (f) constant volume depletion. (a) relative volume, (b) condensed liquid volume, (c) gas z factor, (d) gas density, (e) gas compressibility factor, (f) liquid volume

Fig. 3.22 - Pressure-dependent permeability for fracture, calcite-rich, and organic-rich rocks, from Honarpour et al. (2012).

Fig. 3.23 - Vertical lift curve from Prosper shows a typical PR3 well has a BHP of 1500 psi when producing at $300 \mathrm{STB} /$ Day 
Fig. 3.24- After changing the permeability, the base case simulated production for PR3 is closer to the average observed oil production compared with the simulated oil production using default parameters

Fig. 3.25 - The GOR of the base case model is close to the average GOR of PR3 but not exact.

Fig. 3.26- Comparison between base case simulated oil production and average oil production for PR1 to PR7 (a) to (g), and base case simulated gas production and average gas production for PR8 $(\mathrm{h})$

Fig. 3.27- The simulated 20-year cumulative oil production of PR1 to PR7 (a) to (g) and cumulative gas production of PR8 (h) follow lognormal distributions

Fig. 3.28 - An example well that has already reached dominated boundary flow because of the unit slope in the last $1 / 3 \log$ cycle.

Fig. 3.29- Distribution of minimum decline rate $\left(D_{\min }\right)$ : (a) for boundarydominated flow (BDF) wells, (b) distribution of decline rate at end of history for non-BDF wells, and (c) the combined distribution for $D_{\min }$ (oil)

Fig. 3.30 - Distribution of minimum decline rate $\left(D_{\min }\right)$ for: (a) boundarydominated flow (BDF) wells, (b) distribution of decline rate at end of history for non-BDF wells, and (c) the combined distribution for $D_{\min }$ (gas)

Fig. 3.31 - For oil production, both (a) minimum decline rate $\left(D_{\min }\right)$ and (b) the standard deviation of minimum decline rate $\left(D_{\min }\right)$ increase when decline curve parameter $l$ increases. For (c) gas production, $D_{\min }$ increases when $l$ increases

Fig. 3.32 - The time to reach boundary-dominated flow ranges from 17 months to 50 months with an average of 24 months.

Fig. 3.33 - Average GOR curves sharing the same fluid type have similar shapes ....99

Fig. 3.34- Average GOR and the straight line GOR models for (a) black oil, (b) volatile oil, and (c) condensate fluid types

Fig. 3.35- Initial GOR is not correlated to $\mathrm{N}_{240}$ of (a) black oil and (b) volatile regions, but correlated to $\mathrm{N}_{240}$ of (c) condensate regions 
Fig. 3.36- Standard deviation of $\ln$ (initial GOR) decreases when $\mathrm{N}_{240}$ increases for all three fluid types: (a) black oil, (b) volatile oil, and (c) condensate.

Fig. 3.37- Likelihood (production data) dominated the posterior distribution of a particular well in PR5 (a), while both prior and likelihood contribute to the posterior distribution of the type well of PR5

Fig. 3.38 - Both oil (a) and gas (b) TRR20 follow lognormal distribution of PR5 ... 105

Fig. 3.39- Both (a) prior type curves (generated from reservoir simulation) and (b) posterior type curves bracket the real oil production of PR5. The posterior type curves follow the curvature of the production data much better than the prior type curves.......................................................106

Fig. 3.40 - Probabilistic type curves for oil production of (a) PR1 to (g) PR7 .........107

Fig. 3.41- Probabilistic type curves for gas production of (a) PR1 to (h) PR8 ........108

Fig. 3.42 - Variogram analysis: (a) the distribution of peak month oil, and (b) the variogram of the peak month oil show that the peak oil productions of two wells are correlated when the distance between the two wells is less than 1.5 miles

Fig. 3.43 - Blue circles were drawn around the producing wells with a radius of 1.5 miles; the blue colored area is considered as discovered area while the blank area is considered undiscovered area

Fig. 3.44- The highest established well density (HEWD) for all 8 production regions

Fig. 3.45- Average minimum decline rate increases when number of wells per section increases with a weak correlation.

Fig. 3.46- Geometry drilling efficiency equals 0.75 when the lease line and well has a 45 degree angle

Fig. 3.47- Triangular distribution for variance of summation of reserves/resources.

Fig. 3.48 - The distribution of the future drilling rate varies from half of the 2012 drilling rate to twice of the 2012 drilling rate 
Fig. 3.49 - Distribution of well density, which has HEWD as $\mathrm{P}_{50}, \mathrm{HEWD} / 2$ as the minimum and 22 (twice as the highest HEWD 11 in PR2 and PR5) as the maximum.

Fig. 3.50- Existing oil reserves follow a Laplace distribution, which is closer to normal distribution compared with lognormal distribution....

Fig. 3.51- Existing gas reserves follow a Laplace distribution, which is closer to normal distribution compared with lognormal distribution.....

Fig. 3.52 - Undeveloped oil reserves follow a Logistic distribution, which is closer to normal distribution compared with lognormal distribution ......126

Fig. 3.53 - Undeveloped gas reserves follow a Logistic distribution, which is closer to normal distribution compared with lognormal distribution

Fig. 3.54- The best well known distribution fit for contingent oil resources is Weibull distribution, which is closer to lognormal distribution compared with normal distribution.

Fig. 3.55- The best well known distribution fit for contingent gas resources is Weibull distribution, which is closer to lognormal distribution compared with normal distribution.

Fig. 3.56- The best well known distribution fit for prospective oil resources is Inverse Gauss distribution, which is closer to lognormal distribution compared with normal distribution

Fig. 3.57- The best well known distribution fit for prospective gas resources is Inverse Gauss distribution, which is closer to lognormal distribution compared with normal distribution 


\section{LIST OF TABLES}

Page

Table 2.1 - Relative Error as a Function of MCMC Iterations

Table 2.2- Calculated Decline Parameters and PDTSP Estimates for the Example Barnett Well

Table 2.3- Results of Comparison Between MBM and Bayesian Methods for 197 Wells Using 50 Percent of Known History to Hindcast

Table 2.4- Results of Comparison Between MBM and Bayesian Methods for 197 Wells Using 6 Months to Hindcast

Table 3.1 - Fluid Type Definition Based on Initial GOR

Table 3.2 - Characteristics of Eight Production Regions

Table 3.3 - Counts and Locations of PVT Reports

Table 3.4- Probabilistic Hindcast Studies Show that the Arps Model and the Duong Model Have the Best Coverage Rates

Table 3.5 - Geometry of Reservoir Simulation Base Case Models ...........................72

Table 3.6 - Original Layering and Reservoir Properties from Yao Tian (PR3).......... 74

Table 3.7 — Layering and Reservoir Properties for 11 Layers (PR3) ......................... 74

Table 3.8 - Averaged Reservoir Properties for Upper and Lower Eagle Ford (PR3)......

Table 3.9 - Layering, Perforation, and Reservoir Properties for Base Case Models ... 76

Table 3.10 - Summary of Fluid Properties Used to Calculate Black-oil Correlation for PVT Behavior

Table 3.11 - Summary of Composition and C7+ Properties for Base Case Models......79

Table 3.12- Corey's Exponent Correlations to Calculate Relative Permeability, from Honarpour et al. (2012).....

Table 3.13 - Initial Reservoir Pressure at Perforations for Base Case Models, psia......81 
Table 3.14 - Summary of Matrix and Fracture Permeability and PressureDependent Permeability Curves for Hydraulic Fracture

Table 3.15- Distributions of Reservoir Properties For Monte Carlo Simulation with Reservoir Simulation....

Table 3.16 - Percentiles of Global Parameters for All Production Regions 87

Table 3.17- Percentiles of Organic-Rich Matrix Permeability, nd .87

Table 3.18 - Percentiles of Maximum Fracture Permeability, md .88

Table 3.19 - Percentiles of Thickness of Upper Eagle Ford, $\mathrm{ft}$ .88

Table 3.20 - Percentiles of Thickness of Lower Eagle Ford, $\mathrm{ft}$ .88

Table 3.21 - Percentiles of the Initial Reservoir Pressure, psi .89

Table 3.22 - Percentiles of Bubble Point Pressure for Black Oil Regions, psi 89

Table 3.23 - Percentiles of Composition of $\mathrm{C} 7+$ for Condensate, Volatile-Oil Regions, \%

Table 3.24- Median and Standard Deviation of Lognormal Distributions of $\mathrm{N}_{240}$ and $\mathrm{G}_{240}$

Table 3.25- Recovery Factors of Oil for PR1 to PR7, Gas for PR8, \%

Table 3.26- GOR Slopes for Three Fluid Types 100

Table 3.27- Parameters of Type Probabilistic Decline Curves (Oil) 109

Table 3.28 - Parameters of Type Probabilistic Decline Curves (Gas) 110

Table 3.29 - Summary of TRR20 Oil and Gas for All Production Regions

Table 3.30 - HEWD for All Eight Production Regions

Table 3.31- Summary of $\mathrm{P}_{50}$ Well Count for Reserves and Resources 118

Table 3.32 - Summary of Existing Reserves by PR 123

Table 3.33 - Summary of Undeveloped Reserves by PR 124

Table 3.34- Summary of Contingent Resources by PR 124

Table 3.35- Summary of Prospective Resources by PR 125 
Table 3.36 - Reserves and Resources of the Eagle Ford Play

Table 3.37- Sensitivity of HEWD on Prospective Gas Resources (TCF).................. 131

Table 3.38 - Average EUR and Areas of the Eagle Ford Play (EIA 2011) ..................132

Table 3.39- Comparison between EIA Estimates (2011) and My Estimates..............132 


\section{INTRODUCTION}

\subsection{Introduction of Eagle Ford Shale Play}

U.S. oil production grew more in 2012 than any other year in the history of the domestic oil industry. Daily crude output averaged 6.474 million barrels of oil per day (BOPD) in 2012, up a record 826,000 BOPD from 2011 (Bird 2013). Within the 826,000 BOPD, more than a quarter of it comes from the Eagle Ford shale oil production, increasing by 252,698 BOPD, from 128,619 BOPD in 2011 to 381,317 BOPD in 2012 (Fig. 1.1). The drilling activities in the Eagle Ford shale were as exciting as the production increase. During 2012, the average rig count in the Eagle Ford was 269, compared with 1,809 in the United States and 3,461 in the world.

Geographically, the Eagle Ford play is 50 miles wide and 400 miles long, and covers 23 counties in South-Central Texas. The Eagle Ford play is bracketed among the U.S. Mexico border, the Sligo Shelf Margin, and the San Macros Arch (Fig. 1.2).

Geologically, the Eagle Ford shale consists of Cretaceous sediments that are the source rock for the Austin Chalk formation (Fig. 1.3). Depth of the Eagle Ford formation ranges from 2,500 to 14,000 ft, while the thickness ranges from 120 to $350 \mathrm{ft}$. The Eagle Ford shale has high carbonate content and low clay content, which makes it more brittle and easier to stimulate through hydraulically fracturing compared with other shale plays (Pope et al. 2012). The Eagle Ford shale has been developed play wide since 2008 using horizontal wells with multi-stage hydraulic-fracture treatments. The hydrocarbons being 
produced from the Eagle Ford range from dry gas to gas condensate to volatile oil to black oil.

It is critical to evaluate the reserves and resources early for optimal development. McKinney et al. (2002) stated that suboptimal development plans can result in potential losses of 50\% in the asset value. However, the permeability in the Eagle Ford shale is normally tens or hundreds nanodarcies and yields long transient-flow periods, which complicate production forecasting and reserves estimation. In addition to the extremely low matrix permeability, there are other challenges associated with forecasting production and estimating reserves from hydraulically fractured horizontal wells in shale gas reservoirs. First, multistage fracture treatments in shale reservoirs do not create conventional single bi-wing planar cracks; instead, they create a complex fracture network that exhibits long and wide fracture fairways. Second, there are also natural fractures in shale, which can play an important role in formation of hydraulic fracture geometry and depletion of the reservoirs. Third, adsorbed gas contributes a significant fraction of total original gas in place (Tian et al. 2013); however, the impact on EUR and production is not well understood. Fourth, the history of drilling horizontal wells in the Eagle Ford shale is relatively short, with first production from these wells in 2008. Therefore, long-term production performance and decline characteristics are not clear for hydraulically fractured horizontal wells in this shale reservoir. As a result, there are significant uncertainties associated with the Eagle Ford shale reserve and resource estimation that need to be reliably quantified. 


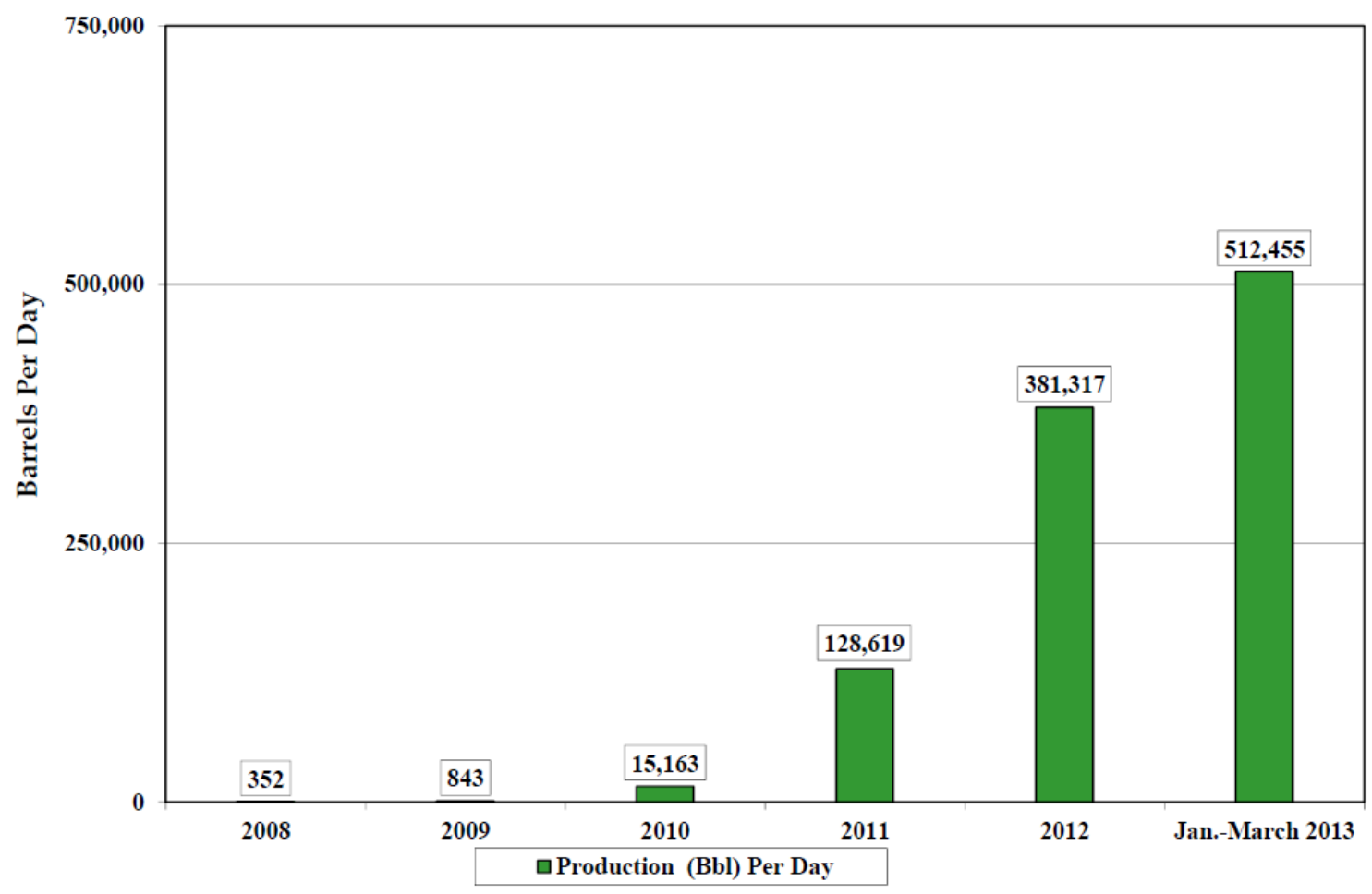

Fig. 1.1 - Railroad Commission of Texas (2013) reported Eagle Ford shale average daily oil production increases significantly from 2008 to 2013 


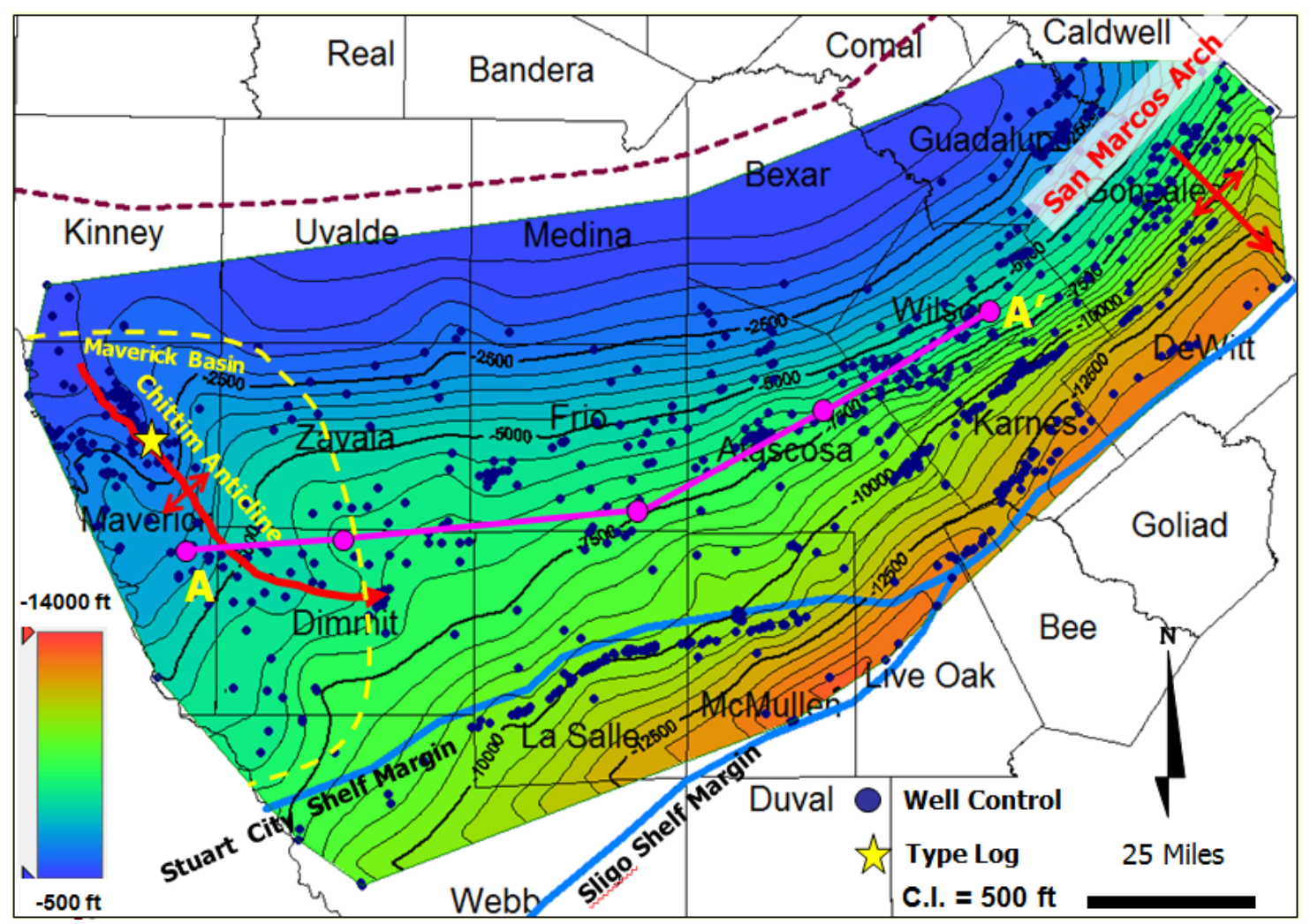

Fig. 1.2 - The Eagle Ford play in the U.S. side is bracketed among the U.S. Mexico border, the Sligo Shelf Margin, and the San Macros Arch 


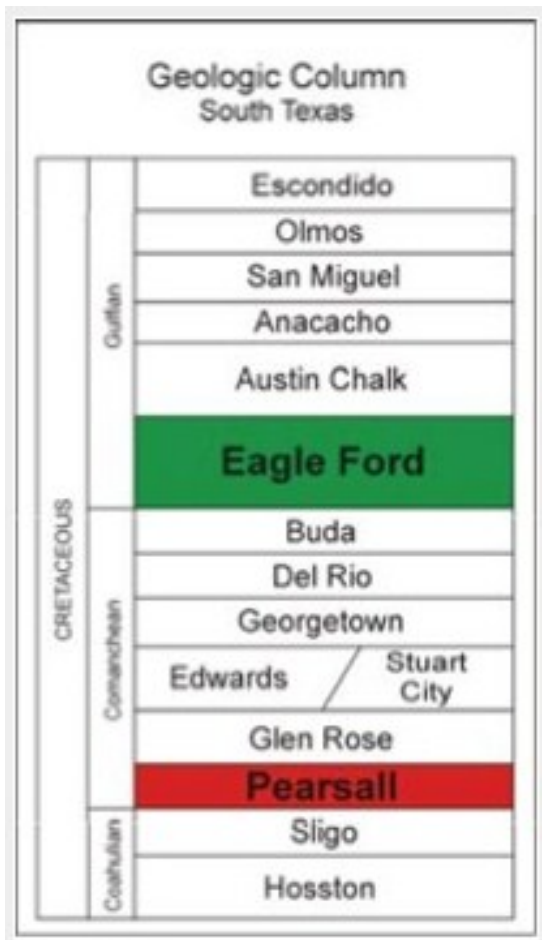

Fig. 1.3 - Geologic Column of south Texas shows the Eagle Ford formation is in upper Cretaceous age

\subsection{Status of The Question}

EIA (2011) estimated the resources of the Eagle Ford shale to be 21 TCF of gas and 3.35 BBO (billion barrels of oil). In Dong et al.'s (2013) estimation, the technically recoverable resources in the dry-gas window range from $\mathrm{P}_{90}$ of 20 TCF to $\mathrm{P}_{10}$ of 182 TCF, with a $\mathrm{P}_{50}$ of 82 TCF of gas. Although I cannot conclude which estimates are the most accurate, I can conclude that there is significant uncertainty associated with the estimation of Eagle Ford resources. McVay and Dossary (2012) stated that typical overconfidence $(50 \%)$ and moderate amounts of optimism $(50 \%)$ can result in an expected disappointment of $30-35 \%$. As a result, it is critical to reliably quantify the 
reserve and resource uncertainties in large unconventional plays like the Eagle Ford shale.

Lee and Sidle (2011) listed the most common methods to estimate reserves in unconventional plays and their associated strengths and limitations. Reservoir-simulation, type-curve, and decline-curve analyses are considered the most useful methods in estimating reserves.

Since 2008, several reservoir simulation studies of the Eagle Ford shale have been published (Bazan et al. 2010; Honarpour et al. 2012). Within these studies, sensitivity analyses have been performed to identify the most influential reservoir properties for oil and gas production. However, the production forecasts were only compared with production of a couple of individual wells but not with the production of all the wells, so the results cannot be used to evaluate field-level reserves. Fan et al. (2011) performed an extensive production data analysis that covers the oil, condensate, and gas windows. However, their production analysis only includes performance indicators, such as best month or best 3 consecutive months, and does not include long-term forecasts. Dong et al. (2013) performed Monte Carlo simulation with reservoir simulation to forecast production and also to quantify reserves uncertainty. However, their work was constrained within the dry gas window. 
Arps' (1945) decline curve is one of the most dominant methods for reserves and resources assessment in unconventional reservoirs such as Eagle Ford shale. However, because of the low permeability and long-term transient flow, production data from hydraulically fractured horizontal wells in shale oil and gas reservoirs often exhibit Arps decline model exponents, $b$, significantly greater than one, indicating transient flow, to which conventional decline curve analysis does not apply without modification. Due to the combination of long transient-flow periods and relatively short production histories, only a small fraction of the hydraulically fractured horizontal shale oil and gas wells have reached a boundary-dominated flow regime for which the Arps decline model is appropriate and from which a reliable production forecast can be obtained.

Several new decline curve models have been developed to estimate reserves in unconventional reservoirs. Ilk et al. (2008) first introduced the power-law decline curve to model the decrease in the decline exponent $b$ with time. However, the model has an extra parameter, and the solution is often non-unique. Valko and Lee (2010) introduced the stretched-exponential-production-decline (SEPD) model that changes from transient flow to boundary-dominated flow smoothly. This model has been adapted to estimate reserves and resources, but it can often underestimate the reserves with limited production data. Duong (2011) developed a model based on linear flow, which is widely observed in unconventional reservoirs. However, since the Duong model assumes linear flow for the entire production period, it can often overestimate reserves. No conclusion 
has yet been reached on which decline curve method works best for shale oil and gas production.

All these factors result in considerable uncertainty in production forecasts and reserves estimation in shale gas reservoirs.

Unfortunately, industry applications of decline curve analysis in shale-gas reservoirs are predominately deterministic. Thus, there is a heated debate between those who believe high $b$ values, relatively steep early declines and flat later declines better predict shale gas well performance and those who believe low $b$ values, less steep early declines followed by less flat later declines better predict performance. Because the difference in reserves estimates can be quite large and the potential impacts on energy policy and capital investment (e.g., in power generation) profound, the debate has reached the mainstream financial press (Dizard 2010).

Jochen and Spivey (1996) and Cheng et al. (2010) developed bootstrap methods that can generate probabilistic decline-curve forecasts and quantify reserves uncertainty for single wells based on existing production. Based on a data set including 100 conventional oil and gas wells, the $\mathrm{P}_{90}-\mathrm{P}_{10}$ range for reserves from Jochen and Spivey's method covered less than $40 \%$ of the "true reserves." Cheng et al.'s method (modified bootstrap) covered $80 \%$ of the true reserves, indicating the method is well calibrated probabilistically for that data set. Both bootstrap methods modify the historical production in some way to generate different realizations for decline curves to match. 
However, modifying the original data is not ideal if it can be avoided. While the modified bootstrap method is well calibrated, it takes 3-5 minutes to calculate the probabilistic reserves for each well. In addition, no commercial software package has incorporated these bootstrap methods to calculate probabilistic reserves. Because of these limitations, the bootstrap methods have not been used extensively in the industry despite the significant uncertainty associated with reserves estimation in shale plays.

The recent published Guidelines for Application of the Petroleum Resources Management System (PRMS) (SPE/AAPG/WPC/SPEE/SEG 2011) and Modernization of Oil and Gas Reporting by the U.S. Securities and Exchange Commission (SEC 2009) have both allowed using probabilistic methodologies to estimate reserves and resources. However, the PRMS guidelines point out that probabilistic methods can be computationally intensive, non-reproducible, and subjective. As a result, deterministic methods are still the predominant methods in reserves estimation even though they lack the ability to quantify the significant uncertainty within the reserves estimation process.

\subsection{Research Objectives}

There are two research objectives for this study:

- Develop a probabilistic methodology that can reliably quantify the reserves uncertainty in unconventional oil and gas plays

- Evaluate U.S. Eagle Ford shale oil and gas reserves, contingent resources and prospective resources 


\subsection{Overview of Methodology}

I first developed an integrated Bayesian probabilistic methodology using Markov Chain Monte Carlo (MCMC) combined with probabilistic decline curve analysis that can reliably quantify the oil and gas reserve and resource uncertainties in unconventional plays. Secondly, I integrated the available production data, engineering data, and geological data using this Bayesian methodology to estimate the oil and gas reserves, as well as contingent and prospective resources of Eagle Ford based on rigorous statistics and engineering principles. 


\section{BAYESIAN PROBABILISTIC DECLINE CURVE ANALYSIS}

In this section, I developed a probabilistic decline curve analysis based on Bayesian framework that can reliably quantify the reserves uncertainty and is rapid, reproducible and objective. I will first give a brief introduction of the existing decline curve models and probabilistic decline curve methods. Then I will introduce the Bayes' theorem and Markov Chain Monte Carlo (MCMC), following with the application of MCMC with Arps Model, a case study of Barnett shale gas wells, comparison between MCMC and MBM, applications and limitations, and conclusions.

\subsection{Decline Curve Models}

\subsubsection{Arps Model}

Arps' decline curve models (Eq. 2.3) have been used for reserves estimation for more than 60 years (Arps 1945). Arps (1945) developed exponential and hyperbolic decline curve models based on constant loss-ratio $(D)$ and decline exponent $(b)$, where $D$ and $b$ are defined in Eq. 2.1 and Eq. 2.2 respectively.

$$
\begin{aligned}
& D=-\frac{d q / d t}{q} \\
& b=\frac{d}{d t}\left(-\frac{1}{D}\right)
\end{aligned}
$$

\footnotetext{
*Part of this chapter is reprinted with permission from Gong, X., Gonzalez, R., Mcvay, D. et al. 2011. Bayesian Probabilistic Decline Curve Analysis Quantifies Shale Gas Reserves Uncertainty. Paper presented at the Canadian Unconventional Resources Conference, Alberta, Canada. SPE 147588. DOI: 10.2118/147588-ms. Copyright [2011] by Society of Petroleum Engineers
} 
By integrating Eq. 2.1 and Eq. 2.2, the Arps model is shown in Eq. 2.3

$$
q(t)=\left\{\begin{array}{cc}
q_{i}\left(1+b D_{i} t\right)^{-\frac{1}{b}}, & (\text { Hyperbolic }) \\
q_{i} \exp \left(-D_{i} t\right), & (\text { Exponential })
\end{array}\right.
$$

Where $q_{i}$ is the initial production rate, $D_{i}$ is the initial loss-ratio, $b$ is the decline component and $t$ is time.

Arps' decline curve models assume the producing well is in boundary-dominated flow and the decline exponent $b$ is between 0 and 1 . In shale gas plays, the flow regime is usually transient flow, not boundary-dominated flow, and the $b$ value is often greater than 1. It was demonstrated by Valko and Lee (2010) that $b$ factors greater than 1 yield to infinite cumulative production as time goes to infinity. Even though the assumptions of Arps' decline curves are usually violated in shale plays, it is still one of the most popular methods for estimating reserves.

\subsubsection{Power-Law Exponential}

The power-law exponential model (Ilk et al. 2008) was the first model designed to improve from Arps' model to match production data from unconventional wells. The motivation is that the authors observed that neither the loss-ratio $(D)$ nor the decline exponent $(b)$ is constant for production data of unconventional wells. The power-law exponential model is defined in Eq. 2.4,

$$
q(t)=q_{i} \exp \left(-D_{\infty} t-D_{1} t^{n}\right)
$$

Where $q_{i}$ is the initial production rate, $D_{l}$ is the initial loss-ratio, $D_{\infty}$ is the loss-ratio at infinity, and $n$ is the decline exponent. 
Matter (2008) stated that there are no unique matches for $D_{\infty}$ when they analyzed gas production from Barnett shale. As a result, $D_{\infty}$ need to be predefined from other sources rather than the production data themselves.

\subsubsection{Stretched Exponential Production Decline Model (SEPD)}

Valko and Lee (2010) introduced the stretched exponential production decline model (SEPD). The two distinguish advantages of using SEPD are: First, the cumulative production for SEPD does not go to infinity while the Arps model with $\mathrm{b}$ greater than one does. Second, the SEPD model has an inflection point from concave up to concave down on log-log scale with only three parameters. The SEPD model is defined in Eq. 2.5

$q(t)=q_{i} \exp \left(-\left(\frac{t}{\tau}\right)^{n}\right)$

Where $q_{i}$ is the initial production rate, $\tau$ is the characteristic time parameter, and $n$ is the decline exponent.

One interesting observation is that if I eliminate the $D_{\infty}$ from the power-law model and rearrange Eq. 2.5, the power-law model and the SEPD model are equivalent. 


\subsubsection{Rate-Decline Linear Flow (Duong)}

Duong (2011) developed a new model specifically for hydraulically fractured horizontal wells derived from linear flow (Eq. 2.6). Under linear flow, $q / G_{p}$ vs. time is a straight line with slope $m$ and intercept $a$.

$\frac{\mathrm{q}}{\mathrm{G}_{\mathrm{p}}}=a t^{-m}$

The rate time relationship can be integrated from Eq. 2.6 and listed as Eq. 2.7.

$\mathrm{q}(\mathrm{t})=q_{i} t^{-m} \exp \left(\frac{a}{1-m}\left(t^{1-m}-1\right)\right)$

\subsection{Previous Probabilistic Methodologies}

Capen (1976) demonstrated that the oil industry has a tendency to underestimate uncertainty. Deterministic methods have been the predominant ways to estimate reserves in the past. Since the publication of Petroleum Resources Management System (SPE et al. 2007) and Modernization of Oil and Gas Reporting (SEC 2009) that allows probabilistic methods to report reserves, more and more companies start to book reserves through probabilistic methods. Anderson et al. (2010) and Abdulal et al. (2011) published type probabilistic decline curves for different field. However, their type probabilistic decline curves are based on predefined distributions of reservoir properties but the associated uncertainty is not quantified. Jochen and Spivey (1996) and Cheng et al. (2010) developed bootstrap methods that can generate probabilistic production forecasts and quantify reserves uncertainty for single wells based on decline curve analysis of existing production. Both bootstrap methods modify the historical production 
in some way to generate different realizations to match; modifying the original data is not ideal if it can be avoided. For a data set including 100 conventional oil and gas wells, the $\mathrm{P}_{90}-\mathrm{P}_{10}$ range for the incremental production of second half from Jochen and Spivey's method covered less than $40 \%$ of the true incremental production while Cheng et al.'s modified bootstrap method covered $80 \%$ of the true incremental production, which is expected if the method is well calibrated probabilistically. While the modified bootstrap method is better calibrated, it takes $3-5$ minutes to calculate probabilistic production forecasts for each well. The excessive time is required because the modified bootstrap method requires 360 least-squares fits for each well, while each least-square fit involves multiple Newton iterations. In addition, I am not aware of any commercial software packages that have incorporated bootstrap methods to calculate probabilistic reserves. Probabilistic decline curve analysis has not been used extensively in the industry despite the significant uncertainty associated with reserves forecasting in shale plays.

\subsection{Introduction to Bayes' Theorem}

The Bayes' theorem used in statistical modeling is

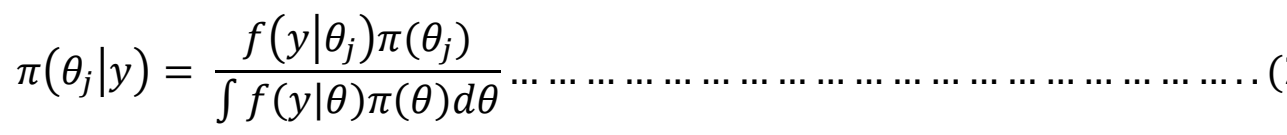

In this work, $\theta_{j}$ is a candidate for decline curve parameters, $\left(\ln \left(q_{i}\right), \ln \left(D_{i}\right) \text {, and } b\right)_{\mathrm{j}}$, and $y$ are the historical production data. 
There are three important components in Bayes' theorem: the prior distribution of parameters $\pi(\theta)$, the likelihood function $f(y \mid \theta)$, and the posterior distribution $\pi(\theta \mid y)$. The prior distribution $\pi(\theta)$ is the probability distribution of parameters before any data have been observed. For example, a uniform distribution of $0 \leq b \leq 2$ is a possible prior distribution for $b$. The likelihood function $f(y \mid \theta)$ is the probability density function of $y$ assuming $\theta$ is the true parameter. For example, if I assume the error between $\ln$ (actual production data) and $\ln$ (calculated production data from the decline curve model), $\varepsilon$, follows the normal distribution $N(0,1)$, then $f(y \mid \theta)=\frac{1}{\sqrt{2 \pi}} \exp \left(-\frac{\varepsilon^{2}}{2}\right)$. The posterior distribution $\pi(\theta \mid y)$ is the distribution of the unknown parameters after all the observed data have been considered. The posterior distribution can be calculated using Bayes' theorem, Eq. 2. Once the posterior distribution is identified, the distribution of a function of the decline curve parameters (e.g., reserves) can be calculated, along with percentiles of the distribution, e.g., $\mathrm{P}_{90}, \mathrm{P}_{50}$, and $\mathrm{P}_{10}$.

The objective of a Bayesian study is to obtain the posterior distribution. However, it can be difficult to directly calculate the posterior distribution because the integral $\int f(y \mid \theta) \pi(\theta) d \theta$ in the denominator often cannot be determined analytically. MCMC simulation is a method to deal with the problem. 


\subsection{Introduction to Markov Chain Monte Carlo (MCMC)}

Markov Chain Monte Carlo (MCMC) methods are a class of algorithms for sampling from probability distributions (e.g., the posterior distribution of $\ln \left(q_{i}\right), \ln \left(D_{i}\right)$, and $b$ ) based on constructing a Markov chain that has the desired posterior distribution. The stabilized state of the chain after a large number of steps is then used as an approximation of the desired distribution.

A Markov chain is a stochastic process $X_{1}, X_{2}, \ldots$ with the property that, $P\left(X_{s}=x_{s} \mid X_{1}=x_{1}, X_{2}=x_{2}, \ldots, X_{s-1}=x_{s-1}\right)=P\left(X_{s}=x_{s} \mid X_{s-1}=x_{s-1}\right)$

In other words, the distribution of $\mathrm{X}_{\mathrm{s}}$ given the whole history of the process is the same as the distribution of $\mathrm{X}_{\mathrm{s}}$ given just the most recent value, $\mathrm{X}_{\mathrm{s}-1}$.

In this work, I use the Metropolis algorithm for MCMC sampling. Since the posterior distribution is unknown, I need to draw samples from another distribution. This distribution is called the proposal distribution, with density function $q\left(\theta \mid \theta_{\text {given }}\right)$, where $\theta$ is the random variable (like $x$ in $f(x)$ ), and $\theta_{\text {given }}$ is the given parameter in the density function (e.g., $n$ in $f(x)=1 / n$ for a uniform distribution). The samples drawn from the proposal distribution using the Metropolis algorithm form a Markov chain $\theta_{1}, \theta_{2}, \ldots, \theta_{n}$, and the Markov chain can be used as a sample of the desired distribution. For each step in the chain, a candidate $\theta_{\text {proposal }}$ is drawn from the proposal distribution. There is probability $\alpha$ that the candidate is accepted $\left(\theta_{s}=\theta_{\text {proposal }}\right)$ and probability $(1-\alpha)$ that the candidate is rejected $\left(\theta_{s}=\theta_{s-1}\right)$. It has been proved that a Markov chain generated using 
the Metropolis algorithm will converge to the desired posterior distribution when the chain is long enough and when the acceptance ratio equals the ratio of the normalized posterior probability of $\theta_{\text {proposal }}$ to $\theta_{t-1}$ (Eq. 2.10). The normalized posterior probability of $\theta_{\text {proposal }}$ equals the posterior probability $\pi\left(\theta_{\text {proposal }} y\right)$ divided by the proposal probability of $\theta_{\text {proposal }}$ given $\theta_{s-1}$, while the normalized posterior probability of $\theta_{s-1}$ equals the posterior probability $\pi\left(\theta_{s-1} \mid y\right)$ divided by the proposal probability of $\theta_{s-1}$ given $\theta_{\text {proposal }}$. The reason the posterior probability is normalized by the proposal probability is because the Markov chain should be independent of the proposal distribution, which means the Markov chains generated using different proposal distributions should converge to the same posterior distribution. If the calculated acceptance ratio is greater than 1 , the acceptance ratio equals 1 .

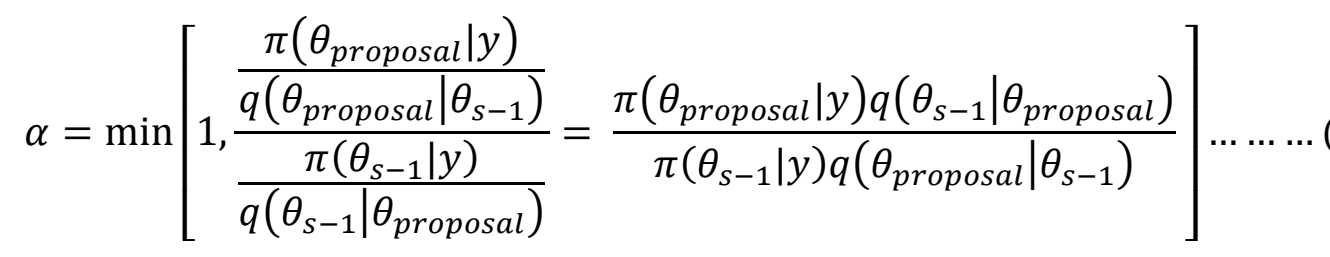

In the Metropolis algorithm, the proposal density function $q$ needs to be symmetric (e.g., a normal distribution), such that $q(x \mid y)=q(y \mid x)$. In this work, I chose the proposal distribution to be an independent truncated normal distribution, $q\left(\theta_{\text {proposal }} \mid \theta_{s-1}\right)$

$$
=\prod_{\vartheta} \frac{1}{\sqrt{2 \pi}} e^{-\frac{\left(\vartheta_{\text {proposal }}-\vartheta_{s-1}\right)^{2}}{2 \sigma_{\theta}^{2}}} \times\left[\Phi\left(\frac{\vartheta_{\text {upper }}-\vartheta_{s-1}}{\sigma_{\vartheta}}\right)-\Phi\left(\frac{\vartheta_{\text {lower }}-\vartheta_{s-1}}{\sigma_{\vartheta}}\right)\right]^{-1} \ldots
$$


In Eq. 2.11, $\vartheta$ is one of the three decline curve parameters and $\sigma_{\vartheta}, \vartheta_{\text {upper }}$, and $\vartheta_{\text {lower }}$ are the standard deviation, upper bound, and lower bound of the proposal distribution of $\vartheta$, and $\Phi$ is the cdf of the standard normal.

Substituting Eq. 2.11 in Eq. 2.10, the acceptance ratio equals,

$$
\begin{aligned}
& \alpha=\min \left[1, \frac{\pi\left(\theta_{\text {proposal }} \mid y\right) q\left(\theta_{s-1} \mid \theta_{\text {proposal }}\right)}{\pi\left(\theta_{s-1} \mid y\right) q\left(\theta_{\text {proposal }} \mid \theta_{s-1}\right)}\right] \\
& =\min \left[1, \frac{\pi\left(\theta_{\text {proposal }} \mid y\right)}{\pi\left(\theta_{s-1} \mid y\right)} \times \prod \frac{\Phi\left(\frac{\vartheta_{\text {upper }}-\vartheta_{s-1}}{\sigma_{\vartheta}}\right)-\Phi\left(\frac{\vartheta_{\text {lower }}-\vartheta_{s-1}}{\sigma_{\vartheta}}\right)}{\left.\Phi\left(\frac{\vartheta_{\text {upper }}-\vartheta_{\text {proposal }}}{\sigma_{\vartheta}}\right)-\Phi\left(\frac{\vartheta_{\text {lower }}-\vartheta_{\text {proposal }}}{\sigma_{\vartheta}}\right)\right]}\right. \\
& =\min \left[1, \frac{f\left(y \mid \theta_{\text {proposal }}\right) \pi\left(\theta_{\text {proposal }}\right)}{f\left(y \mid \theta_{s-1}\right) \pi\left(\theta_{s-1}\right)} \times \prod_{\vartheta} \frac{\Phi\left(\frac{\vartheta_{\text {upper }}-\vartheta_{s-1}}{\sigma_{\vartheta}}\right)-\Phi\left(\frac{\vartheta_{\text {lower }}-\vartheta_{s-1}}{\sigma_{\vartheta}}\right)}{\sigma_{\vartheta}}\right] \ldots
\end{aligned}
$$

\subsection{Application of MCMC with Arps Model}

In this section, I will apply the MCMC methodology with the decline curve parameters $\ln \left(q_{i}\right), \ln \left(D_{i}\right)$, and $b$ of Arps equation. I emphasize that the probabilistic decline curve analysis is conducted independently for each well; however, the set of wells must be analyzed to determine if the method is probabilistically well calibrated. Following I illustrate and explain the methodology in detail.

First, I assume the prior distributions of decline curve parameters $\ln \left(q_{i}\right), \ln \left(D_{i}\right)$, and $b$ are independent uniform distributions with constraints (non-informative prior). For the Barnett shale gas wells, I use $0.01<q_{i}<1000000,0.1<D_{i}<50$, and $0<b<2$, where $q_{i}$ is in 
$\mathrm{Mcf} / \mathrm{d}$ and $D_{i}$ is in $1 /$ year. The density of the prior distribution density of the decline curve parameters $\ln \left(q_{i}\right), \ln \left(D_{i}\right)$, and $b$ is:

$$
\begin{aligned}
& \pi\left(\ln \left(q_{i}\right), \ln \left(D_{i}\right), b\right)=\frac{1}{18.41 \times 6.21 \times 2} \ldots \ldots \ldots \ldots \ldots \ldots \ldots \ldots \ldots \ldots \ldots \ldots \ldots \ldots \ldots \ldots \ldots \\
& \text { where }-4.61<\ln \left(q_{i}\right)<13.8,-2.3<\ln \left(D_{i}\right)<3.91, \text { and } 0<b<2
\end{aligned}
$$

The boundaries for $q_{i}$ are wide enough so any reasonable initial rate is included in the range. The lower boundary for $D_{i}$ was set to be 0.1 so that abnormal production data, especially with limited data, will not cause the decline curves to have unrealistically small initial decline rates. The upper boundary for $D_{i}$ was set to be 50 so that meaninglessly large $D_{i}$ will not influence statistical analysis. The boundaries for $b(0$ and 2) are the $b$ values for exponential (most pessimistic) and linear flow (most optimistic). Second, I calculate the likelihood function. The decline curve parameters $\ln \left(q_{i 1}\right), \ln \left(D_{i 1}\right)$, and $b_{1}$ of the least-squares best fit are used as the initial parameters $\theta_{1}$ in the Markov chain.

The sample standard deviation of the logarithmic residual $(\sigma)$ for the best fit is then calculated,

$$
\sigma=\sqrt{\sum_{i=1}^{t} \frac{\left(y_{i}-\widehat{y}_{l}\right)^{2}}{t-3}}
$$


In Eq. 2.14, $y_{i}$ and $\widehat{y}_{l}$ are observed and modeled production data at month $i$ and $t$ is the number of months of production data available. The sum of residuals squared was divided by $t-3$ because the nonlinear regression model includes 3 decline curve variables.

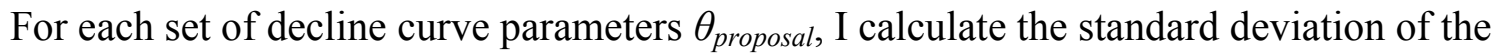
residual between the true monthly production and modeled production,

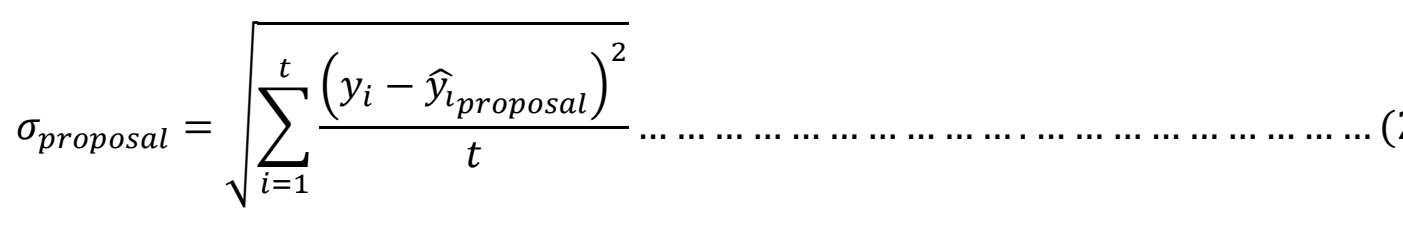

In Eq. 2.15, $y_{i}$ and $\widehat{y}_{l}$ are observed and modeled production data using proposal variables $\theta_{\text {proposal }}$ at month $i$ and $t$ is the total number of months of production data available. The sum of residuals squared was divided by $t$ because the proposal model is independent of the production data.

For the likelihood function, I assume that the sample standard deviation of logarithm residuals ( $\left.\sigma_{\text {proposal }}\right)$ between actual production (first half) and calculated production using the proposal decline curve parameters has a normal distribution $\mathrm{N}(0, \sigma)$, where $\sigma$ is the sample standard deviation of logarithm residuals of the least-squares fit and $\sigma_{\text {proposal }}$ is the sample standard deviation of logarithm residuals of the proposal decline curve (Eq.2.16).

$f\left(y \mid \theta_{\text {proposal }}\right)=\frac{1}{\sqrt{2 \pi} \sigma} \exp \left(-\frac{\sigma_{\text {proposal }}^{2}}{\sigma^{2}}\right)$ 
Third, the proposal distribution in Eq. 5 is used and the acceptance ratio is calculated for each proposed sample. In the Metropolis algorithm, the proposal distribution given step $s-1$ decline curve parameters $\ln \left(q_{i}\right)_{\mathrm{s}-1}, \ln \left(D_{i}\right)_{\mathrm{s}-1}$, and $b_{\mathrm{s}-1}$ is $\ln \left(q_{i}\right)_{\mathrm{proposal}} \sim N\left(\ln \left(q_{i}\right)_{\mathrm{s}-1}, 0.2\right)$, $\ln \left(D_{i}\right)_{\text {proposal }} \sim \mathrm{N}\left(\ln \left(D_{i}\right)_{\mathrm{s}-1}, 0.4\right)$, and $b_{\text {proposal }} \sim N\left(b_{\mathrm{s}-1}, 0.2\right)$ with the same boundaries as in Eq. 2.13, where $N(\mu, \sigma)$ stands for normal distribution with mean $\mu$ and standard deviation $\sigma$. The standard deviations of the proposal distributions $(0.2,0.4$, and 0.2$)$ were chosen to obtain good mixing for the MCMC simulation (Fig. 2.1). Substituting the density of the prior distribution (Eq. 2.13), the likelihood function (Eq. 2.16), and the density of proposal distribution (Eq. 2.11) into the acceptance probability (Eq. 2.12), I have

$$
\begin{aligned}
& \alpha=\min \left[1, \frac{\exp \left(-\frac{\sigma_{\text {proposal }}^{2}}{\sigma^{2}}\right)}{\exp \left(-\frac{\sigma_{s-1}^{2}}{\sigma^{2}}\right)} \times \prod_{\vartheta=\ln \left(q_{i}\right), \ln \left(D_{i}\right), b} \frac{\Phi\left(\frac{\vartheta_{\text {upper }}-\vartheta_{s-1}}{\sigma_{\vartheta}}\right)-\Phi\left(\frac{\vartheta_{\text {lower }}-\vartheta_{s-1}}{\sigma_{\vartheta}}\right)}{\Phi\left(\frac{\vartheta_{\text {upper }}-\vartheta_{\text {proposal }}}{\sigma_{\vartheta}}\right)-\Phi\left(\frac{\vartheta_{\text {lower }}-\vartheta_{\text {proposal }}}{\sigma_{\vartheta}}\right)}\right] \\
& =\min \left[1, \exp \left(\frac{\sigma_{s-1}^{2}-\sigma_{\text {proposal }}^{2}}{\sigma^{2}}\right) \times \prod_{\vartheta=\ln \left(q_{i}\right), \ln \left(D_{i}\right), b} \frac{\Phi\left(\frac{\vartheta_{\text {upper }}-\vartheta_{s-1}}{\sigma_{\vartheta}}\right)-\Phi\left(\frac{\vartheta_{\text {lower }}-\vartheta_{s-1}}{\sigma_{\vartheta}}\right)}{\Phi\left(\frac{\vartheta_{\text {upper }}-\vartheta_{\text {proposal }}}{\sigma_{\vartheta}}\right)-\Phi\left(\frac{\vartheta_{\text {lower }}-\vartheta_{\text {proposal }}}{\sigma_{\vartheta}}\right)}\right]
\end{aligned}
$$

When the preset maximum iteration is reached, the obtained Markov chain of decline curve parameters can be used to calculate $\mathrm{P}_{90}, \mathrm{P}_{50}$, and $\mathrm{P}_{10}$ production forecasts and reserves.

Mixing of the MCMC simulation, mentioned before, is the measure of how fast the Markov chain converges to the desired distribution (posterior distribution). Good mixing 
means the Markov chain does not remain at one value for too many steps and stabilizes within a fixed interval after a short burn-in period. As an example, a Markov chain of 1000 iterations of the decline curve parameters was constructed for one of the 197 wells in this case study. Fig. 2.1 shows the $b$ values of these 1000 iterations. The Markov chain does not remain at any one value for too long and it moves around in the 1.3-to-2 interval with no perceptible burn-in period (the initial $b$ value is 2 , given by least-square best fit of the well), indicating acceptable mixing. Several methods, e.g. Langevin MCMC, can be used to improve mixing and avoid random walk; however, trying to optimize the convergence of the MCMC algorithm is outside of scope of this work.

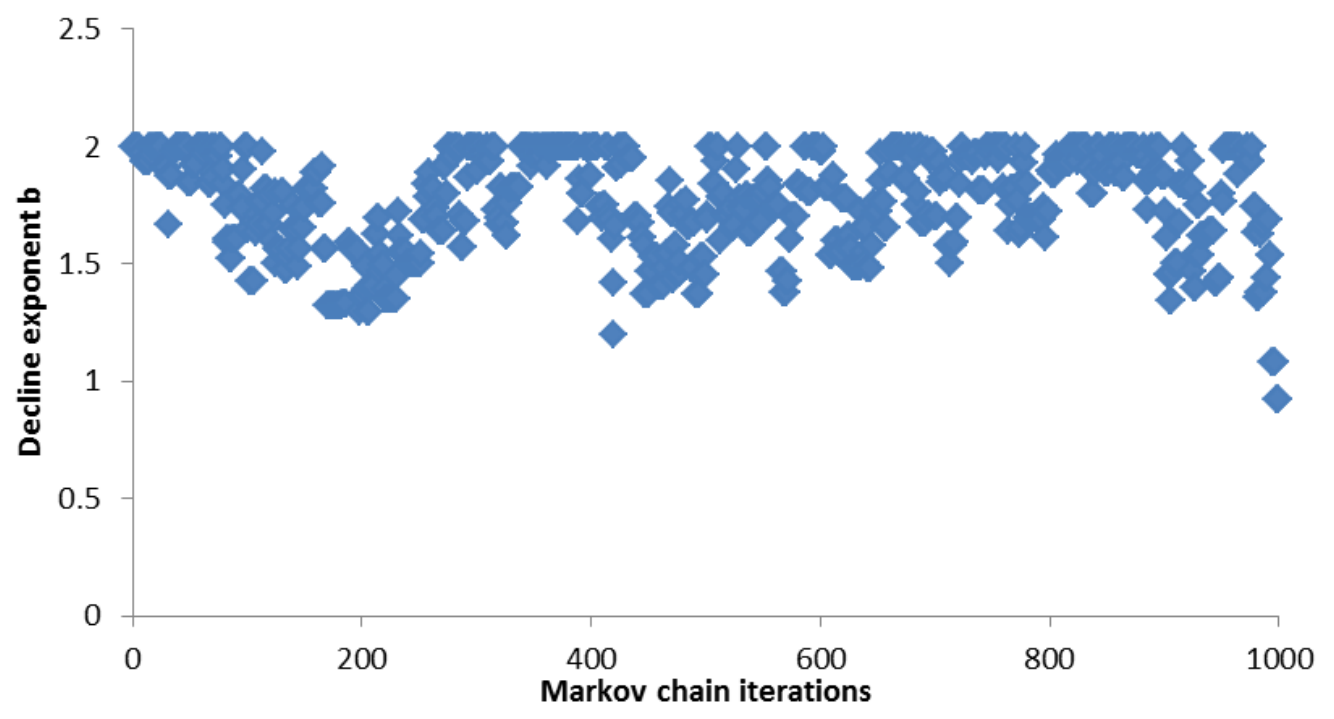

Fig. 2.1- The 1000-iteration Markov chain of one of the horizontal gas wells.

The overall workflow for MCMC using Arps equation is listed below,

1. Set $s=1$ and $\ln \left(q_{i}\right), \ln \left(D_{i}\right)$ and $b$ equal to the least-square best fit. 
2. Generate a sample $\theta_{\text {proposal }}\left(\ln \left(q_{i}\right), \ln \left(D_{i}\right)\right.$ and $\left.b\right)$ from the proposal distribution.

3. Calculate acceptance ratio based on Eq. 6 .

4. Generate a random number between 0 and 1 .

5. If the random number is less than acceptance ratio, accept $\theta_{\text {proposal }}, \theta_{\mathrm{s}}=\theta_{\text {proposal, }}$ otherwise, $\theta_{\mathrm{s}}=\theta_{\mathrm{s}-1}$.

6. $s=s+1$. If $s<$ maximum chain length, go to step 1 .

\subsection{Case Study: Barnett Shale Hydraulically Fractured Gas Wells}

I wanted to test the methodology in shale gas wells developed using modern drilling and completion technology, but I also wanted the production periods to be as long as possible so I could compare predictions to actual production to help validate the methodology. I selected the Barnett shale as the case study play because it is one of the oldest shale gas plays that has been developed using horizontal drilling and multistage hydraulic fracturing techniques. In the test, I performed "hindcasts" in which I assumed a particular fraction of the actual historical production is known (e.g., 6 months) and the remainder of the actual production is unknown. I then matched the assumed known production and forecasted production to the end of the actual historical production period. The "hindcast" cumulative production at the end of the actual historical production period is compared to the actual cumulative production at this time to test the validity of the methodology when using limited production data. I decided that the wells selected in the case study must meet the following criteria: 
- Drilled horizontally and stimulated with single-stage or multi-stage hydraulically fractures.

- Produced for more than 7 years, with first production after 1/1/2002.

- Source of production data is DI Desktop (Drillinginfo, 1998-2011)

Some wells had been restimulated. For those wells, I chose the longest time window without any restimulation, either the interval starting from the initial production date or the interval starting from the date of restimulation. I also deleted significant outliers, and in some cases, periods of sparse, erratic data to obtain more reasonable least-squares fits (Fig. 2.2). Based on these criteria, 197 gas wells with 59-119 months of production were selected for this case study from throughout the entire Barnett shale play.

The objective of the methodology is to generate well-calibrated probabilistic decline curve forecasts; i.e., in $80 \%$ of the wells the actual future production falls between the hindcast $\mathrm{P}_{90}$ and $\mathrm{P}_{10}$ production and, even better, $90 \%, 50 \%$, and $10 \%$ of the time the actual future production is greater than the $\mathrm{P}_{90}, \mathrm{P}_{50}$, and $\mathrm{P}_{10}$ estimates, respectively. While I would like the $\mathrm{P}_{90}-\mathrm{P}_{10}$ interval to be as small as possible, this is not the primary objective. The primary objective is to reliably quantify the uncertainty in reserves estimates. 


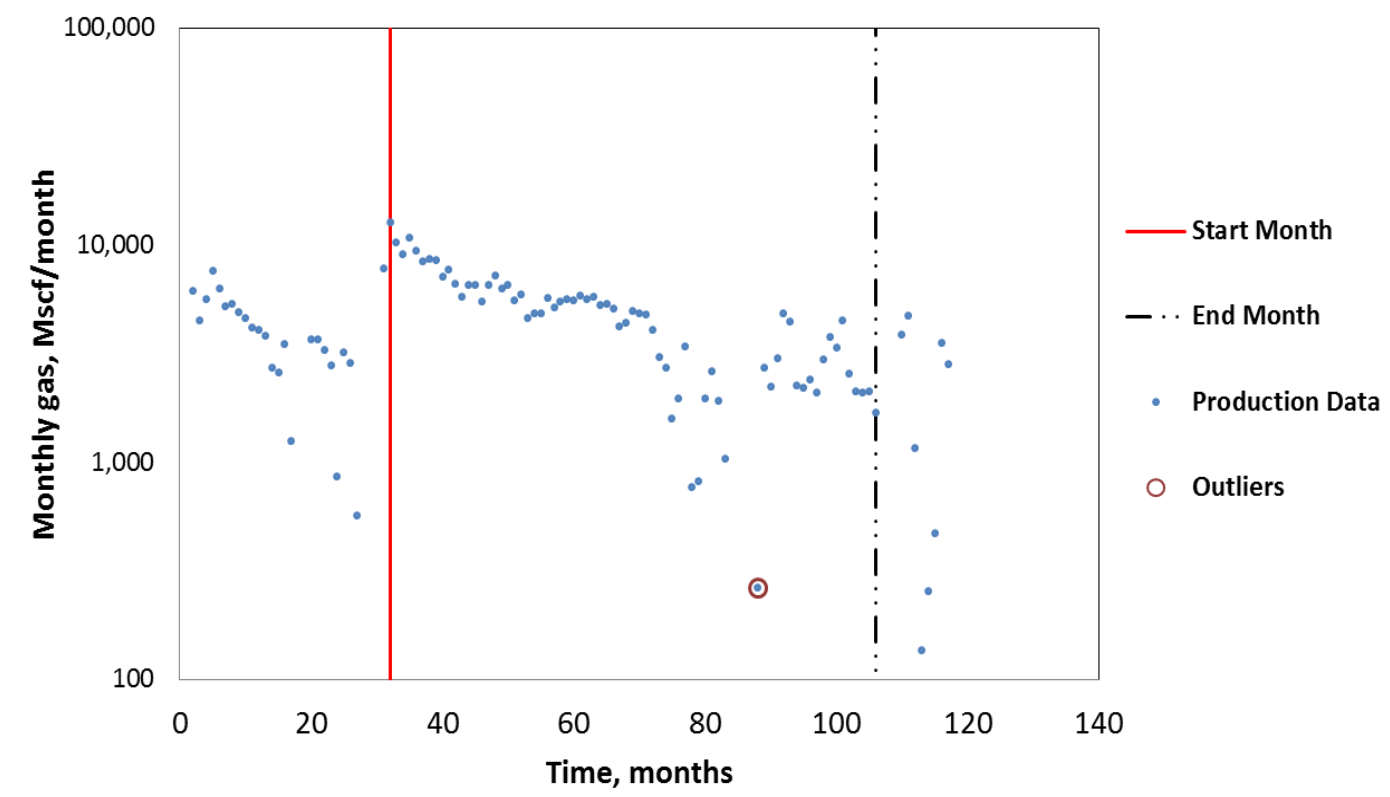

Fig. 2.2 - Example well. The longest time window (months 32 to 106) without any restimulation was chosen as the interval to be analyzed.

I have introduced a step-by-step workflow on how to apply MCMC to generate probabilistic decline curve predictions. In this section, I examine hindcast test results and calibrate the MCMC model so that the calibrated model is reproducible, and quantifies uncertainty reliably with limited production data.

One of the most important properties of probabilistic methods is reproducibility. Since the decline curves are generated probabilistically, every time a simulation is run, the resulting distribution will be different. However, good probabilistic methods require the difference between the resulting distributions for each run using the same data set to be relatively small. In order to find how many iterations are required to generate small errors, 10 sets of simulations were run with MCMC iteration numbers ranging from 100 
to 100,000 for one well with 6 months, 18 months and 36 months of available production. The relative error (equal to sample standard deviation divided by sample average) for $\mathrm{P}_{90}, \mathrm{P}_{50}$, and $\mathrm{P}_{10}$ cumulative production at end of hindcast $(\mathrm{CPEOH})$ are recorded in Table 2.1 and Fig. 2.3. For example, if the tolerance of error is $2 \%$, it requires 20,000 iterations for 6 months of known production, 2,000 iterations for 18 months available, and 1,000 iterations for 36 months available.

\begin{tabular}{|c|c|c|c|c|c|c|c|c|c|c|c|c|}
\hline \multicolumn{13}{|c|}{ Table 2.1 - Relative Error as a Function of MCMC Iterations } \\
\hline \multirow{2}{*}{$\begin{array}{l}\text { Available production } \\
\text { Number of Iterations }\end{array}$} & \multicolumn{4}{|c|}{6 months } & \multicolumn{4}{|c|}{18 months } & \multicolumn{4}{|c|}{36 months } \\
\hline & P90 & P50 & P10 & Average & P90 & P50 & P10 & Average & P90 & P50 & P10 & Average \\
\hline 100 & $27.8 \%$ & $21.1 \%$ & $19.9 \%$ & $22.9 \%$ & $11.2 \%$ & $6.0 \%$ & $5.6 \%$ & $7.6 \%$ & $5.8 \%$ & $2.9 \%$ & $4.2 \%$ & $4.3 \%$ \\
\hline 200 & $22.2 \%$ & $9.7 \%$ & $19.4 \%$ & $17.1 \%$ & $12.4 \%$ & $3.1 \%$ & $7.4 \%$ & $7.6 \%$ & $2.9 \%$ & $1.9 \%$ & $2.9 \%$ & $2.5 \%$ \\
\hline 500 & $21.6 \%$ & $9.6 \%$ & $13.5 \%$ & $14.9 \%$ & $5.0 \%$ & $3.5 \%$ & $5.6 \%$ & $4.7 \%$ & $3.1 \%$ & $1.5 \%$ & $2.0 \%$ & $2.2 \%$ \\
\hline 1,000 & $15.4 \%$ & $7.4 \%$ & $11.0 \%$ & $11.2 \%$ & $4.0 \%$ & $1.7 \%$ & $2.4 \%$ & $2.7 \%$ & $1.9 \%$ & $1.5 \%$ & $2.2 \%$ & $1.9 \%$ \\
\hline 2,000 & $9.3 \%$ & $3.2 \%$ & $4.1 \%$ & $5.6 \%$ & $2.0 \%$ & $1.7 \%$ & $1.3 \%$ & $1.6 \%$ & $1.5 \%$ & $0.7 \%$ & $0.7 \%$ & $1.0 \%$ \\
\hline 5,000 & $4.5 \%$ & $2.8 \%$ & $4.3 \%$ & $3.9 \%$ & $1.9 \%$ & $1.3 \%$ & $1.5 \%$ & $1.6 \%$ & $1.0 \%$ & $0.2 \%$ & $0.5 \%$ & $0.6 \%$ \\
\hline 10,000 & $5.3 \%$ & $1.2 \%$ & $2.6 \%$ & $3.0 \%$ & $0.6 \%$ & $0.7 \%$ & $1.2 \%$ & $0.8 \%$ & $0.8 \%$ & $0.4 \%$ & $0.4 \%$ & $0.5 \%$ \\
\hline 20,000 & $1.8 \%$ & $1.7 \%$ & $2.0 \%$ & $1.8 \%$ & $0.6 \%$ & $0.5 \%$ & $0.6 \%$ & $0.6 \%$ & $0.4 \%$ & $0.2 \%$ & $0.2 \%$ & $0.3 \%$ \\
\hline 50,000 & $3.0 \%$ & $0.8 \%$ & $1.0 \%$ & $1.6 \%$ & $0.5 \%$ & $0.4 \%$ & $0.5 \%$ & $0.5 \%$ & $0.3 \%$ & $0.2 \%$ & $0.3 \%$ & $0.3 \%$ \\
\hline 100,000 & $1.3 \%$ & $0.7 \%$ & $0.7 \%$ & $0.9 \%$ & $0.6 \%$ & $0.2 \%$ & $0.3 \%$ & $0.4 \%$ & $0.2 \%$ & $0.1 \%$ & $0.2 \%$ & $0.2 \%$ \\
\hline
\end{tabular}




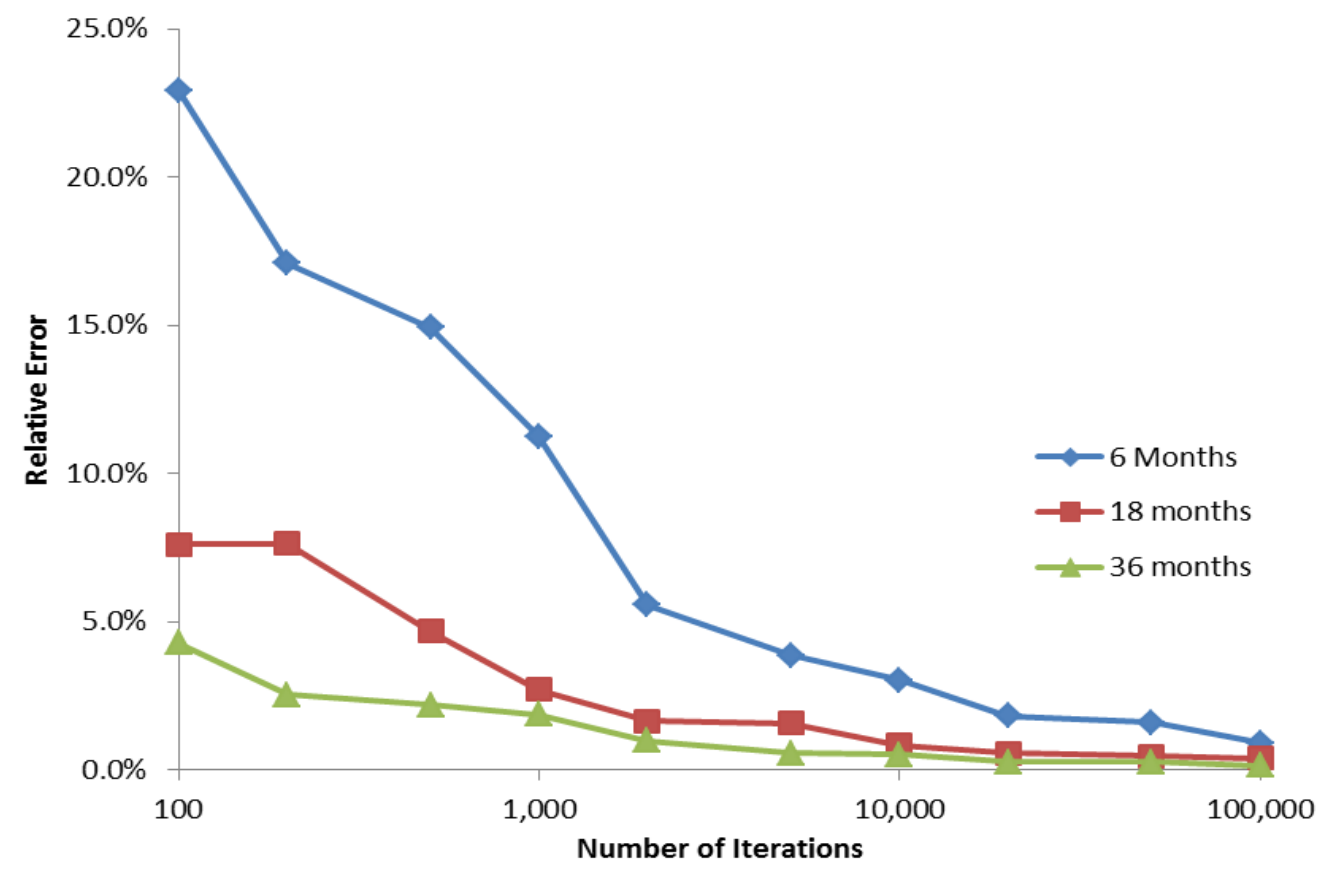

Fig. 2.3 - Relative error decreases as the number of MCMC iterations increases

I performed probabilistic hindcasts for all 197 wells, varying the production data available for matching from 6 months to 36 months. Probabilistic and true cumulative production at end of hindcast $(\mathrm{CPEOH})$, averaged over all wells, were then plotted versus the amount of production data used to hindcast (Fig. 2.4). The frequencies with which the true values exceed the $\mathrm{P}_{90}, \mathrm{P}_{50}$, and $\mathrm{P}_{10}$ values are plotted in Fig. 2.5. The true average $\mathrm{CPEOH}$ values are within the $\mathrm{P}_{90}$ and $\mathrm{P}_{10}$ values for all cases of production data matched, and the $\mathrm{P}_{50}$ is close to the true average $\mathrm{CPEOH}$ when more than 18 months of production data are available for matching. However, when limited production data are available (e.g., 6 months), the probabilistic hindcast $\mathrm{P}_{50}$ is much lower than the true value. The reason is that when there is a sharp decline in production in the first 6 months, the exponential decline fits the data well (because the production curve has not 
had time to flatten yet) and the acceptance ratios for the exponential curve are much higher than they should be. I know that most hydraulically fractured horizontal wells do not follow exponential declines. However, I assumed that the prior distribution for $b$ is a uniform distribution between 0 to 2 (Eq. 2.18), which results in relatively high acceptance ratios for exponential decline curves and underestimation of future production when limited production data are available for matching. To fix this problem, I introduce a new prior distribution that is consistent with our knowledge of shale gas wells. I fit the same 197 wells deterministically with Arps' model, recorded the $b$ value for each well and constructed a histogram, which I fit with a truncated triangular distribution from 0 to 2 (Fig. 2.6). Thus, the new prior distribution for $b$ becomes $\pi(b)=\frac{1}{6}+b * \frac{1}{3}$, when $0<b<2$

I assumed that the prior density decreases with time in the form

$$
\pi_{\text {new }}(\theta)=\pi(b)^{g(t)}
$$

In Eq. $2.19, \pi_{\text {new }}(\theta)$ is the prior density, $\pi(b)$ is the pdf in Eq. 2.18 and $g(t)$ is a function that decreases with time. To obtain the function $g(t)$, I found the best value of $g$ for each $t$ by comparing the $\mathrm{P}_{90}, \mathrm{P}_{50}$, and $\mathrm{P}_{10}$ values with true $\mathrm{CPEOH}$ values. The best relationship between $g$ and $t$ is linear on a semi-log plot (Fig. 2.7), with $\mathrm{R}^{2}=0.92$. The equation for $g(t)$ is

$$
g(t)=8.04 * \exp (-0.128 t)
$$


Eqs. 2.19 and 2.20 were then plugged into Eq. 2.17 to calculate the acceptance ratio. The new model was run with 2000 iterations and the $\mathrm{CPEOH}$ and frequency of true greater than probabilistic hindcasts are plotted in Fig. 2.8 and Fig. 2.9. The $\mathrm{P}_{50} \mathrm{CPEOH}$ using the prior density shown in Eq. 2.18 (Fig. 2.8) is much closer to the true CPEOH at 6 months compared to the $\mathrm{P}_{50} \mathrm{CPEOH}$ using a uniform prior (Fig. 2.4). In addition, the frequencies that the true $\mathrm{CPEOH}$ exceeds the $\mathrm{P}_{90}, \mathrm{P}_{50}$, and $\mathrm{P}_{10} \mathrm{CPEOH}$ using the informative prior (Fig. 2.9) are closer to the desired $90 \%, 50 \%$, and $10 \%$, in contrast to the frequencies that the true $\mathrm{CPEOH}$ exceeds the $\mathrm{P}_{90}, \mathrm{P}_{50}$, and $\mathrm{P}_{10} \mathrm{CPEOH}$ using the noninformative prior (Fig. 2.8).

I have demonstrated that with this probabilistic methodology the uncertainty in $\mathrm{CPEOH}$, or the total amount that will ultimately be produced, deceases with time and more production, which is expected. Since our primary interest is usually in future production (e.g., reserves), I also calculated the uncertainty in the production during the second period, PDTSP (Fig. 2.10). The uncertainty in this "future" production decreases (the $\mathrm{P}_{90}-\mathrm{P}_{10}$ ranges narrow) as the estimated future production decreases with time and more production. However, the relative uncertainty in future production $\left(\mathrm{P}_{90}-\mathrm{P}_{10}\right.$ range divided by future production) remains relatively constant, decreasing only slightly with time and more production (Fig. 2.11). 


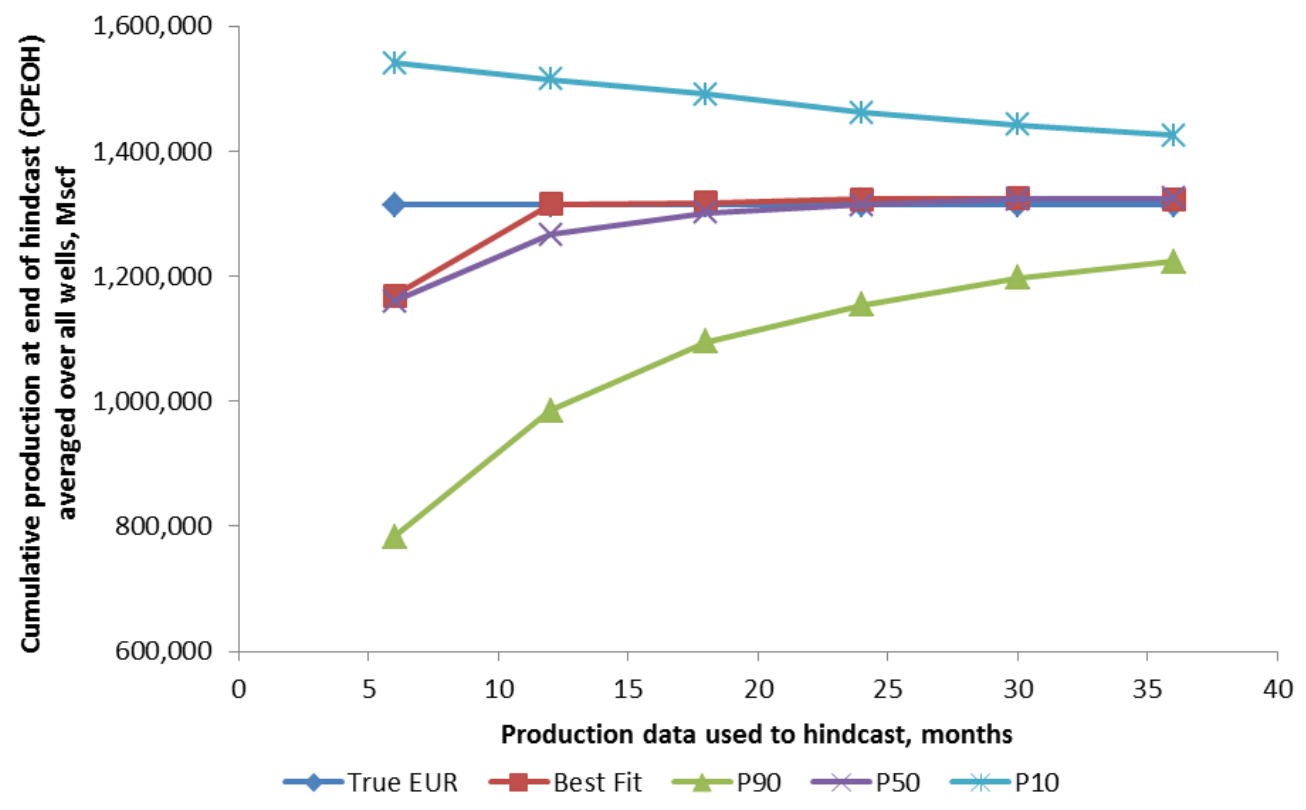

Fig. 2.4- Probabilistic hindcasts averaged over all wells narrow with time in the Barnett well set generated using a non-informative prior distribution.

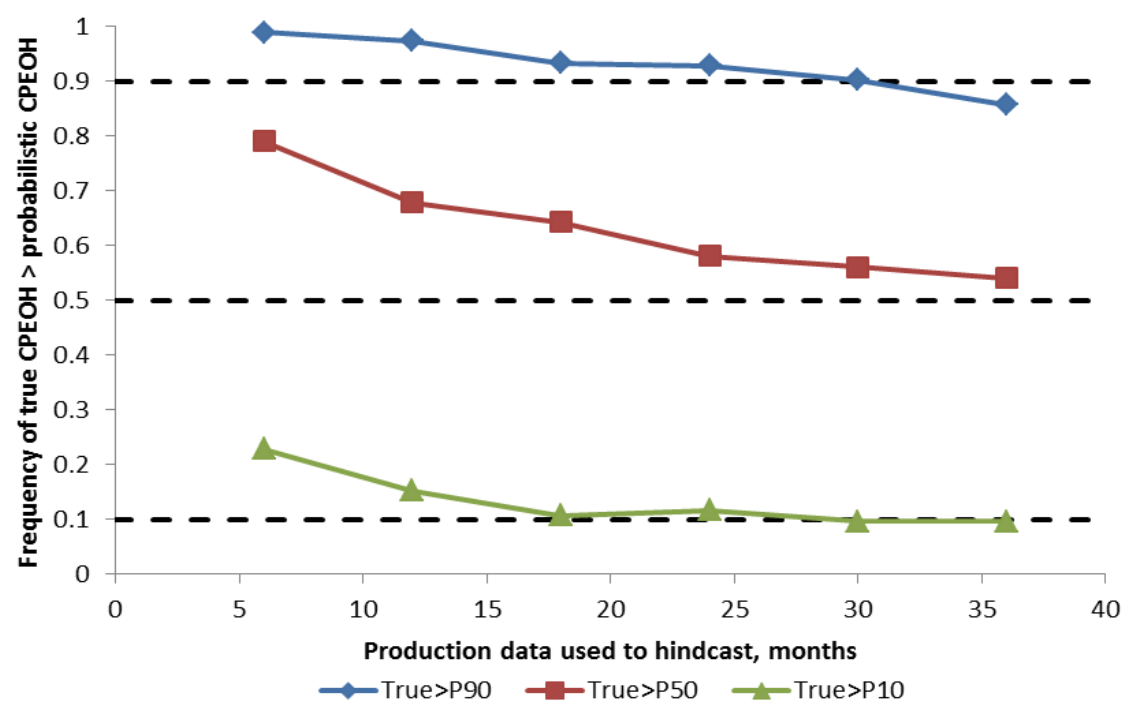

Fig. 2.5- Probabilistic hindcasts underestimate CPEOH in the Barnett well set generated using a non-informative prior distribution. 


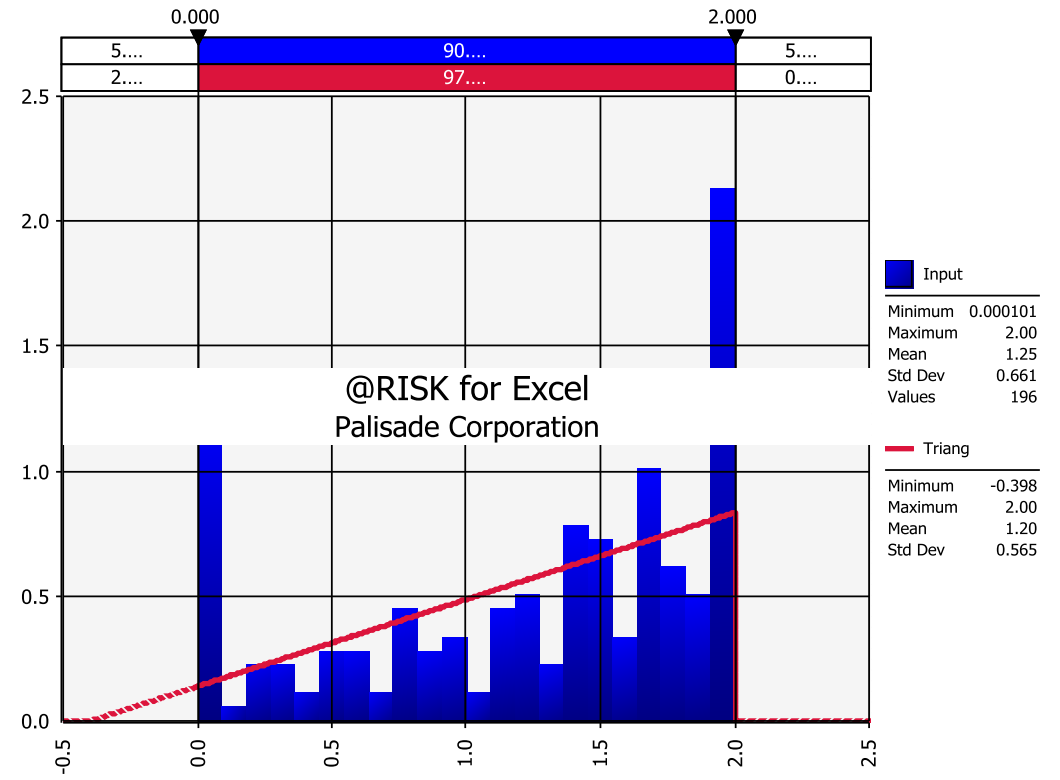

Fig. 2.6 - Histogram of $b$ values for the 197 wells and triangular distribution fit to the histogram.

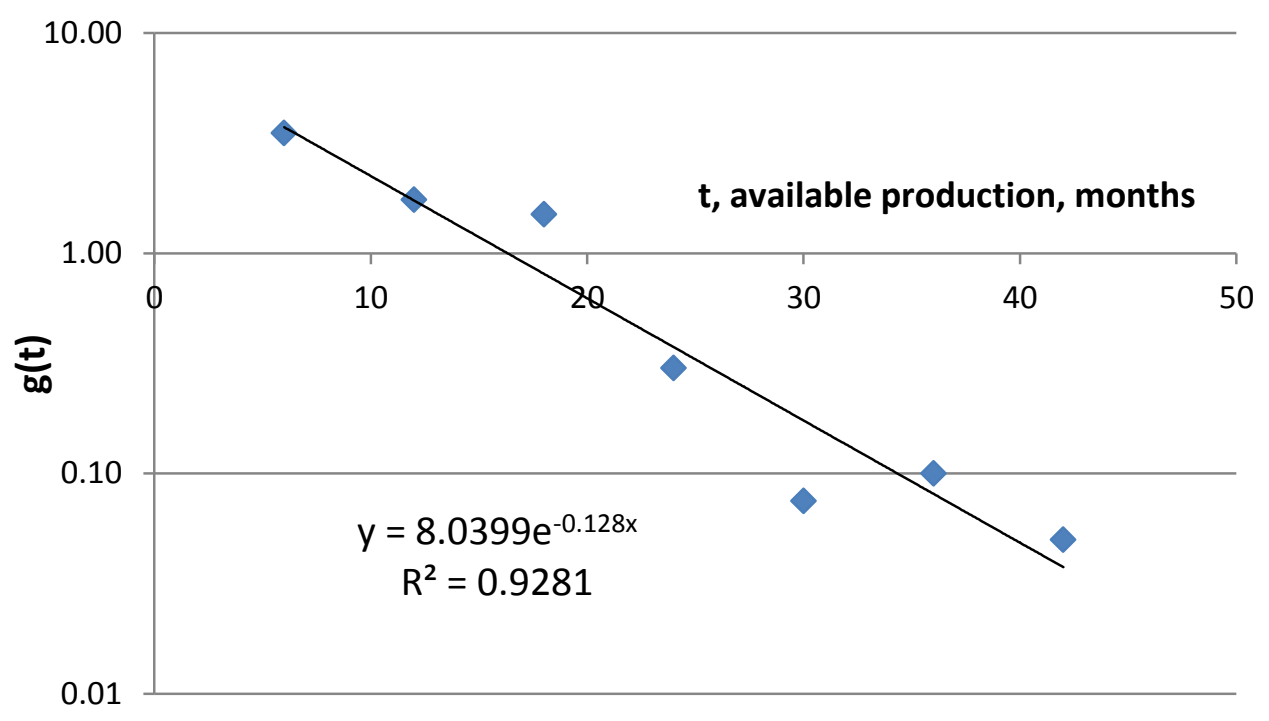

Fig. 2.7- $g(t)$ decreases with increasing $t$ so the prior density has less effect when more production data are available for matching. 


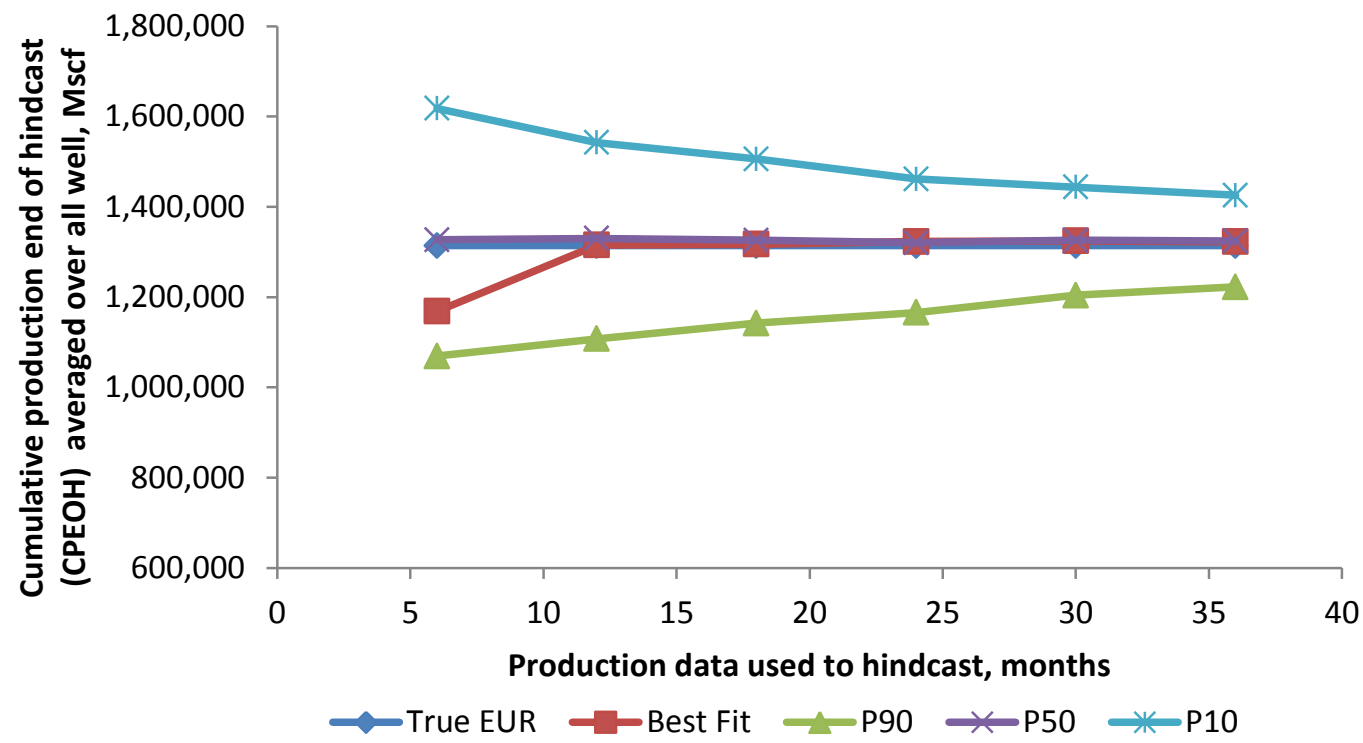

Fig. 2.8 - Probabilistic hindcasts averaged over all wells generated using an informative prior distribution yield better $P_{50}$ estimates than the non-informative estimation in the Barnett well set.

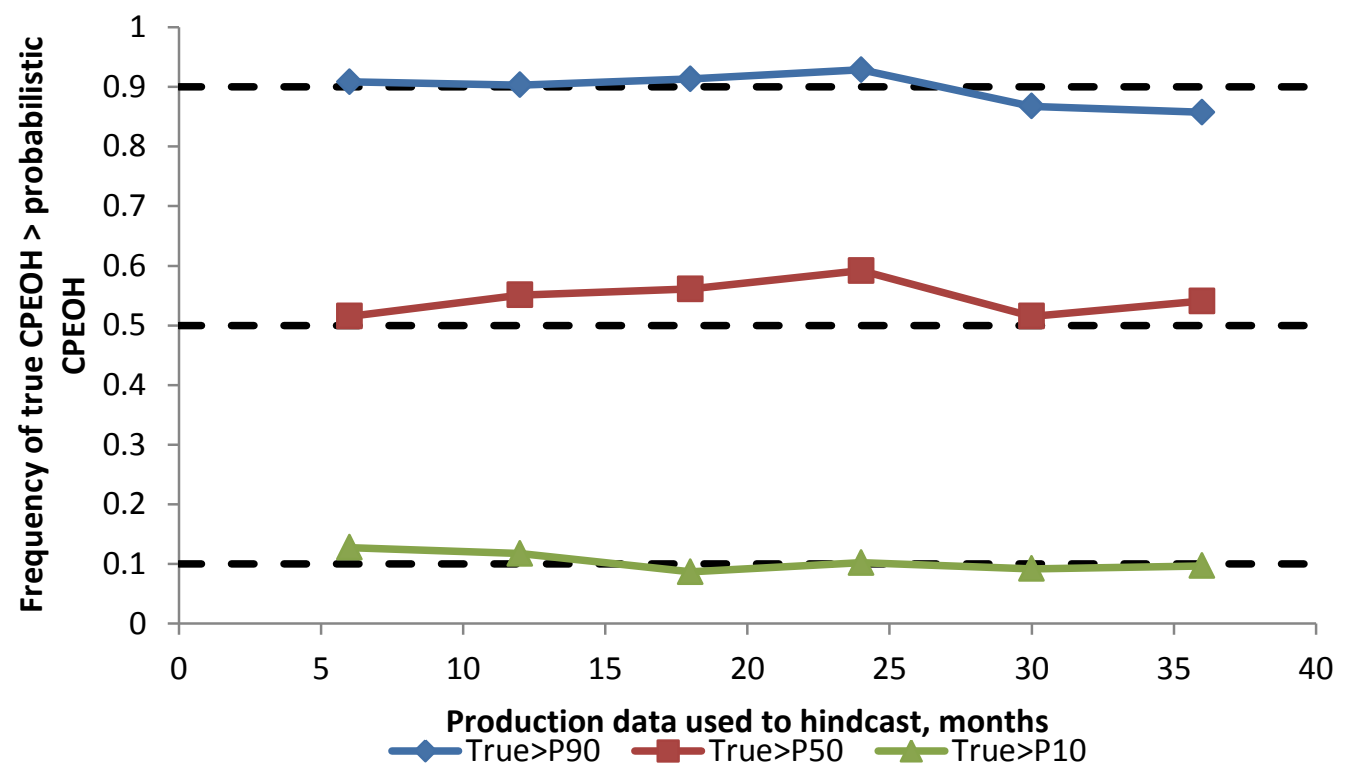

Fig. 2.9- Probabilistic hindcasts generated using an informative prior distribution yield better calibrated $P_{10}, P_{50}$ and $P_{90}$ estimates in the Barnett well set. 


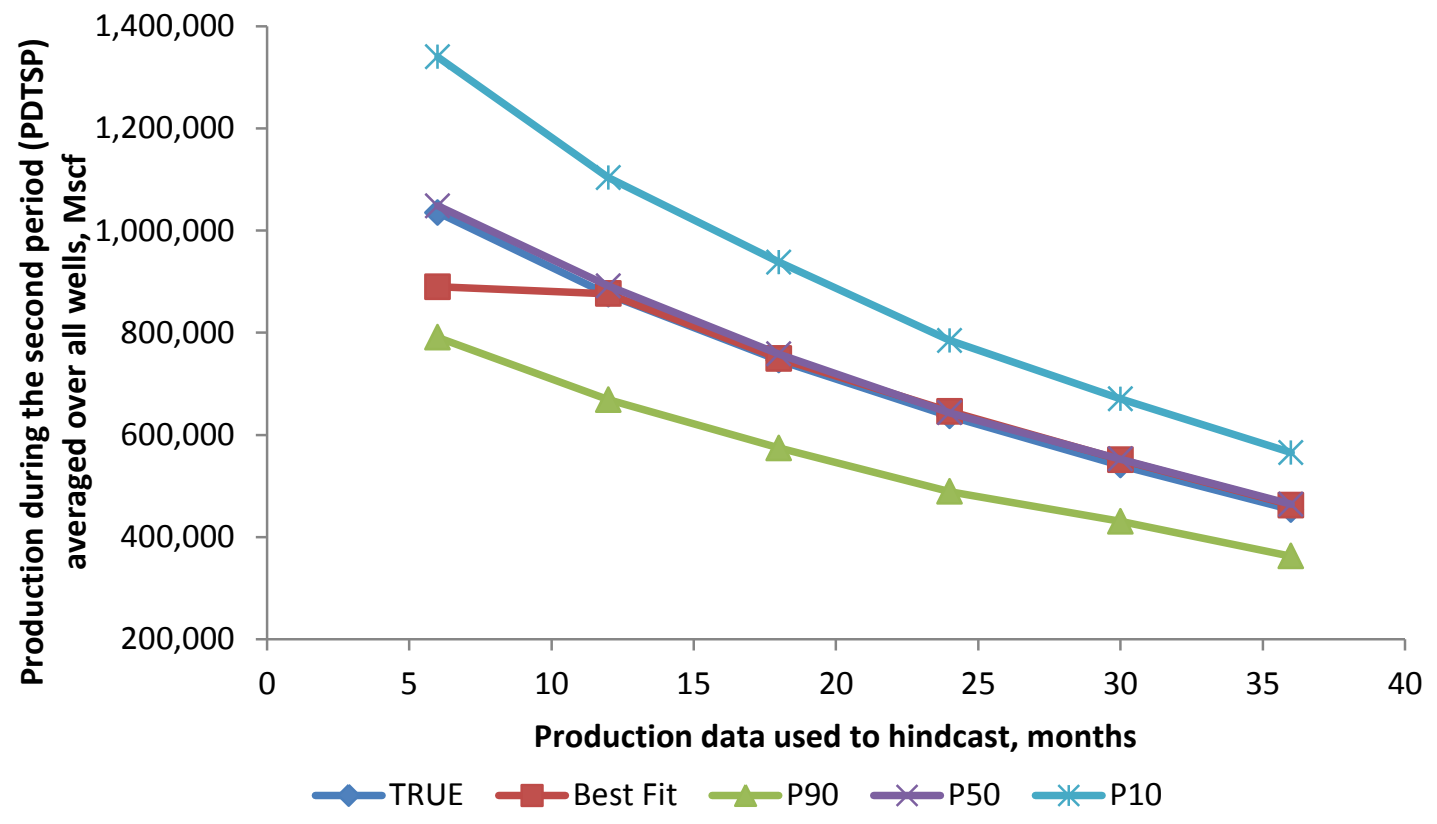

Fig. 2.10 - Uncertainty in PDTSP (future production) decreases with time and more production.

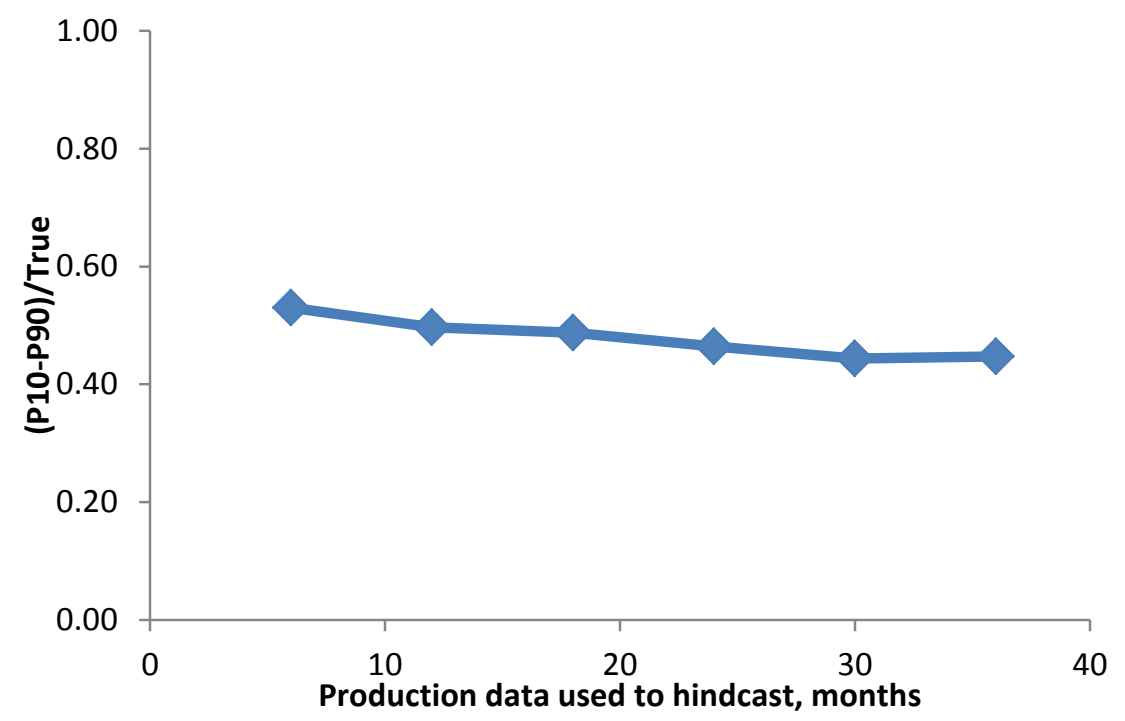

Fig. 2.11- Relative uncertainty in PDTSP (future production) decreases slightly with time and more production. 
The likelihood function (Eq. 2.16) equals the exponential of the ratio of the sum of residuals squared between proposal curves and the best fit. When the model fits the production data almost perfectly, the sample standard deviation between the best fit and the production, $\sigma$ in Eq. 2.14, is very small. As a result, the acceptance ratio calculated by Eq. 2.17 will be small when the model is only a little off the production data, and the uncertainty of the probabilistic hindcast is unrealistically small (Fig. 2.12). To solve this problem, I added an error term to $\sigma^{2}$ in Eq. 2.15 to model the inherent error of production data. The new probabilistic hindcasts generate more realistic uncertainty ranges (Fig. 2.13) with the variance of the inherent error $=0.01$. After experiments, I found that inherent error $=0.001$ gives the most satisfying results for 6 to 42 months available for matching (Fig. 2.14). 


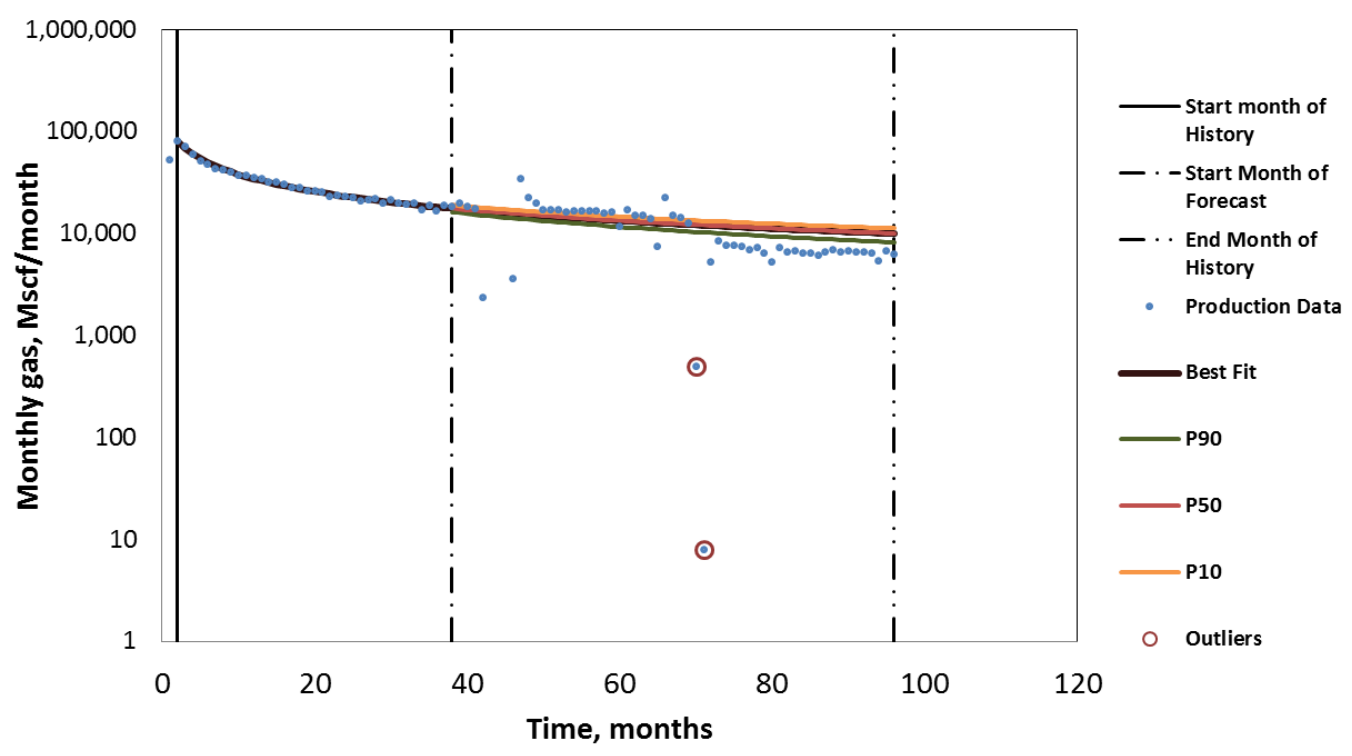

Fig. 2.12 - Well matched production underestimate uncertainty when inherent error is not modeled.

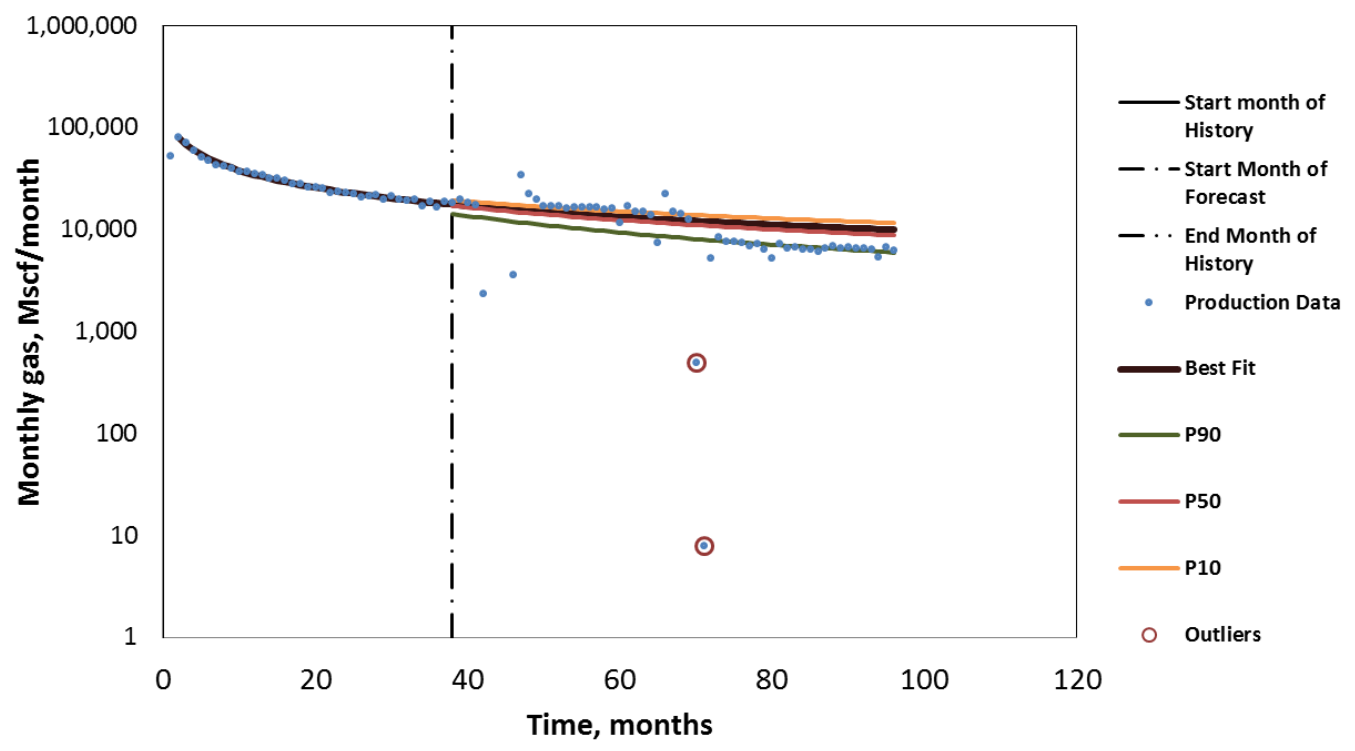

Fig. 2.13 - The range of probabilistic decline curves increases by adding an inherent error with variance $=\mathbf{0 . 0 1}$. 


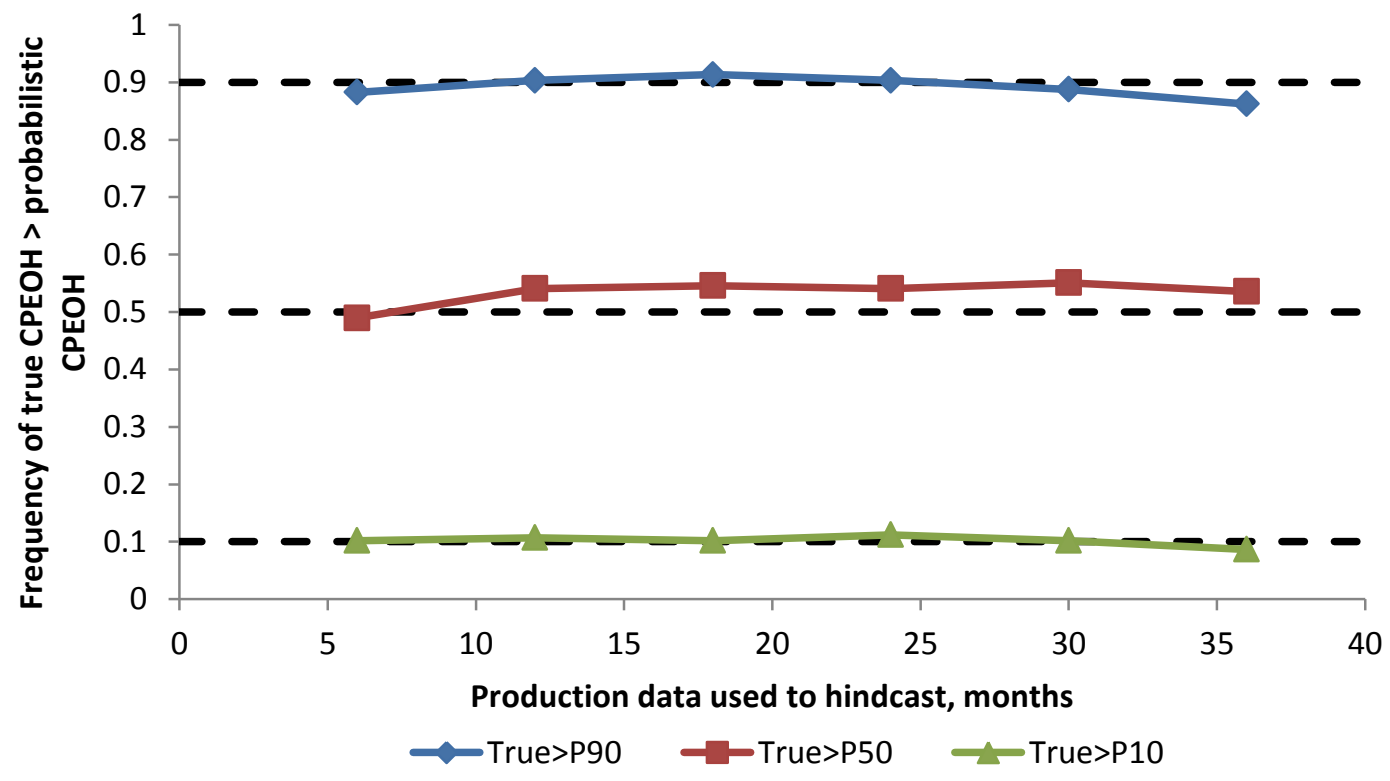

Fig. 2.14- Probabilistic hindcasts generated using an informative prior distribution and inherent error $=0.001$ yield further improved $P_{10}, P_{50}$ and $P_{90}$ estimates in the Barnett well set.

After making the adjustments described above, the proposal density remains the same as Eq. 2.11, the prior density can be calculated from Eqs. $2.18-2.20$, while the updated likelihood function and acceptance ratio are calculated using Eqs. 2.21 and 2.22, respectively.

$$
f\left(y \mid \theta_{\text {proposal }}\right)=\frac{1}{2 \pi \sigma} \exp \left(-\frac{\sigma_{\text {proposal }}^{2}}{\sigma^{2}+0.001}\right)
$$




$$
\begin{aligned}
\alpha=\min & {\left[1, \exp \left(\frac{\sigma_{s-1}^{2}-\sigma_{\text {proposal }}^{2}}{\sigma^{2}+0.001}\right) \times\left(\frac{\frac{1}{6}+b_{\text {proposal }} \times \frac{1}{3}}{\frac{1}{6}+b_{s-1} \times \frac{1}{3}}\right)^{8.04 * \exp (-0.128 t)}\right.} \\
& \left.\times \prod_{\vartheta=\ln \left(q_{i}\right), \ln \left(D_{i}\right), b} \frac{\Phi\left(\frac{\vartheta_{\text {upper }}-\vartheta_{s-1}}{\sigma_{\vartheta}}\right)-\Phi\left(\frac{\vartheta_{\text {lower }}-\vartheta_{s-1}}{\sigma_{\vartheta}}\right)}{\sigma_{\vartheta}}\right] \ldots
\end{aligned}
$$

\subsection{Comparison Between MCMC and Modified Bootstrap Method (MBM)}

In this section, I compare the new Bayesian method with the modified bootstrap method developed by Cheng et al. (2008) using the same data set of 197 Barnett gas wells. Both methods use Arps' decline curves and assume the production during the first period was known and the production during the second period (PDTSP) was unknown. Instead of cumulative production at the end of the hindcast $(\mathrm{CPEOH})$, I will compare the hindcasted PDTSPs from the two methods with the true PDTSPs. Monthly gas production and probabilistic production hindcasts of an example well in the Barnett set are shown in Fig. 2.15. The Bayesian $\mathrm{P}_{90}, \mathrm{P}_{50}$, and $\mathrm{P}_{10}$ probabilistic production profiles are the representative curves of the $10^{\text {th }}, 50^{\text {th }}$ and $90^{\text {th }}$ percentiles of the PDTSPs calculated from 2000 sets of decline curve parameters generated using MCMC with the Metropolis algorithm, while the MBM probabilistic $\mathrm{P}_{90}, \mathrm{P}_{50}$, and $\mathrm{P}_{10}$ production profiles are the $10^{\text {th }}, 50^{\text {th }}$ and $90^{\text {th }}$ percentiles of each month's predicted production. According to Fig. 2.15 and Table 2.2, both the Bayesian method and the MBM bracket the actual monthly production profile as well as true PDTSP inside their respective $\mathrm{P}_{90}$ to $\mathrm{P}_{10}$ ranges. The Bayesian $\mathrm{P}_{90}-\mathrm{P}_{10}$ PDTSP interval (126-269 MMcf) is narrower than the 
MBM $\mathrm{P}_{90}-\mathrm{P}_{10}$ interval (106-345 MMcf), which is more desirable if the two methods quantify the uncertainty equally well.

Results of analysis of the 197 wells using the two methods are summarized in Table 2.3. The first quantity to look at is the coverage rate and fractions of wells in which the actual PDTSPs exceeded the $\mathrm{P}_{90}, \mathrm{P}_{50}$ and $\mathrm{P}_{10}$ PDTSPs. Both methods did a good job of bracketing the true PDTSPs between the $\mathrm{P}_{90}$ and $\mathrm{P}_{10}$ estimates; however, the MCMC method performed slightly better, at $79 \%$ (closer to $80 \%$ ), compared to the MBM, at $76 \%$. The $\mathrm{P}_{90}, \mathrm{P}_{50}$, and $\mathrm{P}_{10}$ PDTSP estimates actually represent the probabilities $\mathrm{P}_{87}, \mathrm{P}_{55}$, and $\mathrm{P}_{9}$ for the Bayesian method and $\mathrm{P}_{89}, \mathrm{P}_{56}$, and $\mathrm{P}_{13}$ for the MBM, indicating both methods are relatively unbiased. The second quantity to look at is the average interval width, or "Average $\left(\left(\mathrm{P}_{10}-\mathrm{P}_{90}\right) /\right.$ True $)$, " which is the average over all the wells of the quantity $\left(\left(\mathrm{P}_{90}-\mathrm{P}_{10}\right) /\right.$ True $)$. Again, I would like this number to be as small as possible as long as the method adequately quantifies the uncertainty. The average interval width of the Bayesian method, 0.57 , is significantly less than the interval width of the MBM, 0.78. Another important measure in the table is the computation time; the MBM took more than 9 hours to finish 197 wells while the Bayesian method took 44 minutes. The two methods are comparable in accuracy; the MBM has relative error of $10 \%, 2 \%$ and $1 \%$ for 6,18 and 36 months, respectively (results not shown), compared to $6 \%, 2 \%$ and $1 \%$ for 6, 18 and 36 months, respectively, for the Bayesian method using 2000 MCMC iterations (Table 2.1). 


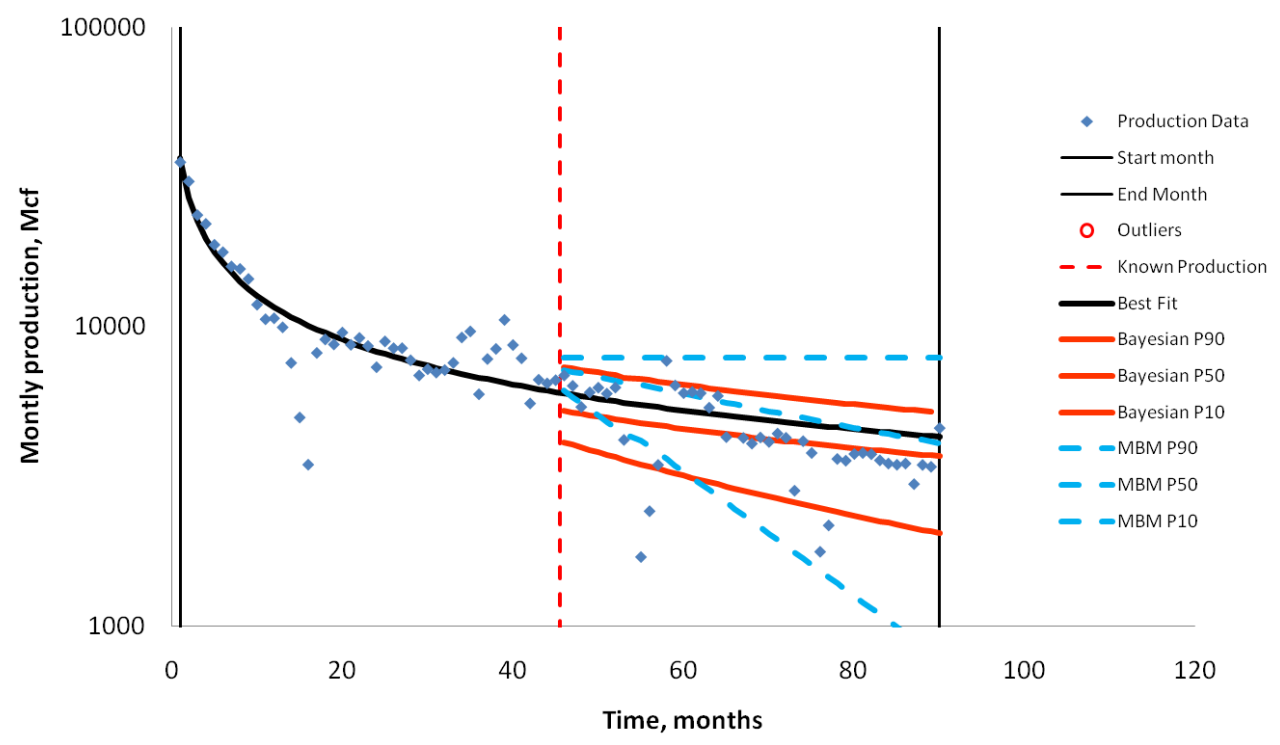

Fig. 2.15- Comparison between probabilistic hindcasts generated using Bayesian and MBM methods for an example well in the Barnett set. 


\begin{tabular}{|c|c|c|c|c|}
\hline \multicolumn{5}{|c|}{$\begin{array}{c}\text { Table 2.2- Calculated Decline Parameters and PDTSP } \\
\text { Estimates for the Example Barnett Well }\end{array}$} \\
\hline & $q_{i}(\mathbf{M c f} / \mathbf{D})$ & $D_{i}(1 /$ year $)$ & $b$ & $\begin{array}{c}\text { PDTSP } \\
\text { (second half), Mscf }\end{array}$ \\
\hline TRUE & 1 & 1 & 1 & 189,589 \\
\hline Best fit & 1,502 & 7.56 & 2.00 & 219,357 \\
\hline Bayesian $\mathbf{P}_{90}$ & 515 & 0.55 & 0.62 & 126,317 \\
\hline Bayesian $P_{50}$ & 2,148 & 17.72 & 1.93 & 190,284 \\
\hline Bayesian $P_{10}$ & 1,147 & 2.29 & 1.82 & 268,979 \\
\hline MBM $\mathbf{P}_{90}$ & 1 & 1 & 1 & 106,263 \\
\hline $\mathbf{M B M} P_{50}$ & 1 & 1 & 1 & 238,630 \\
\hline MBM $P_{10}$ & 1 & 1 & 1 & 344,869 \\
\hline
\end{tabular}




\begin{tabular}{|c|c|c|}
\hline \multicolumn{3}{|c|}{$\begin{array}{c}\text { Table 2.3- Results of Comparison Between MBM and } \\
\text { Bayesian Methods for } 197 \text { Wells Using } 50 \text { Percent of } \\
\text { Known History to Hindcast }\end{array}$} \\
\hline & MBM & Bayesian \\
\hline Coverage Rate & $76 \%$ & $79 \%$ \\
\hline Average Relative Error $\left(\left(\mathrm{P}_{50}\right.\right.$-True $) /$ True $)$ & $-2.4 \%$ & $4.2 \%$ \\
\hline $\begin{array}{c}\text { Average Absolute Error } \operatorname{Abs}\left(\left(\mathrm{P}_{50^{-}}\right.\right. \\
\text {True }) / \text { True })\end{array}$ & $21 \%$ & $19.3 \%$ \\
\hline Sum of $P_{90}$ PDTSPs, Mscf & $51,644,543$ & $61,511,625$ \\
\hline Sum of $P_{50}$ PDTSPs, Mscf & $76,168,202$ & $79,148,239$ \\
\hline Sum of $P_{10}$ PDTSPs, Mscf & $96,325,407$ & $98,076,848$ \\
\hline Sum of True PDTSPs, Mscf & $77,318,176$ & $77,318,176$ \\
\hline Error in True PDTSPs & $1.48 \%$ & $2.36 \%$ \\
\hline Average $\left(\left(\mathrm{P}_{10^{-}} \mathbf{P}_{90}\right) /\right.$ True $)$ & 0.78 & 0.57 \\
\hline Total Computation Time & 9 hours & 44 mins \\
\hline Percentage of True PDTSP $>\mathbf{P}_{90}$ PDTSP & $89 \%$ & $87 \%$ \\
\hline Percentage of True PDTSP $>P_{50}$ PDTSP & $56 \%$ & $55 \%$ \\
\hline Percentage of True PDTSP $>P_{10}$ PDTSP & $13 \%$ & $9 \%$ \\
\hline
\end{tabular}

To test the two methods when limited data are available, I used the same data set of 197 Barnett wells but assume only the first 6 months production is known and the rest is unknown (Table 2.4). The $\mathrm{P}_{90}, \mathrm{P}_{50}$, and $\mathrm{P}_{10}$ PDTSP estimates represent the $\mathrm{P}_{99}, \mathrm{P}_{69}$ and $\mathrm{P}_{11}$ for the MBM while they correspond to exactly $\mathrm{P}_{90}, \mathrm{P}_{50}$, and $\mathrm{P}_{10}$ for the Bayesian method, which shows that the MBM underestimates the PDTSPs with limited production data while the new Bayesian method is unbiased with limited production data. The ability to estimate reserves accurately in the early stage is critical when evaluating 
unconventional plays because most of the unconventional plays are still in the early stage of development and new plays are being targeted.

\begin{tabular}{|c|c|c|}
\hline \multicolumn{3}{|c|}{$\begin{array}{c}\text { Table 2.4- Results of Comparison Between MBM and } \\
\text { Bayesian Methods for } 197 \text { Wells Using } 6 \text { Months to } \\
\text { Hindcast }\end{array}$} \\
\hline & MBM & Bayesian \\
\hline Coverage Rate & $88 \%$ & $80 \%$ \\
\hline Average Relative Error $\left(\left(\mathbf{P}_{50}\right.\right.$-True $) /$ True $)$ & $-9.93 \%$ & $3.79 \%$ \\
\hline Average Absolute Error $\operatorname{Abs}\left(\left(\mathbf{P}_{50}-\right.\right.$ True $) /$ True $)$ & $32 \%$ & $18.45 \%$ \\
\hline Sum of $\mathbf{P}_{90}$ PDTSPs, Mscf & $55,010,808$ & $155,774,373$ \\
\hline Sum of $P_{50}$ PDTSPs, Mscf & $183,201,899$ & $208,967,608$ \\
\hline Sum of $P_{10}$ PDTSPs, Mscf & $328,693,374$ & $271,453,197$ \\
\hline Sum of True PDTSPs, Mscf & $203,840,586$ & $203,840,586$ \\
\hline Error in True PDTSPs & $10.1 \%$ & $2.51 \%$ \\
\hline Average $\left(\left(\mathrm{P}_{10^{-}}-\mathbf{P}_{90}\right) /\right.$ True $)$ & 1.64 & 0.62 \\
\hline Total Computation Time, hours & 9 & 1.5 \\
\hline Percentage of True PDTSP $>$ P $_{90}$ PDTSP & $99 \%$ & $90 \%$ \\
\hline Percentage of True PDTSP $>P_{50}$ PDTSP & $69 \%$ & $50 \%$ \\
\hline Percentage of True PDTSP $>P_{10}$ PDTSP & $11 \%$ & $10 \%$ \\
\hline
\end{tabular}

In the case study of 197 horizontal Barnett shale gas wells, the proposed Bayesian methodology coupled with Arps' decline model reliably quantified the uncertainty in hindcasted production with a narrower $\mathrm{P}_{90}$ to $\mathrm{P}_{10}$ interval and significantly less computation time than the modified bootstrap method (MBM). The Bayesian 
methodology reliably quantified the uncertainty in PDTSP with as little as 6 months of production data.

\subsection{Application and Limitations}

For the hindcast applications presented in this paper, I have demonstrated that the Bayesian methodology is reasonably well calibrated, i.e., that $\mathrm{P}_{90}, \mathrm{P}_{50}$, and $\mathrm{P}_{10}$ estimates correspond to realized frequencies of approximately $90 \%, 50 \%$ and $10 \%$, as desired. This indicates the potential application of the methodology to production forecasting and reserves estimation, which is inherently a probabilistic assessment. The $\mathrm{P}_{90}, \mathrm{P}_{50}$, and $\mathrm{P}_{10}$ production forecasts using all of the historical production can be used to calculate probabilistic reserves, where proved reserves $=\mathrm{P}_{90}$, probable reserves $=\mathrm{P}_{50}-\mathrm{P}_{90}$, and possible reserves $=\mathrm{P}_{10}-\mathrm{P}_{50}$. In our hindcast applications, I matched 6 to 36 months of production data and hindcasted to at most a total time of about 10 years. Being able to generate probabilistically well-calibrated hindcasts in these time frames does not guarantee, of course, that production forecasts of 20-30 years or more and reserves estimates will also be probabilistically well calibrated. But it does increase the likelihood significantly. I believe it is safe to say that if a method is not probabilistically well calibrated for hindcasts, it will almost certainly not be probabilistically well calibrated for forecasts and reserves estimates.

This Bayesian methodology can be easily integrated with other decline curve models. To do this, I need to first replace the Arps model equations (Eq. 2.1) with the appropriate 
equations for a new decline curve model. I then need to define the prior distribution of the parameters (Eq. 2.13) in the new decline curve model. The formulas for calculating the likelihood function, the posterior distribution, and the acceptance ratio will remain the same. The production hindcasts and forecasts can then be performed using the same procedures described in this paper.

This Bayesian methodology can also be applied on other unconventional plays, as well as conventional plays. The primary challenge in applying the methodology is specifying an appropriate prior distribution for the Bayesian updating. The methodology appears to be moderately well calibrated if a non-informative prior is used. However, the calibration can be improved, particularly with short production history, if an informative prior can be used that is tuned to the particular play. An informative prior can be derived from deterministic matching of older wells in the play, if they exist. If the play is relatively new and wells with longer production history do not exist, then it may be possible to use a prior from an analogous play, weighted appropriately based on the similarity of the plays.

I also developed a code called PDCA in excel VBA with Raul Gonzalez and Dr.McVay to perform all the tasks mentioned in this work. 


\subsection{Conclusions}

- For a test case of 197 horizontal, hydraulically fractured Barnett shale gas wells with at least 7 years of production, the proposed Bayesian methodology coupled with Arps' decline curve model reliably quantified the uncertainty of hindcast cumulative production with as little as 6 months of production. The probabilistic estimates $\mathrm{P}_{90}$, $\mathrm{P}_{50}$, and $\mathrm{P}_{10}$ were all well calibrated.

- The Bayesian method had narrower $\mathrm{P}_{90}-\mathrm{P}_{10}$ confidence intervals, had better calibrated $\mathrm{P}_{90}, \mathrm{P}_{50}$, and $\mathrm{P}_{10}$ estimates, and required less computational time for comparable stability than the modified bootstrap methodology presented in the literature. 


\section{ASSESSMENT OF EAGLE FORD SHALE OIL AND GAS RESOURCES}

\subsection{Overview}

The objective of this section is to evaluate Eagle Ford shale oil and gas reserves, contingent resources and prospective resources.

\subsubsection{Workflow}

I started the process by obtaining data from various sources (black boxes in Fig. 3.1). Monthly allocated oil and gas production data until year end 2012 were downloaded from DI Desktop (Drillinginfo, 1998-2011). Oil production was analyzed for all fluid types except dry gas. Tian et al. (2013) analyzed more than 800 vertical wells and built geological maps, such as structure and isopach maps, for the Eagle Ford formation that were used to build simulation models. PVT reports were obtained from the Railroad Commission of Texas (RRC) and Drillinginfo.com (Drillinginfo 2013).

In order to reliably estimate Eagle Ford oil and gas resources, I partitioned the Eagle Ford shale play into eight production regions based on geology, production indicators and fluid types. I compared different decline models by performing probabilistic hindcast studies; the Duong model and the Arps model have the best coverage rate among available models. I used a combination of the Duong and Arps models to model both the linear flow and boundary-dominated flow regimes. For wells with historical data of more than one and half years, I identified the wells that are already in boundarydominated flow if the slope of rate versus material-balance time is close to unity. The distribution of the minimum decline rate where the Duong model switches to the Arps 
model was then estimated from material-balance plots. Gas production for those regions was calculated from the oil production and GOR models, since oil and gas production are highly correlated (Fig. 3.2). The average gas-oil ratio (GOR) of each production region was fitted with GOR models that increase slightly over time. The Duong model was re-parameterized by replacing the initial rate with the cumulative production of oil/gas at 20 years $\left(\mathrm{N}_{240} / \mathrm{G}_{240}\right)$. I integrated geological data and engineering data into reservoir simulation models, and performed probabilistic production forecasts using Monte Carlo simulation with reservoir simulation for each production region. The distributions of $\mathrm{N}_{240} / \mathrm{G}_{240}$ from the reservoir simulation studies were used as the prior distributions of $\mathrm{N}_{240} / \mathrm{G}_{240}$ in the re-parameterized Duong Model (first and second level blue boxes in Fig. 3.1).

Type oil and gas probabilistic decline curves for all production regions were then generated using $\mathrm{MCMC}$ integrated with distributions of $\mathrm{N}_{240} / \mathrm{G}_{240}$ from reservoir simulation forecasts, GOR models, and minimum-decline-rate distributions (first red box in Fig. 3.1).

The Eagle Ford play was then categorized as discovered area or undiscovered area based on distance from existing wells. The highest established well density (HEWD) in each production was observed from Drillinginfo.com (Drillinginfo 2013), and the future well density was modeled with a distribution around the HEWD for each production region. The reserves well count includes only the production from the wells that can be drilled in 
the following five years. The well counts of contingent and prospective resources were calculated based on the discovered area and undiscovered area and corresponding well spacing. The aggregations within each production region were calculated probabilistically while the aggregations between production regions were calculated arithmetically. The reserves, contingent resources, prospective resources and their associated uncertainties were estimated from aggregation of type probabilistic decline curves with probabilistic estimates of well count for each production region and the entire Eagle Ford (second red box in Fig. 3.1).

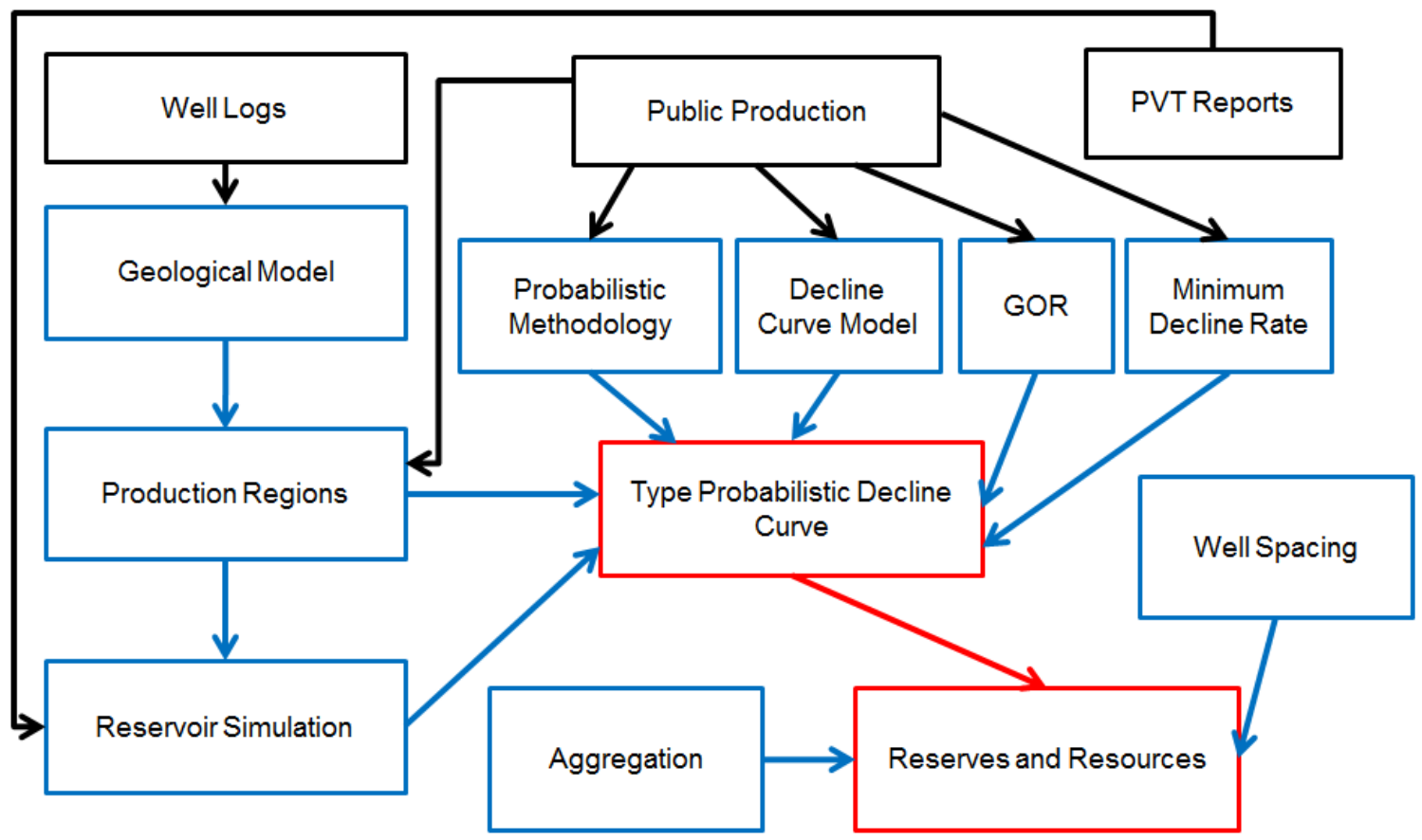

Fig. 3.1 - Workflow of assessment of Eagle Ford shale oil and gas resources, black boxes represent input data, blue boxes represent intermediate steps, and red boxes represent results 


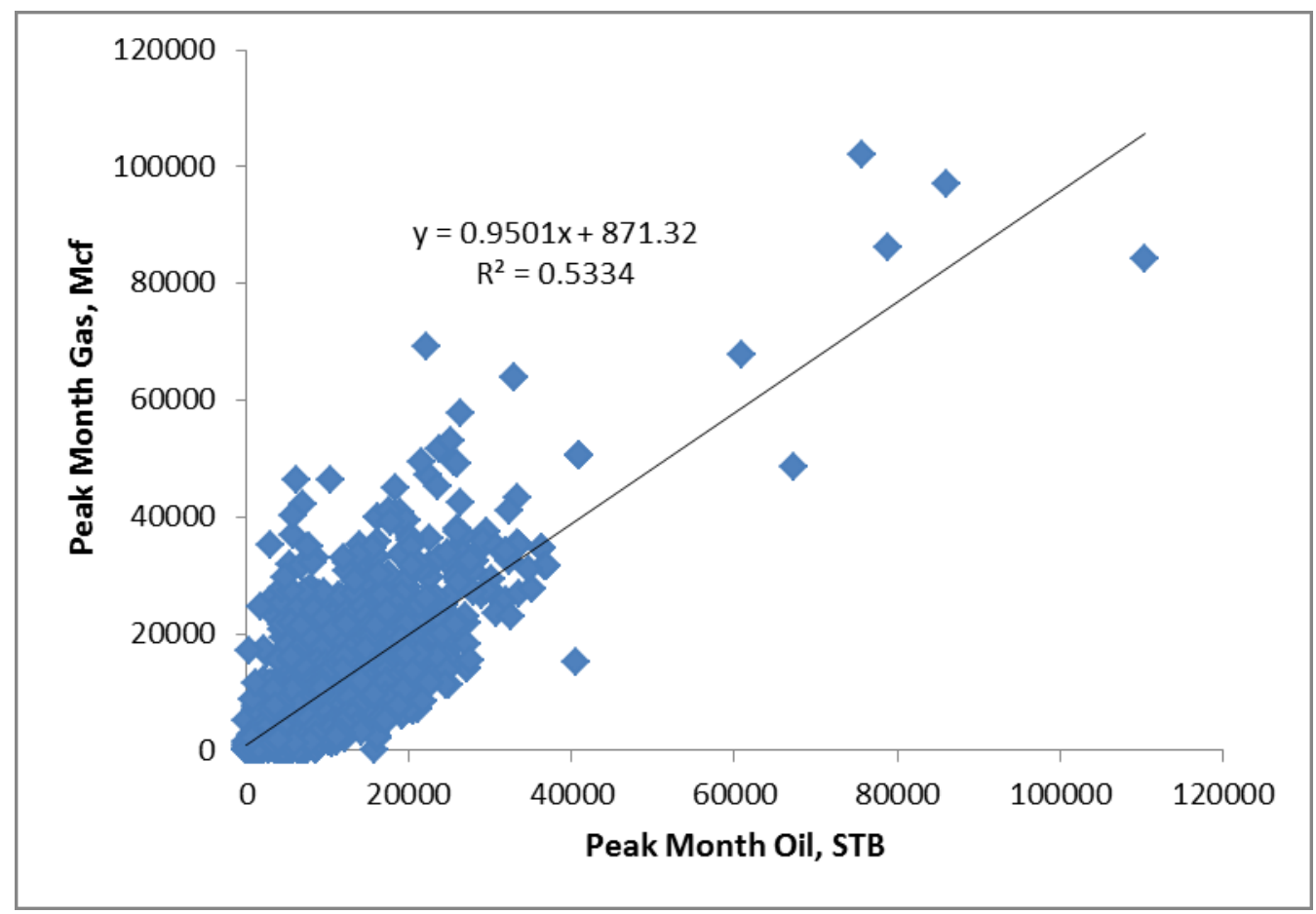

Fig. 3.2 - Peak month oil and peak month gas in black oil window is highly correlated, with $\mathbf{R}^{2}=\mathbf{0 . 5 3}$

\subsubsection{Eagle Ford Geology}

The Eagle Ford shale in south Texas (Fig. 3.3) has been known as the source rock for the Austin Chalk and the East Texas Field. There are extensive outcrops of the Eagle Ford play. The spectacular vertical and lateral exposures of the Eagle Ford strata in west Texas are very useful to examine the properties, characteristics, and sequencestratigraphic settings (Donovan and Staerker 2010). The geological era of the Eagle Ford formation is upper Cretaceous. The Eagle Ford formation was divided into upper Eagle Ford and lower Eagle Ford (Fig. 3.4) by Edman and Pitman (2010). The upper Eagle Ford is in general high in carbonate content and the lower Eagle Ford is in general high 
in organic content. The major kerogen type in the Eagle Ford is type 2 kerogen, which can be either oil-prone or gas-prone. Structurally, the top of the Eagle Ford deepens from northwest to southeast; the depth ranges from 2,500 ft to 14,000 ft (Fig. 3.5).

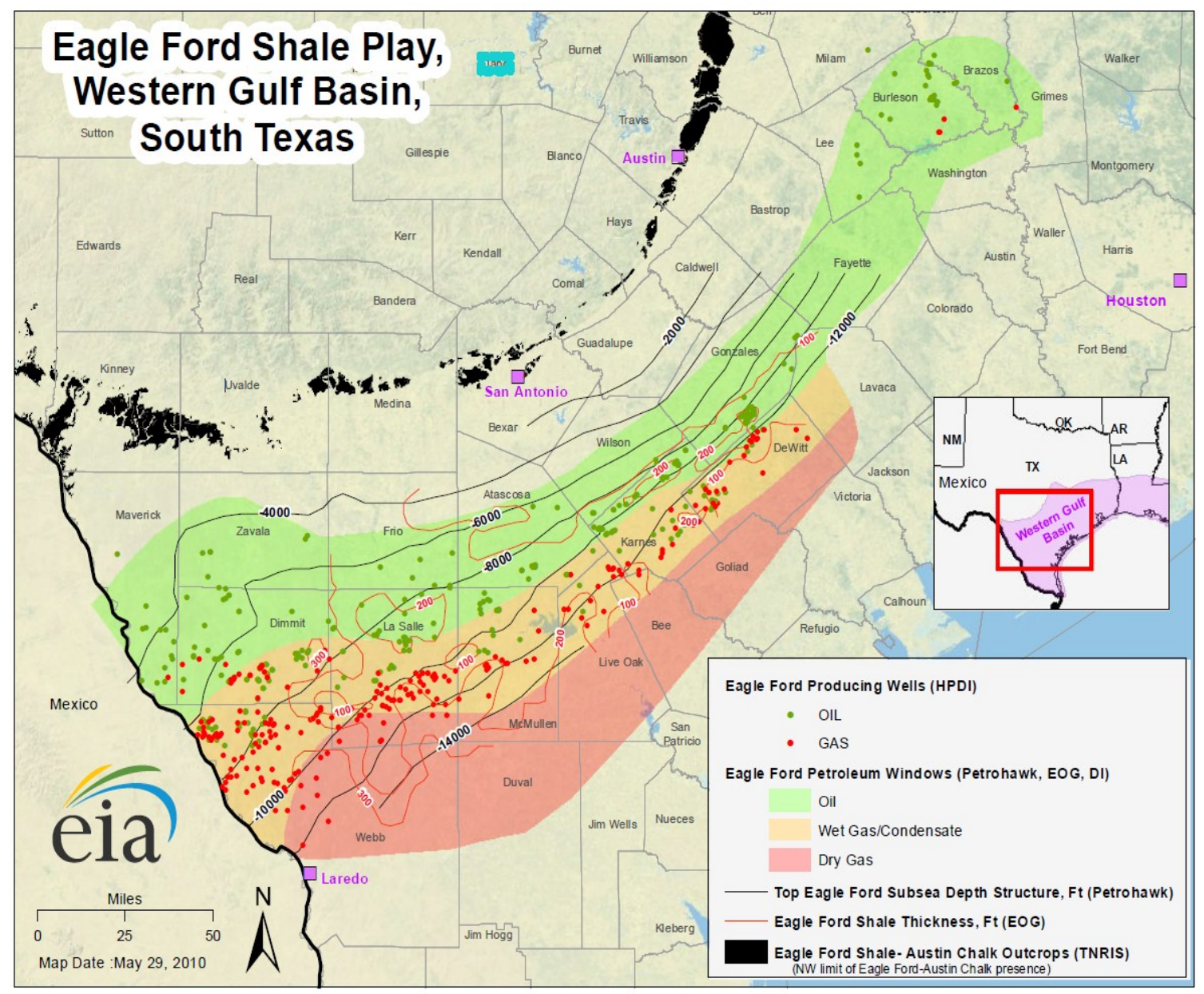

Fig. 3.3 - The Eagle Ford play located in south Texas covers petroleum fluid types from black oil to condensate to dry gas (EIA 2010) 


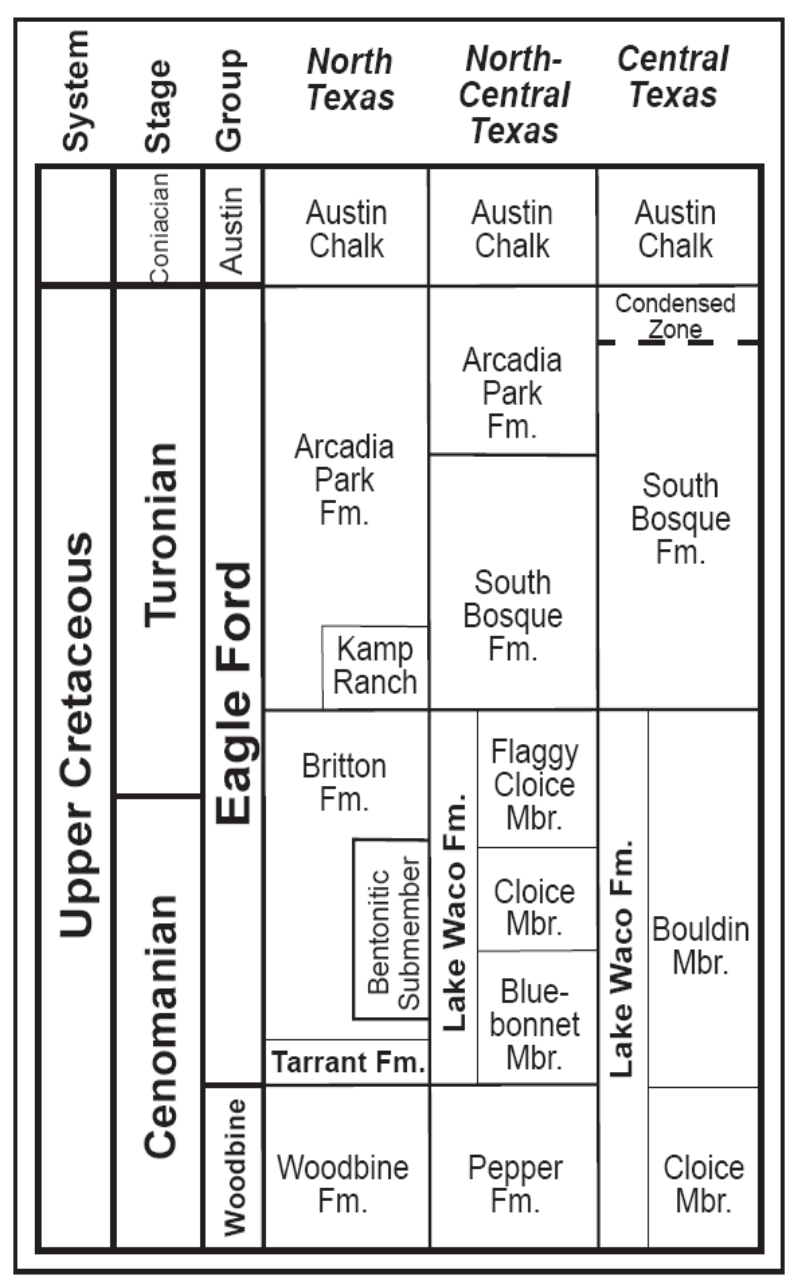

(a)

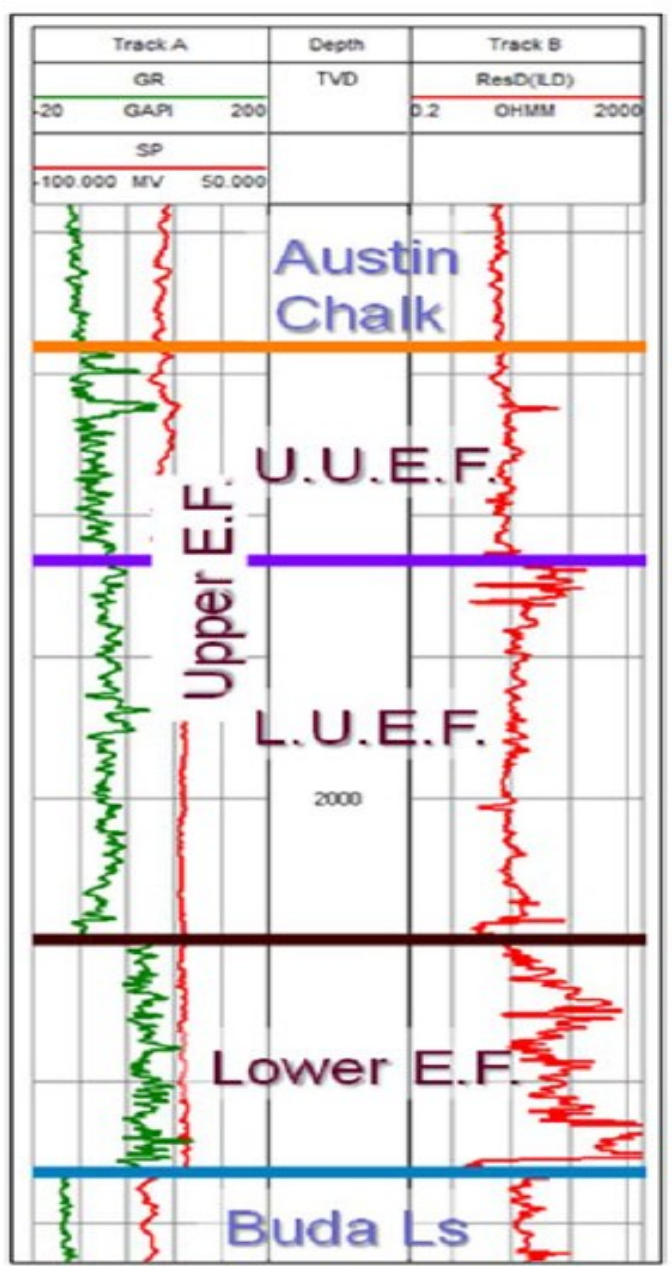

(b)

Fig. 3.4- Geology column and type log: (a) The Eagle Ford formation is in Turonian to Cenomian stage in Cretaceous (Edman and Pitman 2010). (b) Typical well log in Maverick County, Texas, USA shows different log characteristics for upper and lower Eagle Ford (Tian et al. 2013) 


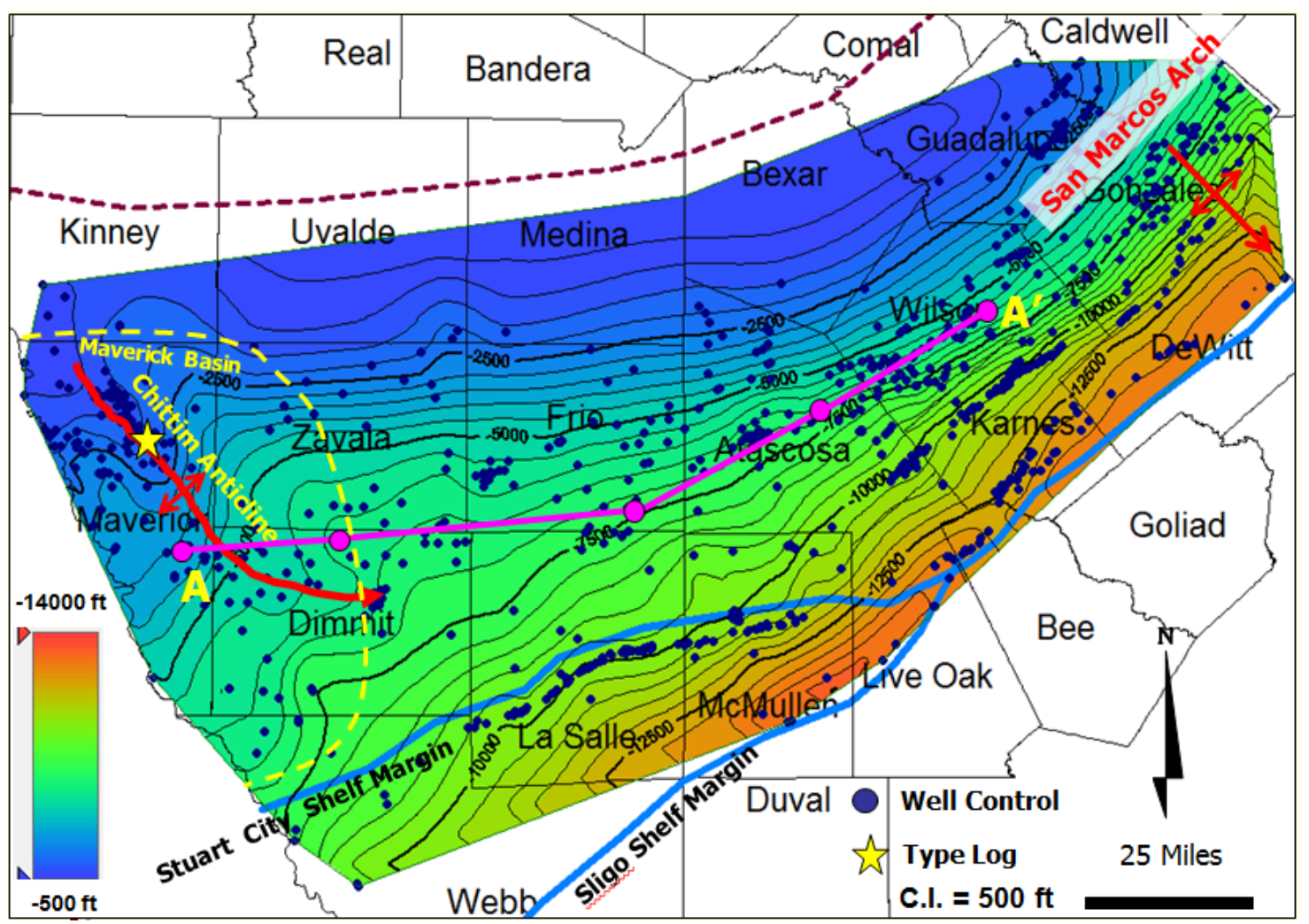

Fig. 3.5 - Structural top of Eagle Ford deepens from northwest to southeast (Tian et al. 2013)

\subsubsection{Eagle Ford Drilling and Completion}

Most, if not all, of the wells drilled in the Eagle Ford are hydraulically-fractured horizontal wells. Lease lines are the dominating factor for lateral lengths. Drilling problems are fairly minimal, and the average spud-to-rig-release is about 20 days with perforated interval exceeding $5000 \mathrm{ft}$ (Pope et al. 2012). The objective of completion in the Eagle Ford shale is to contact as much rock as possible with a fracture network of adequate conductivity. The number of stages ranges from 12 to 16 , liquid treatment volume ranges from 2 to 7 million gallons, and proppant amounts range from 2 to 10 
million pounds (Centurion et al. 2012). The cost of the stimulation can exceed US $\$ 5$ million, which represents $60 \%$ of the total well construction cost (Pope et al. 2012).

\subsubsection{Reserves, Contingent Resources, and Prospective Resources}

The U.S. Security and Exchange Commission (SEC) defined the term "proved reserves" in Rule 4-10 under regulation S-X as such: "proved oil and gas reserves are the estimated quantities of crude oil, natural gas, and natural gas liquids which geological and engineering data demonstrate with reasonable certainty to be recoverable in future years from known reservoirs under existing economic and operating condition.” In 2007, the Society of Petroleum Engineers (SPE), the American Association of Petroleum Geologists (AAPG), the World Petroleum Council (WPC), and the Society of Petroleum Evaluation Engineers (SPEE) jointly published the Petroleum Resources Management System (PRMS). The definitions and guidelines in PRMS "are designed to provide a common reference for the international petroleum industry, including national reporting and regulatory disclosure agencies, and to support petroleum project and portfolio management requirements." (SPE et al. 2007) The basic principle in PRMS is that "the estimation of petroleum resource quantities involves the interpretation of volumes and values that have an inherent degree of uncertainty." (SPE et al. 2007) These quantities are associated with development projects at various stages of design and implementation. The SEC published the Modernization of Oil and Gas Reporting (2009), which allowed using probabilistic methodologies to define reserves. 
Definitions of reserves, contingent resources and prospective resources in PRMS are shown in Fig. 3.6 and following:

- Reserves are those quantities of petroleum anticipated to be commercially recoverable by application of development projects to known accumulations from a given date forward under defined conditions.

- Contingent Resources are those quantities of petroleum estimated, as of a given date, to be potentially recoverable from known accumulations, but the applied project(s) are not yet considered mature enough for commercial development due to one or more contingencies.

- Prospective Resources are those quantities of petroleum estimated, as of a given date, to be potentially recoverable from undiscovered accumulations by application of future development projects.

I followed the PRMS rules in this work to estimate reserves, contingent resources and prospective resources. 


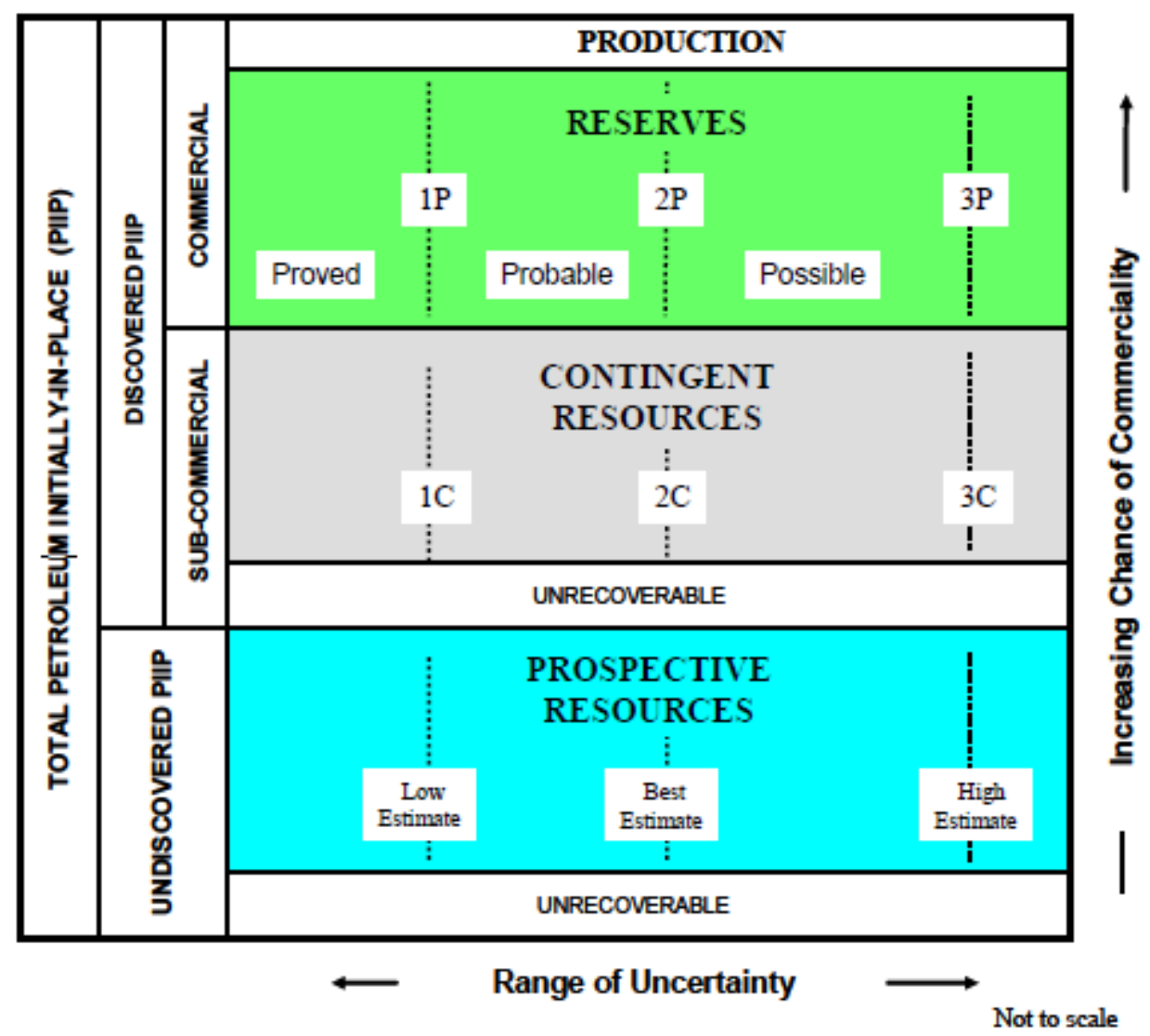

Fig. 3.6- Flow chart and generalized division of resource and reserve categories, from PRMS (SPE et al. 2007)

\subsection{Data Acquisition}

\subsubsection{Production Data}

I gathered allocated production data from DI Desktop (Drillinginfo 1998-2011) up through December 2012. In Texas, the production data are originally reported at the lease level; the allocated production data are calculated from well tests by DI Desktop. I included in the study a total of 4402 wells (with last production of December 2012) that satisfy the following criteria: 
- Initial production after $1 / 1 / 2008$

- Produced from the Eagle Ford formation

- Counties: Atascosa, Bee, Dewitt, Dimmit, Fayette, Frio, Gonzalez, Karnes, La Salle, Lavaca, Live Oak, Maverick, McMullen, Webb, Wilson, Zavala

- Horizontal wells or directional wells

Quality checks of all the oil and gas production data for all wells were performed to generate meaningful results. Wells that include too few months of production data $(<3$ months) and with irregular behavior (production too noisy or increasing) were excluded from the study (Fig. 3.7). For wells that are included in the study, if there is an obvious sudden production change, only the higher production part is analyzed (Fig. 3.8).

Significant outliers from primary production trends were also deleted (Fig. 3.8).

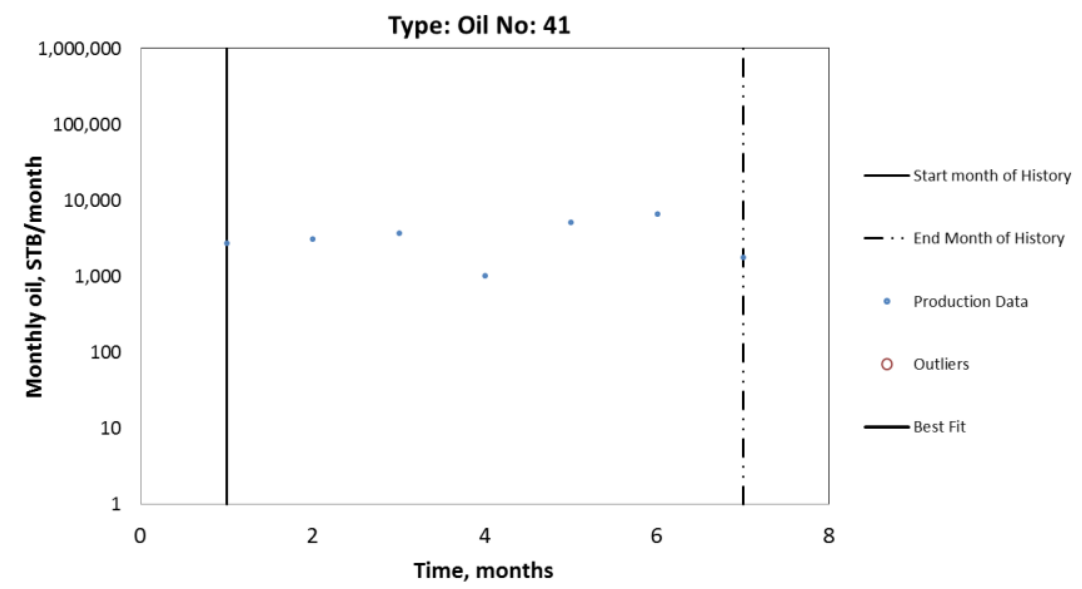

Fig. 3.7- An example well with increasing monthly production that was excluded from the study 


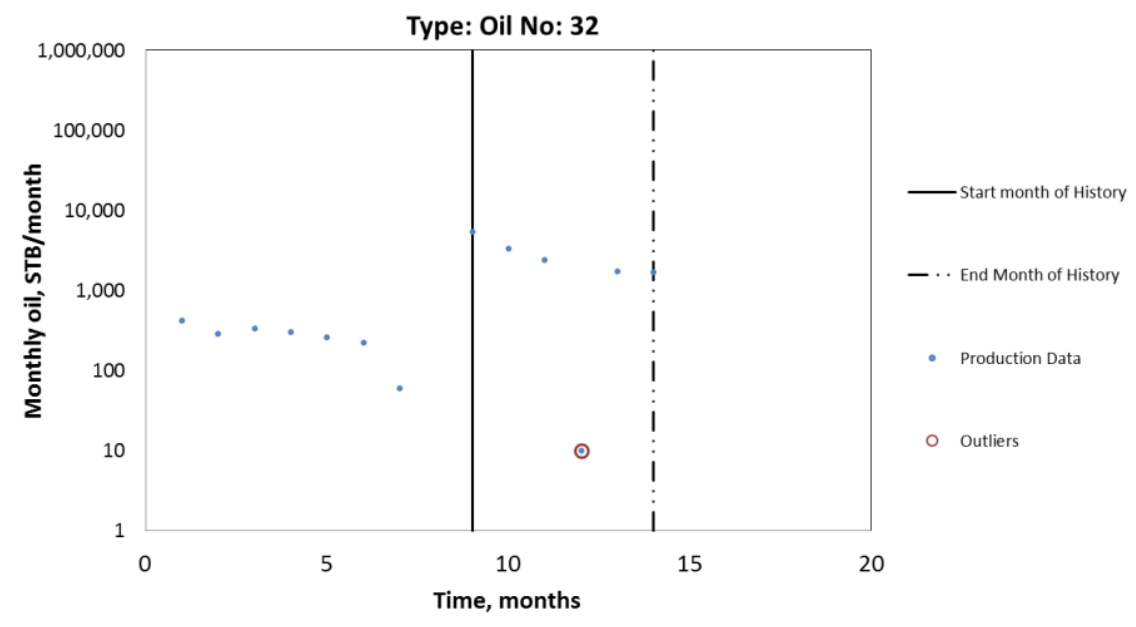

Fig. 3.8 - An example well in which only the higher production period was analyzed and an outlier was excluded

\subsubsection{Geological Data}

Tian et al. (2013) analyzed more than 800 vertical wells and built geological maps, such as structure (Fig. 3.5) and isopach maps, for the Eagle Ford formation that were used to build simulation models. The geological maps were then mapped into gridblocks of 1000 $\mathrm{ft}$ by $1000 \mathrm{ft}$ (Fig. 3.9) so that distributions of geological properties such as formation depth and thickness can be generated. A geological model consisting of 340,000 gridblocks was created for the 7 million acres of the Eagle Ford play. The distribution of depth for the entire Eagle Ford is shown in Fig. 3.10. Yao Tian* also provided type logs for all production regions, which were used to model reservoir properties in reservoir simulation models.

* Personal communication with Yao Tian 2013. College Station: Texas A\&M University. 


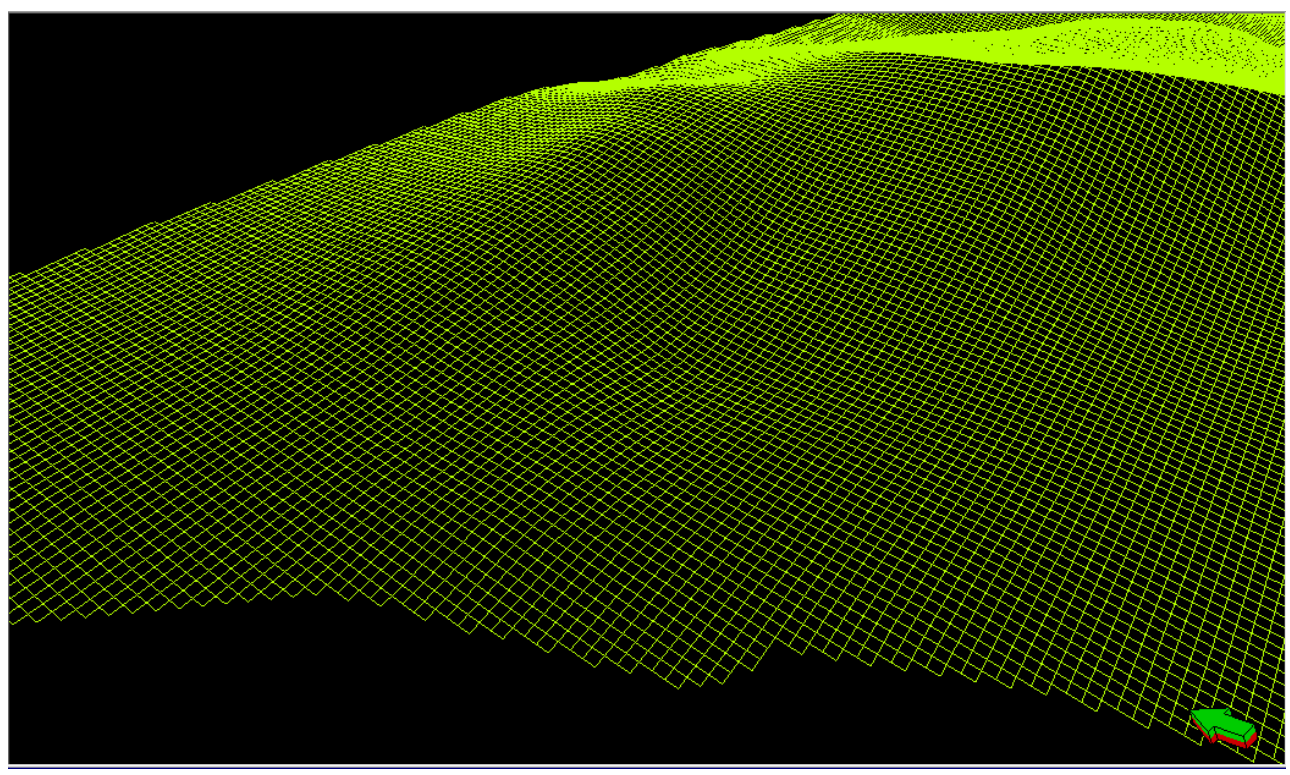

Fig. 3.9- Gridblocks of $1000 \mathrm{ft}$ by $1000 \mathrm{ft}$ used to calculate distributions of reservoir properties.

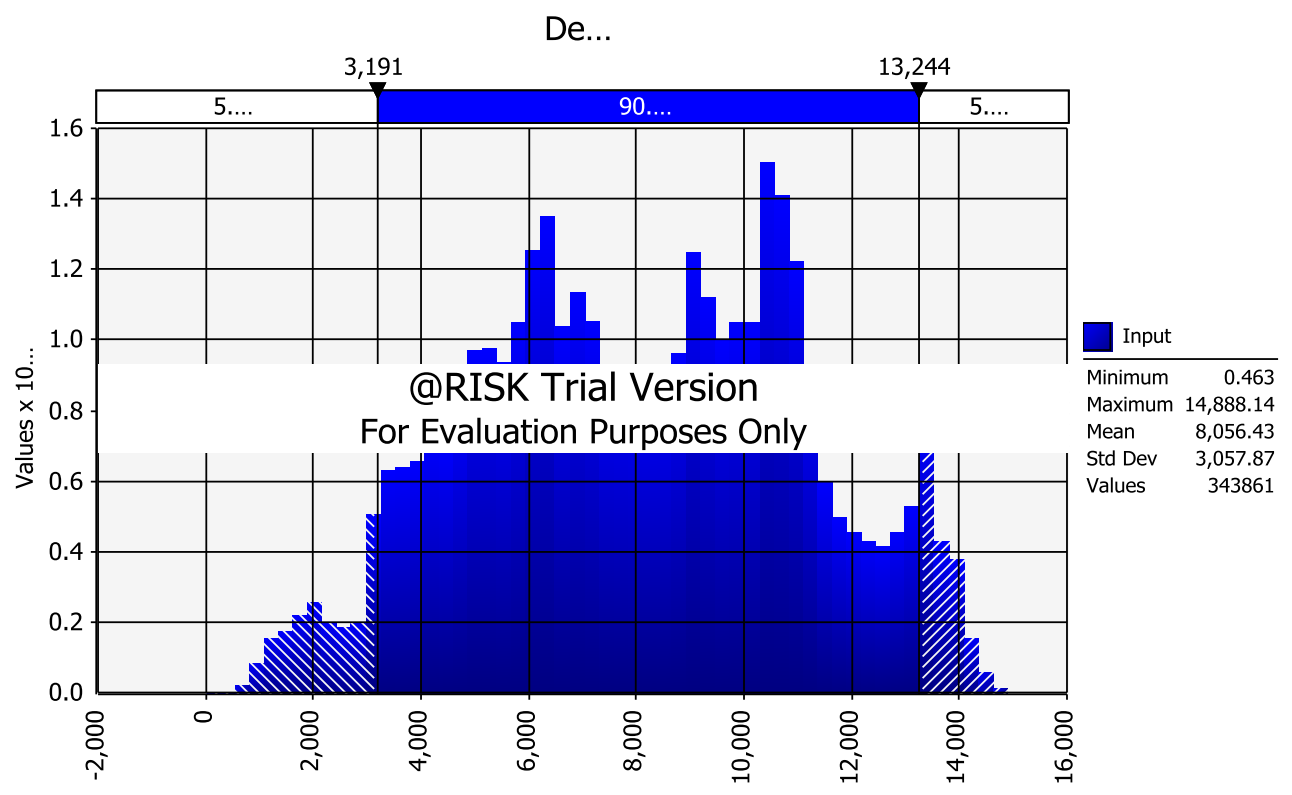

Fig. 3.10 - Histogram of the top of the Eagle Ford formation 


\subsubsection{PVT Data}

PVT data were obtained from the Railroad Commission of Texas (RRC) and Drillinginfo.com (Drillinginfo 2013). From the RRC, I gathered a total of 106 partial PVT reports and 28 full reports with constant composition expansion tests and constant volume depletion tests. All partial PVT reports include composition to $\mathrm{C} 7+$ of the petroleum fluid, C7+ molecular weight, initial producing GOR, oil API gravity, and gas specific gravity. The full reports include all the information mentioned above, with additional information such as measured bubble point or dew point, initial reservoir pressure and temperature, constant composition expansion tests, and constant volume depletion tests. Most, if not all, of the PVT reports were for wells in the condensate windows for RRC reporting purposes. From Drillinginfo.com, I gathered gas specific gravity and oil density data that were used in the black-oil correlations to calculate the PVT models.

\subsection{Partition of Eagle Ford Shale Play into Eight Production Regions}

The Eagle Ford shale has complex geology, covers all fluid types from black oil to dry gas, and has variable production performance. In order to accurately evaluate the entire Eagle Ford shale resources, I partitioned the Eagle Ford play into eight production regions so that fluid type, performance indicators, and geology are similar within production regions but are different between production regions. The fluid type for each producing well is defined by the initial gas-oil ratio based on Dr. McCain's criteria (2009) (Table 3.1). The fluid type varies from black oil to volatile oil to condensate to 
dry gas from north to south (Fig. 3.11). The second-month oil production provided by Drillinginfo.com (Drillinginfo 2013) was used as the performance indicator and it generally decreases from east to west (Fig. 3.12). The upper Eagle Ford is present in the west and middle part but is not present in the east part (Fig. 3.13), while the lower Eagle Ford is present through the entire Eagle Ford. Based on these characteristics, I partitioned the Eagle Ford play into the eight production regions listed in Table 3.2 and shown in Fig. 3.11 to Fig. 3.13. The counts and production regions for the PVT reports are listed in Table 3.3.

An interesting observation is that some of the area in Production Region 1 (PR1) is very shallow (less than 3,000 ft deep). The wells in these shallow areas are likely to be nonproductive because of the low initial reservoir pressure associated with shallow depth, so these areas were excluded from this study (Fig. 3.14 and Fig. 3.15).

\begin{tabular}{|cc|}
\hline Table 3.1- Fluid Type Definition Based on Initial GOR \\
\hline Fluid Type & Initial GOR, SCF/STB \\
\cline { 2 - 2 } Black Oil & $0-1,500$ \\
Volatile Oil & $3,200-10,000$ \\
Condensate & $10,000-100,000$ \\
Dry Gas & $>100,000$ \\
\hline
\end{tabular}




\begin{tabular}{|cccccc|}
\hline \multicolumn{5}{c}{ Table 3.2-Characteristics of Eight Production Regions } \\
\hline $\begin{array}{c}\text { Production } \\
\text { Region }\end{array}$ & $\begin{array}{c}\text { True } \\
\text { PR1 }\end{array}$ & Fluid Type & Initial Oil & Rertical & Area, \\
PR2 & Condensate/Volatile Oil & Medium-Low & Upper and Lower & 6,505 & 942,734 \\
PR3 & Black Oil & Medium & Upper and Lower & 7,719 & $1,617,410$ \\
PR4 & Condensate & Medium-Low & Upper and Lower & 10,874 & 584,070 \\
PR5 & Black Oil & Medium-High & Lower & 9,450 & 977,484 \\
PR6 & Volatile Oil & High & Lower & 12,286 & 338,000 \\
PR7 & Condensate & Medium & Lower & 13,470 & 478,888 \\
PR8 & Dry Gas & None & Upper and Lower & 10,532 & $1,201,185$ \\
\hline
\end{tabular}

\begin{tabular}{|ccc|}
\hline \multicolumn{2}{|c|}{ Table 3.3-Counts and Locations of PVT Reports } \\
\hline Production Region & PVT report Count & Full Report Count \\
\cline { 2 - 3 } PR2 & 39 & 2 \\
PR3 & 3 & 1 \\
PR4 & 17 & 2 \\
PR6 & 36 & 23 \\
PR7 & 11 & 0 \\
Total & 106 & 28 \\
\hline
\end{tabular}

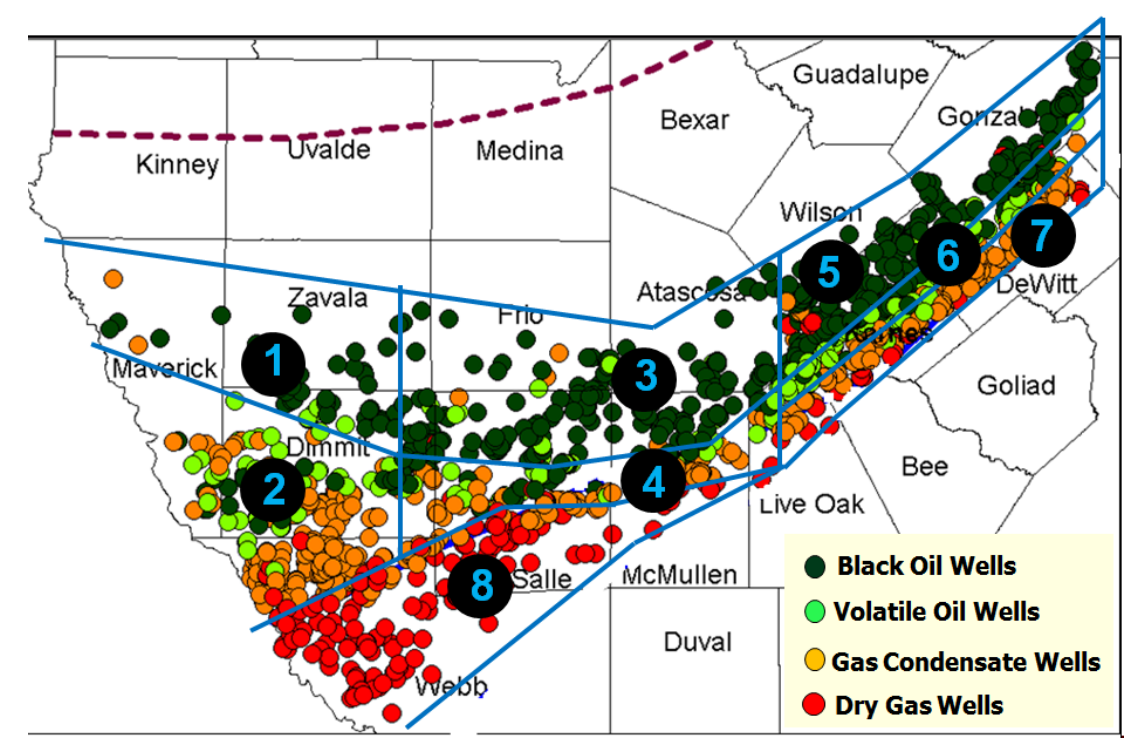

Fig. 3.11 - Fluid type changes from black oil to dry gas from north to south 


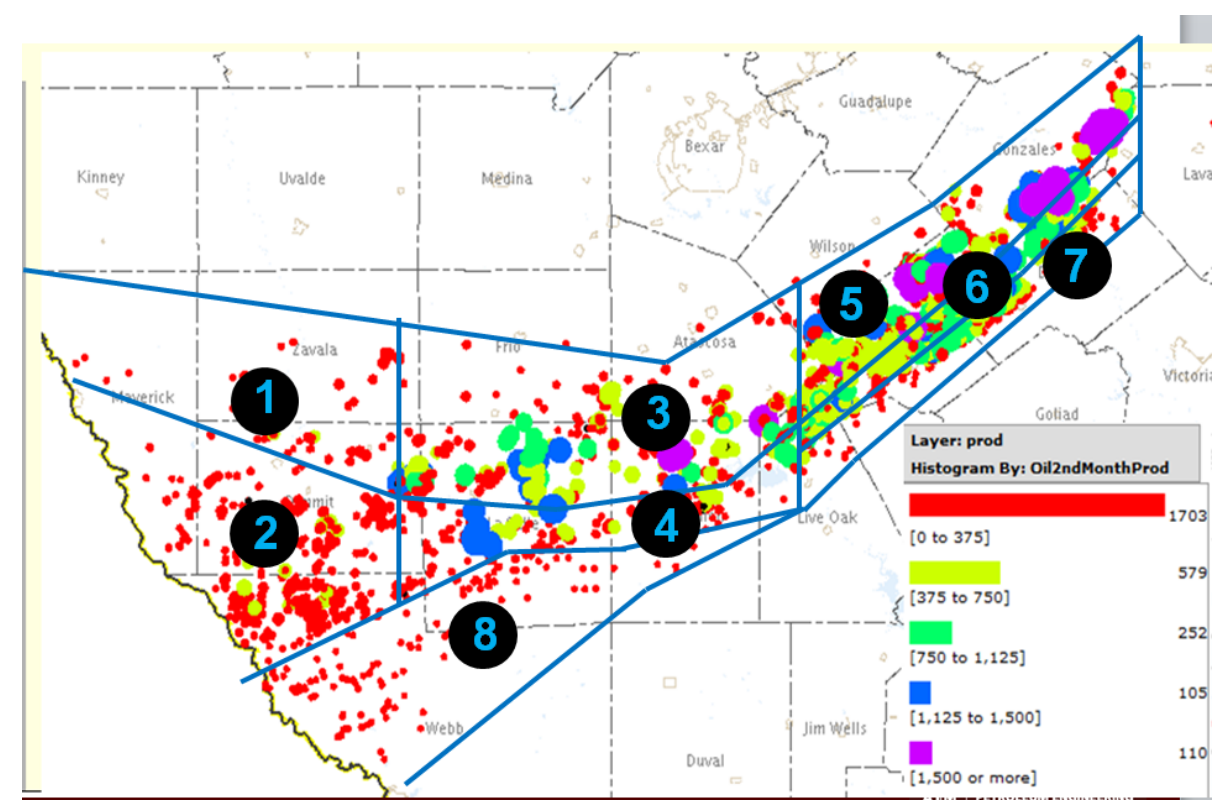

Fig. 3.12 - Second-month oil production was used as the production indicator and it decreases from east to west

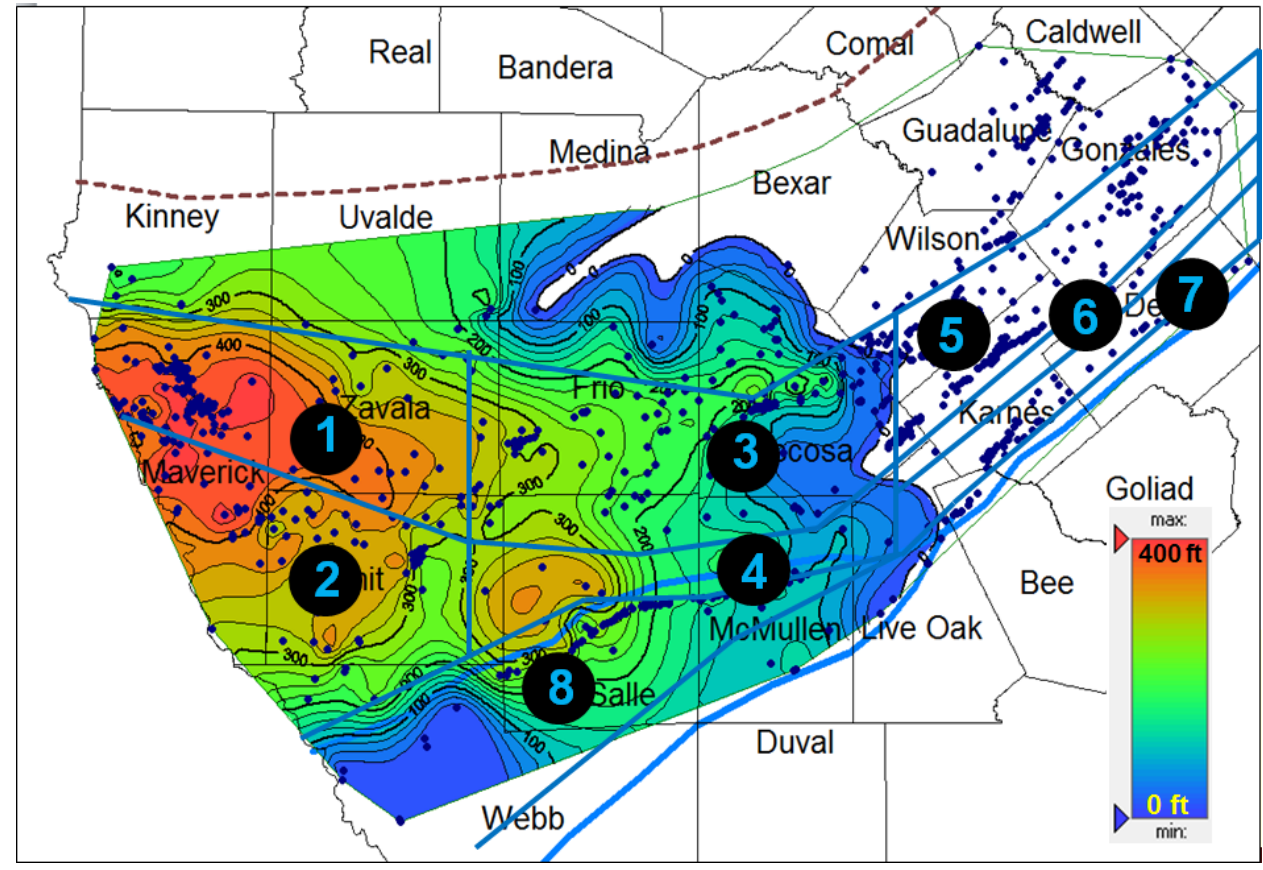

Fig. 3.13 - Upper Eagle Ford formation is only present in west and middle part of the Eagle Ford play 


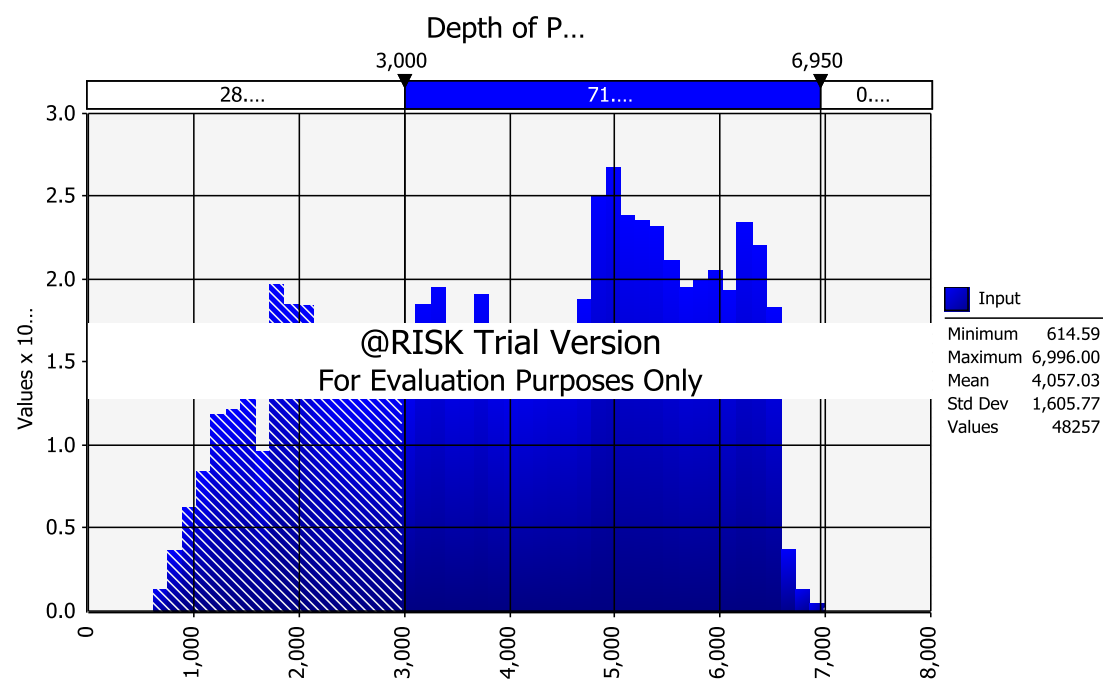

Fig. 3.14- Areas that have depth below $3000 \mathrm{ft}$ were excluded from the study inside of Production Region 1 (PR1)

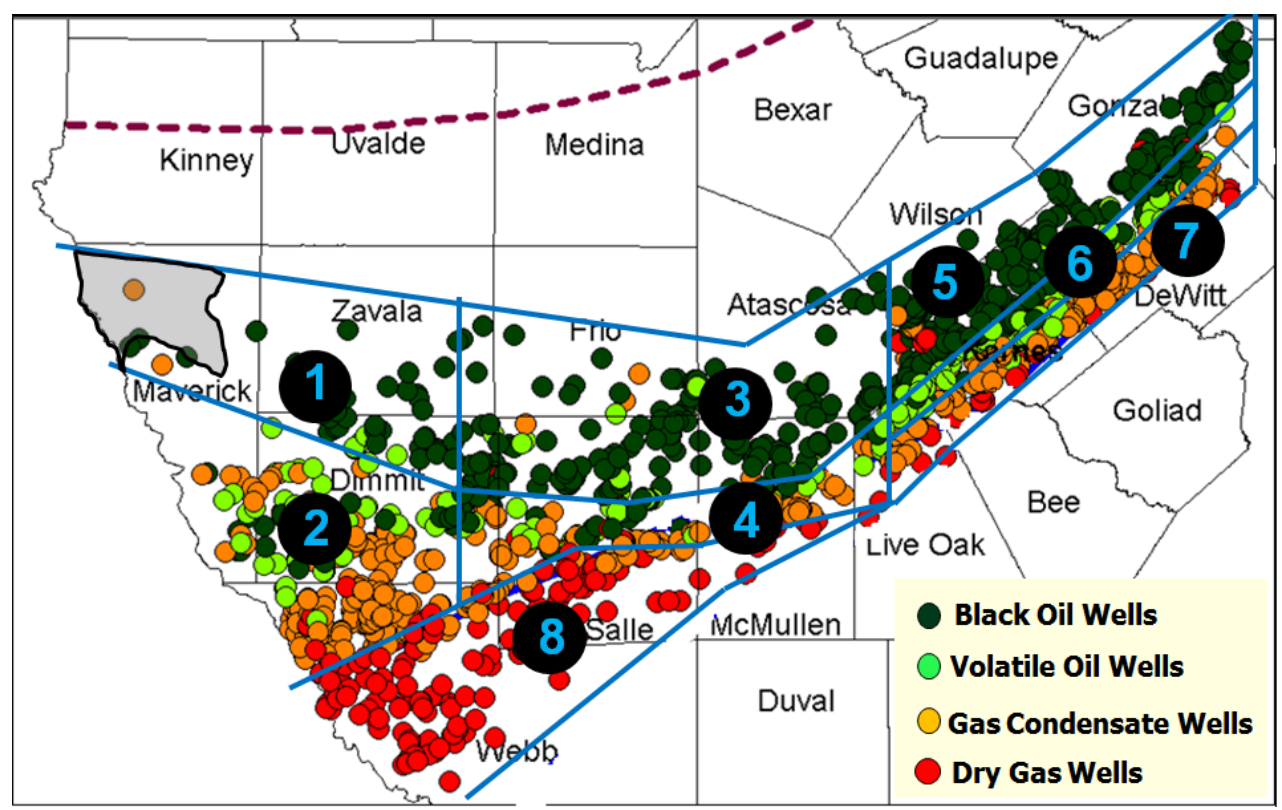

Fig. 3.15- Areas in the northwest corner of PR1 is excluded from the study because the depth is below $3000 \mathrm{f}$ 


\subsection{Decline Curve Model Selection}

\subsubsection{Probabilistic Hindcast Studies}

The best way to determine which decline curve model to use is to perform hindcast studies. I selected 4 regions, PR2, PR3, PR6, and PR8, that cover all four fluid types: condensate, black oil, volatile oil, and dry gas, respectively. For condensate (PR2), black oil (PR3), and volatile oil (PR6) regions, oil production was analyzed. For the dry gas region (PR8), gas production was analyzed. Since the Eagle Ford shale is still early in development, only wells with more than a year of production were selected in the hindcast study. In the hindcast study, the first six months of production were assumed known and the actual production during the second period (PDTSP) was compared with the hindcasted PDTSP using different decline curve models with MCMC.

The probabilistic results were shown in Fig. 3.16. The desired result is that proportion correct equals probability assigned for the entire distribution, i.e., a straight line with unit slope on a plot of proportion correct vs. probability assigned ("perfect" line in Fig. 3.16). According to Fig. 3.16, the Arps model and the Duong model are consistently close to the unit slope; the SEPD model underestimates the PDTSPs in all regions except PR3; and the Power-Law model significantly overestimates the PDTSPs in all regions except PR8. Table 3.4 shows that the average coverage rates for the Arps model and the Duong model are 0.74, the Power-Law model 0.62, and the SEPD model 0.68. 
The Arps model and the Duong model were well calibrated in the hindcast studies. There was no significant difference between the coverage rates; however, the Arps model is designed to model boundary-dominated flow, while the Duong model is designed to model linear flow. I decided to use a combination of the Duong and Arps models to model both the linear flow and boundary-dominated flow regimes. The Arps tail is necessary because the probabilistic Duong model consistently overestimates PDTSPs since the PDTSP $>\mathrm{P}_{90}, \mathrm{P}_{50}$, and $\mathrm{P}_{10}$ are consistently smaller than $0.1,0.5$, and 0.9 , respectively for all production regions (Table 3.4).

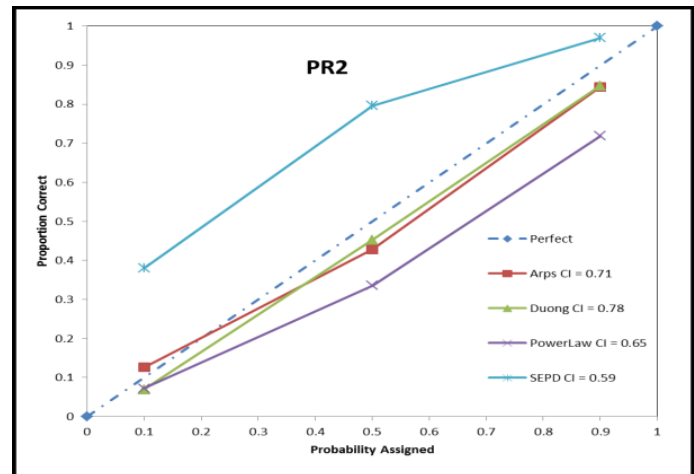

(a)

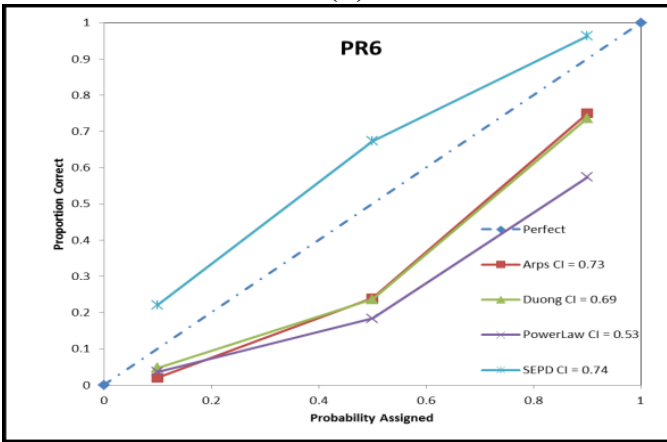

(c)

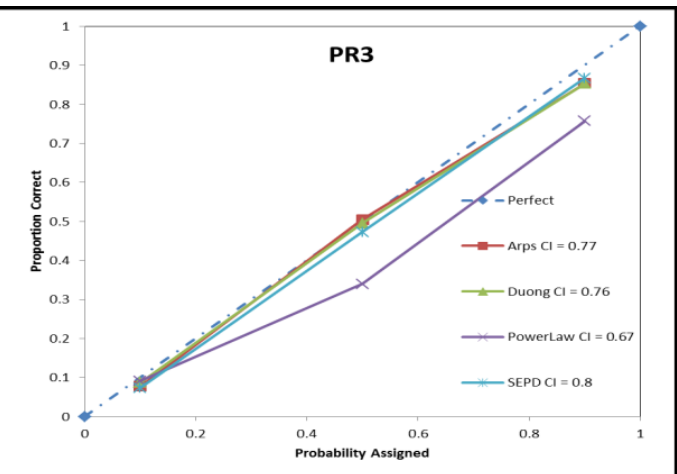

(b)

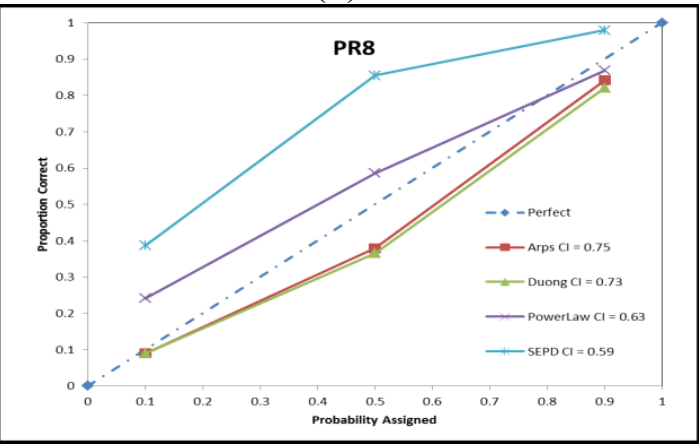

(d)

Fig. 3.16- Production hindcasts show that the Arps model and the Duong model have the best coverage rate for oil production of condensate region PR2 (a), black oil region PR3 (b), and volatile oil region PR6(c), and gas production of dry gas region PR8 (d) 


\begin{tabular}{|c|c|c|c|c|}
\hline \multicolumn{5}{|c|}{$\begin{array}{c}\text { Table 3.4- Probabilistic Hindcast Studies Show that the } \\
\text { Arps Model and the Duong Model Have the Best Coverage } \\
\text { Rates }\end{array}$} \\
\hline Decline Curve Model & Arps & Duong & Power-Law & $\underline{\text { SEPD }}$ \\
\hline \multicolumn{5}{|c|}{ PR2 (Condensate) } \\
\hline PDTSP $>P_{90}$ & 0.84 & 0.85 & 0.72 & 0.97 \\
\hline PDTSP $>P_{50}$ & 0.43 & 0.45 & 0.34 & 0.80 \\
\hline $\mathrm{PDTSP}>\mathrm{P}_{10}$ & 0.13 & 0.07 & 0.07 & 0.38 \\
\hline Coverage Rate & 0.72 & 0.78 & 0.65 & 0.59 \\
\hline \multicolumn{5}{|c|}{ PR3 (Black Oil) } \\
\hline PDTSP $>P_{90}$ & 0.85 & 0.85 & 0.76 & 0.87 \\
\hline PDTSP $>P_{50}$ & 0.50 & 0.50 & 0.34 & 0.47 \\
\hline$P D T S P>P_{10}$ & 0.08 & 0.09 & 0.09 & 0.07 \\
\hline Coverage Rate & 0.78 & 0.77 & 0.67 & 0.79 \\
\hline \multicolumn{5}{|c|}{ PR6 (Volatile Oil) } \\
\hline PDTSP $>P_{90}$ & 0.75 & 0.74 & 0.57 & 0.96 \\
\hline PDTSP $>P_{50}$ & 0.24 & 0.24 & 0.18 & 0.67 \\
\hline PDTSP $>P_{10}$ & 0.02 & 0.05 & 0.04 & 0.22 \\
\hline Coverage Rate & 0.73 & 0.69 & 0.54 & 0.74 \\
\hline \multicolumn{5}{|c|}{ PR8 (Dry Gas) } \\
\hline PDTSP $>P_{90}$ & 0.84 & 0.82 & 0.87 & 0.98 \\
\hline $\mathrm{PDTSP}>\mathrm{P}_{50}$ & 0.38 & 0.37 & 0.59 & 0.86 \\
\hline PDTSP $>P_{10}$ & 0.09 & 0.09 & 0.24 & 0.39 \\
\hline Coverage Rate & 0.75 & 0.73 & 0.63 & 0.59 \\
\hline $\begin{array}{c}\text { Average Coverage Rate for All } \\
4 \text { PRs }\end{array}$ & 0.74 & 0.74 & 0.62 & 0.68 \\
\hline
\end{tabular}

\subsubsection{Re-parameterize Duong Model}

Since geological and engineering data from the Eagle Ford play are available, I would like to utilize them as the prior information for the probabilistic decline-curve analysis. I performed reservoir simulation with Monte Carlo simulation for each production region to provide additional information for probabilistic decline curve analysis so that the probabilistic decline curves calculated do not depend solely on production data but also on valuable geological and engineering data. In order to fully utilize the reservoir 
simulation results, the oil and gas cumulative production was selected as the optimal parameter from the reservoir simulation runs to use instead of other parameters like initial production rate. I re-parameterized the Duong model so it includes as a decline curve parameter the cumulative oil production at 20 years $\left(\mathrm{N}_{240}\right)$ for PR1 to PR7 or cumulative gas production at 20 years $\left(\mathrm{G}_{240}\right)$ for PR8. I started with the original Duong model:

$\frac{\mathrm{q}}{\mathrm{G}_{\mathrm{p}}}=a t^{-m}$

$\mathrm{q}(\mathrm{t})=q_{1} t^{-m} \exp \left(\frac{a}{1-m}\left(t^{1-m}-1\right)\right)$

The unit of $t$ is months, instead of days in the original model (Duong 2011), since I am using monthly production from public data bases; changing the time unit does not change the form of Eq. 3.1 or Eq. 3.2.

First, I calculate the rate at month 240 (end of 20 years),

$$
\begin{aligned}
q_{240} & =G_{240} a 240^{-m} \ldots \ldots \ldots \ldots \ldots \ldots \ldots \ldots \\
q_{240} & =q_{1} 240^{-m} \exp \frac{a}{1-m}\left(240^{1-m}-1\right)
\end{aligned}
$$

I then solve $q_{I}$ from Eq. 3.3 and Eq. 3.4 as a function of $\mathrm{G}_{240}$,

$$
q_{1}=\frac{G_{240} a}{\exp \frac{a}{1-m}\left(240^{1-m}-1\right)} .
$$


I start with Eq. 3.2, and substitute $q_{1}$ using Eq. 3.5,

$$
\begin{aligned}
& q=q_{1} t^{-m} \exp \frac{a}{1-m}\left(t^{1-m}-1\right) \\
& =\frac{G_{240} a t^{-m}}{\exp \frac{a}{1-m}\left(240^{1-m}-1\right)} \exp \frac{a}{1-m}\left(t^{1-m}-1\right) \\
& =G_{240} a t^{-m} \exp \frac{a}{1-m}\left(t^{1-m}-240^{1-m}\right) \ldots \ldots \ldots \ldots
\end{aligned}
$$

I then defined $l=m-1$ since I found that $m-1$ follows a lognormal distribution for the best-fitted $m$ from the Eagle Ford wells,

$$
q=G_{240} a t^{-(l+1)} \exp \frac{a}{-l}\left(t^{-l}-240^{-l}\right)
$$

Eq. 3.7 is the re-parameterized Duong model with decline curve parameters $\mathrm{G}_{240}\left(\mathrm{~N}_{240}\right)$, $a$, and $l$. This model was used in the following sections for production forecasts.

\subsection{Integration of Geological and Engineering Data Through Reservoir Simulation}

\subsubsection{Overview}

Since empirical decline curve models depend purely on production data, the forecasted recovery factor can exceed one without any other information. Reservoir simulation studies were performed to provide valuable information to complement the decline curve analysis. The combination can generate more reasonable production forecasts that take account of the geological and engineering data as well as the production data. 
In order to generate meaningful results, I build a base case model representative of each production region. The base case models have geological, reservoir, and fluid properties as well as oil and gas production typical of the respective production regions. In building these base case models, the well spacing and fracture spacing were the widest within the industry standard so that the well is in linear flow longer. The cumulative production from the reservoir simulation studies are used as the prior information for the cumulative production parameter $\left(\mathrm{N}_{240}\right.$ or $\left.\mathrm{G}_{240}\right)$ in the re-parameterized Duong model. Monte Carlos simulation with reservoir simulation was performed to generate the distributions of 20year cumulative production for oil or gas $\left(\mathrm{N}_{240}\right.$ or $\left.\mathrm{G}_{240}\right)$.

\subsubsection{Initialization of Base Case Reservoir Simulation Models}

\section{Reservoir Geometry}

Before defining the reservoir geometry, I surveyed through the public data bases for the typical drilling and completion standard in the Eagle Ford shale. The average perforated interval for all the horizontal wells in the Eagle Ford is $4694 \mathrm{ft}$, the number of stages ranges from 12 to 18 , well spacing ranges from 60 acres/well to 160 acres/well in the Eagle Ford according to Drillinginfo.com (Drillinginfo 2013). I selected wider fracture spacings and wider well spacing from these ranges. The reservoir geometry for the base case models are: perforated interval $=4694 \mathrm{ft}$, number of stages $=12$, average successful clusters per stage $=2$, and well spacing $=160$ acres $/$ well. A single well base case model was created for each production region. The reservoir model size is $1 / 48$ of the entire well based on symmetry to speed up reservoir simulation. Fig. 3.17 and Table 3.5 show 
the reservoir geometry and key reservoir geometry parameters of the base case reservoir simulation models. The hydraulic fracture was explicitly modeled where the fracture conductivity decreases from the center to the tip in the fracture (Y-Z) plane (Honarpour et al. 2012) (Fig. 3.18). The fracture width was set as $2 \mathrm{ft}$ for calculation purposes; Alkouh et al. (2012) shows that reservoir models with the same fracture conductivity but different fracture widths yield similar results.

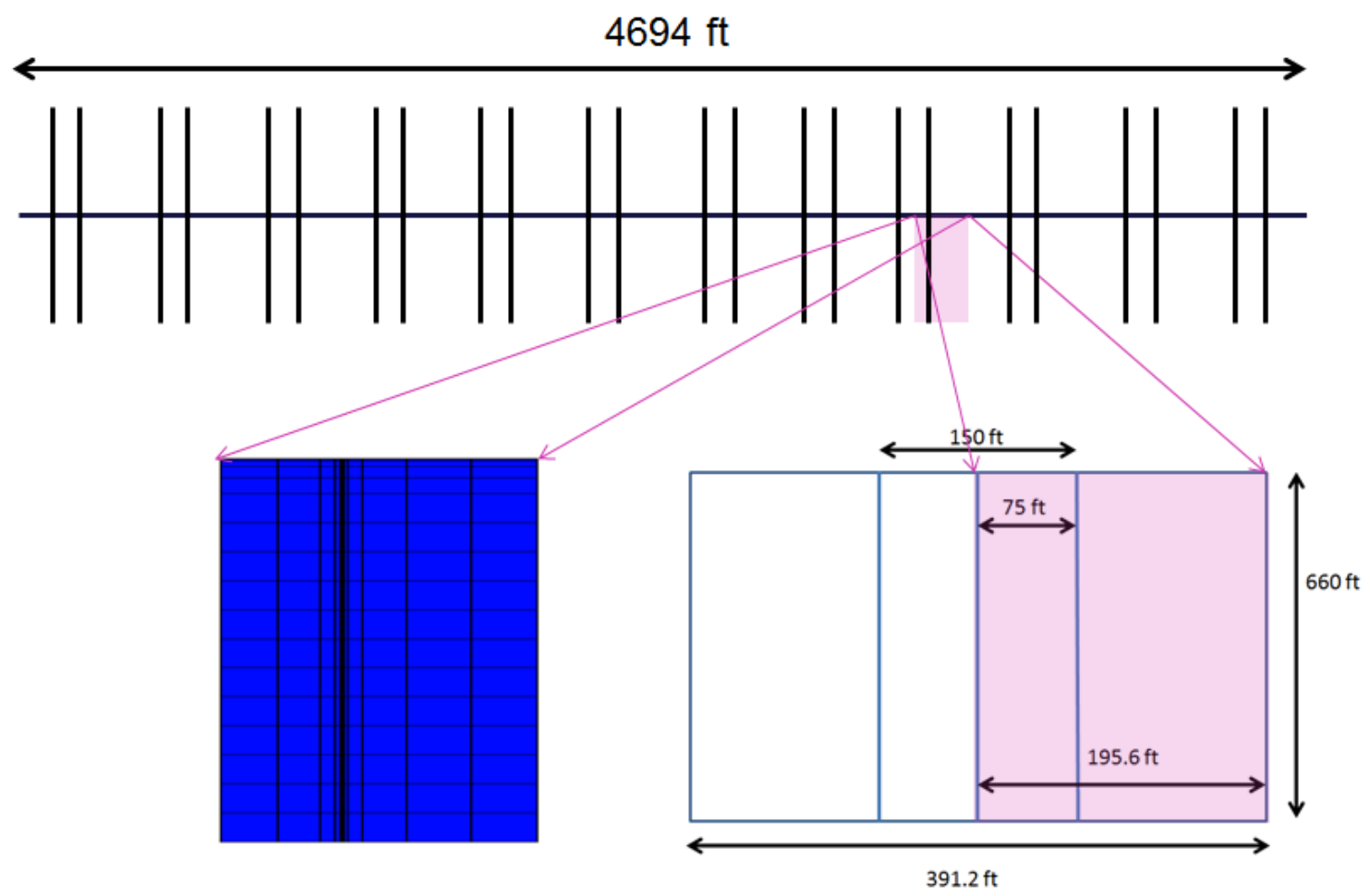

Fig. 3.17- Geometry for base case reservoir model for all production regions 


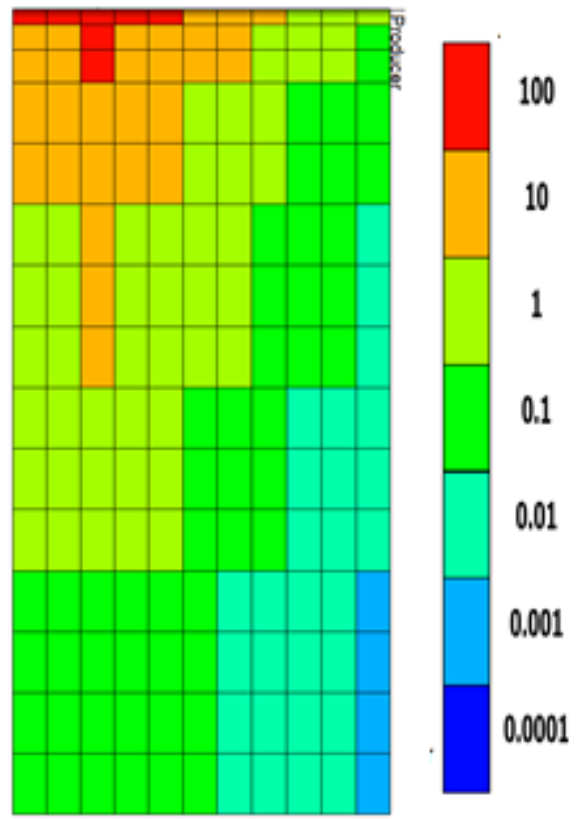

Fig. 3.18 - Fracture permeability decreases logarithmically from perforation to the boundary of reservoir in the fracture plane.

\begin{tabular}{|cccc|}
\hline \multicolumn{4}{|c|}{ Table 3.5- Geometry of Reservoir Simulation Base Case Models } \\
Entire Well & & Fractional Model & \\
Perforated Interval, $\mathrm{ft}$ & 4694 & $\mathrm{X}, \mathrm{ft}$ & 195.6 \\
Number of Stages & 12 & $\mathrm{Y}, \mathrm{ft}$ & 660 \\
Successful Cluster per Stage & 2 & Number of gridblocks in X direction & 11 \\
Number of Hydraulically Fractures & 24 & Number of gridblocks in Y direction & 17 \\
Distance Between Fractures, $\mathrm{ft}$ & 150 & Number of gridblocks in Z direction & 11 \\
Well Spacing, acres/well & 160 & Fraction of Well & $1 / 48$ \\
Distance Between Wells, $\mathrm{ft}$ & 1320 & & \\
\hline
\end{tabular}

\section{Reservoir Properties}

Reservoir properties, such as thickness, porosity, and water saturation, were provided by Yao Tian* from type logs for all production regions. Fig. 3.19 shows a type log with a triple combo of gamma ray, resistivity and density logs for production region 3(PR3). 
The original reservoir properties provided by Yao Tian* are shown in Table 3.6. The seven layers in Table 3.6 were further divided into eleven layers so that the thickness of each layer is similar (Table 3.7). To simplify the reservoir model, I assigned the eleven layers to either upper Eagle Ford or lower Eagle Ford. The averaged reservoir properties within each formation are used in the base case reservoir models (Table 3.8). Fig. 3.20 shows the type logs for all production regions. Table 3.9 shows the averaged reservoir properties for all production regions; the numbers in parentheses are the perforated layers, which are in the middle of the lower Eagle Ford formation to have the most surface contact of the organic-rich shale (Pope et al. 2012).

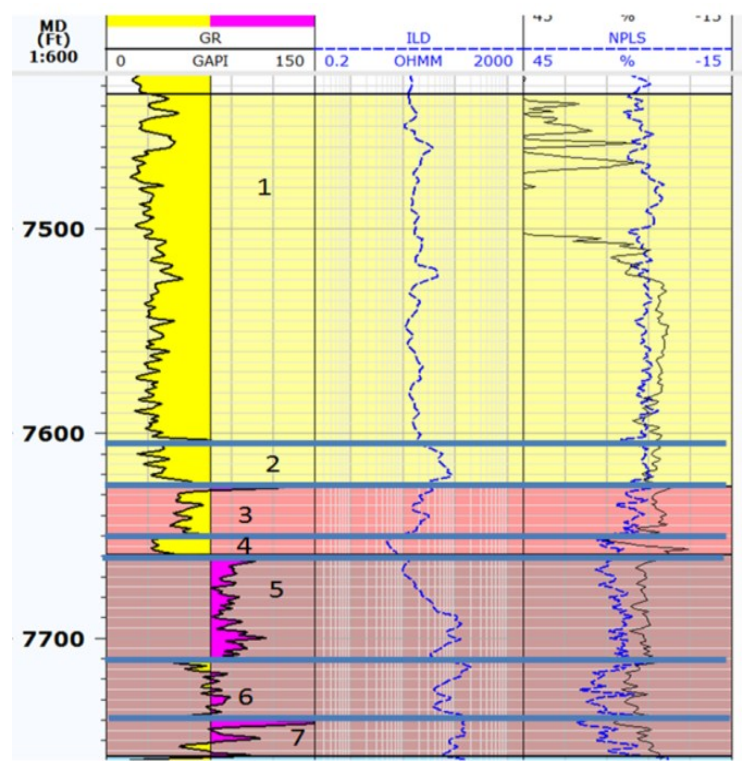

Fig. 3.19- Type log of production region 3 (PR3) that was used to build the static base case reservoir model

* Personal communication with Yao Tian 2013. College Station: Texas A\&M University. 


\begin{tabular}{|ccccc|}
\hline \multicolumn{5}{|c}{ Table 3.6- Original Layering and Reservoir Properties from Yao Tian (PR3) } \\
\hline Layers & $\underline{\text { Depth, } \mathrm{ft}}$ & Thickness, $\mathrm{ft}$ & $\frac{\text { Porosity } \%}{6}$ & $\frac{\text { Sw, \% }}{65}$ \\
\cline { 3 - 5 } 2 to 4 & $7435-7603$ & 168 & 6 & 35 \\
5 & $7603-7659$ & 56 & 10 & 20 \\
6 & $7659-7711$ & 52 & 9 & 20 \\
7 & $7711-7740$ & 29 & 10 & 40 \\
\hline
\end{tabular}

\begin{tabular}{|cccc|}
\hline \multicolumn{4}{|c|}{ Table 3.7- Layering and Reservoir Properties for 11 Layers (PR3) } \\
\hline$\frac{\text { Layers }}{1}$ & $\frac{\text { Thickness, } \mathrm{ft}}{33.6}$ & $\frac{\text { Porosity, } \%}{6 \mathrm{~W}, \%}$ & 65 \\
2 & 33.6 & 6 & 65 \\
3 & 33.6 & 6 & 65 \\
4 & 33.6 & 6 & 65 \\
5 & 33.6 & 6 & 65 \\
6 & 28 & 6 & 35 \\
7 & 28 & 6 & 35 \\
8 & 26 & 10 & 20 \\
9 & 26 & 10 & 20 \\
10 & 29 & 9 & 20 \\
11 & 20 & 10 & 40 \\
\hline
\end{tabular}

\begin{tabular}{|cccc|}
\hline \multicolumn{4}{|c|}{ Table 3.8-Averaged Reservoir Properties for } \\
Upper and Lower Eagle Ford (PR3) \\
\hline$\frac{\text { Layers }}{1 \text { to } 7}$ & $\frac{\text { Thickness (ft) }}{32}$ & $\frac{\text { Porosity \% }}{6}$ & $\frac{\text { Sw, \% }}{56}$ \\
8 to 11 & 25 & 10 & 25 \\
\hline
\end{tabular}




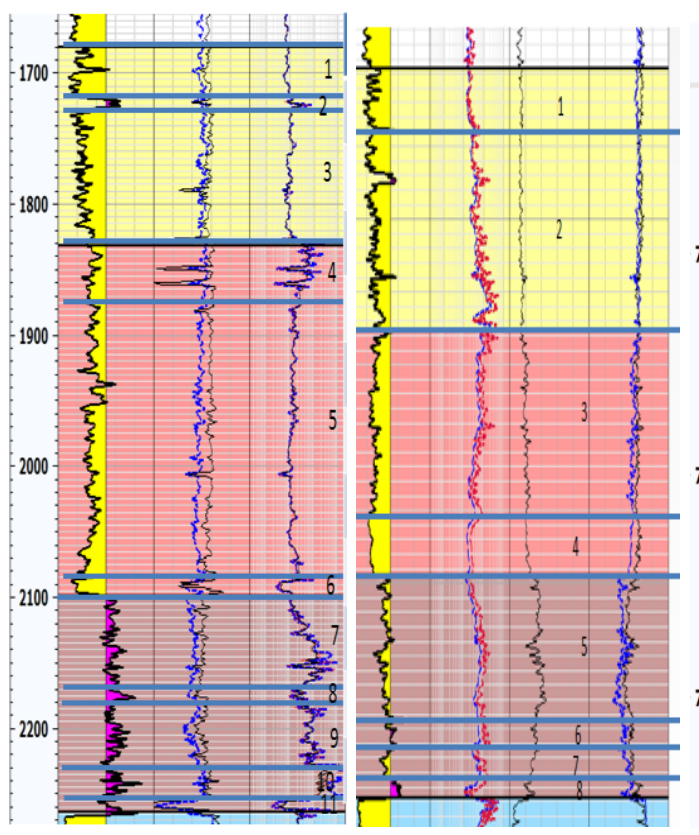

(a)

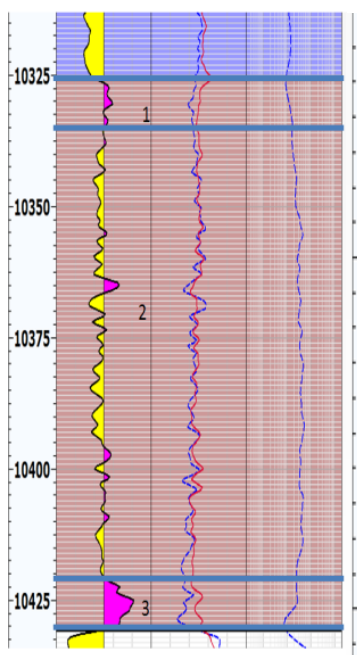

(e) (b)

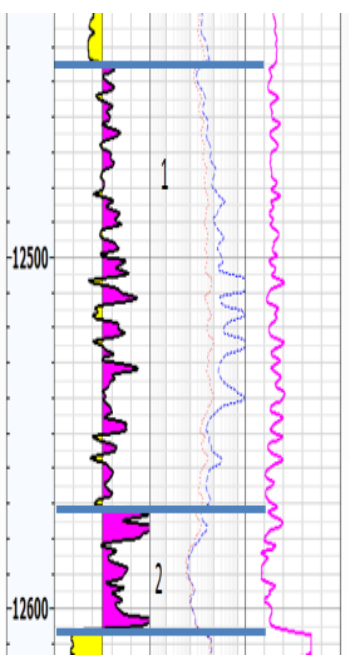

(f)

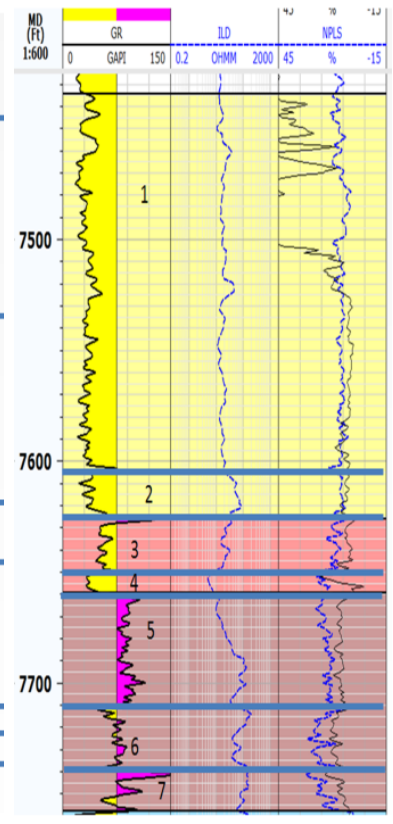

(c)

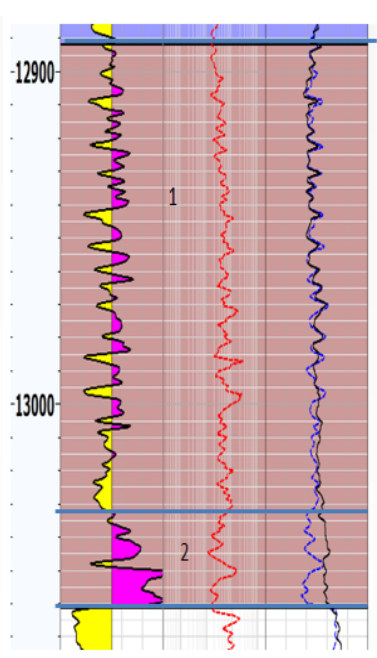

$(\mathrm{g})$

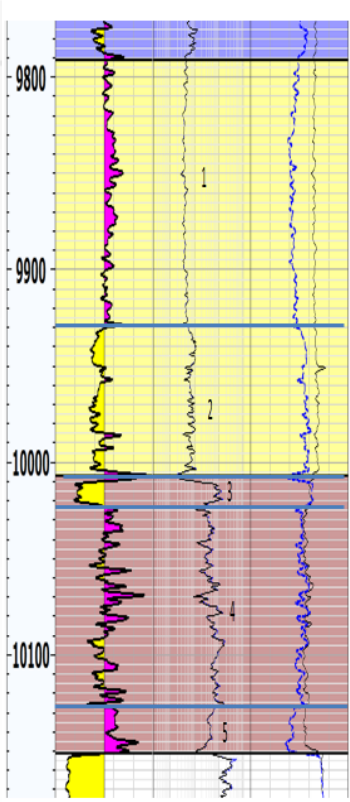

(d)

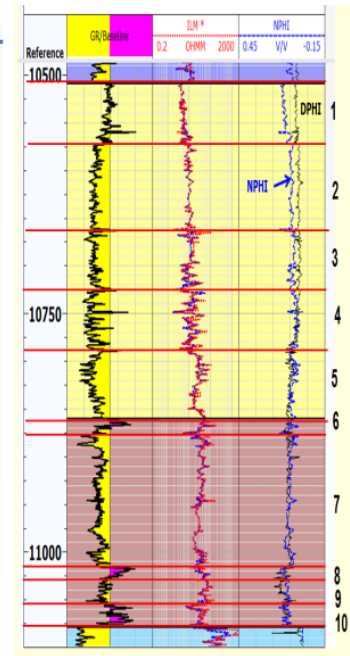

(h)

Fig. 3.20 - Type logs for production regions 1 (a) to 8 (h) 


\begin{tabular}{|c|c|c|c|c|c|}
\hline \multicolumn{6}{|c|}{$\begin{array}{c}\text { Table 3.9- Layering, Perforation, and Reservoir Properties for Base Case } \\
\text { Models }\end{array}$} \\
\hline Production Region & Formation & Layers & Thickness (ft) & Porosity \% & Sw, \% \\
\hline \multirow{2}{*}{ PR1 } & Upper & 1 to 6 & 70 & 6 & 40 \\
\hline & Lower & 7 to $11(8)$ & 32.8 & 10 & 20 \\
\hline \multirow{2}{*}{ PR2 } & Upper & 1 to 6 & 52 & 7 & 50 \\
\hline & Lower & 7 to $11(8)$ & 32.8 & 10.5 & 20 \\
\hline \multirow{2}{*}{ PR3 } & Upper & 1 to 7 & 30 & 6 & 55 \\
\hline & Lower & 8 to $11(9)$ & 30 & 10 & 20 \\
\hline \multirow{2}{*}{ PR4 } & Upper & 1 to 6 & 52 & 7 & 50 \\
\hline & Lower & 7 to $11(8)$ & 32.8 & 10.5 & 20 \\
\hline PR5 & Lower & 1 to $11(6)$ & 10 & 8.5 & 20 \\
\hline PR6 & Lower & 1 to $11(6)$ & 14 & 12 & 16 \\
\hline PR7 & Lower & 1 to $11(6)$ & 15 & 12 & 15 \\
\hline \multirow{2}{*}{ PR8 } & Upper & 1 to 6 & 23 & 9 & 70 \\
\hline & Lower & 7 to $11(8)$ & 23 & 12 & 35 \\
\hline$* \mathrm{Nu}$ & rs in the par & theses repre & nt the perforat & layer & \\
\hline
\end{tabular}

\section{Components}

I used the black-oil correlation in CMG (2013) to calculate the reservoir properties for black-oil regions and the dry-gas region. The black-oil correlation requires input data of reservoir temperature, initial producing GOR (to calculate bubble point or dew point), oil API gravity, and gas gravity (air $=1)$.

To calculate average temperature, I first calculated the average depth for each production region. The average temperature gradient, which equals $0.02^{\circ} \mathrm{F} / \mathrm{ft}$, was calculated from the initial reservoir temperature vs. the true vertical depth (TVD) in the 28 full PVT reports. The average temperature equals the surface temperature $60^{\circ} \mathrm{F}$ plus 0.02 times average depth of each production region. Oil API gravity and gas gravity were averaged 
within each production region. Initial GOR equals the summation of first three month gas production divided by the summation of first three month oil production within each production region. The input parameters required to calculate the black-oil correlation are shown in Table 3.10. Only the black oil regions PR1, PR3, PR5, and the dry gas region PR8 used the black-oil correlation; the parameters for other production regions are shown for comparison purposes.

\begin{tabular}{|c|c|c|c|c|}
\hline \multicolumn{5}{|c|}{$\begin{array}{c}\text { Table 3.10 - Summary of Fluid Properties Used to Calculate Black-oil Correlation } \\
\text { for PVT Behavior }\end{array}$} \\
\hline & Temperature, ${ }^{\circ} \underline{\mathrm{F}}$ & Oil API Gravity & $\begin{array}{l}\text { Gas Gravity } \\
\qquad \text { (Air }=1)\end{array}$ & $\frac{\text { Initial GOR, }}{\underline{\text { SCF/STB }}}$ \\
\hline PR1 (Black Oil) & 158 & 35.7 & 0.76 & 873 \\
\hline PR2 (Condensate) & 189 & 54.5 & 0.75 & 9,269 \\
\hline PR3 (Black Oil) & 218 & 41.0 & 0.75 & 1,030 \\
\hline PR4 (Condensate) & 278 & 52.4 & 0.74 & 11,623 \\
\hline PR5 (Black Oil) & 244 & 42.1 & 0.78 & 1,007 \\
\hline PR6 (Volatile Oil) & 307 & 50.5 & 0.73 & 2,781 \\
\hline PR7 (Condensate) & 329 & 58.8 & 0.71 & 11,230 \\
\hline PR8 (Dry Gas) & 271 & 54.9 & 0.61 & 850,543 \\
\hline
\end{tabular}

For condensate regions PR2, PR4, and PR7, and volatile-oil region PR6, PengRobinson's correlation equation of state model was used. Three full reports from PR2, PR4, and PR6 (assuming PR7 has the same fluid as PR6 with different composition since there is no full PVT report available in PR7) with constant composition expansion (CCE) and constant volume depletion (CVD) data were imported into the Winprop module of CMG (2013). The compositions of the reservoir fluids as well as gas gravity and density of heptane plus $(\mathrm{C} 7+)$ were also imported into Winprop. Quality checks 


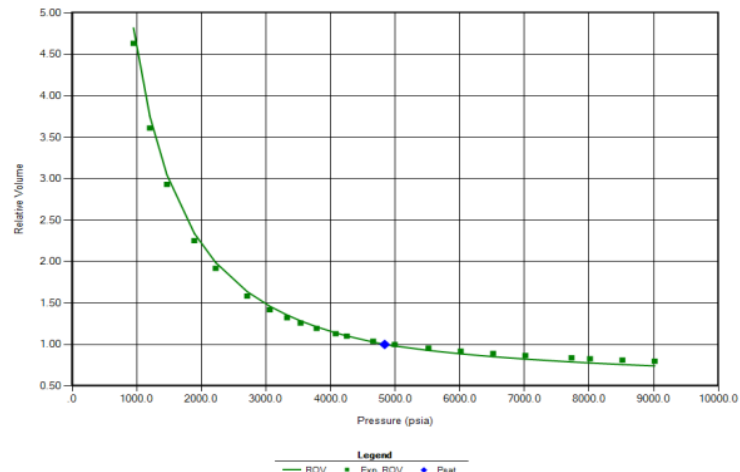

(a)

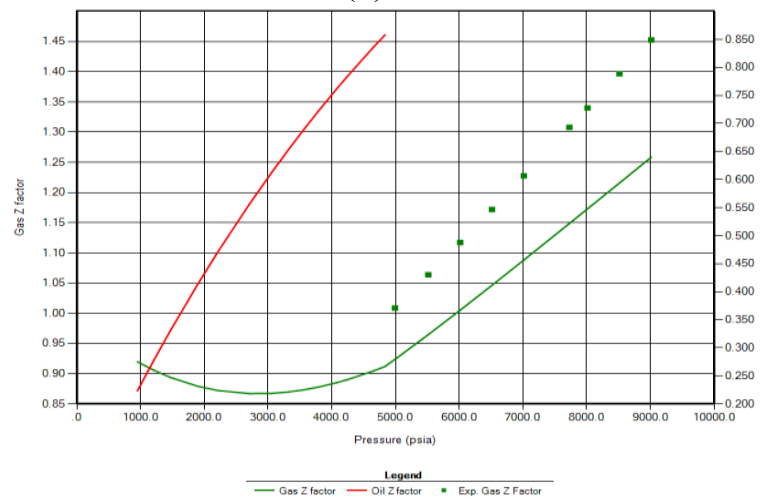

(c)

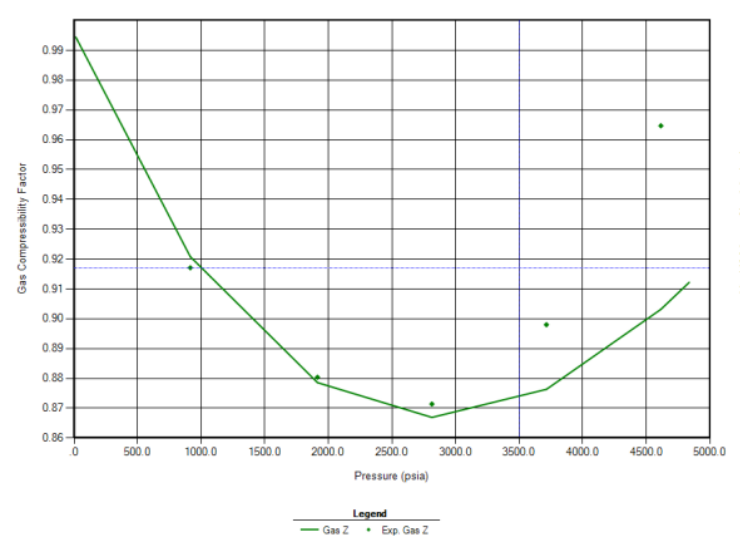

(e)

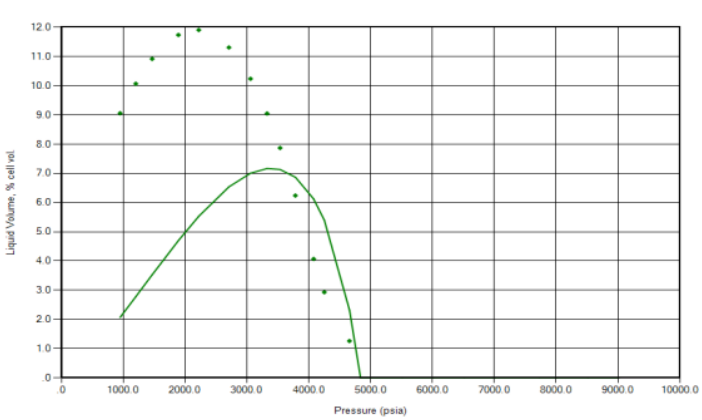

(b)

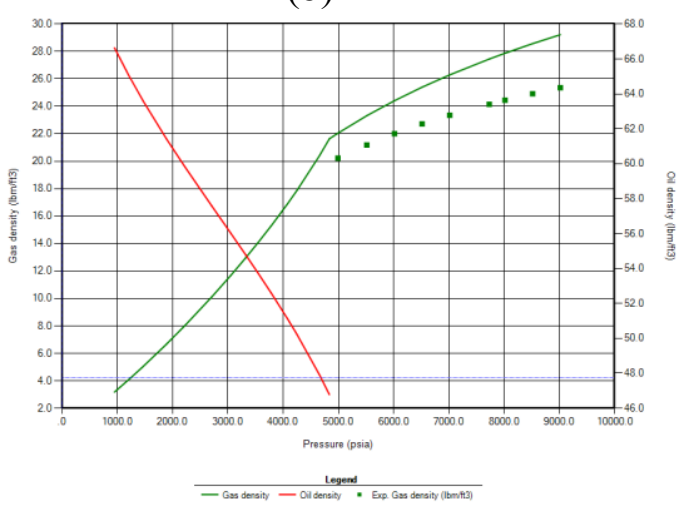

(d)

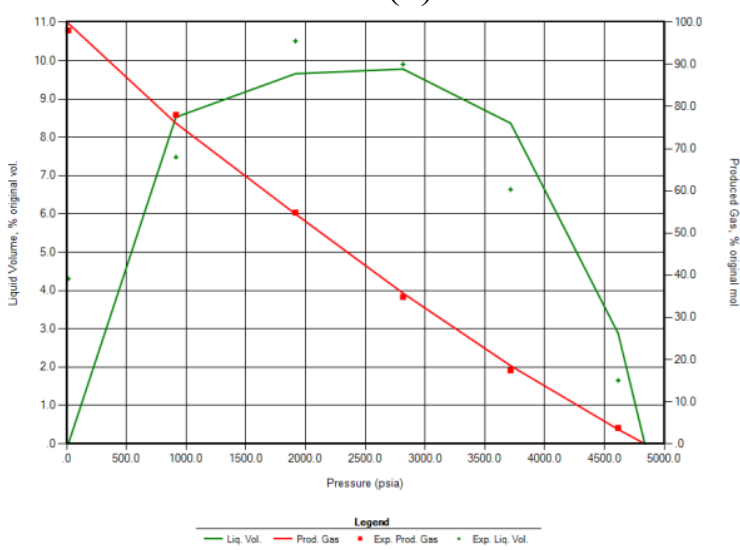

(f)

Fig. 3.21- Comparison between EOS generated PVT curves and lab measurements from a full PVT report in PR4 (green: oil properties, red: gas properties): (a) to (d) constant composition expansion experiment and (e) to (f) constant volume depletion. (a) relative volume, (b) condensed liquid volume, (c) gas $\mathrm{z}$ factor, (d) gas density, (e) gas compressibility factor, (f) liquid volume 


\begin{tabular}{|cccccc|}
\hline \multicolumn{6}{|c}{ Table 3.11-Summary of Composition and C7+ Properties for Base Case Models } \\
\hline Component & $\begin{array}{c}\text { PR2 } \\
\text { (Condensate) }\end{array}$ & $\begin{array}{c}\text { PR4 } \\
\text { (Condensate) }\end{array}$ & $\begin{array}{c}\text { PR6 } \\
\text { (Volatile Oil) }\end{array}$ & $\begin{array}{c}\text { PR7 } \\
\text { (Condensate) }\end{array}$ \\
H2S & 0.00 & 0.00 & 0.00 & 0.00 \\
N2 & 0.07 & 0.13 & 0.14 & 0.11 \\
CO2 & 0.81 & 1.62 & 1.12 & 1.27 \\
C1 & 65.57 & 65.58 & 62.54 & 69.57 \\
C2 & 12.98 & 12.58 & 11.76 & 11.37 \\
C3 & 6.17 & 5.74 & 5.59 & 4.86 \\
IC4 & 1.50 & 1.37 & 1.36 & 1.42 \\
NC4 & 2.42 & 2.28 & 2.32 & 1.95 \\
IC5 & 1.08 & 0.98 & 1.17 & 1.05 \\
NC5 & 1.02 & 0.98 & 1.10 & 0.84 \\
C6 & 1.38 & 1.25 & 1.55 & 1.17 \\
C7+ & 7.04 & 7.47 & 11.36 & 6.37 \\
\hline C7+ Molecular & 177.11 & 162.66 & 164.63 & 156.69 \\
Weight & & & & \\
C7+ Specific & 0.80 & 0.79 & 0.80 & 0.79 \\
Gravity (water =1) & & & & \\
\hline
\end{tabular}

the equation of state matches of the 3 full PTV reports were performed using default parameter values in Winprop. Fig. 3.21 shows the comparison between measured laboratory data and fluid properties calculated from the equation of state using default values for PR4. The matches can be improved but are acceptable. The average compositions as well as C7+ properties for PR2, PR4, PR6, and PR7 are shown in Table 3.11 and were used in the respective base case simulation models. 


\section{Rock Properties}

Three different rock property regions are present in the reservoir model, the organic-rich shale (lower Eagle Ford), the calcite-rich shale (upper Eagle Ford), and the hydraulic fractures. The calcite-rich shale normally has a lower porosity but higher matrix permeability compared with the organic-rich rock (Honarpour et al. 2012). I assumed a 3-to-1 permeability ratio between calcite-rich rock and organic-rich rock. Honarpour et al.'s (2012) pressure-dependent permeability curves (Fig. 3.22) and Corey's exponent correlations for relative permeability (Table 3.12) were used in the base case models. Since natural fractures are not modeled explicitly in my reservoir models, the matrix permeability in my models represents the effective permeability for both the matrix and natural fractures.

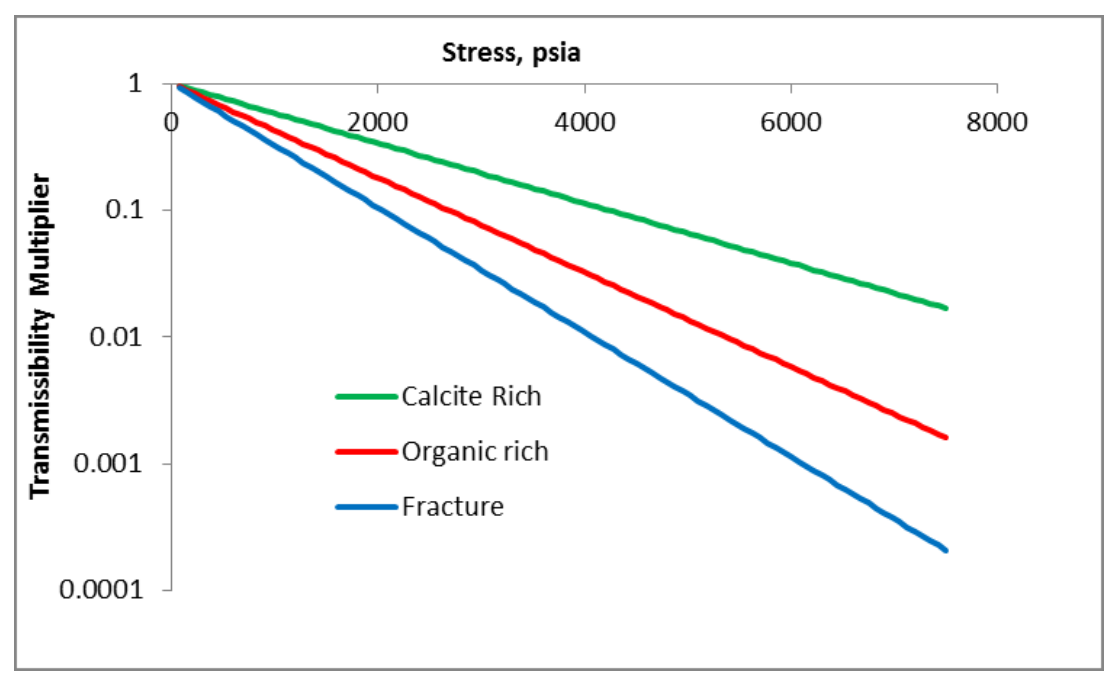

Fig. 3.22 - Pressure-dependent permeability for fracture, calcite-rich, and organicrich rocks, from Honarpour et al. (2012) 


\begin{tabular}{|c|c|c|c|c|c|}
\hline \multirow{2}{*}{\multicolumn{6}{|c|}{\begin{tabular}{|r|} 
Table 3.12- Corey's Exponent Correlations to \\
from Honarpour et a \\
Organic-rich
\end{tabular}}} \\
\hline & & \multicolumn{4}{|c|}{$\begin{array}{ll} & \text { Organic-rich } \\
\end{array}$} \\
\hline \multicolumn{2}{|c|}{ gas Phase } & \multicolumn{2}{|c|}{ oil phase } & \multicolumn{2}{|c|}{ water phase } \\
\hline Sgc & 0.2 & Sorg & 0.5 & Swmin & 0.25 \\
\hline Corey Gas & 3 & Corey O/W & 5 & Swcr & 0.25 \\
\hline Krg at Swmin & 0.5 & Corey O/G & 4.5 & & \\
\hline Krg at Sorg & 0.01 & Kro at Somax & 0.4 & & \\
\hline \multicolumn{6}{|c|}{ Calcite-rich } \\
\hline \multicolumn{2}{|c|}{ gas Phase } & \multicolumn{2}{|c|}{ oil phase } & \multicolumn{2}{|c|}{ water phase } \\
\hline Sgc & 0.15 & Sorg & 0.3 & Swmin & 0.5 \\
\hline Corey Gas & 2 & Corey O/W & 4 & Swcr & 0.55 \\
\hline Krg at Swmin & 0.7 & Corey O/G & 3.5 & & \\
\hline Krg at Sorg & 0.01 & Kro at Somax & 0.6 & & \\
\hline \multicolumn{6}{|c|}{ Fracture } \\
\hline \multicolumn{2}{|c|}{ gas Phase } & \multicolumn{2}{|c|}{ oil phase } & \multicolumn{2}{|c|}{ water phase } \\
\hline Sgc & 0.05 & Sorg & 0.1 & Swmin & 0.1 \\
\hline Corey Gas & 1.2 & Corey O/W & 2.5 & Swcr & 0.1 \\
\hline Krg at Swmin & 0.9 & Corey O/G & 1.5 & & \\
\hline Krg at Sorg & $0.05-0.5$ & Kro at Somax & 0.7 & & \\
\hline
\end{tabular}

\section{Initial Conditions}

The initial pressure gradient was calculated from full PVT reports to be $0.66 \mathrm{psi} / \mathrm{ft}$ for west and middle regions (PR1, PR2, PR3, PR4, and PR8) and $0.82 \mathrm{psi} / \mathrm{ft}$ for east regions (PR5, PR6, and PR7). Initial reservoir pressure for the base case models (Table 3.13) were calculated by multiplying the average depth at the perforations and the respective pressure gradient for each production region plus surface pressure 14.7 psia.

Table 3.13 - Initial Reservoir Pressure at Perforations for Base Case Models, psia

\begin{tabular}{|ccccccccc|}
\hline & $\underline{P R 1}$ & $\underline{P R 2}$ & $\underline{P R 3}$ & $\underline{P R 4}$ & $\underline{P R 5}$ & $\underline{P R 6}$ & $\underline{\text { PR7 }}$ & $\underline{P R 8}$ \\
Pressure, psia & 3,246 & 4,259 & 5,216 & 7,210 & 7,593 & 10,155 & 11,071 & 6,985 \\
\hline
\end{tabular}




\section{Well Constraints}

Since no pressure data are available, constant bottom-hole pressure (BHP) was assumed to be the main well constraint. A Prosper (Petroleum Experts 2013) model shows BHP equals 1500 psi for a typical horizontal well with 5-1/2 inch outside diameter (OD), 4.67 inch inside diameter (ID), $7881 \mathrm{ft} \mathrm{TVD,} 5000 \mathrm{ft}$ lateral, and 300 psia well-head pressure, producing at $300 \mathrm{STB} / \mathrm{D}$ in PR3 (Fig. 3.23).

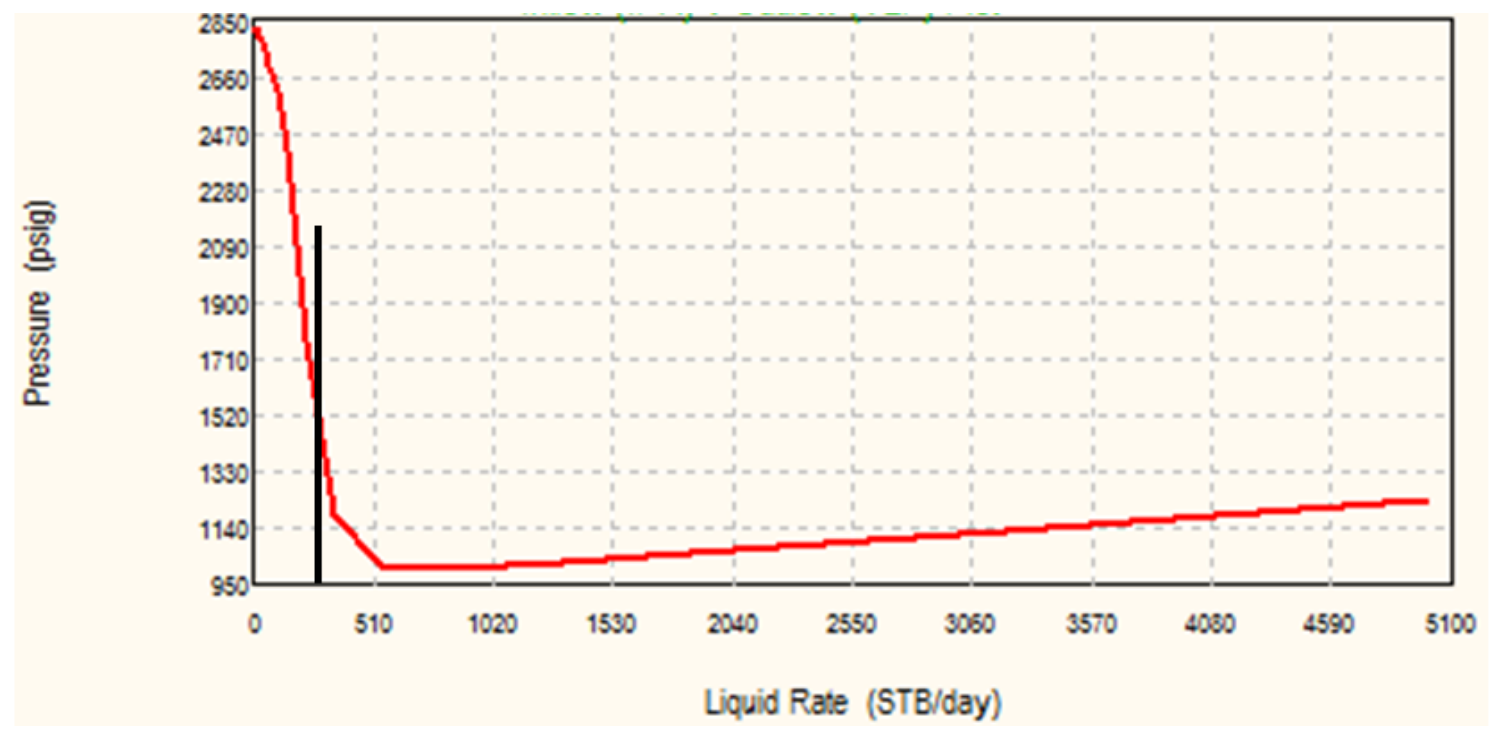

Fig. 3.23 - Vertical lift curve from Prosper shows a typical PR3 well has a BHP of 1500 psi when producing at 300 STB/Day

\section{Base Case Production Comparisons}

Matrix permeability of organic-rich rocks, fracture conductivity, and pressure-dependent permeability for hydraulic fractures were varied so that the simulated production of base case models is close to the average observed production of each production region. The average observed production of each region is by normalizing all wells to the same 
starting month, and average production from all wells for each month's production. After changing the permeabilities, the simulated oil production of the base case model is much close to the average production of PR3 (Fig. 3.24). The simulated GOR and average GOR in PR3 are shown in Fig. 3.25. The GOR match can be improved but is acceptable for the base case models since only the distributions of 20-year cumulative oil production for PR1 to PR7 are used as the prior distributions for probabilistic decline curve analysis. Table 3.14 shows the organic-rich matrix permeability, maximum fracture permeability (fracture width $=2 \mathrm{ft}$ ), and the pressure-dependent permeability of the hydraulic fracture for the base case models of all production regions. The oil and gas production comparison between the simulated production and the average production for all production regions are shown in Fig. 3.26.

The matches are good at the initial rates and at the end of the production period, there is a $5 \%$ to $15 \%$ mismatch in the middle of the production periods for most production regions. 


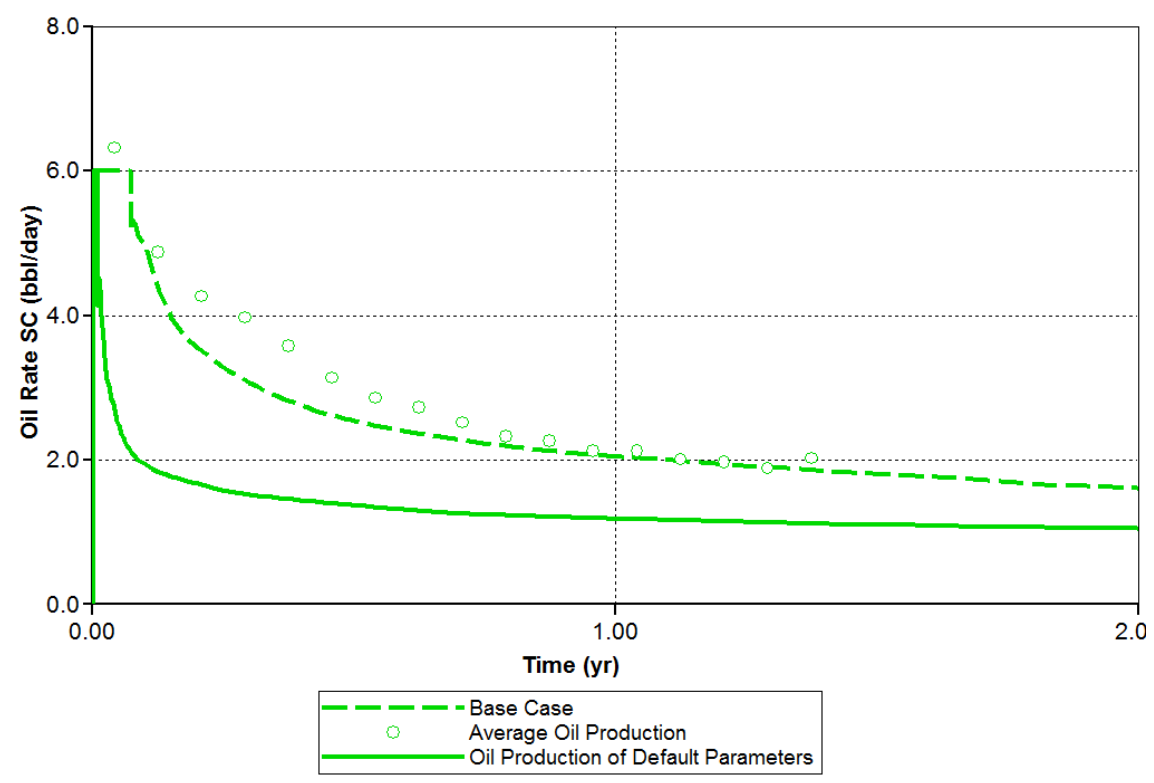

Fig. 3.24- After changing the permeability, the base case simulated production for PR3 is closer to the average observed oil production compared with the simulated oil production using default parameters

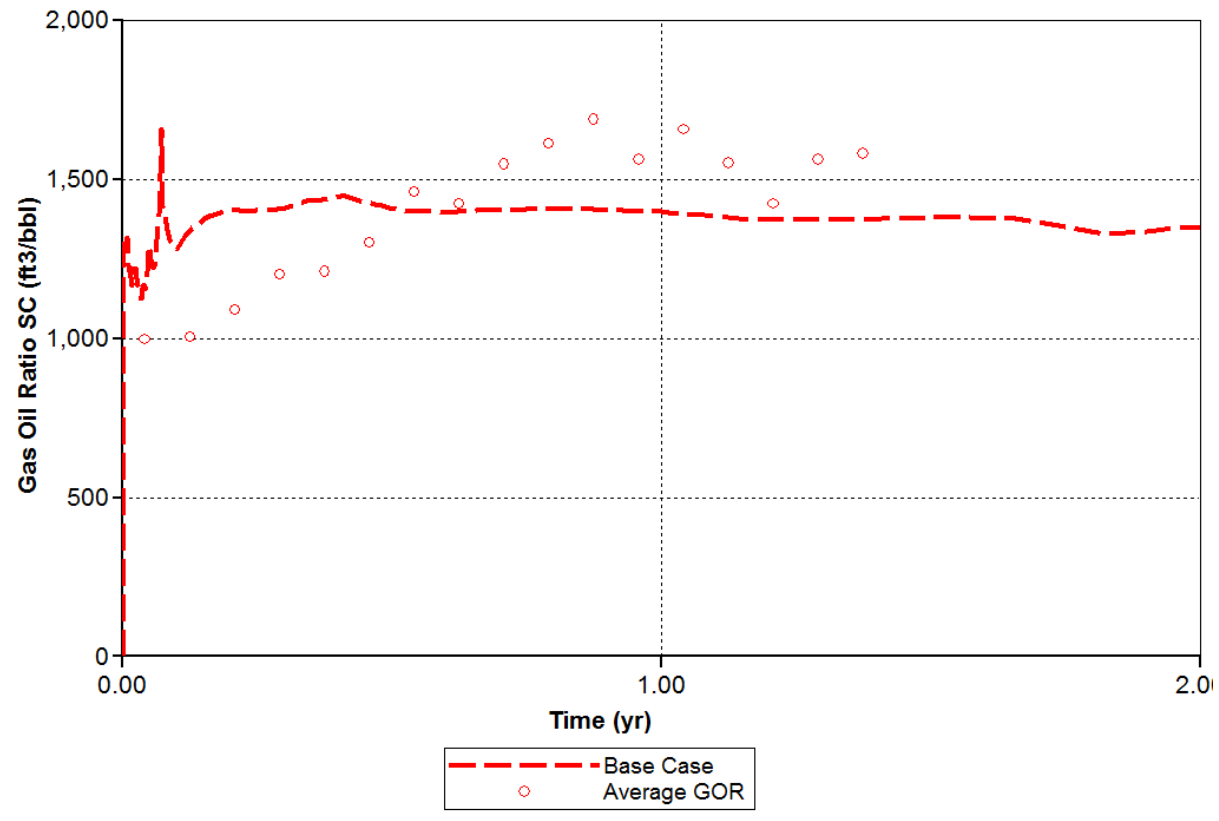

Fig. 3.25- The GOR of the base case model is close to the average GOR of PR3 but not exact 


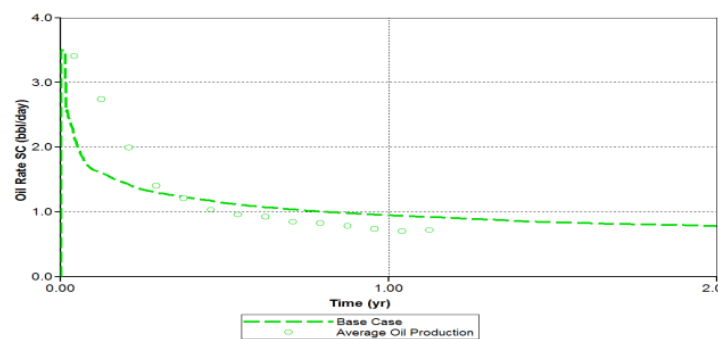

(a)

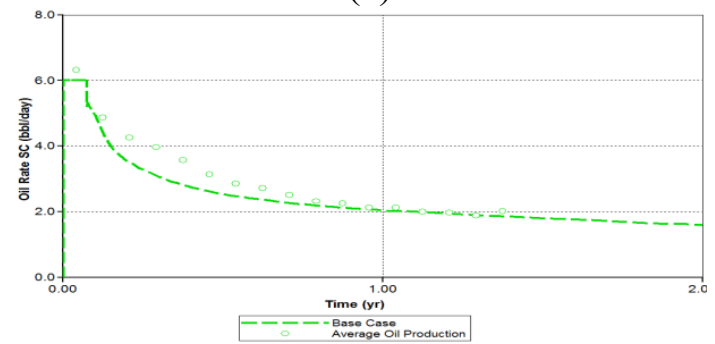

(c)

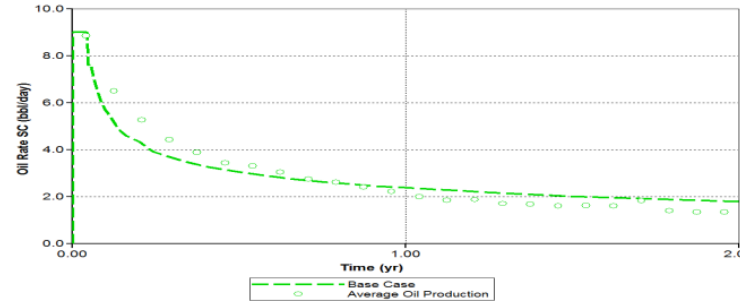

(e)

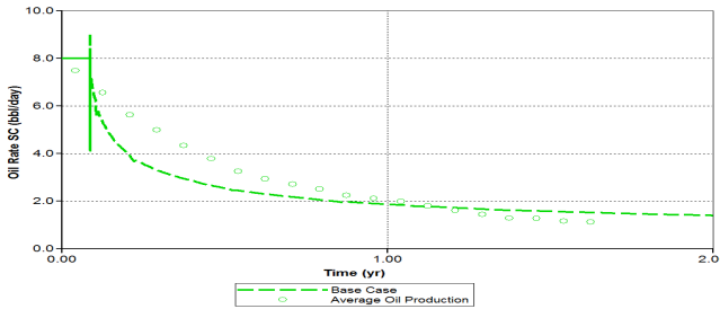

$(\mathrm{g})$

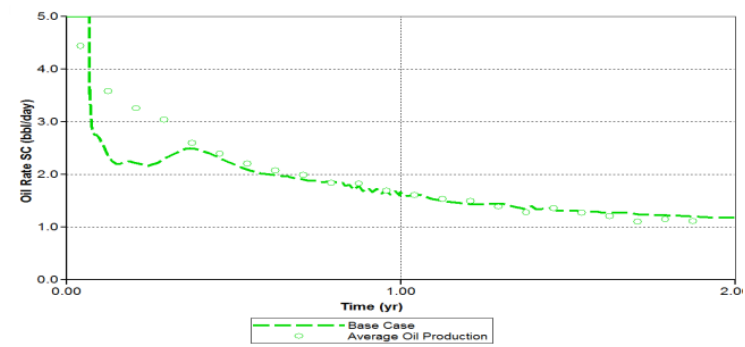

(b)

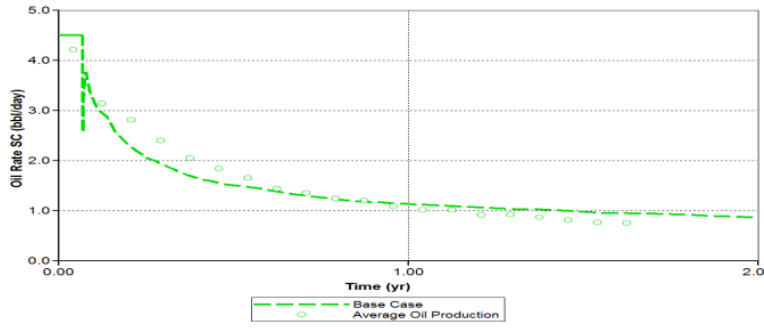

(d)

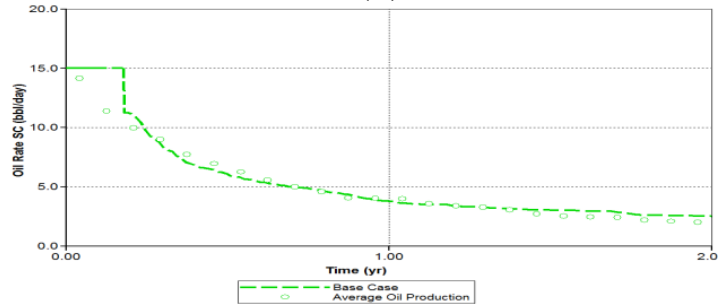

(f)

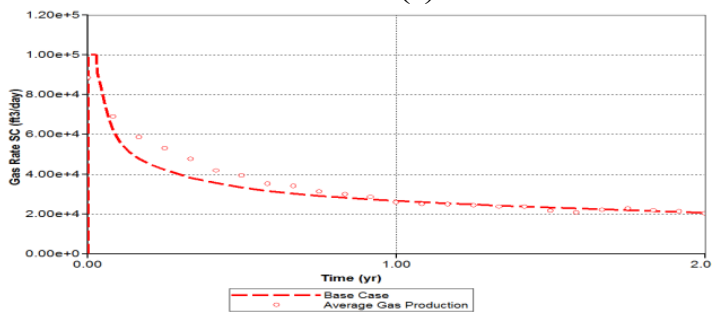

(h)

Fig. 3.26 - Comparison between base case simulated oil production and average oil production for PR1 to PR7 (a) to (g), and base case simulated gas production and average gas production for PR8 (h) 


\begin{tabular}{|c|c|c|c|}
\hline \multicolumn{4}{|c|}{$\begin{array}{l}\text { Table 3.14- Summary of Matrix and Fracture Permeability and Pressure-Dependent } \\
\text { Permeability Curves for Hydraulic Fracture }\end{array}$} \\
\hline & $\begin{array}{c}\text { Organic Rich } \\
\text { Matrix Perm, nd }\end{array}$ & $\begin{array}{l}\text { Maximum Fracture Permeability } \\
\text { with 2-ft Fracture Width, md }\end{array}$ & $\begin{array}{c}\text { Pressure-Dependent } \\
\text { Permeability Curve for Fracture }\end{array}$ \\
\hline Default & 20 & 40 & Fracture \\
\hline PR1 & 50 & 10 & Calcite \\
\hline PR2 & 24 & 80 & Calcite \\
\hline PR3 & 90 & 40 & Calcite \\
\hline PR4 & 12 & 80 & Fracture \\
\hline PR5 & 800 & 120 & Calcite \\
\hline PR6 & 150 & 60 & Fracture \\
\hline PR7 & 50 & 100 & Calcite \\
\hline PR8 & 90 & 5 & Calcite \\
\hline
\end{tabular}

\subsubsection{Monte Carlo Simulation with Reservoir Simulation}

To generate distributions of $\mathrm{N}_{240}$ for PR1 to PR7 and $\mathrm{G}_{240}$ for PR8, I performed Monte Carlo simulation with reservoir simulation. I first identified the parameters that are uncertain and defined the distributions for those parameters. The uncertain parameters I identified are: maximum fracture permeability, matrix permeability, thickness of upper and lower Eagle Ford, vertical permeability multiplier, volume modifier, initial pressure, bubble point (black-oil models), and composition of heptane plus (compositional models). The distribution types and the descriptions of the parameters are shown in Table 3.15. The $\mathrm{P}_{90}, \mathrm{P}_{50}$, and $\mathrm{P}_{10}$ of the common parameters for all production regionsBHP, vertical permeability multiplier, and volume multiplier - are shown in Table 3.16. The $\mathrm{P}_{90}, \mathrm{P}_{50}$, and $\mathrm{P}_{10}$ of the other parameters for each production region are shown in Table 3.17 to Table 3.23 . 


\begin{tabular}{|c|c|c|}
\hline \multicolumn{3}{|c|}{$\begin{array}{l}\text { Table 3.15- Distributions of Reservoir Properties For Monte Carlo Simulation } \\
\text { with Reservoir Simulation }\end{array}$} \\
\hline$\underline{\text { Parameter }}$ & Distribution & Description \\
\hline Bottom hole pressure, psia & Uniform & 500 to 1500 \\
\hline Maximum fracture permeability, md & Lognormal & Mean $=$ base case, $S D=1.25$ \\
\hline $\begin{array}{l}\text { Organic-rich matrix permeability, nd } \\
\text { Thickness of Upper and Lower Eagle }\end{array}$ & Lognormal & Mean $=$ base case, $\mathrm{SD}=1.25$ \\
\hline Ford, $\mathrm{ft}$ & Uniform & Based on Isopach \\
\hline Vertical permeability multiplier & Triangular & Mean $=0.1, \mathrm{SD}=1$ \\
\hline Volume modifier & Triangular & Mean $=1, S D=0.75$ \\
\hline Initial pressure, psi & Discrete & Based on structure and gradient \\
\hline Bubble point, psi & Uniform & Original-600 to original \\
\hline Composition for methane and $\mathrm{C} 7+$ & Discrete & Based on PVT reports \\
\hline
\end{tabular}

\begin{tabular}{|cccc|}
\hline Table 3.16- Percentiles of Global Parameters for All Production Regions \\
\hline Parameter & $\mathrm{P}_{90}$ & $\mathrm{P}_{50}$ & $\mathrm{P}_{10}$ \\
\cline { 2 - 4 } Bottom hole pressure, psia & 700 & 1500 & 2300 \\
Vertical permeability multiplier & 0.028 & 0.1 & 0.36 \\
Volume modifier & 0.38 & 1 & 2.62 \\
\hline
\end{tabular}

\begin{tabular}{|cccc|}
\hline \multicolumn{4}{|c|}{$\begin{array}{c}\text { Table 3.17- } \\
\text { Percentiles of Organic-Rich Matrix } \\
\text { Permeability, nd }\end{array}$} \\
\hline Production Regions & $\mathrm{P}_{90}$ & $\mathrm{P}_{50}$ & $\mathrm{P}_{10}$ \\
\cline { 2 - 4 } PR1 & 10 & 50 & 248 \\
PR2 & 5 & 24 & 119 \\
PR3 & 18 & 90 & 446 \\
PR4 & 2 & 12 & 59 \\
PR5 & 161 & 800 & 3966 \\
PR6 & 30 & 150 & 744 \\
PR7 & 10 & 50 & 248 \\
PR8 & 18 & 90 & 446 \\
\hline
\end{tabular}




\begin{tabular}{|cccc|}
\hline Table 3.18 - $\begin{array}{c}\text { Percentiles of Maximum Fracture } \\
\text { Permeability, md }\end{array}$ \\
\hline Production Regions & $\mathrm{P}_{90}$ & $\mathrm{P}_{50}$ & $\mathrm{P}_{10}$ \\
\cline { 2 - 4 } PR1 & 2 & 10 & 50 \\
PR2 & 16 & 80 & 397 \\
PR3 & 8 & 40 & 198 \\
PR4 & 16 & 80 & 397 \\
PR5 & 24 & 120 & 595 \\
PR6 & 12 & 60 & 297 \\
PR7 & 20 & 100 & 496 \\
PR8 & 1 & 5 & 25 \\
\hline
\end{tabular}

\begin{tabular}{|cccc|}
\hline \multicolumn{4}{|c|}{ Table 3.19- $\begin{array}{c}\text { Percentiles of Thickness of Upper } \\
\text { Eagle Ford, ft }\end{array}$} \\
\hline Production Regions & $\mathrm{P}_{90}$ & $\mathrm{P}_{50}$ & $\mathrm{P}_{10}$ \\
\cline { 2 - 4 } PR1 & 291 & 411 & 496 \\
PR2 & 86 & 314 & 515 \\
PR3 & 25 & 199 & 364 \\
PR4 & 103 & 167 & 351 \\
PR8 & 7 & 136 & 240 \\
\hline
\end{tabular}

\begin{tabular}{|c|c|c|c|}
\hline \multicolumn{4}{|c|}{$\begin{array}{c}\text { Table 3.20- Percentiles of Thickness of Lower } \\
\text { Eagle Ford, } \mathrm{ft}\end{array}$} \\
\hline Production Regions & $\mathrm{P}_{90}$ & $\mathrm{P}_{50}$ & $\mathrm{P}_{10}$ \\
\hline PR1 & 141 & 181 & 200 \\
\hline PR2 & 94 & 172 & 200 \\
\hline PR3 & 75 & 111 & 130 \\
\hline PR4 & 100 & 141 & 208 \\
\hline PR5 & 60 & 107 & 153 \\
\hline PR6 & 120 & 152 & 205 \\
\hline PR7 & 104 & 166 & 220 \\
\hline PR8 & 95 & 115 & 215 \\
\hline
\end{tabular}




\begin{tabular}{|cccc|}
\hline \multicolumn{3}{|c|}{ Table 3.21- $\begin{array}{c}\text { Percentiles of the Initial Reservoir } \\
\text { Pressure, psi }\end{array}$} \\
\cline { 1 - 4 } Production Regions & $\mathrm{P}_{90}$ & $\mathrm{P}_{50}$ & $\mathrm{P}_{10}$ \\
\cline { 2 - 4 } PR1 & 2,138 & 3,295 & 4,258 \\
PR2 & 2,442 & 4,309 & 5,997 \\
PR3 & 3,806 & 5,109 & 6,847 \\
PR4 & 5,483 & 7,192 & 8,943 \\
PR5 & 5,207 & 7,764 & 9,402 \\
PR6 & 9,553 & 10,089 & 10,813 \\
PR7 & 10,404 & 11,061 & 11,595 \\
PR8 & 7,460 & 8,651 & 10,111 \\
\hline
\end{tabular}

\begin{tabular}{|c|c|c|c|}
\hline \multicolumn{4}{|c|}{$\begin{array}{c}\text { Table 3.22- Percentiles of Bubble Point Pressure for } \\
\text { Black Oil Regions, psi }\end{array}$} \\
\hline Production Regions & $\mathrm{P}_{90}$ & $\mathrm{P}_{50}$ & $\mathrm{P}_{10}$ \\
\hline PR1 & 2900 & 3200 & 3500 \\
\hline PR3 & 4000 & 4300 & 4600 \\
\hline PR5 & 3200 & 3500 & 3800 \\
\hline
\end{tabular}

\begin{tabular}{|cccc|}
\hline \multicolumn{4}{|c|}{$\begin{array}{c}\text { Table 3.23- Percentiles of Composition of C7+ for } \\
\text { Condensate, Volatile-Oil Regions, } \%\end{array}$} \\
\hline Production Regions & $\mathrm{P}_{90}$ & $\mathrm{P}_{50}$ & $\mathrm{P}_{10}$ \\
\cline { 2 - 4 } PR2 & 4.19 & 6.64 & 10.56 \\
PR4 & 4.54 & 7.87 & 13.19 \\
PR6 & 8.32 & 11.36 & 13.46 \\
PR7 & 4.37 & 6.37 & 8.96 \\
\hline
\end{tabular}

A total of 210 iterations of Monte Carlo simulation with reservoir simulation were performed for each production region using Latin Hypercube sampling. The $\mathrm{N}_{240}$ of PR1 to PR7 and $\mathrm{G}_{240}$ of PR8 all follow lognormal distributions (Fig. 3.27). The median of $\mathrm{N}_{240}$ and $\mathrm{G}_{240}$, as well as the standard deviation of $\ln \left(\mathrm{N}_{240}\right)$ and $\ln \left(\mathrm{G}_{240}\right)$, are shown in 
Table 3.24. The $\mathrm{P}_{90}, \mathrm{P}_{50}$, and $\mathrm{P}_{10}$ of recovery factors for all production regions are shown in Table 3.25.

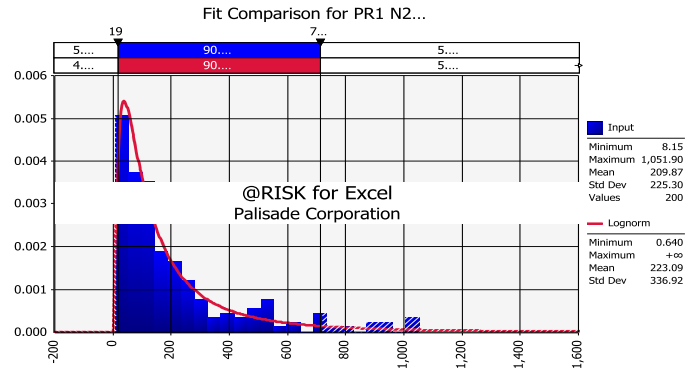

(a)

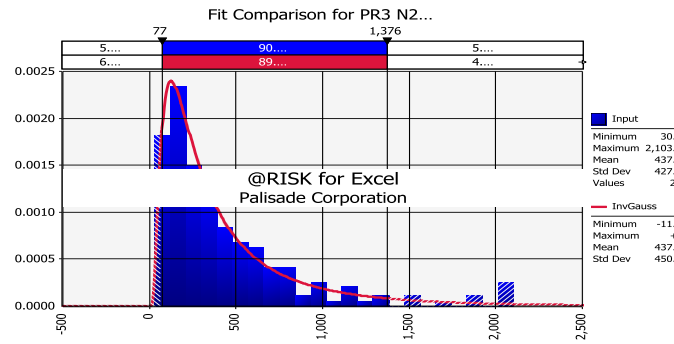

(c)

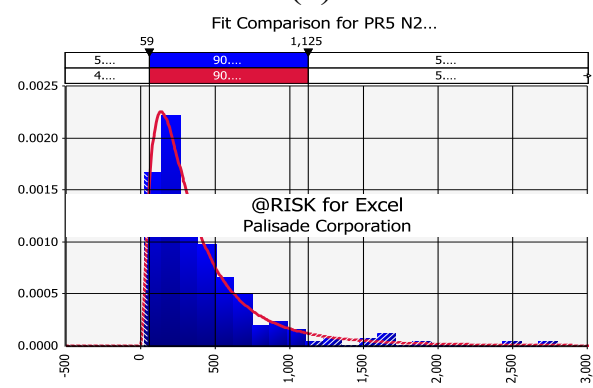

(e)

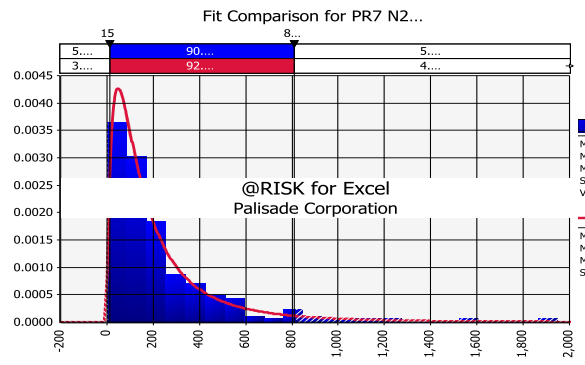

(g)

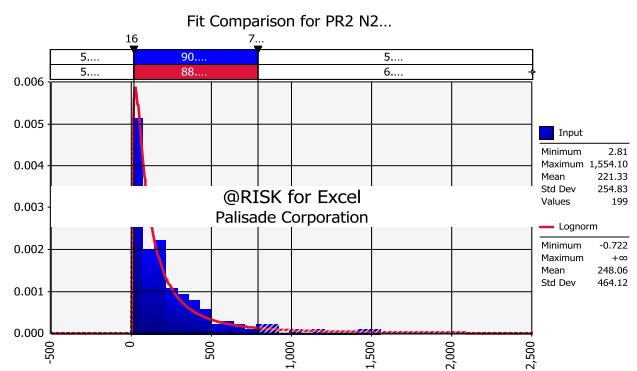

(b)

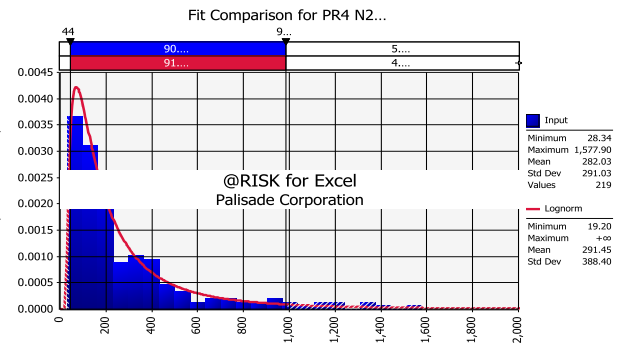

(d)

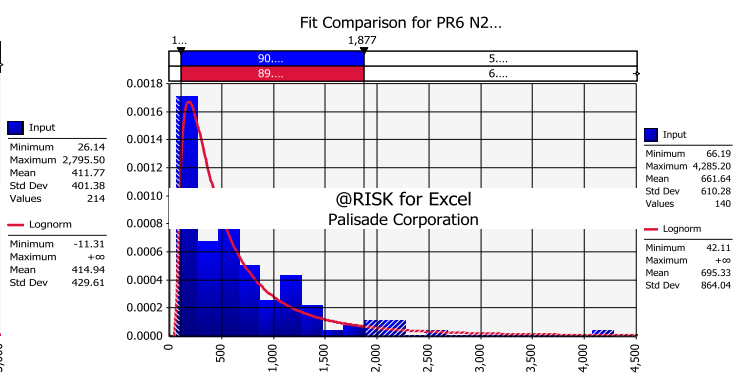

(f)

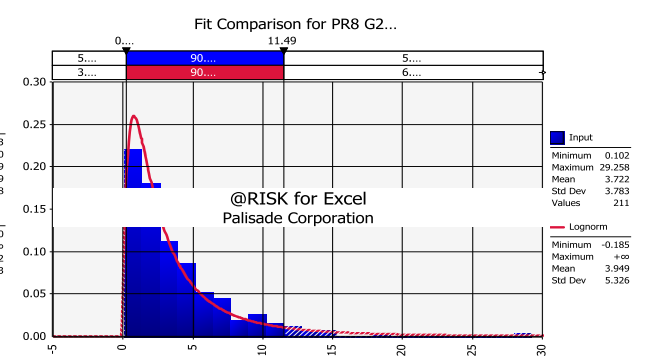

(h)

Fig. 3.27- The simulated 20-year cumulative oil production of PR1 to PR7 (a) to (g) and cumulative gas production of PR8 (h) follow lognormal distributions 


\begin{tabular}{|ccc|}
\hline $\begin{array}{c}\text { Table 3.24- Median and Standard } \\
\text { Deviation of Lognormal Distributions } \\
\text { of } \mathbf{N}_{\mathbf{2 4 0}} \text { and } \mathbf{G}_{\mathbf{2 4 0}}\end{array}$ \\
\hline \multicolumn{4}{|c|}{$\mathrm{N}_{240}$, STB } \\
PR1 & $\frac{\text { Median }}{123,733}$ & $\frac{\text { SD of } \ln \left(\mathrm{N}_{240}\right)}{1.08}$ \\
PR2 & 115,943 & 1.24 \\
PR3 & 296,880 & 0.89 \\
PR4 & 186,188 & 0.90 \\
PR5 & 283,663 & 0.89 \\
PR6 & 458,351 & 0.88 \\
PR7 & 132,374 & 1.17 \\
\hline \multicolumn{4}{|c}{$\mathrm{G}_{240}$, Bcf } \\
PR8 & $\frac{\text { Median }}{2.19}$ & $\frac{\text { SD of } \ln \left(\mathrm{G}_{240}\right)}{1.15}$ \\
\hline
\end{tabular}

\begin{tabular}{|c|c|c|c|c|}
\hline \multicolumn{5}{|c|}{$\begin{array}{c}\text { Table } 3.25 \text { - Recovery Factors of Oil for } \\
\text { PR1 to PR7, Gas for PR8, \% }\end{array}$} \\
\hline \multicolumn{2}{|c|}{ Percentiles } & $\mathrm{P}_{90}$ & $\mathrm{P}_{50}$ & $\mathrm{P}_{10}$ \\
\hline \multirow[t]{7}{*}{ Oil } & PR1 & 0.03 & 0.56 & 2.75 \\
\hline & PR2 & 0.29 & 4.01 & 17.10 \\
\hline & PR3 & 1.05 & 3.61 & 12.44 \\
\hline & PR4 & 1.22 & 4.01 & 12.77 \\
\hline & PR5 & 1.19 & 4.53 & 10.86 \\
\hline & PR6 & 3.12 & 5.05 & 11.34 \\
\hline & PR7 & 0.90 & 4.18 & 13.76 \\
\hline Gas & PR8 & 2.69 & 13.44 & 36.26 \\
\hline
\end{tabular}

\subsection{Generation of Type Probabilistic Decline Curves}

\subsubsection{Estimation of Minimum Decline Rate}

A combination of the Duong model transitioning to the Arps model with $b=0.3$ was used to model production with both linear flow and boundary-dominated flow regimes (Joshi and Lee 2013). In order to identify which wells have reached boundary-dominated 
flow, I plotted the production rate vs. material-balance time (material-balance time $=$ cumulative production divided by rate). I identified a well as being in boundarydominated flow if the slope of rate vs. material-balance time is greater than 0.95 (around 1) for the last third of the log cycle (Fig. 3.28) per John Lee's recommendation.* The time when the well reaches boundary-dominated flow was identified when the rate vs. material-balance time slope is closest to one. The minimum decline rate $\left(D_{\min }\right)$ is set equal to the decline rate of the Duong model at that time. To ensure the calculated minimum decline rate from the Duong model is representative of the minimum decline rate from the production data, only the wells for which the Duong model fit the production data well were selected for this study.

A total of 364 wells with oil production from PR1 to PR7 and 100 wells with gas production from PR8 were selected. Within these wells, 57 oil wells and 19 gas wells were identified as being in boundary-dominated flow. For oil production, the minimum decline rates of the wells that reached boundary-dominated flow were recorded and follow a lognormal distribution (Fig. 3.29 (a)). For the wells that have not reached boundary-dominated flow, the decline rate at the end of history was recorded (Fig. 3.29 (b)). The minimum decline rate should be less than the decline rate at the end of the history of those wells that have not reached boundary-dominated flow. I assumed that the minimum decline rate of the wells that have not reached boundary-dominated

\footnotetext{
* Personal communication with John Lee 2013. College Station: Texas A\&M University
} 
flow should follow the same lognormal distribution as the minimum decline rate of the wells that reached boundary-dominated flow, but truncated at the decline rate at the end of the history. I combined the minimum decline rate for the wells that have reached boundary-dominated flow (Fig. 3.31 (a)) and the minimum decline rate drawn randomly from the truncated lognormal distribution for the wells that have not reached boundarydominated flow (Fig. 3.31 (b)). The combination is the distribution of the minimum decline rate of oil production for PR1 to PR7 (Fig. 3.29 (c)). The same process was done for gas production from PR8 (Fig. 3.30).

I also calculated the correlation between minimum decline rate and decline curve parameters of the re-parameterized Duong model, and found a significant correlation between minimum decline rate and decline curve parameter $l$. The correlation between (a) the minimum decline rate and decline curve parameter $l$ and (b) the standard deviation of $\ln \left(D_{\text {min }}\right)$ with the decline curve parameter $l$ are shown in Fig. 3.31. Eq. 3.8 summarizes the models of the minimum decline rate for both oil and gas. 


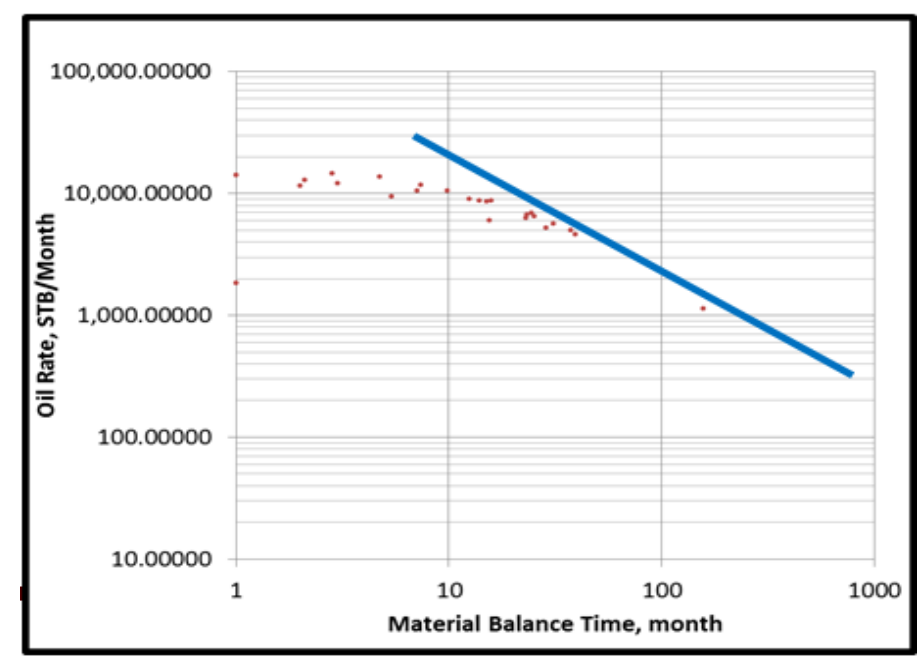

Fig. 3.28 - An example well that has already reached dominated boundary flow because of the unit slope in the last $1 / 3 \log$ cycle

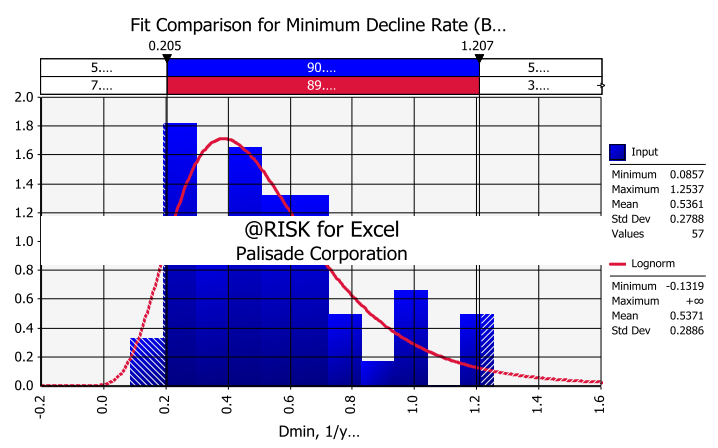

(a)

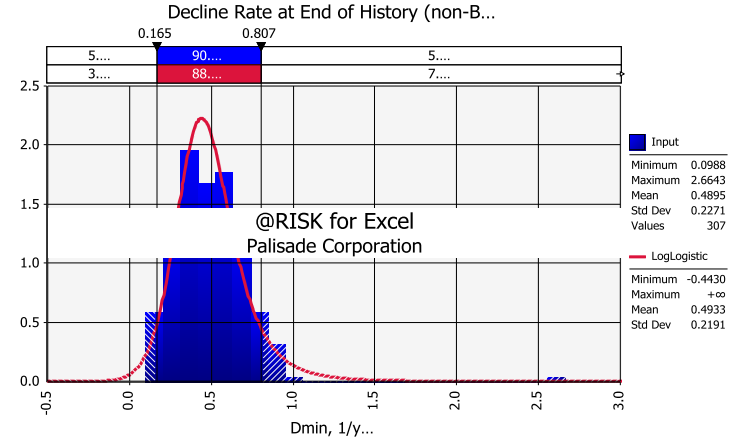

(b)

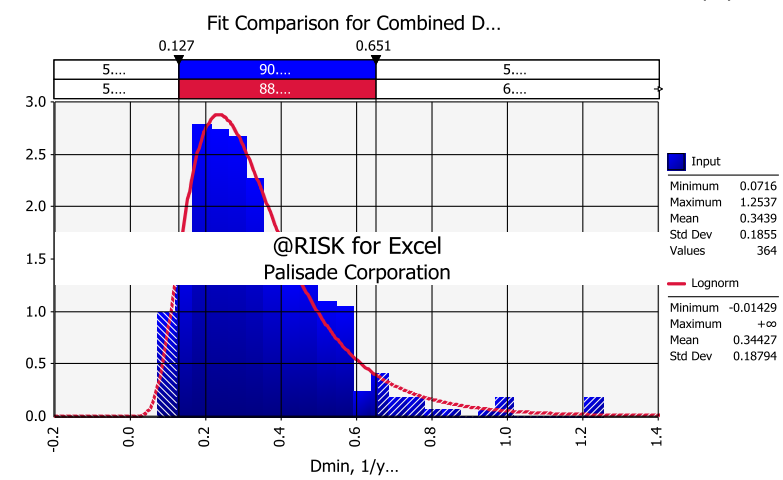

(c)

Fig. 3.29 - Distribution of minimum decline rate $\left(D_{\min }\right)$ : (a) for boundarydominated flow (BDF) wells, (b) distribution of decline rate at end of history for non-BDF wells, and (c) the combined distribution for $D_{\min }$ (oil) 


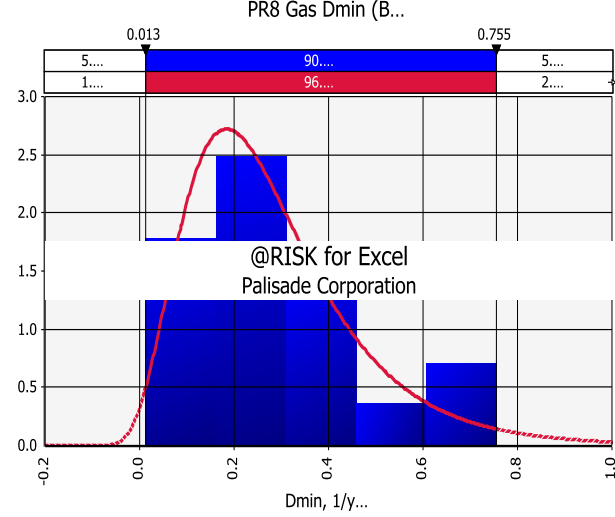

(a)

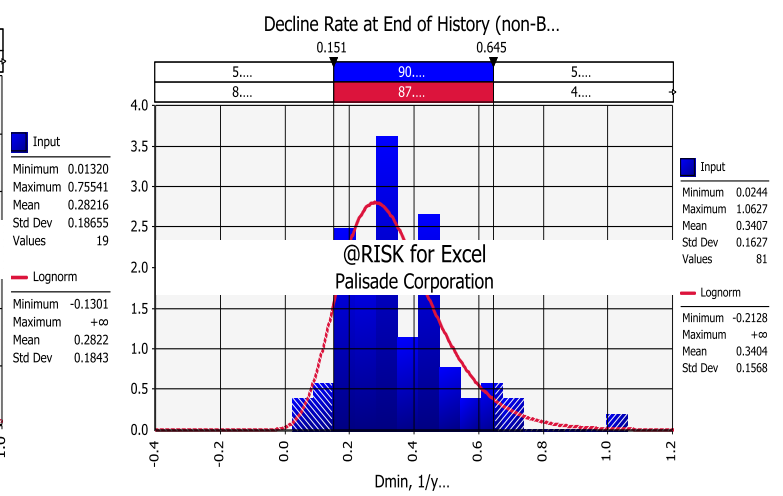

(b)

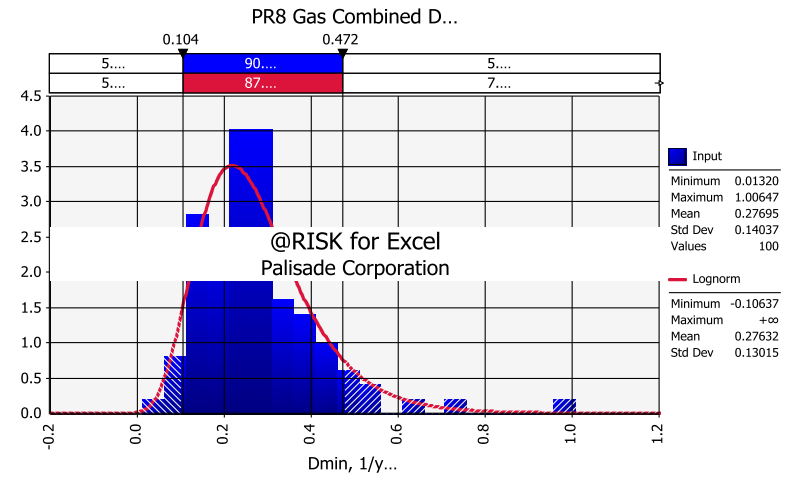

(c)

Fig. 3.30 - Distribution of minimum decline rate $\left(D_{\min }\right)$ for: (a) boundarydominated flow (BDF) wells, (b) distribution of decline rate at end of history for non-BDF wells, and (c) the combined distribution for $D_{\min }$ (gas) 


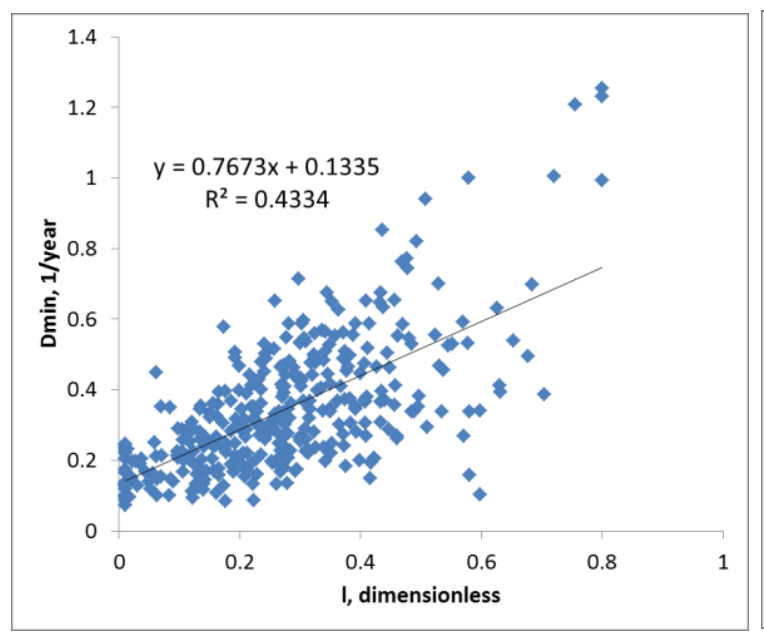

(a)

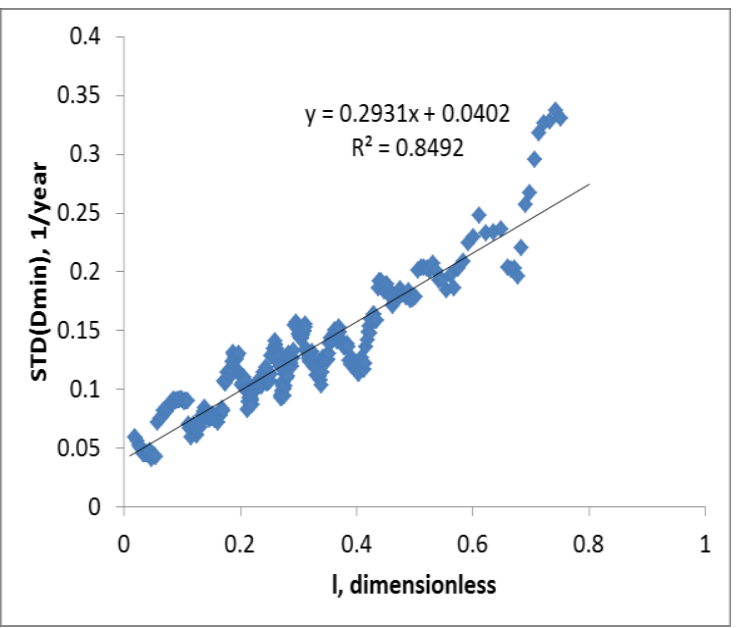

(b)

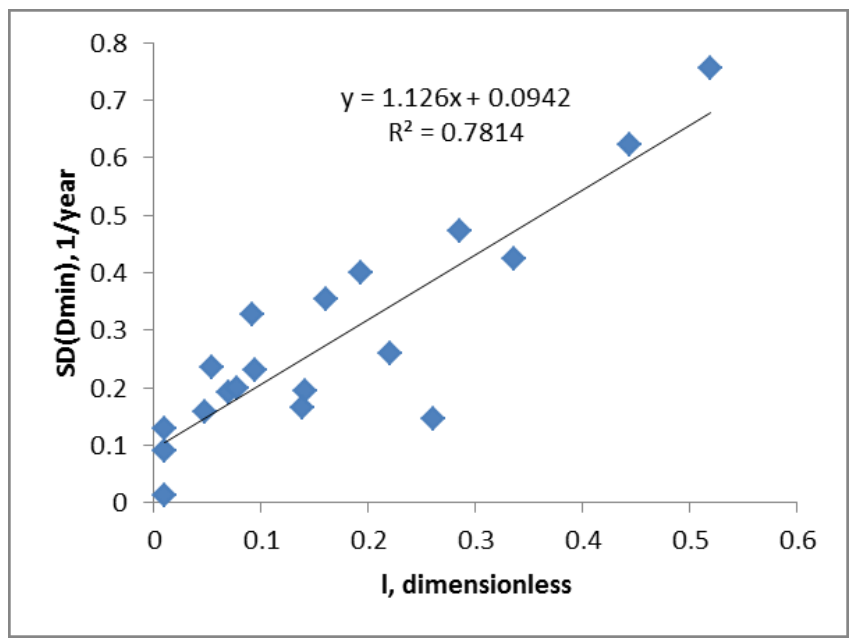

(c)

Fig. 3.31 - For oil production, both (a) minimum decline rate $\left(D_{\min }\right)$ and (b) the standard deviation of minimum decline rate $\left(D_{\min }\right)$ increase when decline curve parameter $l$ increases. For (c) gas production, $D_{\min }$ increases when $l$ increases

$$
\begin{gathered}
\operatorname{Mean}\left(\operatorname{Dmin}_{\text {Oil }}\right)=0.763 \times l+0.1335, S D\left(\operatorname{Dmin}_{\text {oil }}\right)=0.2931 \times l+0.0402 \\
\operatorname{Mean}\left(\operatorname{Dmin}_{\text {gas }}\right)=1.126 \times l+0.0942, \quad S D\left(\text { Dmin }_{\text {gas }}\right)=0.08723 \ldots \ldots \ldots \ldots
\end{gathered}
$$


The distribution of the time when the oil production reached boundary-dominated flow is shown in (Fig. 3. 36)

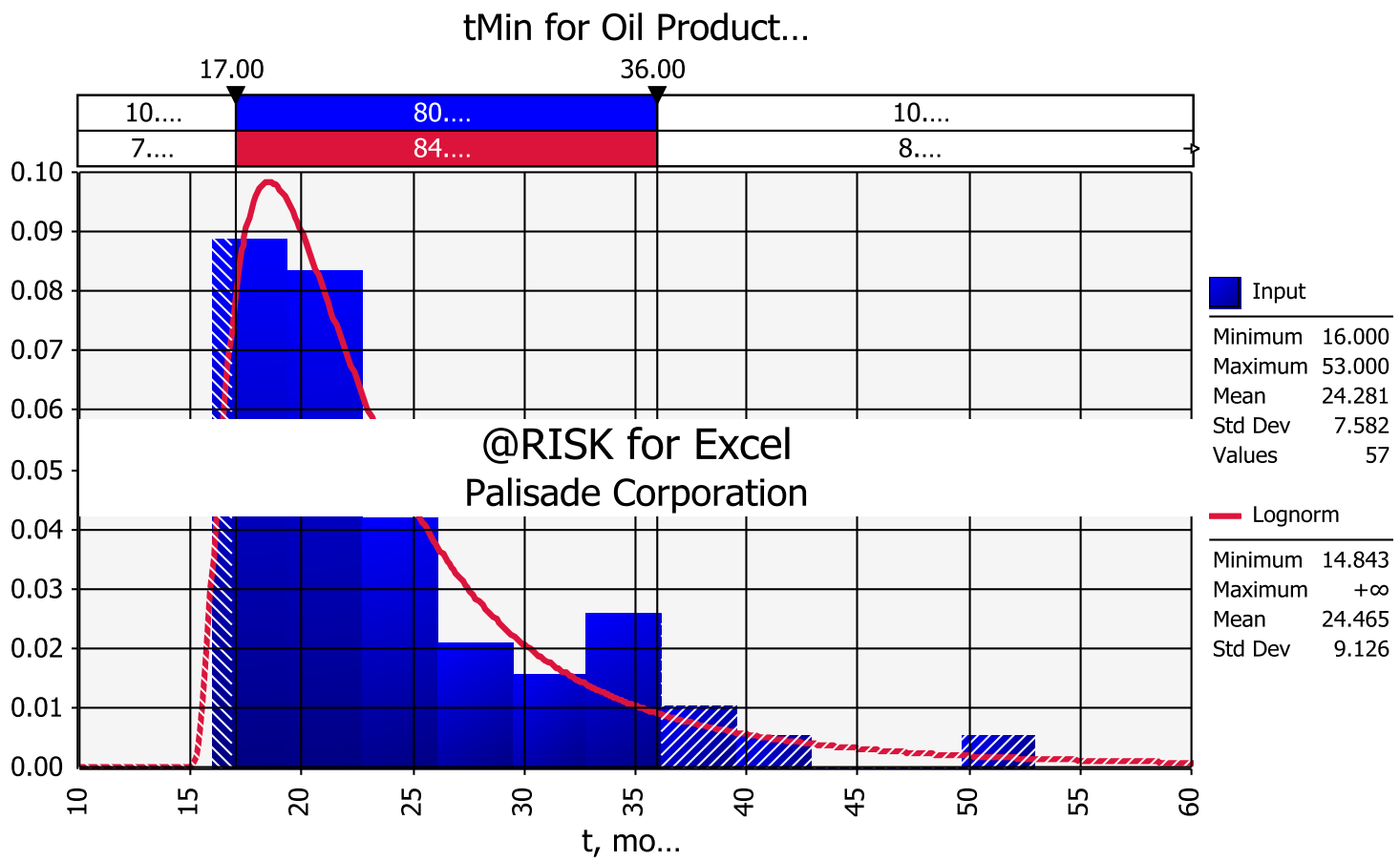

Fig. 3.32 - The time to reach boundary-dominated flow ranges from 17 months to 50 months with an average of 24 months.

\subsubsection{Generation of GOR Model}

Since production forecasts were performed on oil production for PR1 to PR7, I built GOR models to calculate gas production for those production regions. I first normalized oil and gas production of all the wells in the production regions to the same starting month. I then divided the sum of gas production by the sum of oil production for each month to get the average GOR curves for all production regions (Fig. 3.33). I found that 
the GOR curves for the same fluid type are very similar. So I combined GOR curves within each fluid type and ended up with three average GOR curves for black oil, volatile oil, and condensate regions. I then fit two straight lines to bracket the majority of the data; the last several data points were ignored because the well count of the later months is significantly lower than the well count of the earlier months (Fig. 3.34). The slopes for those two straight lines are shown in Table 3.26. However, since the production history is short, the GOR may increase faster or slower of the slightly increasing models. As a result, it is possible the slightly increasing models can underestimate the uncertainty.

I collected the initial GOR for all the wells in black oil, volatile oil, and condensate regions. By comparing the initial GOR with the best-fit decline curve parameters, I found the only significant correlation was between the initial GOR and $\mathrm{N}_{240}$ for the condensate regions (Fig. 3.35). However, the standard deviation of $\ln$ (initial GOR) decreases when $\mathrm{N}_{240}$ increases for all three fluid types (Fig. 3.36). The median of the initial GOR and the standard deviation of the $\ln$ (initial GOR) for all three fluid types are shown in Eq. 3.9. 


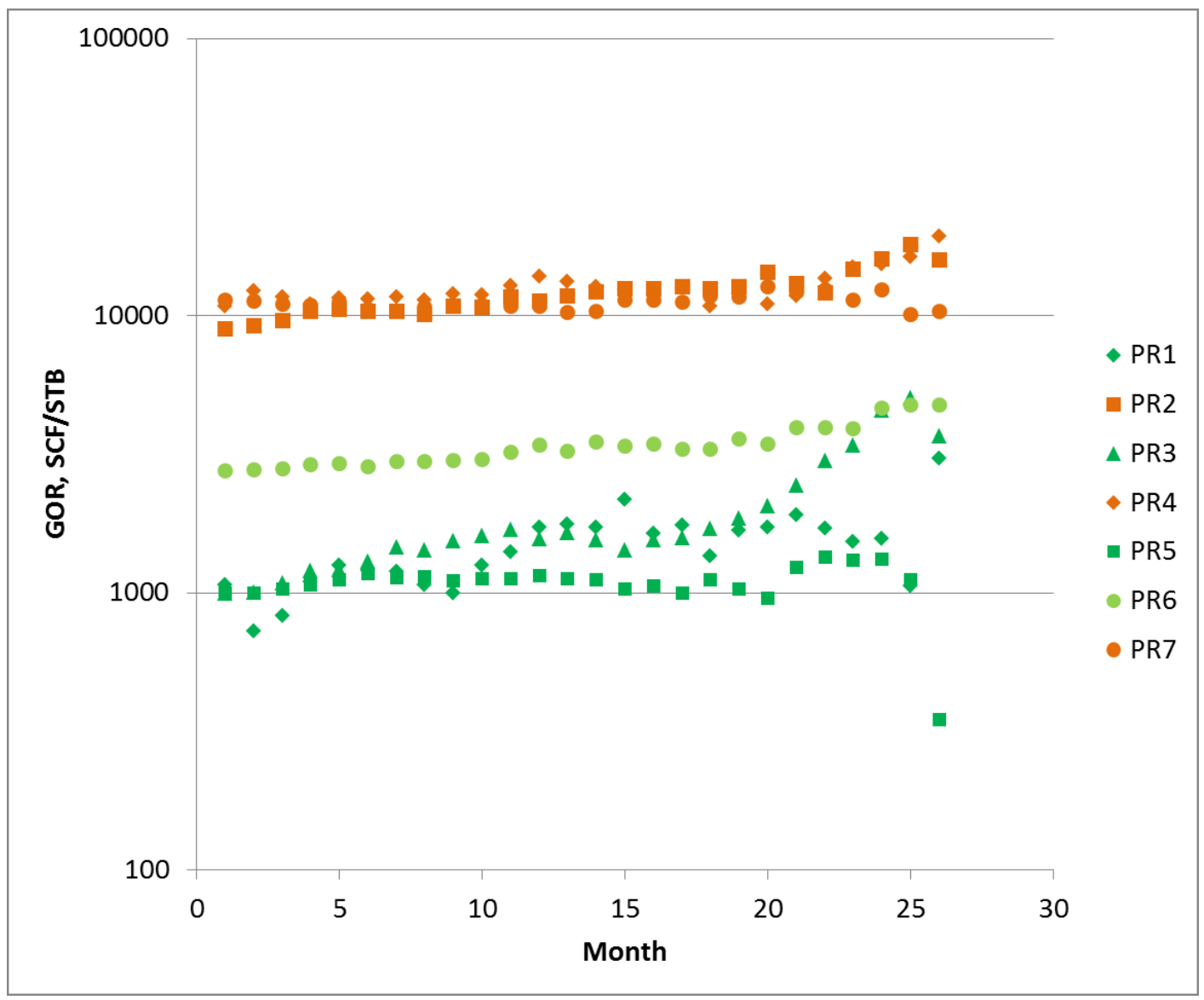

Fig. 3.33 - Average GOR curves sharing the same fluid type have similar shapes 


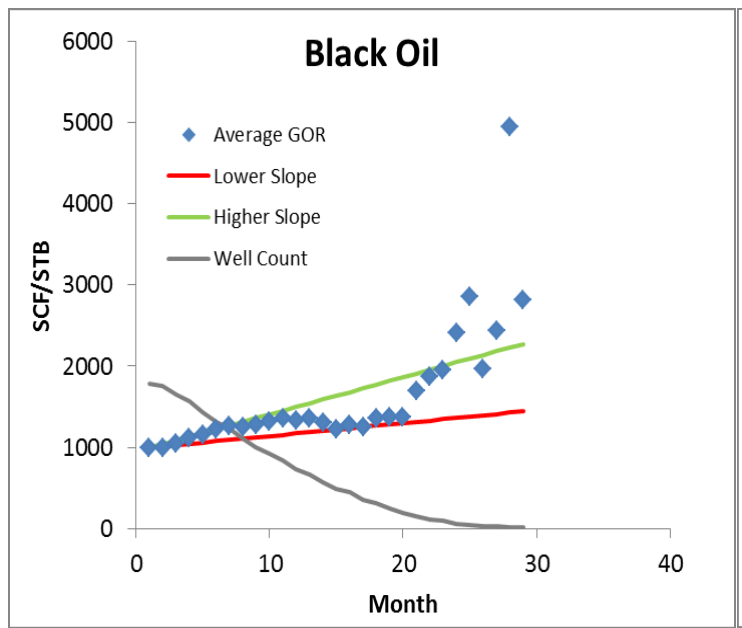

(a)

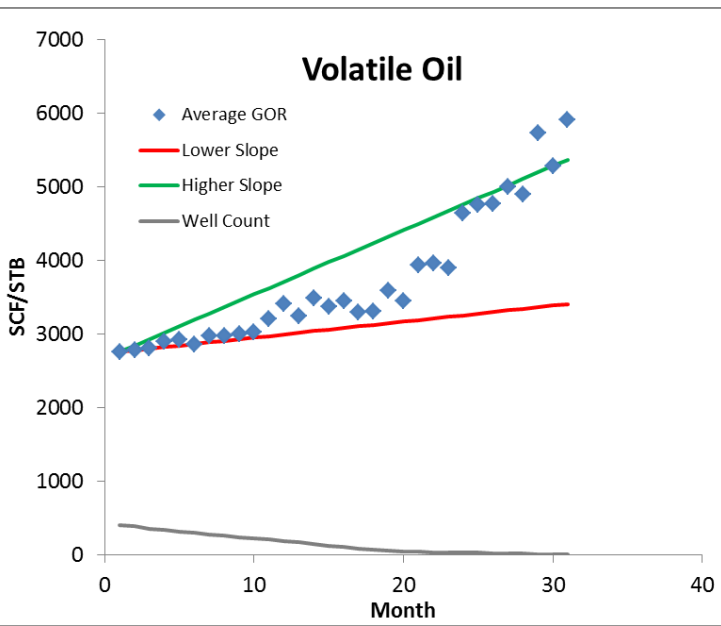

(b)

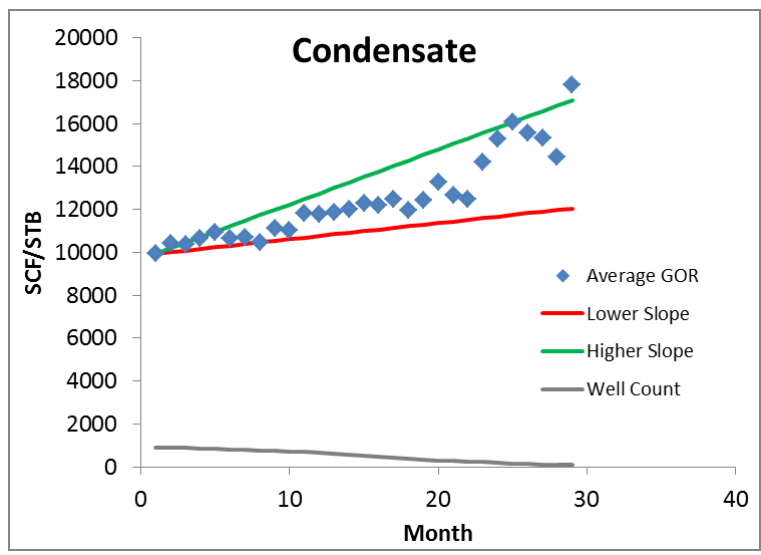

(c)

Fig. 3.34 - Average GOR and the straight line GOR models for (a) black oil, (b) volatile oil, and (c) condensate fluid types

Table 3.26- GOR Slopes for Three Fluid Types

\begin{tabular}{ccc} 
Fluid Type & Lower Slope, SCF/STB/month & Higher Slope, SCF/STB/month \\
\cline { 2 - 3 } Black Oil & 16 & 46 \\
Volatile Oil & 22 & 87 \\
Condensate & 75 & 256
\end{tabular}




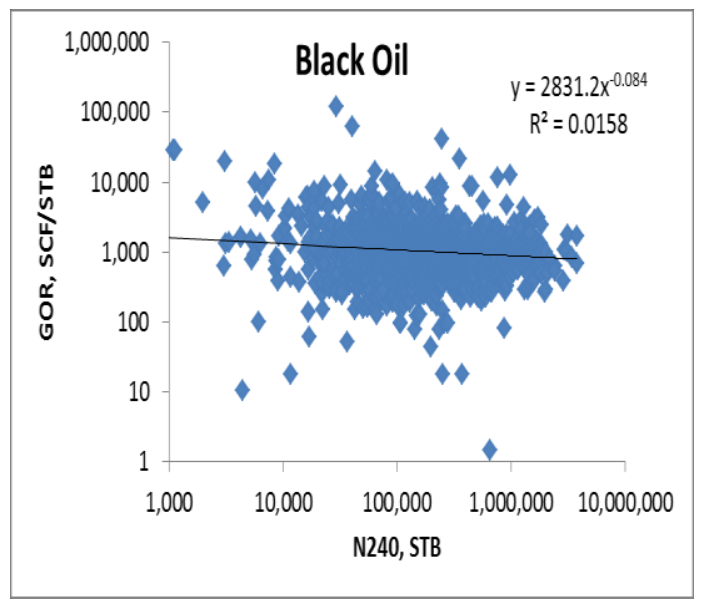

(a)

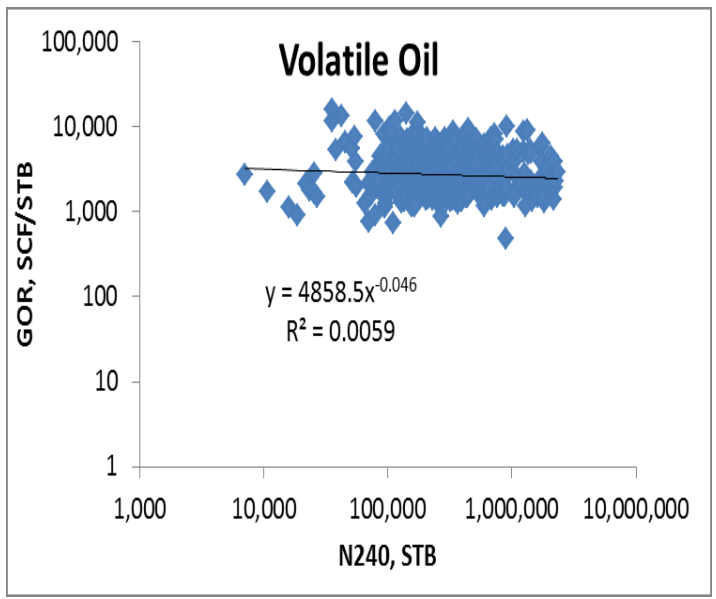

(b)

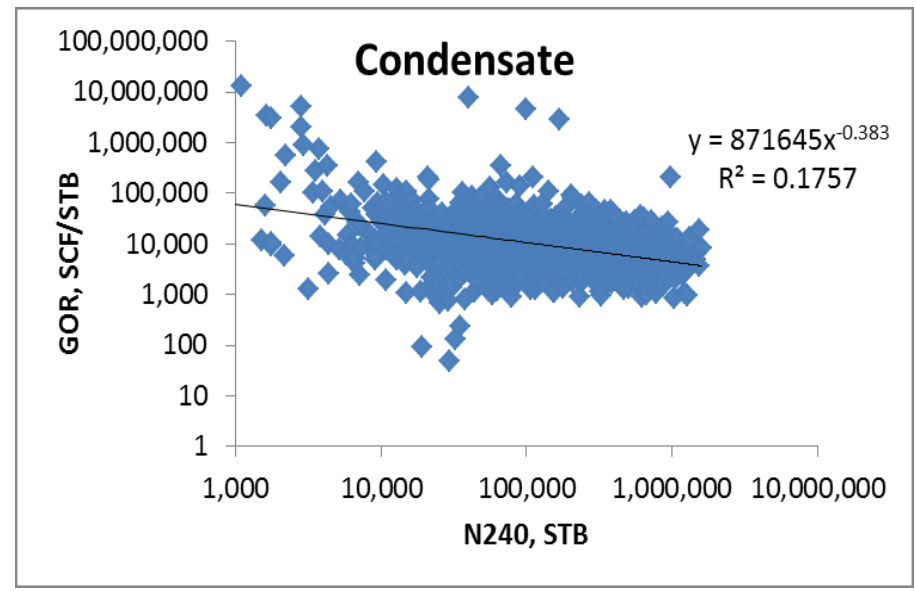

(c)

Fig. 3.35- Initial GOR is not correlated to $\mathrm{N}_{240}$ of (a) black oil and (b) volatile regions, but correlated to $\mathrm{N}_{240}$ of (c) condensate regions 


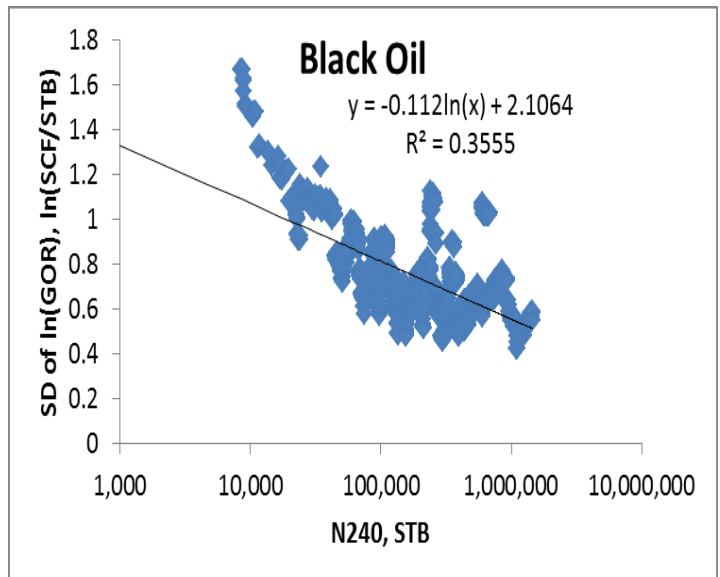

(a)

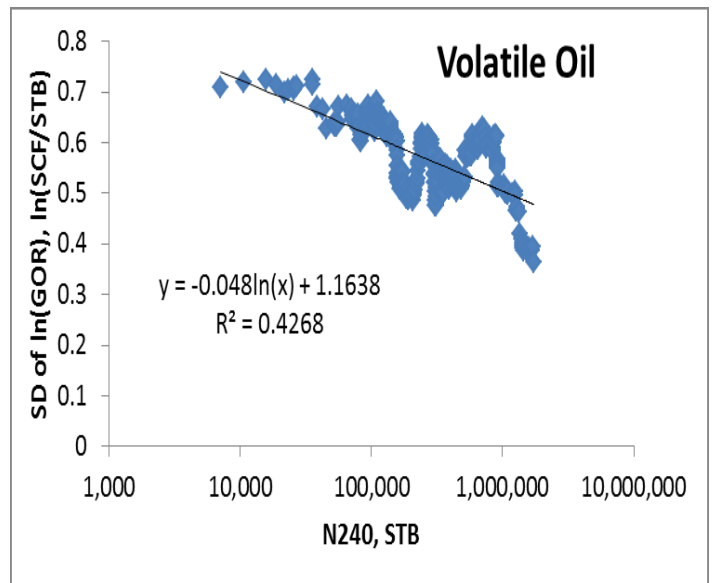

(b)

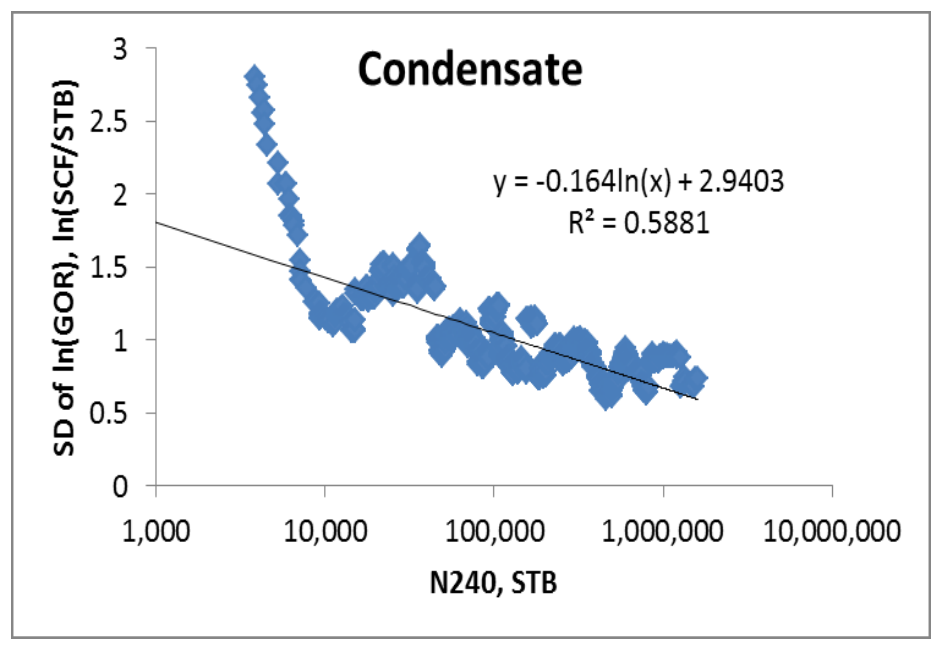

(c)

Fig. 3.36 - Standard deviation of $\ln$ (initial GOR) decreases when $\mathbf{N}_{240}$ increases for all three fluid types: (a) black oil, (b) volatile oil, and (c) condensate 


$$
\begin{aligned}
& \operatorname{Mean}(I G O R)=1020 \\
& S D(\ln (I G O R))=2.1064-0.112 \times \ln (N 240) \text { for black oil } \\
& \operatorname{Mean}(I G O R)=2721, \\
& S D(\ln (I G O R))=1.1638-0.0481 \times \ln (N 240) \text { for volatile oil } \\
& \operatorname{Mean}(I G O R)=871645 \times \ln (N 240)^{0.383}, \\
& S D(\ln (I G O R))=2.1064-0.112 \times \ln (N 240) \text { for condensate.. (3.9) }
\end{aligned}
$$

\subsubsection{Generation of Type Probabilistic Decline Curves}

In order to calculate reserves or resources for new wells, probabilistic type curves need to be generated for each production region. The type curves for each production region represent the distributions of oil and gas production of a new well with similar drilling and completion technology in a pre-defined area. I generated the probabilistic type curves using the following steps:

- Perform probabilistic decline curve forecast with MCMC for all existing wells within each production region, save all the decline curve parameters associated with each iteration of the Markov Chain of all the wells

- Perform Monte Carlo simulation to randomly draw 100,000 parameter sets from all the iterations of all wells as the distribution of all decline curve parameters

- Perform Monte Carlo simulation to draw initial GOR, GOR slope, and minimum decline rate based on Eq. 3.8 for minimum decline rate, Eq. 3.9 for initial GOR, and uniform distribution for GOR slope with boundaries in Table 3.26 for all 100,000 draws. 
- Calculate technical recoverable resources of 20 years (TRR20) of oil and gas for each set of decline curve parameters and other parameters; generate two ranked lists of parameters based on TRR20 oil and TRR20 gas.

- Average all the parameters within a predefined band (1000 sets in this case) around the $\mathrm{P}_{90}, \mathrm{P}_{50}$, and $\mathrm{P}_{10}$ of oil and gas TRR20 from the ranked lists.

- Correct the $\mathrm{N}_{240}$ or $\mathrm{G}_{240}$ parameter so that the TRR20 calculated from the average parameters equal to the $\mathrm{P}_{90}, \mathrm{P}_{50}$, and $\mathrm{P}_{10}$ of oil and gas TRR20

Fig. 3.37 shows the relationship between prior distribution (from reservoir simulation studies), likelihood function (from production data), and posterior distribution for a single well in PR5 and for the type well for PR5. For the single well, the likelihood function dominates the prior density. For the type well, both prior density and likelihood function contribute to the posterior distribution. The posterior distributions of oil and gas TRR20 of PR5 follow lognormal distributions (Fig. 3.38). Both prior and posterior probabilistic type curves bracket the majority of the production data, while the posterior probabilistic type curves capture the curvature of the production data much better than the prior type curves generated from simulation studies for oil production in PR5 (Fig. 3.39). Fig. 3.40 and Fig. 3.41 show the oil and gas type probabilistic decline curves for all the production regions, respectively. Table 3.27 and Table 3.28 show all the parameters for the oil and gas type decline curves, respectively. Table 3.29 shows the $\mathrm{P}_{90}, \mathrm{P}_{50}, \mathrm{P}_{10}$, mean, and standard deviation of TRR20 for all eight production regions. 


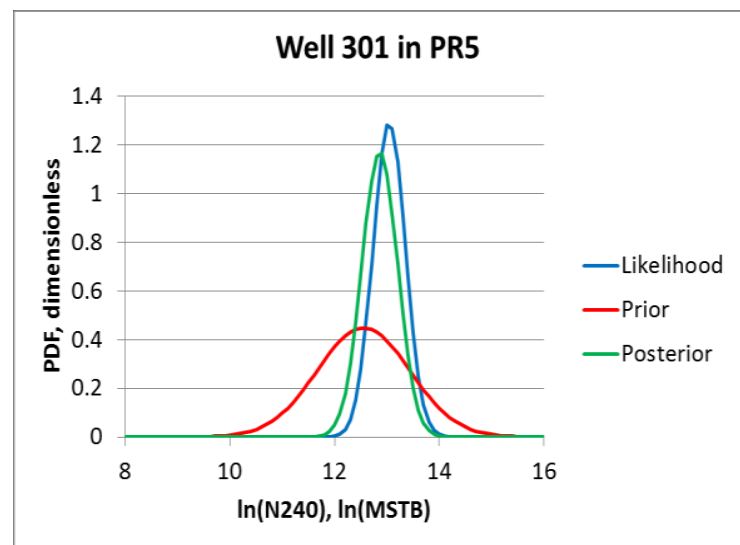

(a)

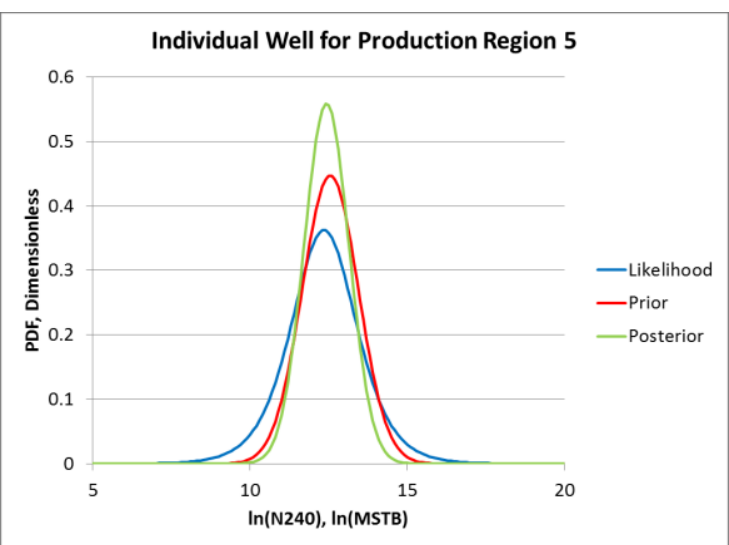

(b)

Fig. 3.37- Likelihood (production data) dominated the posterior distribution of a particular well in PR5 (a), while both prior and likelihood contribute to the posterior distribution of the type well of PR5

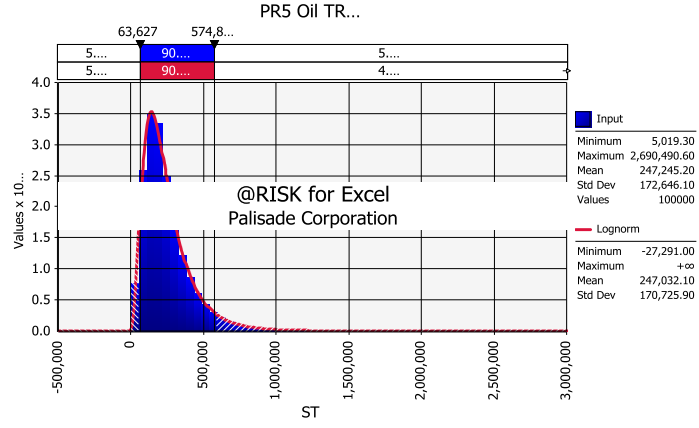

(a)

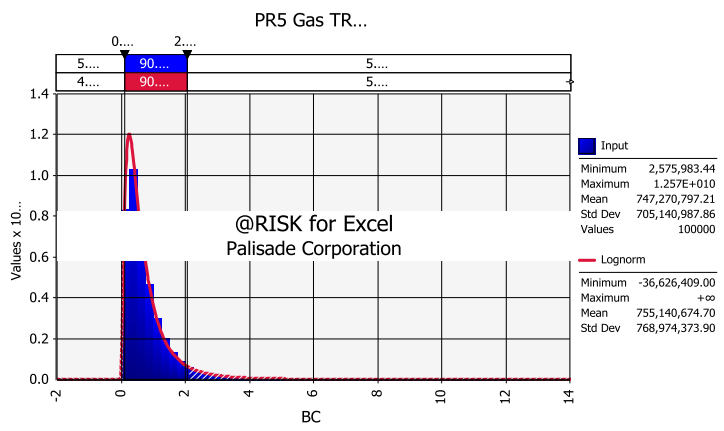

(b)

Fig. 3.38 - Both oil (a) and gas (b) TRR20 follow lognormal distribution of PR5 


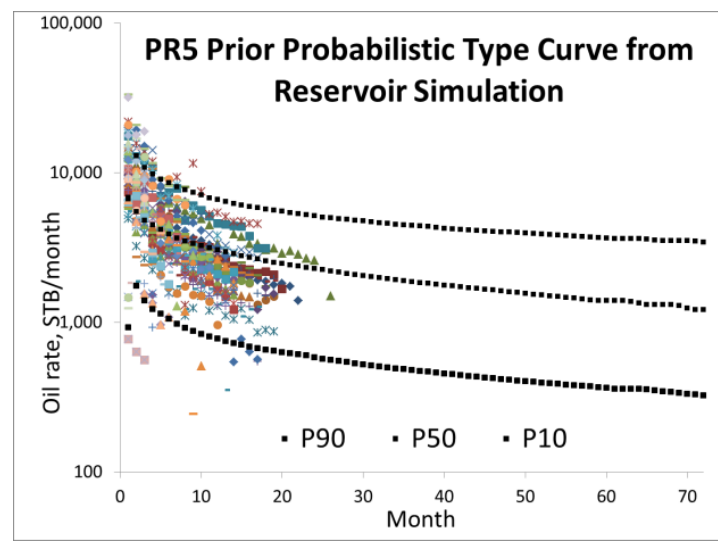

(a)

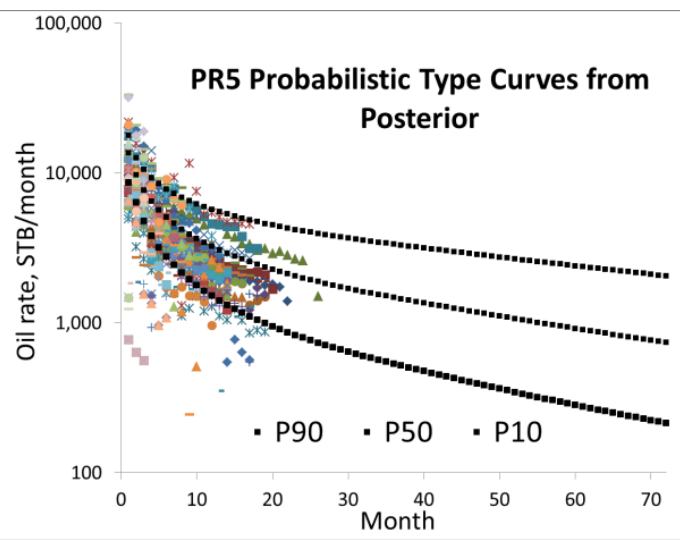

(b)

Fig. 3.39 - Both (a) prior type curves (generated from reservoir simulation) and (b) posterior type curves bracket the real oil production of PR5. The posterior type curves follow the curvature of the production data much better than the prior type curves 

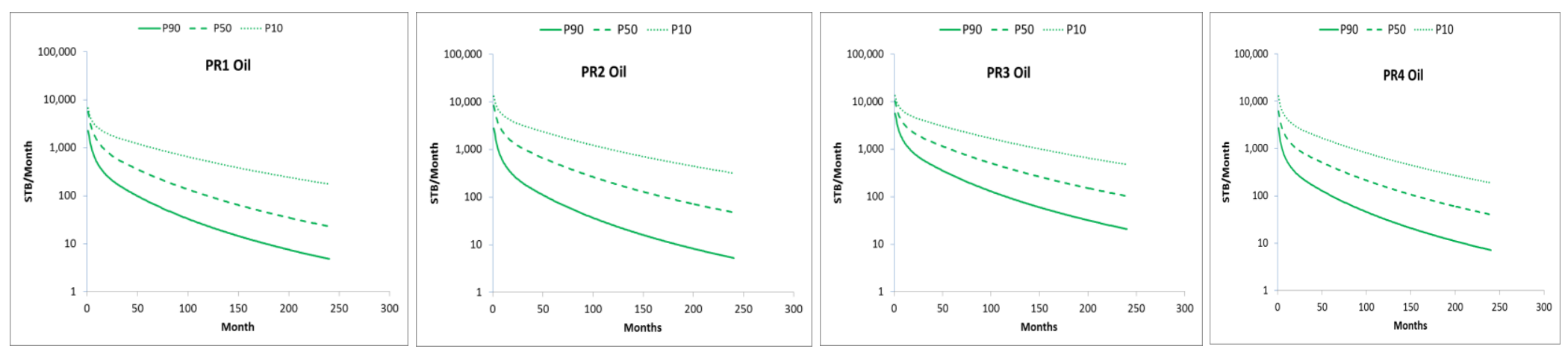

(a)

(b)

(c)

(d)
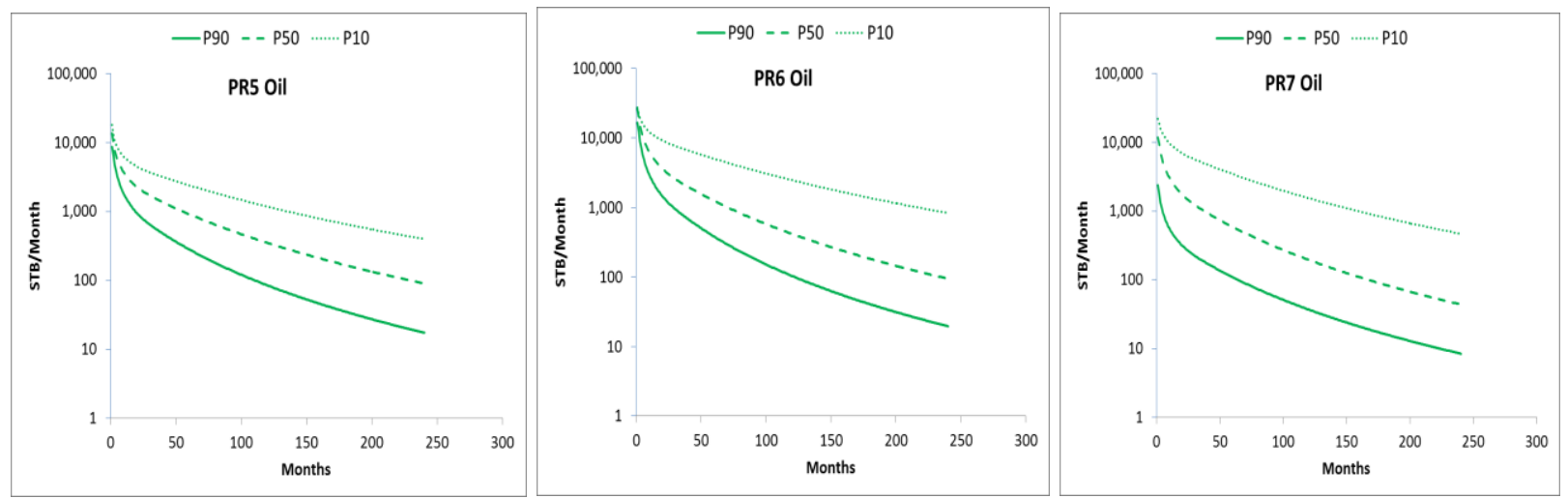

(e)

(f)

(g)

Fig. 3.40 - Probabilistic type curves for oil production of (a) PR1 to (g) PR7 


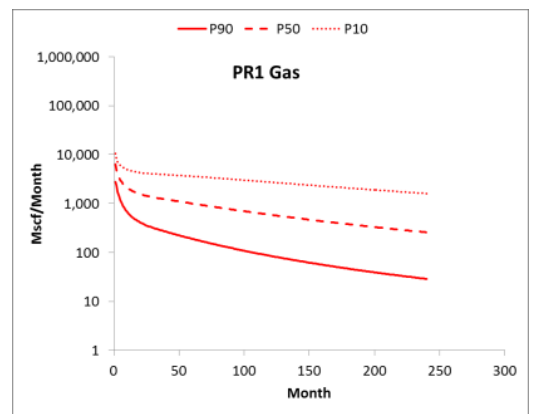

(a)

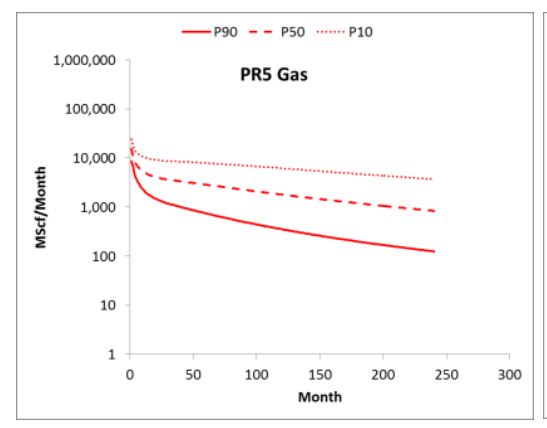

(e)

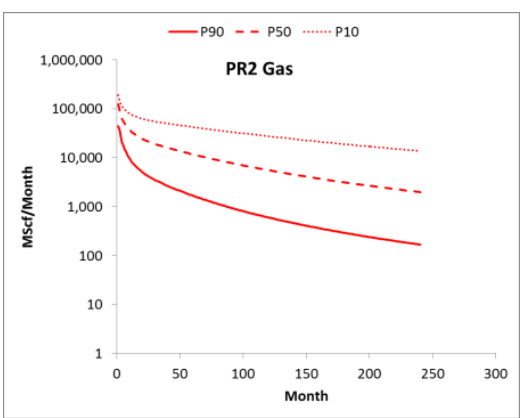

(b)

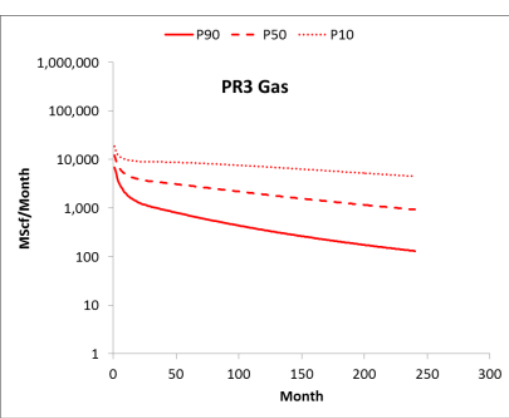

(c)

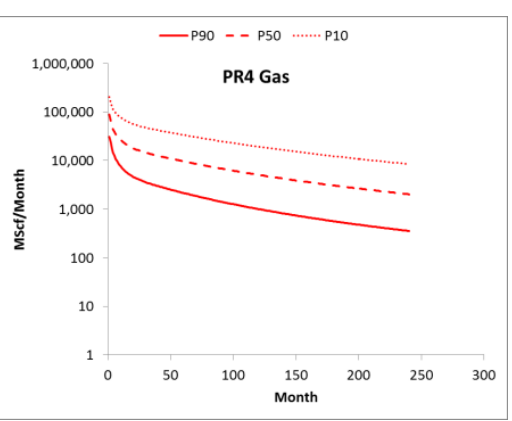

(d)

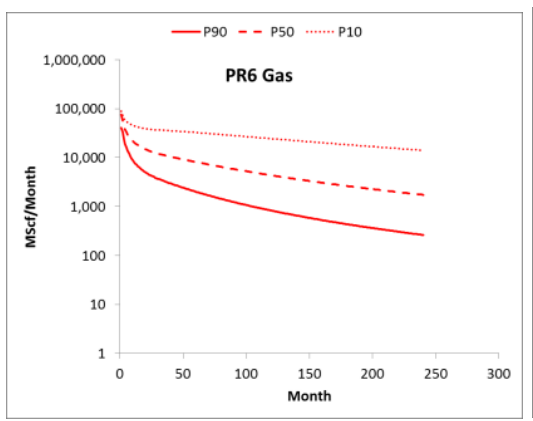

(f)

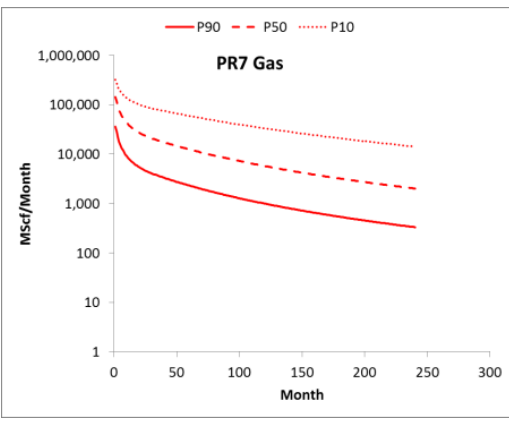

$(\mathrm{g})$

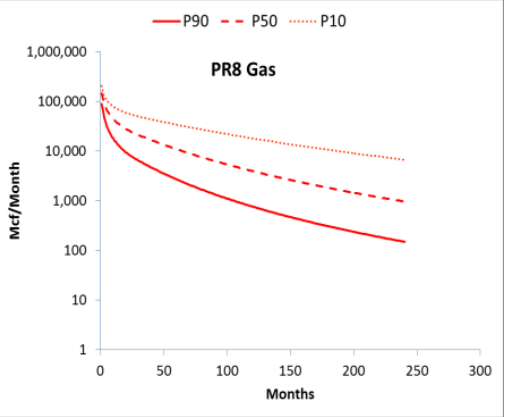

(h)

Fig. 3.41 - Probabilistic type curves for gas production of (a) PR1 to (h) PR8 


\begin{tabular}{|c|c|c|c|c|c|c|}
\hline \multicolumn{7}{|c|}{ Table 3.27- Parameters of Type Probabilistic Decline Curves (Oil) } \\
\hline Production Regions & $\underline{\text { Percentiles }}$ & $\underline{N}_{240}$, STB & $\underline{a}$ & $\underline{I}$ & $\underline{D}_{\min } 1 /$ year & $\underline{\text { TRR20, STB }}$ \\
\hline \multirow{3}{*}{ PR1 } & $\mathrm{P}_{90}$ & 26,038 & 0.91 & 0.30 & 0.37 & 23,059 \\
\hline & $\mathrm{P}_{50}$ & 83,163 & 0.89 & 0.24 & 0.30 & 72,345 \\
\hline & $\mathrm{P}_{10}$ & 250,220 & 0.85 & 0.10 & 0.18 & 199,612 \\
\hline \multirow{3}{*}{ PR2 } & $\mathrm{P}_{90}$ & 29,819 & 0.91 & 0.31 & 0.37 & 26,699 \\
\hline & $\mathrm{P}_{50}$ & 147,652 & 0.87 & 0.20 & 0.29 & 124,438 \\
\hline & $\mathrm{P}_{10}$ & 488,856 & 0.85 & 0.10 & 0.19 & 382,868 \\
\hline \multirow{3}{*}{ PR3 } & $\mathrm{P}_{90}$ & 84,165 & 0.89 & 0.24 & 0.32 & 71,994 \\
\hline & $\mathrm{P}_{50}$ & 244,998 & 0.86 & 0.16 & 0.25 & 199,662 \\
\hline & $\mathrm{P}_{10}$ & 647,920 & 0.86 & 0.07 & 0.17 & 488,506 \\
\hline \multirow{3}{*}{ PR4 } & $\mathrm{P}_{90}$ & 32,078 & 0.83 & 0.25 & 0.33 & 27,941 \\
\hline & $\mathrm{P}_{50}$ & 111,213 & 0.84 & 0.19 & 0.27 & 93,645 \\
\hline & $\mathrm{P}_{10}$ & 345,766 & 0.84 & 0.13 & 0.22 & 282,178 \\
\hline \multirow{3}{*}{ PR5 } & $\mathrm{P}_{90}$ & 96,287 & 0.88 & 0.29 & 0.37 & 84,686 \\
\hline & $\mathrm{P}_{50}$ & 243,618 & 0.83 & 0.18 & 0.27 & 204,650 \\
\hline & $\mathrm{P}_{10}$ & 569,238 & 0.79 & 0.09 & 0.18 & 457,435 \\
\hline \multirow{3}{*}{ PR6 } & $\mathrm{P}_{90}$ & 152,147 & 0.90 & 0.35 & 0.42 & 136,613 \\
\hline & $\mathrm{P}_{50}$ & 370,024 & 0.88 & 0.24 & 0.32 & 318,489 \\
\hline & $\mathrm{P}_{10}$ & $1,195,584$ & 0.88 & 0.09 & 0.19 & 925,599 \\
\hline \multirow{3}{*}{ PR7 } & $\mathrm{P}_{90}$ & 32,570 & 0.86 & 0.24 & 0.31 & 28,227 \\
\hline & $\mathrm{P}_{50}$ & 175,393 & 0.92 & 0.25 & 0.32 & 151,288 \\
\hline & $\mathrm{P}_{10}$ & 835,202 & 0.92 & 0.13 & 0.22 & 653,800 \\
\hline
\end{tabular}




\begin{tabular}{|c|c|c|c|c|c|c|c|c|}
\hline \multicolumn{9}{|c|}{ Table 3.28 - Parameters of Type Probabilistic Decline Curves (Gas) } \\
\hline Production Regions & Percentiles & $\mathrm{N}_{240}(\mathrm{STB})$ & $a$ & I & $D_{\min }, 1 /$ year & GORI, SCF/STB & GORS, SCF/STB/Month & TRR20 (Bcf) \\
\hline \multirow{4}{*}{ PR1 } & $\mathrm{P}_{90}$ & 30,493 & 0.97 & 0.38 & 0.42 & 843 & 30 & 0.04 \\
\hline & $\mathrm{P}_{50}$ & 82,908 & 0.85 & 0.19 & 0.27 & 1,421 & 31 & 0.19 \\
\hline & $\mathrm{P}_{10}$ & 217,407 & 0.83 & 0.08 & 0.17 & 2,017 & 33 & 0.71 \\
\hline & $\mathrm{P}_{90}$ & 21,174 & 0.95 & 0.35 & 0.42 & 21,248 & 157 & 0.48 \\
\hline \multirow[t]{3}{*}{ PR2 } & $\mathrm{P}_{50}$ & 74,178 & 0.84 & 0.18 & 0.26 & 31,950 & 164 & 2.43 \\
\hline & $\mathrm{P}_{10}$ & 283,074 & 0.84 & 0.09 & 0.18 & 24,768 & 178 & 8.16 \\
\hline & $\mathrm{P}_{90}$ & 90,361 & 0.92 & 0.30 & 0.37 & 914 & 29 & 0.14 \\
\hline \multirow[t]{3}{*}{ PR3 } & $\mathrm{P}_{50}$ & 230,246 & 0.85 & 0.14 & 0.23 & 1,368 & 30 & 0.55 \\
\hline & $\mathrm{P}_{10}$ & 569,436 & 0.84 & 0.06 & 0.16 & 1,645 & 33 & 1.73 \\
\hline & $\mathrm{P}_{90}$ & 38,246 & 0.88 & 0.28 & 0.35 & 9,377 & 156 & 0.48 \\
\hline \multirow[t]{3}{*}{ PR4 } & $\mathrm{P}_{50}$ & 97,289 & 0.84 & 0.18 & 0.26 & 16,656 & 164 & 1.97 \\
\hline & $\mathrm{P}_{10}$ & 192,352 & 0.84 & 0.12 & 0.20 & 31,730 & 175 & 6.54 \\
\hline & $\mathrm{P}_{90}$ & 104,379 & 0.92 & 0.32 & 0.40 & 878 & 29 & 0.16 \\
\hline \multirow[t]{3}{*}{ PR5 } & $\mathrm{P}_{50}$ & 241,936 & 0.83 & 0.16 & 0.25 & 1,281 & 30 & 0.54 \\
\hline & $\mathrm{P}_{10}$ & 501,826 & 0.80 & 0.07 & 0.17 & 1,770 & 33 & 1.57 \\
\hline & $\mathrm{P}_{90}$ & 165,476 & 0.97 & 0.39 & 0.45 & 2,205 & 51 & 0.51 \\
\hline \multirow[t]{3}{*}{ PR6 } & $\mathrm{P}_{50}$ & 357,999 & 0.85 & 0.22 & 0.29 & 3,282 & 54 & 1.66 \\
\hline & $\mathrm{P}_{10}$ & $1,081,779$ & 0.86 & 0.08 & 0.18 & 3,761 & 58 & 6.35 \\
\hline & $\mathrm{P}_{90}$ & 33,071 & 0.90 & 0.28 & 0.36 & 13,563 & 157 & 0.54 \\
\hline \multirow[t]{2}{*}{ PR7 } & $\mathrm{P}_{50}$ & 124,575 & 0.91 & 0.24 & 0.31 & 18,929 & 164 & 2.70 \\
\hline & $\mathrm{P}_{10}$ & 394,432 & 0.90 & 0.14 & 0.22 & 26,192 & 173 & 11.35 \\
\hline \multirow{4}{*}{ PR8 } & Percentiles & $\mathrm{G}_{240}$ (BCF) & $a$ & 1 & $D_{\min }, 1 /$ year & GORI, SCF/STB & GORS, SCF/STB/Month & TRR20 (Bcf) \\
\hline & $\mathrm{P}_{90}$ & 0.97 & 0.86 & 0.28 & 0.41 & NA & NA & 0.84 \\
\hline & $\mathrm{P}_{50}$ & 3.01 & 0.87 & 0.18 & 0.30 & NA & NA & 2.42 \\
\hline & $\mathrm{P}_{10}$ & 7.91 & 0.81 & 0.07 & 0.15 & NA & NA & 6.39 \\
\hline
\end{tabular}




\begin{tabular}{|c|c|c|c|c|c|c|c|c|c|c|}
\hline \multicolumn{11}{|c|}{ Table 3.29- Summary of TRR20 Oil and Gas for All Production Regions } \\
\hline \multirow[b]{2}{*}{ Production Regions } & \multicolumn{5}{|c|}{ Oil TRR20, STB } & \multicolumn{5}{|c|}{ Gas TRR20, BCF } \\
\hline & $\mathbf{P}_{90}$ & $\mathbf{P}_{50}$ & $\mathbf{P}_{10}$ & Mean & SD & $\mathbf{P}_{90}$ & $\mathbf{P}_{50}$ & $\mathbf{P}_{10}$ & Mean & SD \\
\hline PR1 & 23,059 & 72,345 & 199,612 & 100,688 & 96,760 & 0.04 & 0.19 & 0.71 & 0.32 & 0.38 \\
\hline PR2 & 26,699 & 124,438 & 382,868 & 173,595 & 169,270 & 0.48 & 2.43 & 8.16 & 3.62 & 3.89 \\
\hline PR3 & 71,994 & 199,662 & 488,506 & 254,858 & 226,309 & 0.14 & 0.55 & 1.73 & 0.81 & 0.94 \\
\hline PR4 & 27,941 & 93,645 & 282,178 & 133,376 & 129,414 & 0.48 & 1.97 & 6.54 & 2.97 & 3.27 \\
\hline PR5 & 84,686 & 204,650 & 457,435 & 247,402 & 172,769 & 0.16 & 0.54 & 1.57 & 0.75 & 0.70 \\
\hline PR6 & 136,613 & 318,489 & 925,599 & 453,708 & 412,886 & 0.51 & 1.66 & 6.35 & 2.79 & 3.35 \\
\hline PR7 & 28,227 & 151,288 & 653,800 & 269,239 & 318,648 & 0.54 & 2.70 & 11.35 & 4.75 & 5.89 \\
\hline PR8 & & & & & & 0.84 & 2.42 & 6.39 & 3.25 & 3.11 \\
\hline
\end{tabular}


The average ratio of $\mathrm{P}_{10}: \mathrm{P}_{50}: \mathrm{P}_{90}$ of TRR20 for all production regions, based on Table 3.27 and Table 3.28 , are $10.8: 3.4: 1$ and $13.8: 4: 1$ for oil and gas respectively. According to Table 3.29, the best region for oil TRR20 is PR6, with a mean of 453,708 STB, while the best region for gas TRR20 is PR7, with a mean of $4.75 \mathrm{BCF}$.

\subsection{Reservoir Area, Well Density and Well Count}

\subsubsection{Reservoir Area}

According to PRMS (SPE et al. 2007), the criteria between reserves and contingent resources is commerciality; the criteria between contingent resources and prospective resources is discovery. Based on Table 3.29, a simple calculation, assuming oil price of $\$ 100 /$ STB and gas price of $\$ 4 / \mathrm{MSCF}$, shows the lowest mean monetary values among all the production regions are PR1 with $\$ 11.2$ million and PR8 with $\$ 13$ million. Compared with the typical drilling and completion cost of $\$ 8$ million (Pope et al. 2012), the mean monetary value is greater than typical well cost for all production regions. The

discovery criteria is more challenging, Dobson et al. (2012) introduced a methodology to define which part of the field is discovered and which part of the field is not discovered. I adopted their idea that the area within a certain radius of the existing wells could be considered the discovered area, and the area outside of the radius of the existing wells could be considered the undiscovered area. To identify the radius, I calculated the variogram of the peak month oil production ( Fig.3.42(a)). Based on the variogram, when the distance between the two wells is below 1.5 miles, there is significant correlation between the peak month oil productions (Fig.3.42(b)). I used 1.5 miles as the 
radius and drew blue circles around all existing wells. In Fig. 3.43, the blue colored area is considered discovered area for reserves and contingent resources, and the blank area is considered as the undiscovered area for prospective resources.

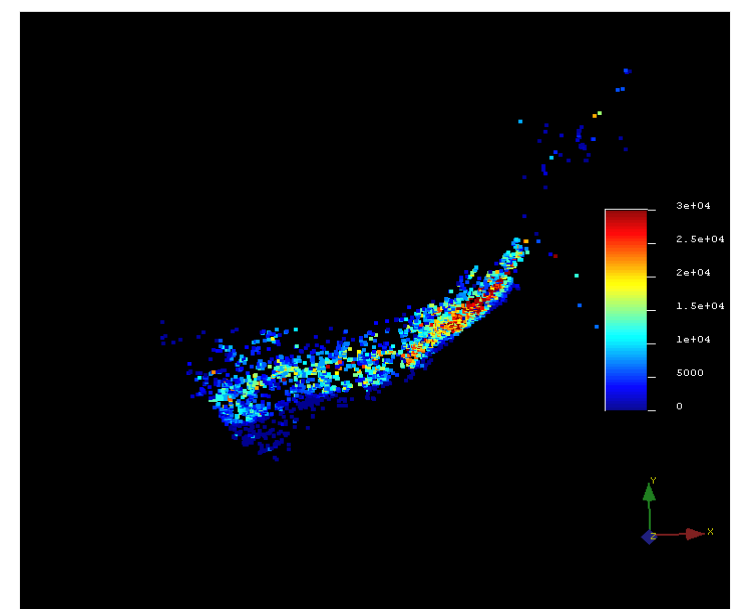

(a)

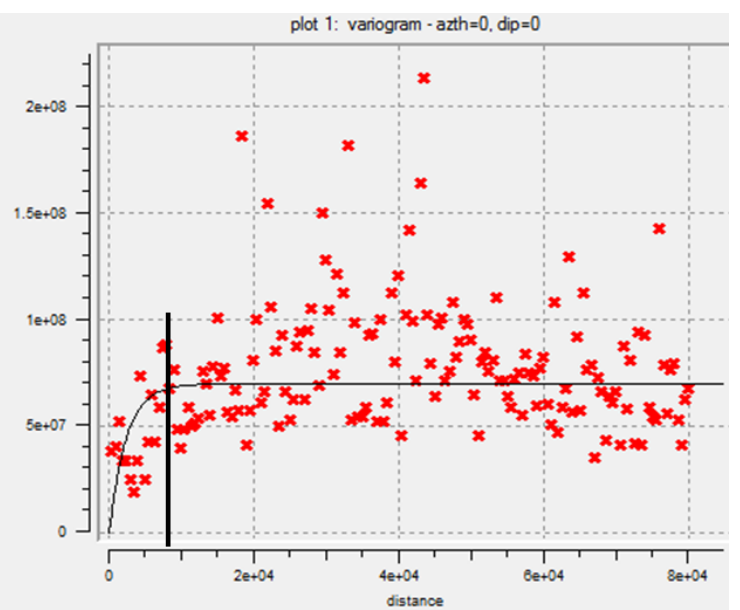

(b)

Fig. 3.42 - Variogram analysis: (a) the distribution of peak month oil, and (b) the variogram of the peak month oil show that the peak oil productions of two wells are correlated when the distance between the two wells is less than 1.5 miles 


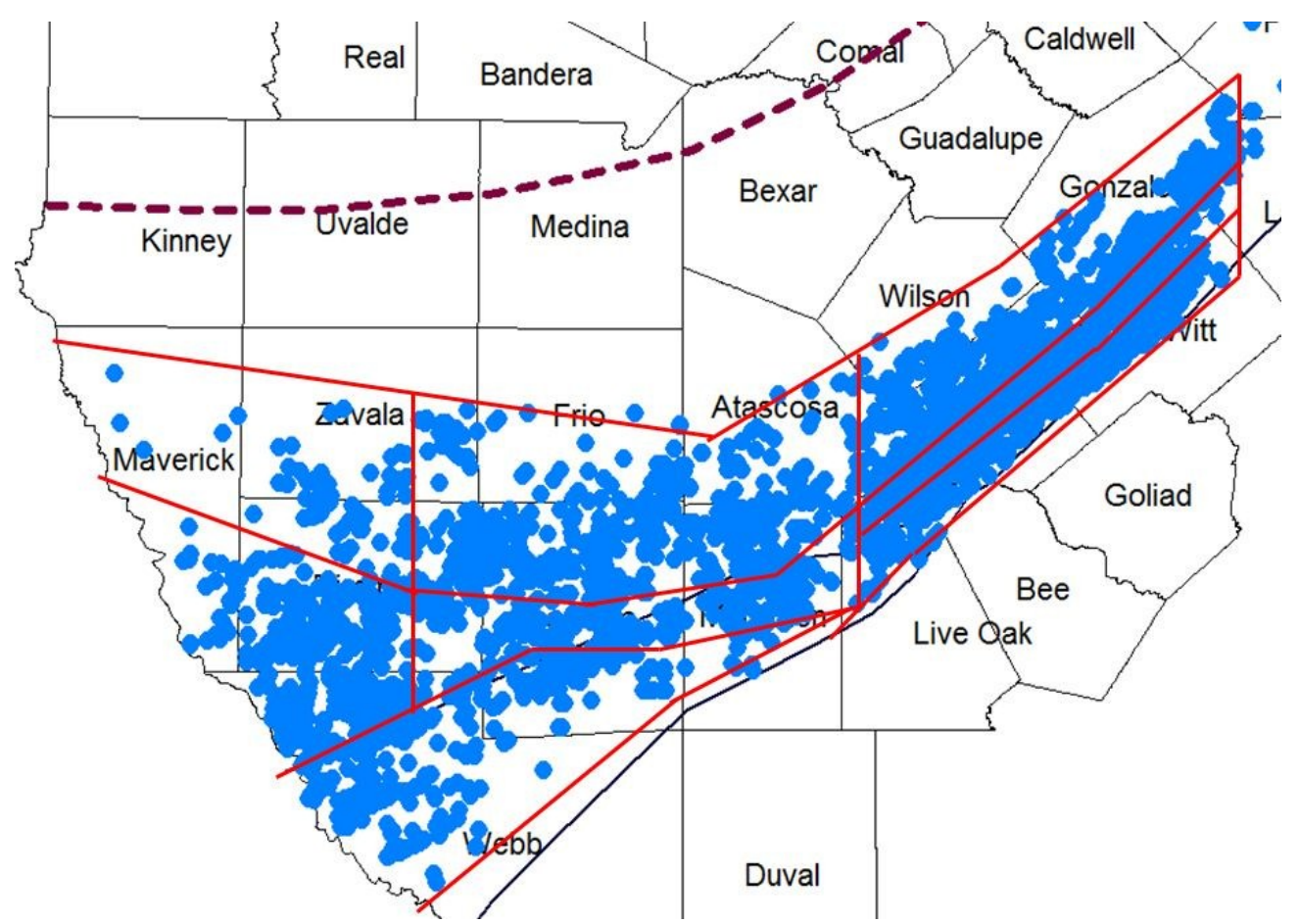

Fig. 3.43 - Blue circles were drawn around the producing wells with a radius of 1.5 miles; the blue colored area is considered as discovered area while the blank area is considered undiscovered area

\subsubsection{Well Density}

The well spacing varies significantly among different production regions. So a single well spacing for all the regions is not an appropriate assumption. I identified the highest established well densities (HEWD) for each production region. The HEWD of a production region is the highest well density that has been drilled in patterns within that production region. The well patterns for all the production regions are shown in Fig. 3.44, while the HEWD for all production regions are shown in Table 3.30. Another observation is that there was a weak correlation between the minimum decline rate and 
HEWD; although the correlation is not strong, it is significant enough to include it in the reserves/resources calculation (Fig. 3.45).
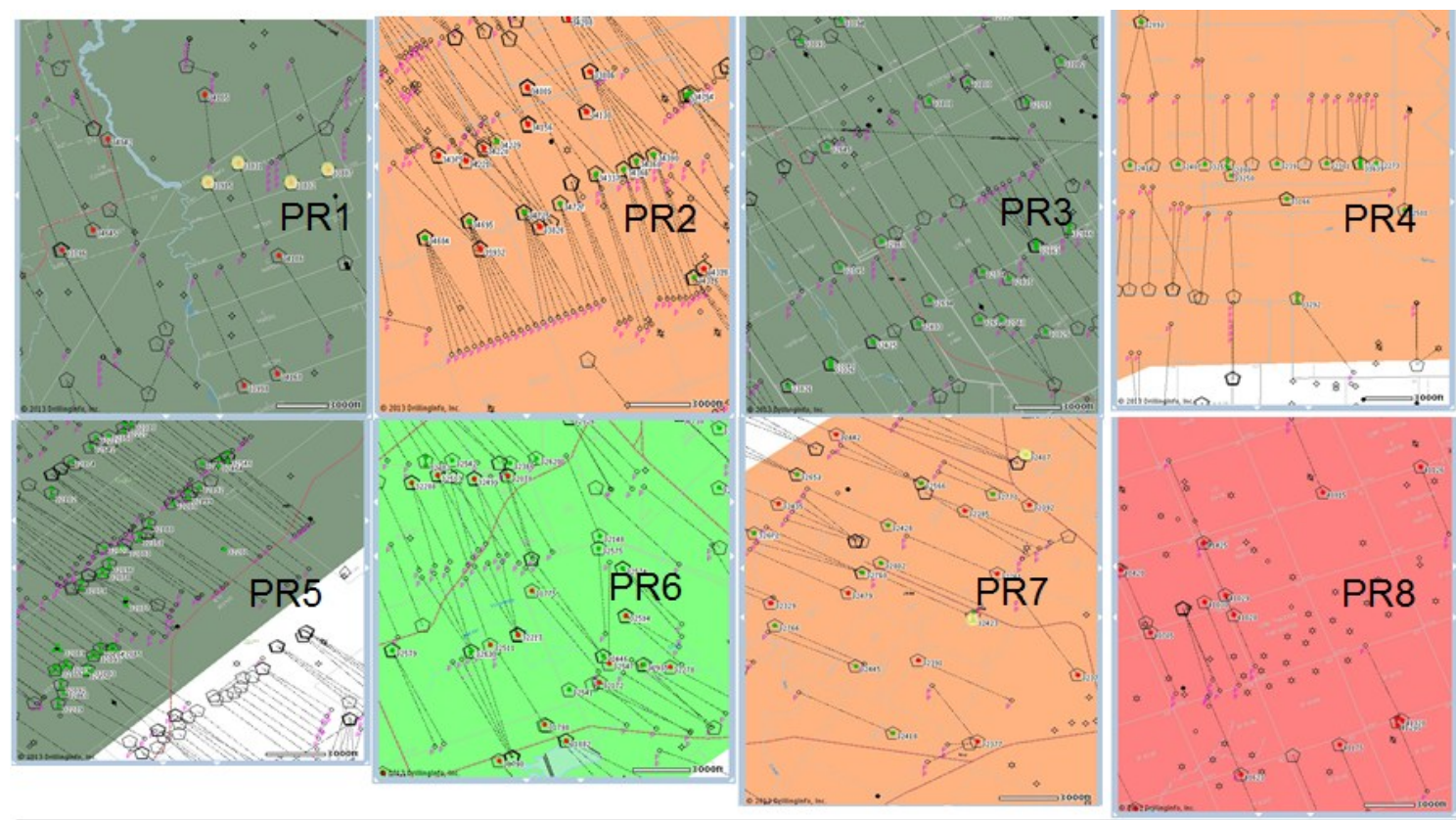

Fig. 3.44 - The highest established well density (HEWD) for all 8 production regions

\begin{tabular}{|ccc|}
\hline \multicolumn{2}{|c|}{ Table 3.30- } & HEWD for All Eight Production Regions \\
\cline { 1 - 2 } Production Regions & Number of wells/Section & Well spacing, Acres/Well \\
\cline { 2 - 3 } PR1 & 3.1 & 206 \\
PR2 & 11.2 & 57 \\
PR3 & 4.0 & 160 \\
PR4 & 6.7 & 96 \\
PR5 & 11.2 & 57 \\
PR6 & 10.5 & 61 \\
PR7 & 6.0 & 106 \\
PR8 & 2.0 & 320 \\
\hline
\end{tabular}




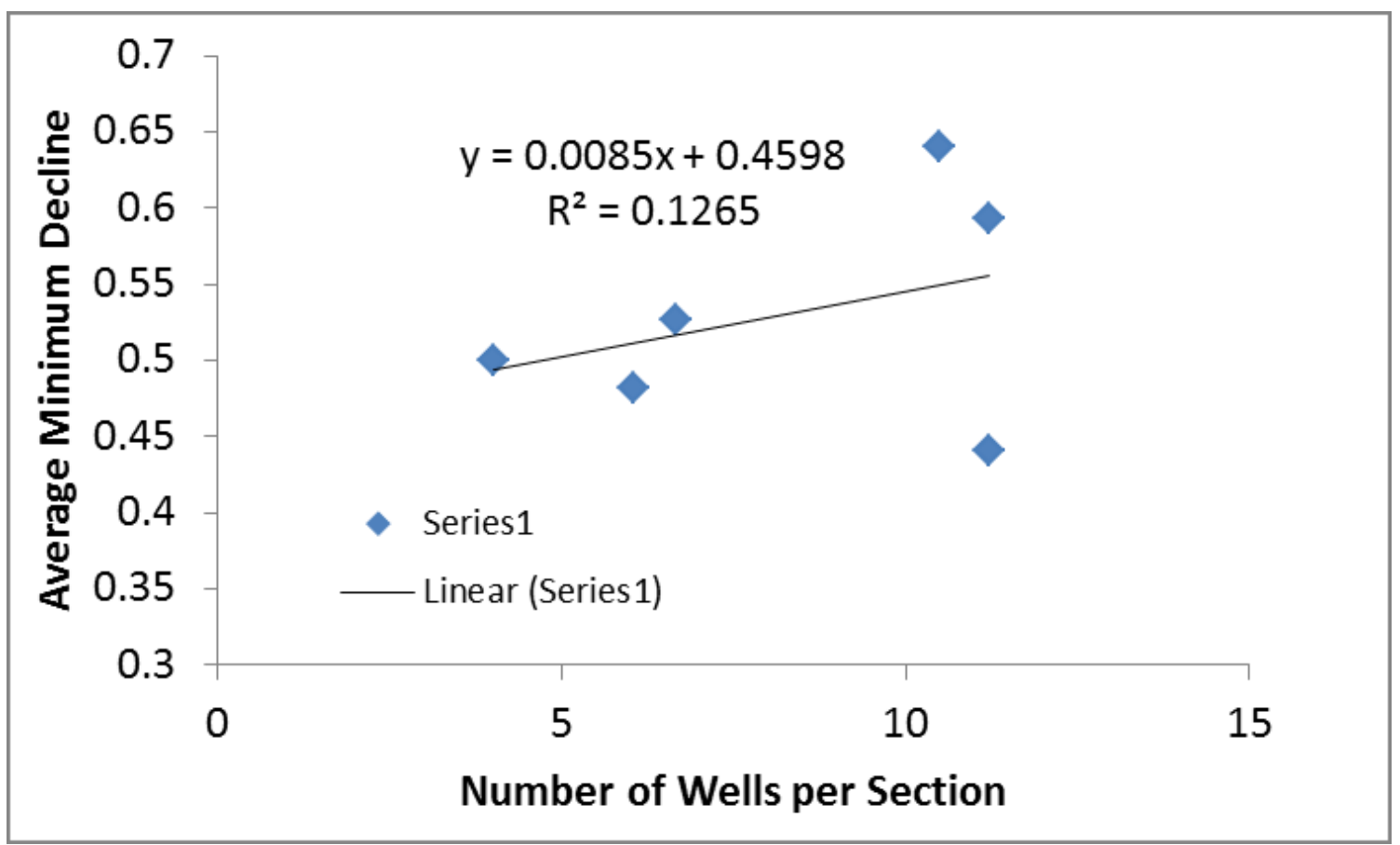

Fig. 3.45- Average minimum decline rate increases when number of wells per section increases with a weak correlation

\subsubsection{Well Count}

PRMS (SPE et al. 2007) recommended that only the production of the wells that will be drilled in the next five years can be considered as reserves. This contingency is the primary constraint for the Eagle Ford play. I assumed the drilling rate in the next five years will be similar to the drilling rate in 2012 for each production region. However, not all the areas can be drilled because of two major reasons: geology/politics, and geometry. Geology is not a big issue in the Eagle Ford play because the formation is fairly uniform, and there are not a lot faults. Politics is not a big issue either because there are very few cities in this area. I defined the average drilling efficiency factor for the geology/politics to be 0.9 . The geometry is a bigger issue because there are a lot of 
operators in the Eagle Ford shale, and their leases may not be continuous. If the lease line is irregular or there is a significant angle between the lease line and the direction of the horizontal wells (Fig. 3.46), as much as $25 \%$ of the area will not be utilized. I defined the average geometry drilling efficiency to be 0.875 (average of 0.75 and 1).

The well count of existing reserves is constant because the wells are already drilled. The well count for undeveloped reserves equals the minimum of the well count of the next five years and the maximum well capacity of each production region given the well density. The well count for contingent resources equals the discovered area times the well density, subtracted by the existing well count and the undeveloped reserves well count. The well count for prospective resources equals the undiscovered area times the well density. Table 3.31 shows the well count calculation assuming the $\mathrm{P}_{50}$ drilling efficiency, 2012 drilling rate, and well density equals HEWD.

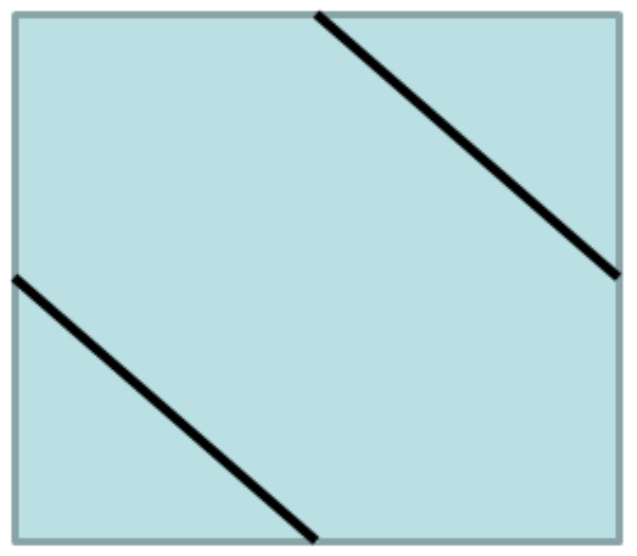

Fig. 3.46- Geometry drilling efficiency equals 0.75 when the lease line and well has a 45 degree angle 


\begin{tabular}{|cccccccccccc|}
\hline \multicolumn{10}{|c|}{ Table 3.31-Summary of P $_{\mathbf{5 0}}$ Well Count for Reserves and Resources } \\
\hline Production Region & $\underline{P R 1}$ & $\underline{\text { PR2 }}$ & $\underline{\underline{P R 3}}$ & $\underline{\underline{P R 4}}$ & $\underline{\text { PR5 }}$ & $\underline{\text { PR6 }}$ & $\underline{\text { PR7 }}$ & $\underline{\text { PR8 }}$ & $\underline{\text { Total }}$ \\
Area (Acres) & 799,836 & 942,734 & $1,617,410$ & 584,070 & 977,484 & 338,000 & 478,888 & $1,201,185$ & $6,939,607$ \\
Reserves/Contingent Area (Acres) & 173,590 & 550,944 & $1,017,488$ & 414,105 & 675,539 & 318,336 & 370,863 & 565,281 & $4,086,146$ \\
Prospective Area (Acres) & 626,246 & 391,790 & 599,922 & 169,965 & 301,945 & 19,664 & 108,025 & 635,904 & $2,853,461$ \\
Current Well spacing (Acres/Well) & 206 & 57 & 160 & 96 & 57 & 61 & 106 & 320 & \\
Drilling Efficiency Factor & 0.7875 & 0.7875 & 0.7875 & 0.7875 & 0.7875 & 0.7875 & 0.7875 & 0.7875 \\
Existing Well Count & 102 & 839 & 913 & 428 & 1020 & 561 & 310 & 229 & 4,402 \\
Reserves Well Count & 235 & 2,035 & 2,710 & 965 & 2,710 & 1,545 & 730 & 365 & 11,295 \\
Contingent Well Count & 327 & 4,738 & 1,385 & 2,004 & 5,603 & 2,004 & 1,715 & 797 & 18,572 \\
Prospective Well Count & 2,394 & 5,413 & 2,953 & 1,394 & 4,172 & 254 & 803 & 1,565 & 18,947 \\
Total Well Count & 3,058 & 13,025 & 7,961 & 4,813 & 13,505 & 4,364 & 3,558 & 2,956 & 53,216 \\
\hline
\end{tabular}




\subsection{Reserves and Resources Evaluation}

\subsubsection{Aggregation within Production Regions}

There are two very different ways that are widely used to aggregate production between wells. Some authors (Dong et al. 2012) aggregate the $\mathrm{P}_{90}, \mathrm{P}_{50}, \mathrm{P}_{10}$ production arithmetically; other authors (Dobson et al. 2011) perform Monte Carlo simulations assuming independence between the wells. There is a big difference between those two aggregation methods; adding wells arithmetically assume 100\% dependence, while adding wells independently assume $100 \%$ independence. To illustrate the difference between the two methods, I give the following a simple example. Assuming a production region has 10,000 wells where the cumulative oil production for each well has a normal distribution with mean $=200,000 \mathrm{STB}$ and standard deviation $=150,000 \mathrm{STB}$. The arithmetic method will generate $\mathrm{P}_{90}$ reserves $=0.08$ billion barrels of oil $(\mathrm{BBO}), \mathrm{P}_{50}$ reserves $=2 \mathrm{BBO}$, and $\mathrm{P}_{10}$ reserves $=3.92 \mathrm{BBO}$; the independence assumption will generate $\mathrm{P}_{90}$ reserves $=1.98 \mathrm{BBO}, \mathrm{P}_{50}$ reserves $=2 \mathrm{BBO}$, and $\mathrm{P}_{10}$ reserves $=2.02 \mathrm{BBO}$. While the $\mathrm{P}_{50}$ reserves of the two methods are the same, the $\mathrm{P}_{10}$ vs. $\mathrm{P}_{90}$ ratios are 49 and 1 using the two methods, respectively.

On one hand, the wells in each production region share the same reservoir, similar fluid, similar completion and drilling technology. If one of the above parameters changes, the production of all the wells in that production region will increase or decrease together, so the production between the wells are correlated to each other. On the other hand, unconventional reservoirs are well known as statistical plays. Two wells $1000 \mathrm{ft}$ apart 
can have very different reserves. The truth is I do not know the true correlation between the wells, but the correlation should neither be $100 \%$ dependence nor $100 \%$ independence. The variance of summation of $n$ wells' reserves/resources, assuming $100 \%$ dependence, is $n^{2} s^{2}$ where the variance of summation of $n$ wells' reserves/resources, assuming $100 \%$ independence, is $n s^{2}$. I defined a triangular distribution for the variance of sum of reserves/resources with $n s^{2}$ as the minimum and $n^{2} s^{2}$ as the maximum with most likely at $n^{1.5} s^{2}$ (Fig. 3.47).

PRMS pointed out that the probabilistic aggregation can only be done within the field, reservoir, or project. The aggregation within production regions was calculated probabilistically; while the aggregation between production regions was calculated arithmetically.

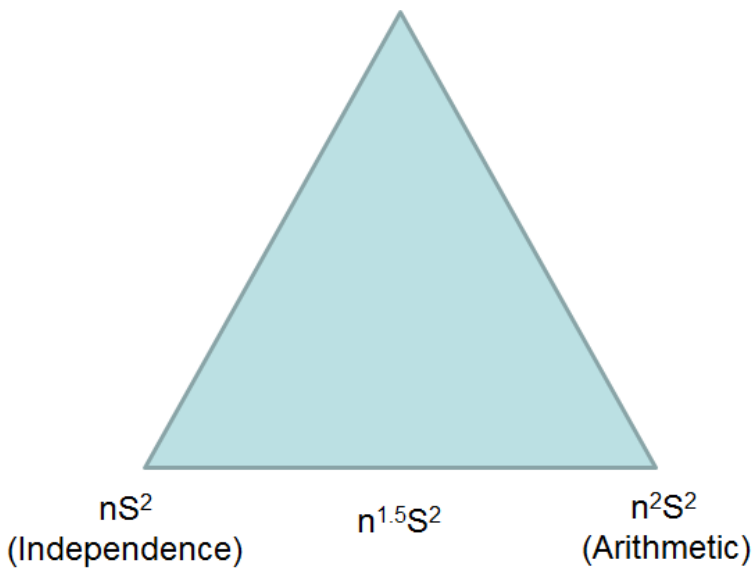

Fig. 3.47- Triangular distribution for variance of summation of reserves/resources. 


\subsubsection{Reserves and Resources Estimation}

To calculate reserves and resources, I need to define the distributions for some key parameters. I defined the drilling rate for the next five years to follow a triangular distribution, with the minimum as half the 2012 drilling rate, the maximum as twice of the 2012 drilling rate, and most likely as the 2012 drilling rate (Fig. 3.48). For the drilling efficiency factor, I assumed a uniform distribution with minimum and maximum equal to 0.8 and $1,0.75$ and 1 for geology/politics drilling efficiency factor and geometry drilling efficiency factor respectively. The well density distribution is a combination of two uniform distributions, with maximum equal to 22 , minimum equal to $\mathrm{HEWD} / 2$, and $\mathrm{P}_{50}$ equal to HEWD (Fig. 3.49). The philosophy behind the well density distribution is that all the production regions have the same potential to be drilled densely no matter the current HEWD, but the production regions that have already been drilled densely will not end up with a very low well density in the end.

Based on the distributions and the aggregation methodology mentioned above, the $\mathrm{P}_{90}$, $\mathrm{P}_{50}$, and $\mathrm{P}_{10}$ of existing reserves, undeveloped reserves, contingent resources, and prospective resources for each production region are shown in Table 3.32 to Table 3.35. The distributions of existing reserves and the undeveloped reserves are close to symmetrical. The best common distributions that fitted the existing reserves and the undeveloped reserves were Laplace distribution and Log-logistic distribution, respectively, which ware closer to normal distribution when compared with lognormal distribution (Fig. 3.50 to Fig. 3.53). The contingent resources and the prospective 
resources were skewed to the right. The best common distributions that fitted the contingent resources and the prospective resources are Weibull distribution and Inverse Gaussian distribution, respectively, which are closer to lognormal distribution when compared with normal distribution (Fig. 3.50 to Fig. 3.53).

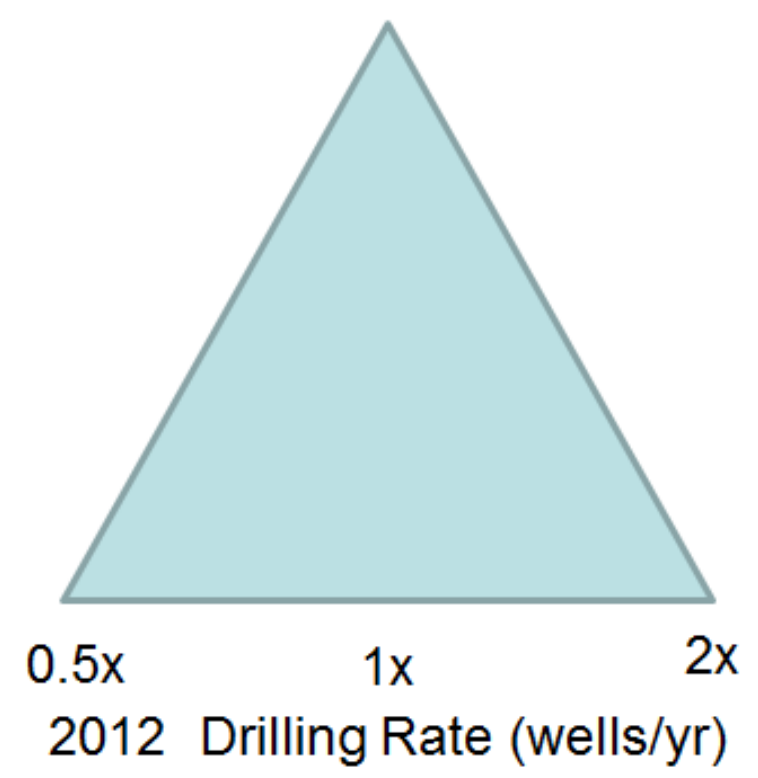

Fig. 3.48 - The distribution of the future drilling rate varies from half of the 2012 drilling rate to twice of the $\mathbf{2 0 1 2}$ drilling rate 


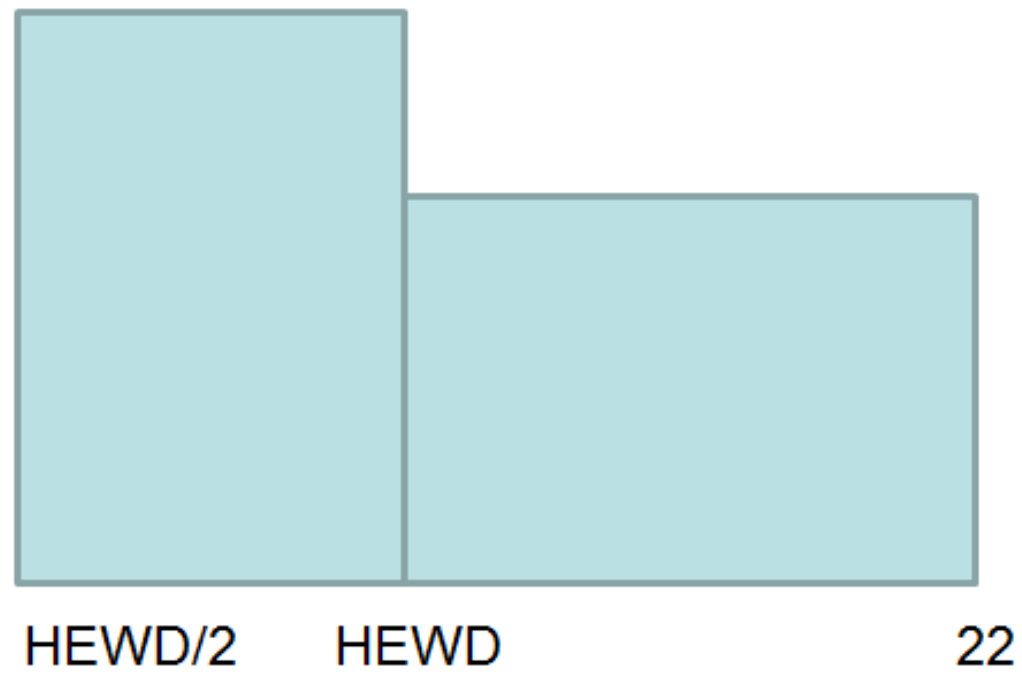

Fig. 3.49 - Distribution of well density, which has HEWD as $P_{50}, H E W D / 2$ as the minimum and 22 (twice as the highest HEWD 11 in PR2 and PR5) as the maximum

\begin{tabular}{|c|c|c|c|c|c|c|}
\hline \multicolumn{7}{|c|}{ Table 3.32 - Summary of Existing Reserves by PR } \\
\hline \multirow[b]{2}{*}{ Production Regions } & \multicolumn{3}{|c|}{ TRR20 of Oil, BBO } & \multicolumn{3}{|c|}{ TRR20 of Gas, TCF } \\
\hline & $\mathrm{P}_{90}$ & $\mathrm{P}_{50}$ & $\mathrm{P}_{10}$ & $\mathrm{P}_{90}$ & $\mathrm{P}_{50}$ & $\mathrm{P}_{10}$ \\
\hline PR1 & 0.01 & 0.01 & 0.02 & 0.03 & 0.05 & 0.07 \\
\hline PR2 & 0.08 & 0.10 & 0.13 & 1.70 & 2.50 & 3.29 \\
\hline PR3 & 0.13 & 0.17 & 0.20 & 0.44 & 0.61 & 0.77 \\
\hline PR4 & 0.03 & 0.04 & 0.05 & 0.65 & 1.05 & 1.45 \\
\hline PR5 & 0.15 & 0.18 & 0.21 & 0.48 & 0.64 & 0.80 \\
\hline PR6 & 0.14 & 0.18 & 0.21 & 0.89 & 1.27 & 1.64 \\
\hline PR7 & 0.04 & 0.06 & 0.07 & 0.75 & 1.15 & 1.55 \\
\hline PR8 & & & & 0.55 & 0.63 & 0.72 \\
\hline Total & 0.59 & 0.74 & 0.89 & 5.50 & 7.89 & 10.28 \\
\hline
\end{tabular}




\begin{tabular}{|c|c|c|c|c|c|c|}
\hline \multicolumn{7}{|c|}{ Table 3.33 - Summary of Undeveloped Reserves by PR } \\
\hline \multirow[b]{2}{*}{ Production Regions } & \multicolumn{3}{|c|}{ TRR20 of Oil, BBO } & \multicolumn{3}{|c|}{ TRR20 of Gas, TCF } \\
\hline & $\mathrm{P}_{90}$ & $\mathrm{P}_{50}$ & $\mathrm{P}_{10}$ & $\mathrm{P}_{90}$ & $\mathrm{P}_{50}$ & $\mathrm{P}_{10}$ \\
\hline PR1 & 0.01 & 0.02 & 0.04 & 0.04 & 0.07 & 0.12 \\
\hline PR2 & 0.22 & 0.35 & 0.55 & 4.41 & 7.33 & 11.50 \\
\hline PR3 & 0.43 & 0.69 & 1.03 & 1.30 & 2.18 & 3.36 \\
\hline PR4 & 0.08 & 0.13 & 0.20 & 1.64 & 2.84 & 4.54 \\
\hline PR5 & 0.43 & 0.67 & 1.01 & 1.25 & 2.00 & 3.10 \\
\hline PR6 & 0.43 & 0.69 & 1.09 & 2.47 & 4.27 & 6.86 \\
\hline PR7 & 0.11 & 0.20 & 0.32 & 1.86 & 3.45 & 5.63 \\
\hline PR8 & 0.00 & 0.00 & 0.00 & 0.66 & 1.17 & 1.89 \\
\hline Total & 1.71 & 2.75 & 4.25 & 13.64 & 23.32 & 37.01 \\
\hline
\end{tabular}

\begin{tabular}{|cccccccc|}
\hline \multicolumn{1}{c}{ Table 3.34- Summary of Contingent Resources by PR } \\
\hline & \multicolumn{4}{c}{ TRR20 of Oil, BBO } & \multicolumn{5}{c|}{ TRR20 of Gas, TCF } \\
Production Regions & $\mathrm{P}_{90}$ & $\mathrm{P}_{50}$ & $\mathrm{P}_{10}$ & $\mathrm{P}_{90}$ & $\mathrm{P}_{50}$ & $\mathrm{P}_{10}$ \\
PR1 & 0.00 & 0.04 & 0.32 & 0.01 & 0.13 & 0.91 \\
PR2 & 0.25 & 0.84 & 1.76 & 5.33 & 17.21 & 34.46 \\
PR3 & 0.00 & 0.50 & 4.33 & 0.00 & 1.67 & 12.76 \\
PR4 & 0.07 & 0.29 & 0.99 & 1.44 & 6.52 & 20.46 \\
PR5 & 0.40 & 1.41 & 2.97 & 1.21 & 4.21 & 8.51 \\
PR6 & 0.07 & 0.93 & 2.39 & 0.41 & 5.71 & 14.01 \\
PR7 & 0.13 & 0.51 & 1.83 & 2.27 & 9.09 & 29.99 \\
PR8 & & & & 0.59 & 3.40 & 34.08 \\
Total & 0.92 & 4.52 & 14.59 & 11.25 & 47.93 & 155.19 \\
\hline
\end{tabular}




\begin{tabular}{|cccccccc|}
\hline \multicolumn{4}{|c}{ Table 3.35-Summary of Prospective Resources by PR } \\
\hline & \multicolumn{4}{c}{ TRR20 of Oil, BBO } & \multicolumn{5}{c|}{ TRR20 of Gas, TCF } \\
Production Regions & $\mathrm{P}_{90}$ & $\mathrm{P}_{50}$ & $\mathrm{P}_{10}$ & $\mathrm{P}_{90}$ & $\mathrm{P}_{50}$ & $\mathrm{P}_{10}$ \\
PR1 & 0.14 & 0.28 & 1.25 & 0.41 & 0.90 & 3.54 \\
PR2 & 0.56 & 0.96 & 1.59 & 11.89 & 20.06 & 31.67 \\
PR3 & 0.43 & 0.86 & 3.05 & 1.35 & 2.75 & 8.99 \\
PR4 & 0.10 & 0.20 & 0.48 & 2.31 & 4.49 & 9.97 \\
PR5 & 0.62 & 1.06 & 1.73 & 1.90 & 3.16 & 4.97 \\
PR6 & 0.06 & 0.12 & 0.21 & 0.34 & 0.73 & 1.28 \\
PR7 & 0.11 & 0.24 & 0.62 & 2.01 & 4.24 & 10.11 \\
PR8 & & & & 2.84 & 6.30 & 40.44 \\
Total & 2.03 & 3.72 & 8.93 & 23.05 & 42.63 & 110.98 \\
\hline
\end{tabular}

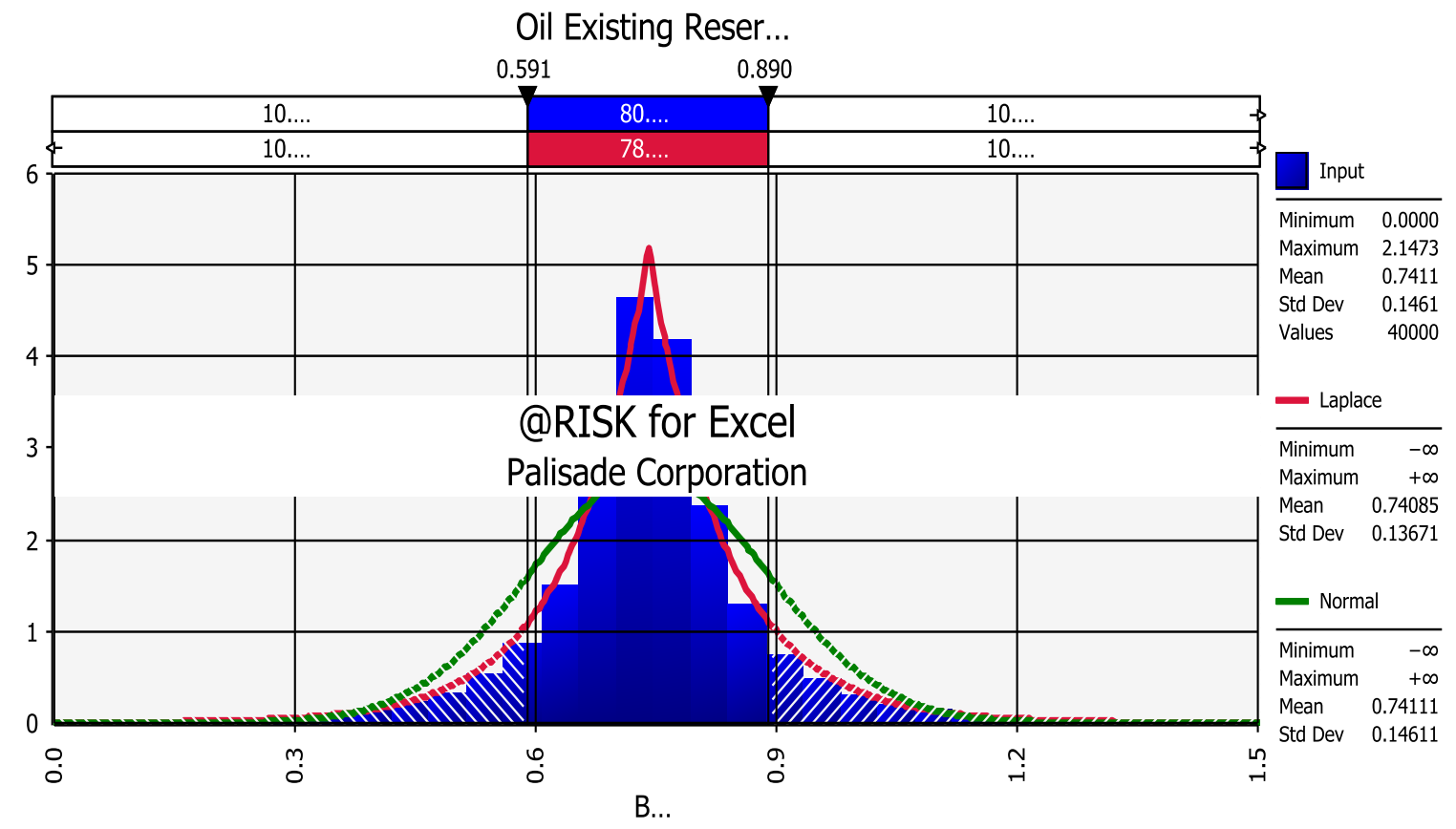

Fig. 3.50 - Existing oil reserves follow a Laplace distribution, which is closer to normal distribution compared with lognormal distribution 


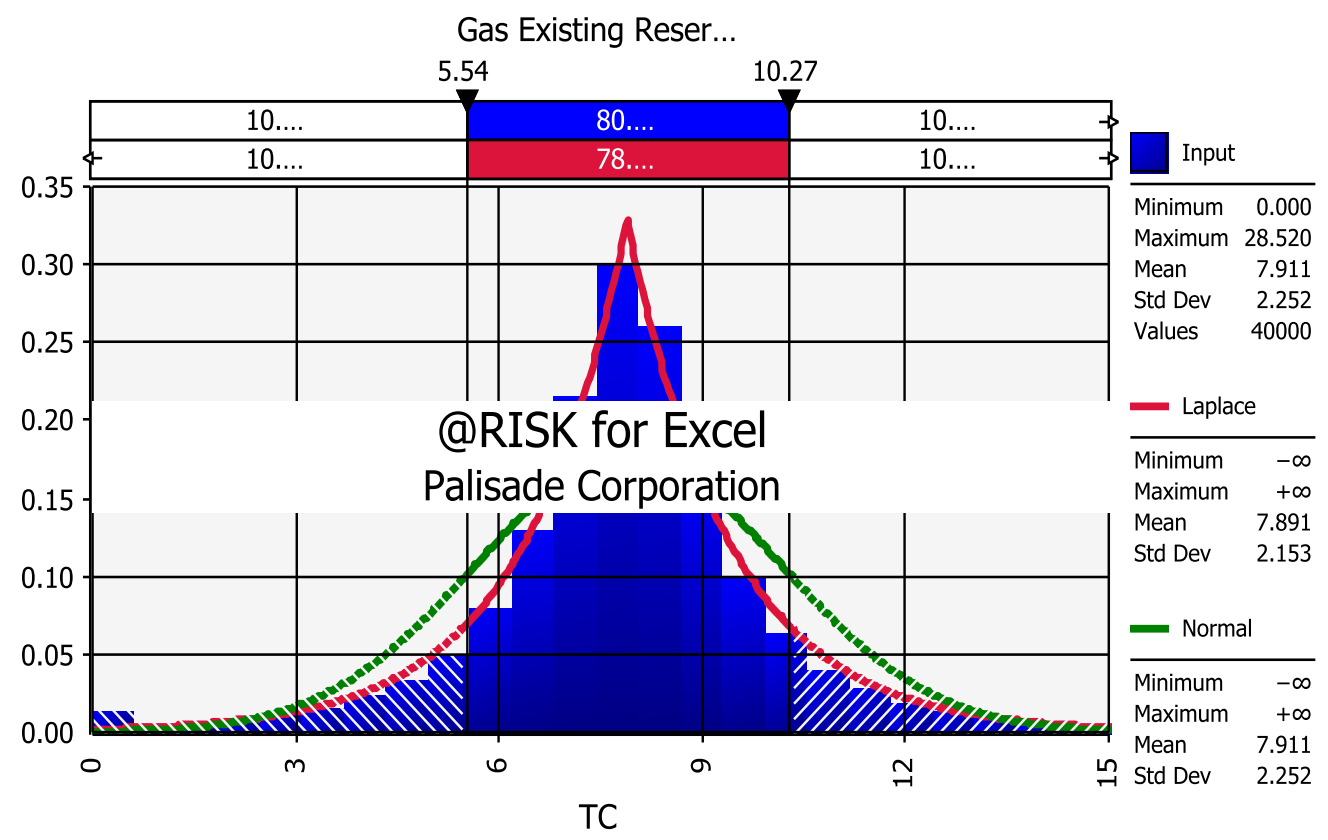

Fig. 3.51- Existing gas reserves follow a Laplace distribution, which is closer to normal distribution compared with lognormal distribution

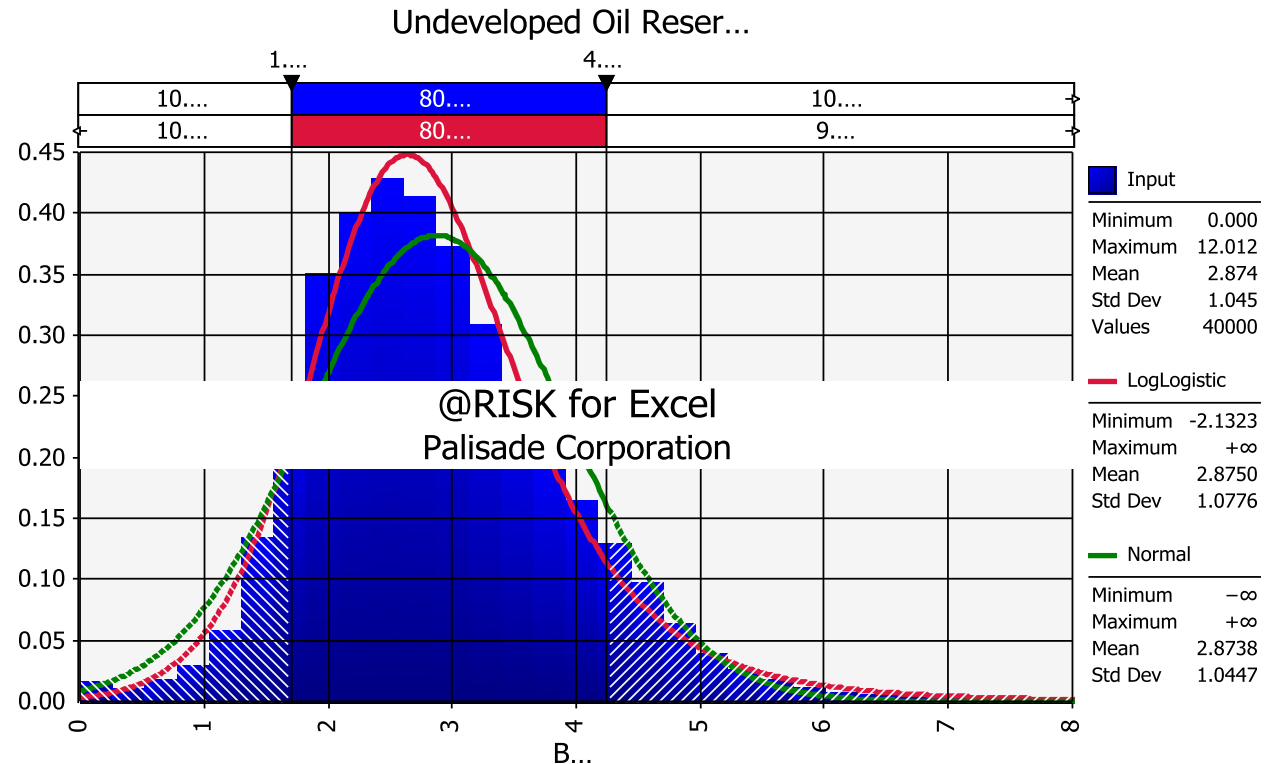

Fig. 3.52 - Undeveloped oil reserves follow a Logistic distribution, which is closer to normal distribution compared with lognormal distribution 


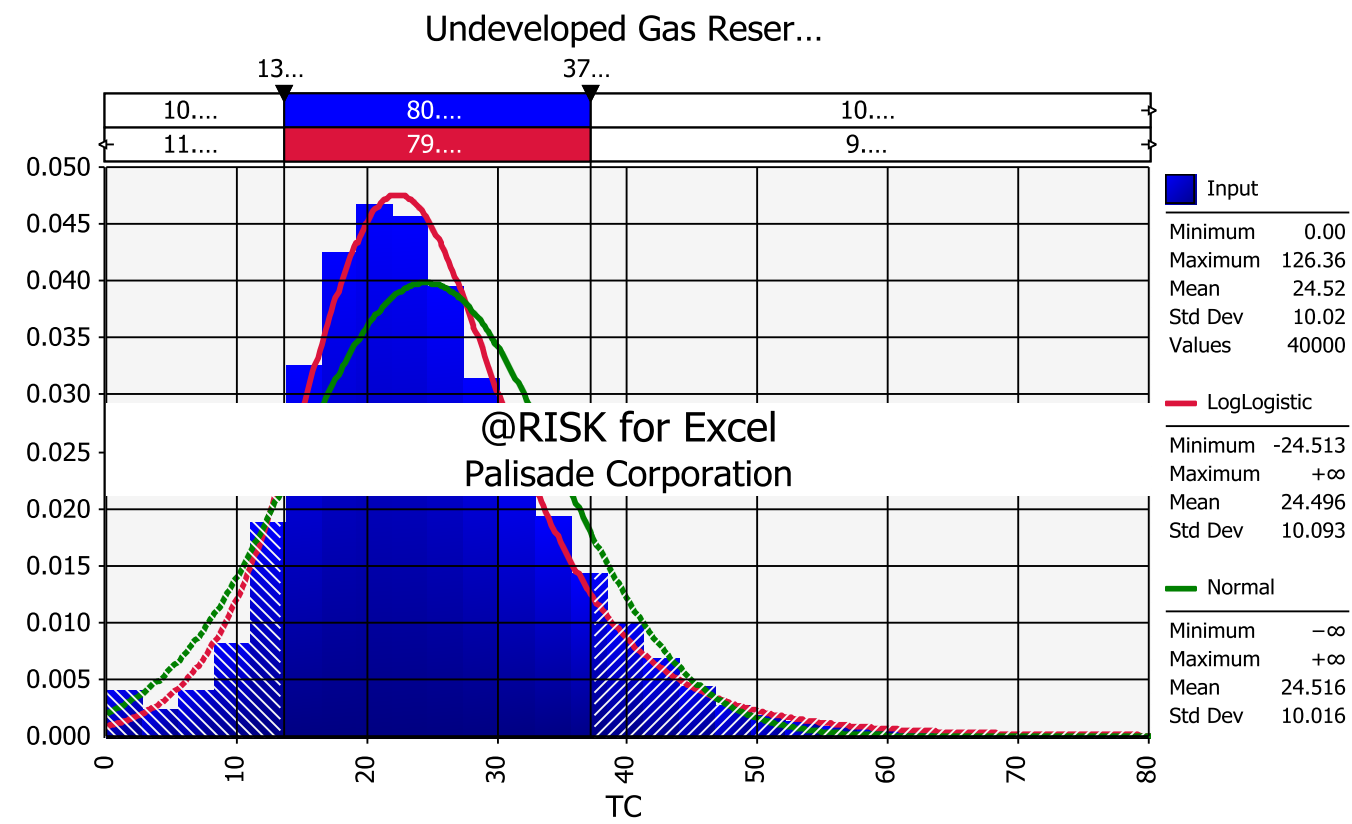

Fig. 3.53 - Undeveloped gas reserves follow a Logistic distribution, which is closer to normal distribution compared with lognormal distribution

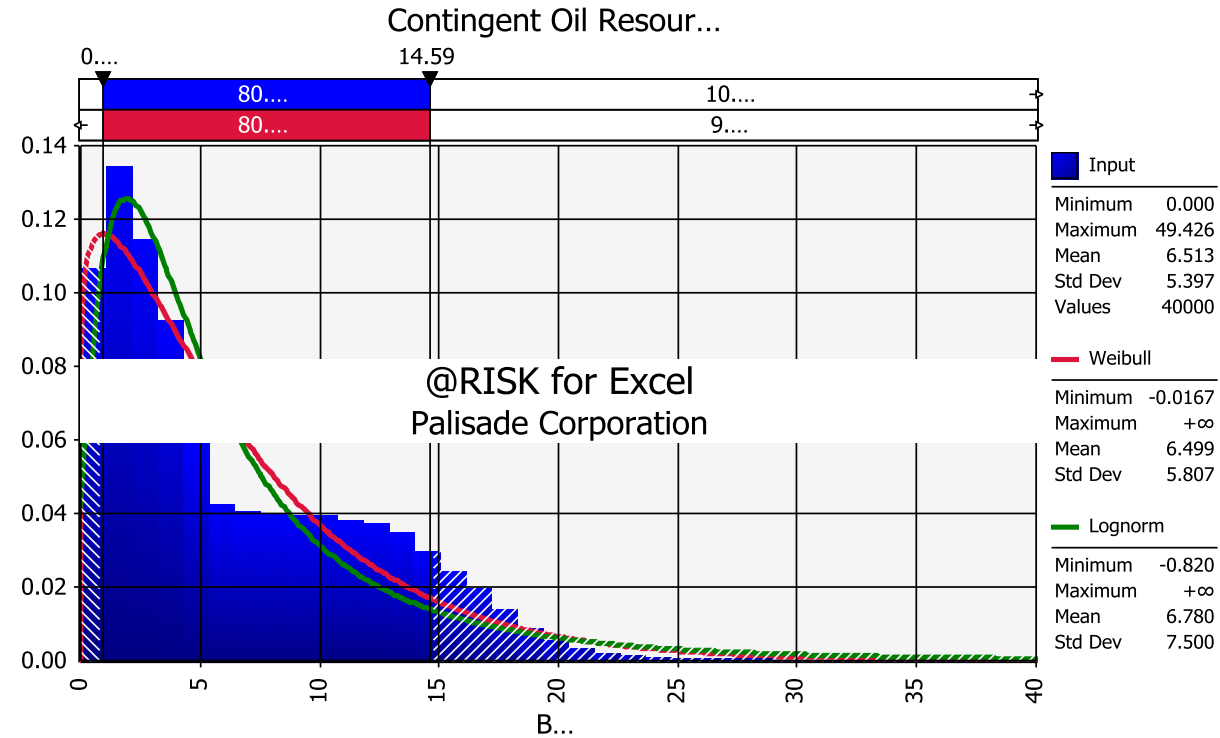

Fig. 3.54 - The best well known distribution fit for contingent oil resources is Weibull distribution, which is closer to lognormal distribution compared with normal distribution 


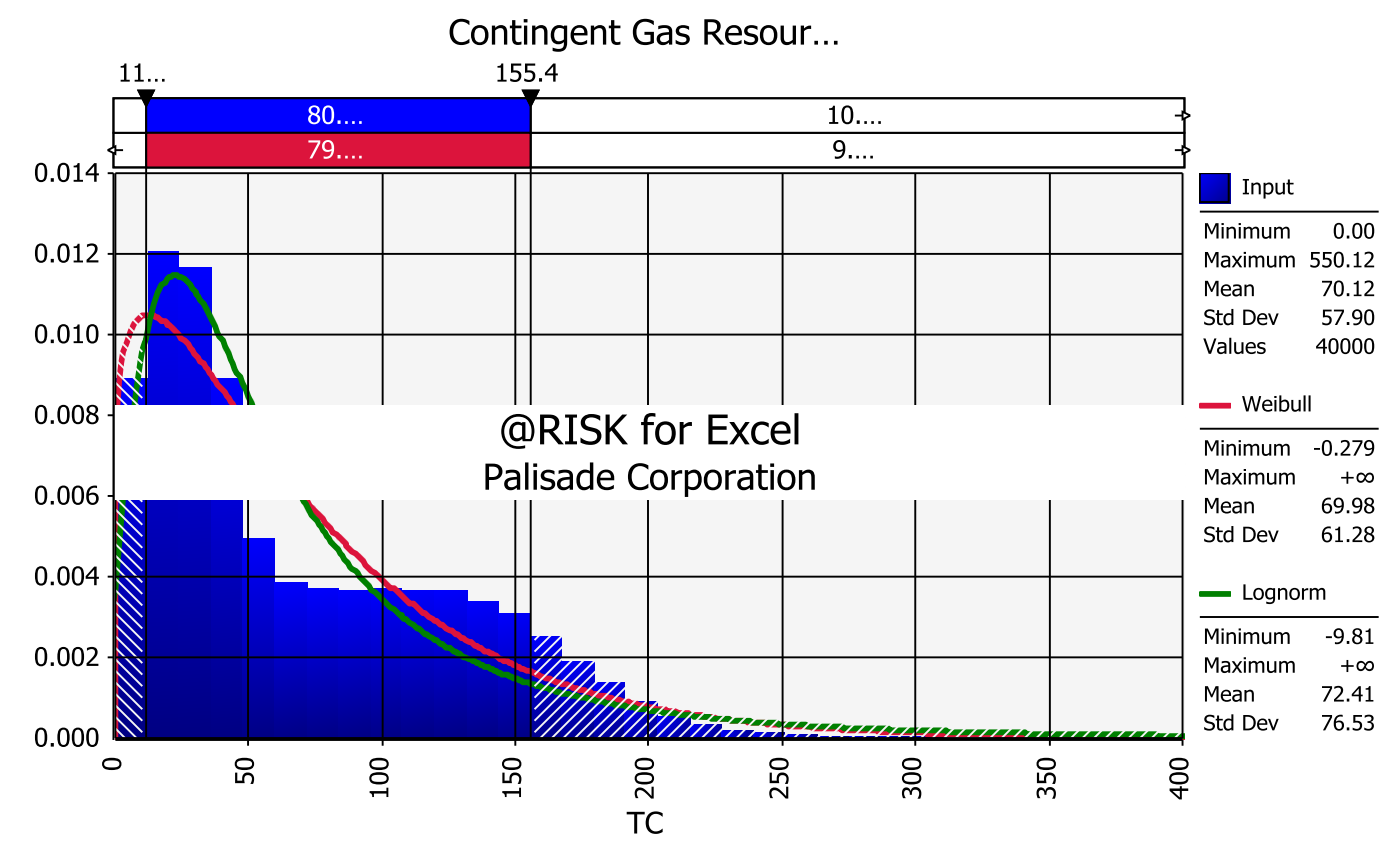

Fig. 3.55- The best well known distribution fit for contingent gas resources is Weibull distribution, which is closer to lognormal distribution compared with normal distribution

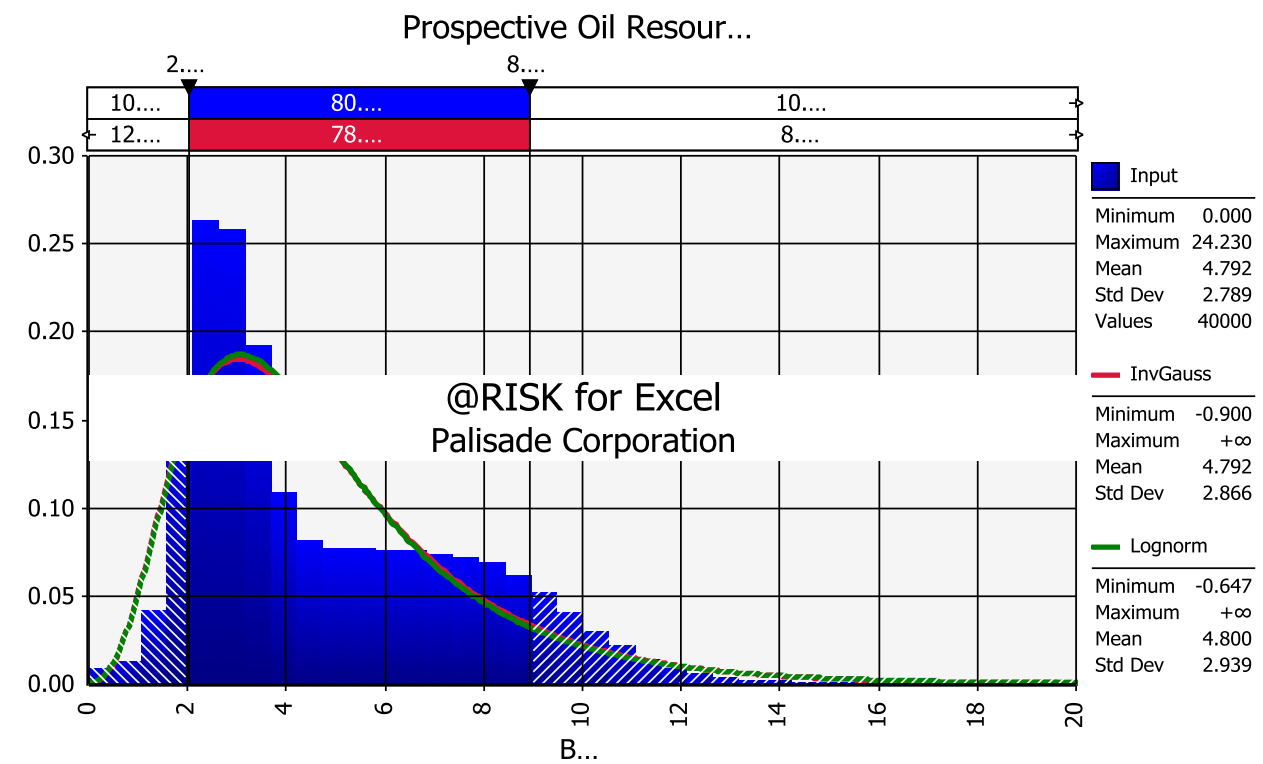

Fig. 3.56 - The best well known distribution fit for prospective oil resources is Inverse Gauss distribution, which is closer to lognormal distribution compared with normal distribution 


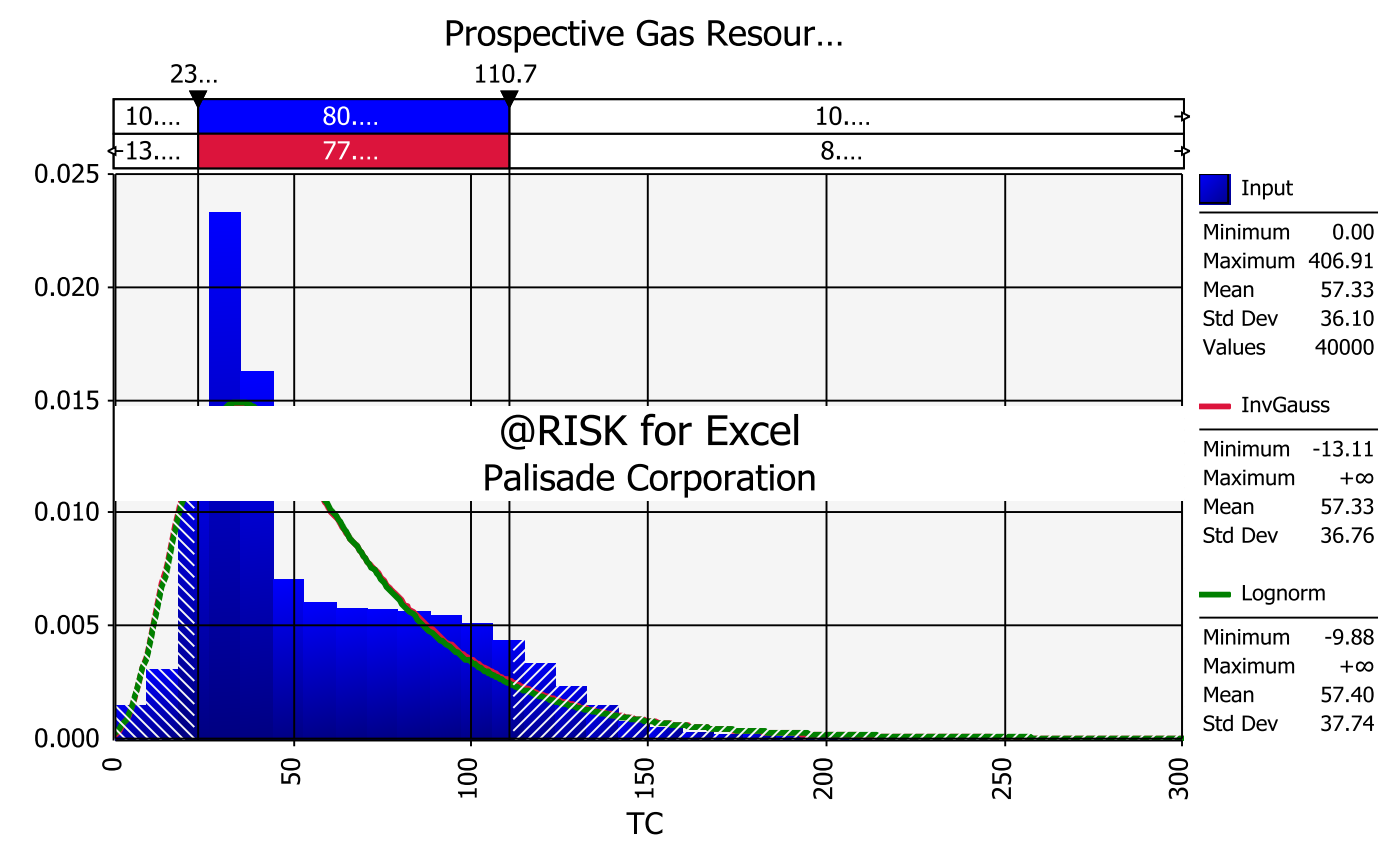

Fig. 3.57- The best well known distribution fit for prospective gas resources is Inverse Gauss distribution, which is closer to lognormal distribution compared with normal distribution

\begin{tabular}{|cccccccc|}
\hline \multicolumn{8}{|c|}{ Table 3.36- Reserves and Resources of the Eagle Ford Play } \\
\hline & \multicolumn{3}{c|}{ Oil, BBO } & \multicolumn{5}{c|}{ Gas, TCF } \\
Cumulative & $\mathrm{P}_{90}$ & $\mathrm{P}_{50}$ & $\mathrm{P}_{10}$ & $\mathrm{P}_{90}$ & $\mathrm{P}_{50}$ & $\mathrm{P}_{10}$ \\
Existing Reserves & 0.264 & 0.264 & 0.264 & 1.37 & 1.37 & 1.37 \\
Undeveloped Reserves & 0.59 & 0.74 & 0.89 & 5.50 & 7.89 & 10.28 \\
Total Reserves & 1.71 & 2.75 & 4.25 & 13.64 & 23.32 & 37.01 \\
Contingent Resources & 2.30 & 3.49 & 5.14 & 19.13 & 31.21 & 47.28 \\
Prospective Resources & 0.92 & 4.52 & 14.59 & 11.25 & 47.93 & 155.19 \\
Total Resources & 2.03 & 3.72 & 8.93 & 23.05 & 42.63 & 110.98 \\
& 2.95 & 8.25 & 23.53 & 34.30 & 90.57 & 266.17 \\
\hline
\end{tabular}

According to Table 3.32 and Table 3.33, the PR3, PR5, and PR6 have the highest oil $\mathrm{P}_{90}$, $\mathrm{P}_{50}$, and $\mathrm{P}_{10}$ reserves, while the $\mathrm{PR} 2$ has the highest gas $\mathrm{P}_{90}, \mathrm{P}_{50}$, and $\mathrm{P}_{10}$ reserves. The 
reason is those four production regions have more existing wells, higher drilling rate in 2012, and higher oil and gas TRR20 values.

According to Table 3.34 and Table 3.35, PR5 has the highest $\mathrm{P}_{90}$ and $\mathrm{P}_{50}$ contingent and prospective oil resources, while PR3 has the highest $\mathrm{P}_{10}$ contingent and prospective oil resources. $\mathrm{PR} 2$ has the highest $\mathrm{P}_{90}$ and $\mathrm{P}_{50}$ gas contingent and prospective resources, while PR8 has the highest $\mathrm{P}_{10}$ prospective gas resources. The reason is that all four production regions have bigger area, higher oil and gas TRR20 values. PR5 and PR2 have the highest HEWD $=11$ wells/section for higher $\mathrm{P}_{90}$ and $\mathrm{P}_{50}$ oil and gas resources, while PR3 and PR8 have the lower HEWD $=4$ and 2 wells/section for the higher $\mathrm{P}_{10}$ oil and gas resources.

Under PRMS (SPE et al. 2007), the 1P, 2P, and 3P reserves are corresponding to the $\mathrm{P}_{90}$, $\mathrm{P}_{50}$, and $\mathrm{P}_{10}$ reserve estimates using the probabilistic methodology.

The reserves and resources calculation are highly dependent on HEWD. The HEWD can change because of different reasons, for example, an increase in gas price can result in an increase of the HEWD of dry gas region PR8. I ran a sensitivity analysis on prospective resources of gas in PR8 assuming two different HEWD $=2$ and 8 wells per section. Table 3.37 shows that the $\mathrm{P}_{90}$ and $\mathrm{P}_{50}$ resource estimates increase significantly because HEWD increases. However, the original $\mathrm{P}_{90}$ to $\mathrm{P}_{10}$ range still bracket most of the new $\mathrm{P}_{90}$ to $\mathrm{P}_{10}$ range given the higher HEWD. 


\begin{tabular}{|c|c|c|c|}
\hline \multicolumn{4}{|c|}{$\begin{array}{l}\text { Table 3.37- Sensitivity of HEWD on } \\
\text { Prospective Gas Resources (TCF) }\end{array}$} \\
\hline \multicolumn{4}{|c|}{$\begin{array}{lll}\mathrm{P}_{90} & \mathrm{P}_{50} & \mathrm{P}_{10}\end{array}$} \\
\hline \multicolumn{4}{|c|}{ 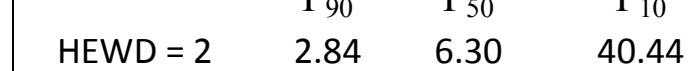 } \\
\hline HEWD = & 12.26 & $21.4 \varepsilon$ & +4.9 \\
\hline
\end{tabular}

\subsubsection{Comparison with 2011 EIA Estimates}

I compared the EIA 2011 estimates (Table 3.38) with my estimates. Since the EIA estimates are deterministic and exclusive, I compared the mean $/ \mathrm{P}_{50}$ of my estimates, the sum of reserves and resources with the EIA 2011 estimates (Table 3.39). Based on the comparison, I concluded the following:

- The EIA estimate oil, condensate, and dry gas areas are $1.43,0.56$, and 0.13 million acres, which are much less than my black oil, volatile oil, condensate and dry gas areas of $3.39,0.34,2.00$, and 1.20 million acres.

- EIA estimates did not include oil production for condensate or gas regions, or gas production for oil regions.

- The EIA estimated ultimate recovery (EUR) for oil wells is 300,000 STB, which is close to the mean of black oil regions PR3 and PR5 with 254,000 and 247,000 STB, respectively, the volatile oil region PR6 with 454,000 STB, and the condensate region PR7 with 269,000 STB. The EIA estimates of gas production for dry gas and condensate are 5.5 and $4.5 \mathrm{BCF}$, which are a little higher than the mean of condensate regions PR2, PR4, and PR7 of 3.62, 2.97 and 4.75 BCF, and dry gas region PR8 of $3.25 \mathrm{BCF}$. 
- The EIA well density for black-oil, condensate, and dry gas window are 5, 8, 4 wells per section, which is close to the HEWD of PR1, PR3, PR4, PR7 and PR8 with 3.1, 4.0, 6.7, 6.0 and 2.0, respectively, but much lower than the HEWD of PR2, PR5 and PR6 with 11.2, 11.2, and 10.5.

- The EIA estimate resources for oil and gas were $3.35 \mathrm{BBO}$ and $21 \mathrm{TCF}$, which are much lower to my $\mathrm{P}_{50}$ total reserve and resource estimates of $11.74 \mathrm{BBO}$ and 122 TCF

Table 3.38 - Average EUR and Areas of the Eagle Ford Play (EIA 2011)

\begin{tabular}{|l|r|r|r|}
\hline & \multicolumn{1}{|c|}{$\begin{array}{c}\text { Dry Gas } \\
\text { Zone }\end{array}$} & \multicolumn{1}{c|}{$\begin{array}{c}\text { Condensate } \\
\text { Zone }\end{array}$} & \multicolumn{1}{c|}{$\begin{array}{c}\text { Oil } \\
\text { Zone }\end{array}$} \\
\hline Area (sq. miles) & 200 & 890 & 2,233 \\
\hline EUR (Bcf/ well) & 5.5 & 4.5 & 300 \\
\hline EUR (MBO/ well) & & & 5 \\
\hline Well Spacing (wells/ sq. mile) & 4 & 8 & 3.35 \\
\hline TRR (BBO) & & & \\
\hline TRR (Tcf) & 4.38 & 16.43 & \\
\hline
\end{tabular}

Table 3.39- Comparison between EIA Estimates (2011) and My Estimates

\begin{tabular}{|c|c|c|c|c|c|c|}
\hline & \multicolumn{2}{|c|}{ Oil Region } & \multicolumn{2}{|c|}{ Condensate Region } & \multicolumn{2}{|c|}{ Gas Region } \\
\hline & EIA & Gong & EIA & Gong & EIA & Gong \\
\hline Area (Million Acres) & 1.43 & 3.73 & 0.57 & 2.01 & 0.13 & 1.20 \\
\hline No. of wells / section & 5 & 8.6 & 8 & 8 & 4 & 2 \\
\hline Mean EUR (MSTB, BCF) & 300 & $319 \& 1.45$ & 4.5 & $192 \& 3.78$ & 5.5 & 3.25 \\
\hline $\mathrm{P}_{50}$ Total $(\mathrm{BBO}, \mathrm{TCF})$ & 3.35 & $7.81 \& 30.34$ & 16.43 & $3.93 \& 79.93$ & 4.38 & 11.51 \\
\hline & & EIA & \multicolumn{4}{|c|}{ Gong } \\
\hline $\mathrm{P}_{50}$ Total (BBO, TCF) & & $3.35 \& 21$ & \multicolumn{4}{|c|}{$11.74 \& 122$} \\
\hline
\end{tabular}




\section{CONCLUSIONS}

Based on hindcasts of 197 hydraulically fractured horizontal Barnett-shale gas wells with 59-119 months of production data available, I conclude the following:

- The proposed Bayesian methodology coupled with Arps' decline curve model reliably quantified the uncertainty of hindcasted cumulative production with as little as 6 months of production. The probabilistic estimates $\mathrm{P}_{90}, \mathrm{P}_{50}$, and $\mathrm{P}_{10}$ were all well calibrated.

- The Bayesian method had narrower $\mathrm{P}_{90}-\mathrm{P}_{10}$ confidence intervals, had better calibrated $\mathrm{P}_{90}, \mathrm{P}_{50}$, and $\mathrm{P}_{10}$ estimates, and required less computational time for comparable stability than the modified bootstrap methodology presented in the literature.

Based on hindcasts and forecasts of 20 years of 4402 hydraulically fractured horizontal Eagle Ford oil and gas wells with 1-44 months of production data available, reservoir simulation studies, geological studies, and production analysis, I conclude the following:

- $\quad$ The estimated 1P, 2P, and 3P reserves for the Eagle Ford are 2.3, 3.5, and 5.1 BBO and 13.6, 23.3, and 37 TCF for oil and gas, respectively.

- The contingent oil resources range from a $\mathrm{P}_{90}$ of 0.9 to $\mathrm{P}_{10}$ of 14.6 MMSTB, with a $\mathrm{P}_{50}$ of 4.5 MMSTB; the contingent gas resources range from a $\mathrm{P}_{90}$ of 11.2 to $\mathrm{P}_{10}$ of $155 \mathrm{TCF}$, with a $\mathrm{P}_{50}$ of $47.9 \mathrm{TCF}$. The prospective oil resources range from a $\mathrm{P}_{90}$ of 2.0 to $\mathrm{P}_{10}$ of $8.9 \mathrm{MMSTB}$, with a $\mathrm{P}_{50}$ of $3.7 \mathrm{MMSTB}$; the prospective gas resources range from a $\mathrm{P}_{90}$ of 23 to $\mathrm{P}_{10}$ of $111 \mathrm{TCF}$, with a $\mathrm{P}_{50}$ of $42.6 \mathrm{TCF}$. 
- In the probabilistic hindcast studies assuming 6 months of production known and the rest unknown for all four fluid types, the Duong model and the Arps model yielded the highest average coverage rate at $74 \%$; the SEPD model yielded $68 \%$, and the Power-Law model yielded 62\%. The combination of the Duong and Arps models was used to model linear flow to boundary-dominated flow.

- The volatile-oil region in the east (PR6) has the highest $\mathrm{P}_{50}$ and mean of oil TRR20 with 318,000 and $454,000 \mathrm{STB}$, respectively; the condensate region in the east (PR7) has the highest $\mathrm{P}_{50}$ and mean of gas TRR20 with 2.7 and $4.7 \mathrm{BCF}$, respectively. The distributions of TRR20 of oil and gas for all production regions follow lognormal distributions.

- According to this study, the $\mathrm{P}_{50}$ total reserve and resource estimates for oil and gas are $11.74 \mathrm{BBO}$ and $122 \mathrm{TCF}$, which are much higher than the EIA (2011) resource estimates of $3.35 \mathrm{BBO}$ and $21 \mathrm{TCF}$. 


\section{NOMENCLATURE}

a Duong intercept constant, $1 /$ month

AAPG American association of petroleum geologists

$b \quad$ Decline exponent for Arps model, dimensionless

BBO Billion barrels of oil

BCF Billion cubic feet

BOPD Barrels of oil per day

$\mathrm{CPEOH} \quad$ Cumulative production at end of hindcasts, Mcf or STB

$D_{i} \quad$ Initial decline rate, $1 /$ year

$D_{\min } \quad$ Minimum decline rate, $1 /$ year

$\mathrm{D}_{\infty} \quad$ Power Law decline at "infinite time" constant, 1/year

EIA The U.S. Energy Information Administration

$f \quad$ Likelihood function

$g \quad$ Power exponent of probability density function of prior distribution

GOR Gas oil ratio, scf/STB

G240 Re-parameterized Duong model parameter, cumulative gas production of

20 years, $\mathrm{Mcf}$

HEWD Highest established well densities

ID Wellbore inside diameter, inches

IGOR Initial GOR of first month, scf/STB

$l \quad$ Decline curve parameter in re-parameterized Duong model, $l=m-1$

$m \quad$ Duong slope constant 


\begin{tabular}{ll} 
MBM & Modified bootstrap method \\
Mcf & Thousand cubic feet \\
MCMC & Markov Chain Monte Carlo \\
$n$ & Decline exponent in power-law and SEPD model \\
N240 & Re-parameterized Duong model parameter, cumulative oil production of \\
& 20 years \\
OD & Wellbore outside diameter, inches \\
PDCA & Probabilistic decline curve analysis \\
PDTSP & Production during the second period, Mcf or STB \\
PR & Production region \\
PRMS & Petroleum resources management system \\
P10 & Value at confidence level 10\% \\
P $_{50}$ & Value at confidence level $50 \%$ \\
P90 & Value at confidence level 90\% \\
RRC & Railroad Commission of Texas \\
SEC & The U.S. Security and Exchange Commission \\
SEPD & Stretched exponential decline model \\
SPE & Society of petroleum engineers \\
SPEE & Society of petroleum evaluation engineers \\
STB & Standard cubic feet \\
TRR20 & Technical recoverable resources of 20 years, STB or BCF \\
TCF & Trillion cubic feet \\
\hline
\end{tabular}




\begin{tabular}{ll} 
TVD & True vertical depth, $\mathrm{ft}$ \\
WPC & World petroleum council \\
$\theta$ & Acceptance probability in MCMC, dimensionless \\
$\vartheta$ & Decline curve parameters \\
$\theta_{j}$ & One of the decline curve parameters \\
$\theta_{\text {lower }}$ & Parameters of step j in MCMC \\
$\theta_{\text {upper }}$ & Lower boundary of proposal distribution \\
$\theta_{\text {proposal }}$ & Parameters drawn from proposal distribution \\
$\sigma$ & Sample variance from best fit \\
$\sigma_{\text {proposal }}$ & Sample variance from proposal parameters \\
$\sigma_{j}$ & Sample variance from step j in MCMC \\
$\sigma_{\vartheta}$ & Standard deviation of proposal distribution of parameter $\vartheta$ \\
$\Phi$ & Cumulative density function of standard normal distribution \\
$\tau$ & Characteristic time parameter for SEPD model, month \\
$\varepsilon$ & Logarithm residual between actual production and decline curve \\
$\pi$ & production \\
\hline
\end{tabular}




\section{REFERENCES}

Abdulal, H.J., Samandarli, O., and Wattenbarger, B.A. 2011. New Type Curves for Shale Gas Wells with Dual Porosity Model. Paper presented at the Canadian Unconventional Resources Conference, Alberta, Canada. Society of Petroleum Engineers SPE-149367-MS. DOI: 10.2118/149367-ms.

Alkouh, A.B., Patel, K., Schechter, D. et al. 2012. Practical Use of Simulators for Characterization of Shale Reservoirs. Paper presented at the SPE Canadian Unconventional Resources Conference, Calgary, Alberta, Canada. Society of Petroleum Engineers SPE-162645-MS. DOI: 10.2118/162645-ms.

Anderson, D.M., Nobakht, M., Moghadam, S. et al. 2010. Analysis of Production Data from Fractured Shale Gas Wells. Paper presented at the SPE Unconventional Gas Conference, Pittsburgh, Pennsylvania, USA. Society of Petroleum Engineers SPE-131787-MS. DOI: 10.2118/131787-ms.

Arps, J.J. 1945. Analysis of Decline Curves. AIME 160: 228-247.

Bazan, L.W., Larkin, S.D., Lattibeaudiere, M.G. et al. 2010. Improving Production in the Eagle Ford Shale with Fracture Modeling, Increased Conductivity and Optimized Stage and Cluster Spacing Along the Horizontal Wellbore. Paper presented at the Tight Gas Completions Conference, San Antonio, Texas, USA. Society of Petroleum Engineers SPE-138425-MS. DOI: 10.2118/138425-ms.

Bird, D. 2013. EIA: U.S. 2012 Crude Output Up 14.6\% to Highest Level Since 1995. http://online.wsj.com/article/SB100014241278873246624045783305917460829 34.html. 
Capen, E.C. 1976. The Difficulty of Assessing Uncertainty (Includes Associated Papers 6422 and 6423 and 6424 and 6425 ). SPE Journal of Petroleum Technology 28 (8): 843-850. DOI: 10.2118/5579-pa.

Centurion, S.M., Cade, R., and Luo, X. 2012. Eagle Ford Shale: Hydraulic Fracturing, Completion, and Production Trends: Part Ii. Paper presented at the SPE Annual Technical Conference and Exhibition, San Antonio, Texas, USA. Society of Petroleum Engineers SPE-158501-MS. DOI: 10.2118/158501-ms.

Cheng, Y., Wang, Y., McVay, D. et al. 2010. Practical Application of a Probabilistic Approach to Estimate Reserves Using Production Decline Data. 2 (1): pp. 19-31. DOI: 10.2118/95974-pa.

CMG (Computer Modeling Group). 2013. CMG suite, http://www.cmgl.ca/

Dobson, M.L., Lupardus, P.D., Divine, T. et al. 2011. A Practical Solution to Describe the Proved Area within a Resource Play Using Probabilistic Methods. Paper presented at the SPE Production and Operations Symposium, Oklahoma City, Oklahoma, USA. Society of Petroleum Engineers SPE-142319-MS. DOI: $10.2118 / 142319-\mathrm{ms}$.

Donovan A. D. and Staerker T. S. 2010. Sequence Stratigraphy of the Eagle Ford (Boquillas) Formation in the Subsurface of South Texas and Outcrops of West Texas: Gulf Coast Association of Geological Societies Transactions v.60, p. 861899.

Dong, Z., Holditch, S.A., and McVay, D.A. 2012. Resource Evaluation for Shale Gas Reservoirs. Paper presented at the SPE Hydraulic Fracturing Technology 
Conference, The Woodlands, Texas, USA. Society of Petroleum Engineers SPE152066-MS. DOI: 10.2118/152066-ms.

Dossary, M. and McVay, D.A. 2012. The Value of Assessing Uncertainty. Paper presented at the SPE Annual Technical Conference and Exhibition, San Antonio, Texas, USA. Society of Petroleum Engineers SPE-160189-MS. DOI: 10.2118/160189-ms.

Duong, A.N. 2011. Rate-Decline Analysis for Fracture-Dominated Shale Reservoirs. SPE Reservoir Evaluation \& Engineering 14 (3). DOI: 10.2118/137748-pa

Dizard, J. 2010. Debate over Shale Gas Decline Fires Up. Financial Times. http://www.ft.com/cms/s/0/705f4cf0-d307-11df-9ae9-00144feabdc0.html \#axzz2ZB5QXLtK

Drillinginfo. 1998-2011. DI Desktop, http://www.hpdi.com/.

Drillinginfo. 2013. Drillinginfo.com, http://www.drillinginfo.com/.

EIA. 2010. Eagle Ford Shale Play, Western Gulf Basin, South Texas, Map retreived June 2010.

http://www.eia.gov/oil_gas/rpd/shaleusa9.pdf.

EIA. 2011. Review of Emerging Resources: U.S. Shale Gas and Shale Oil Plays. U.S. Department of Energy, Washington, DC 20585.

Edman J. D. and Pitman J. K. 2010. Geochemistry of Eagle Ford Group Source Rocks and Oils from the First Shot Field Area, Texas: Gulf Coast Association of Geological Societies Transactions v.60, p. 217-234. 
Fan, L., Martin, R.B., Thompson, J.W. et al. 2011. An Integrated Approach for Understanding Oil and Gas Reserves Potential in Eagle Ford Shale Formation. Paper presented at the Canadian Unconventional Resources Conference, Alberta, Canada. Society of Petroleum Engineers SPE-148751-MS. DOI: 10.2118/148751-ms.

Honarpour, M.M., Arasteh, N.R.N.A.O.F., and Yao, Z. 2012. Characterization of Critical Fluid Pvt, Rock, and Rock-Fluid Properties - Impact on Reservoir Performance of Liquid Rich Shales. Paper presented at the SPE Annual Technical Conference and Exhibition, San Antonio, Texas, USA. Society of Petroleum Engineers.

Ilk, D., Rushing, J.A., Perego, A.D. et al. 2008. Exponential Vs. Hyperbolic Decline in Tight Gas Sand: "Understanding the Origin and Implications for Reserve Estimates Using Arps' Decline Curves.” Paper presented at the SPE Annual Technical Conference and Exhibition, Denver, Colorado, USA. Society of Petroleum Engineers 116731. DOI: 10.2118/116731-ms.

Jochen, V.A. and Spivey, J.P. 1996. Probabilistic Reserves Estimation Using Decline Curve Analysis with the Bootstrap Method. Paper presented at the SPE Annual Technical Conference and Exhibition, Denver, Colorado. 1996 Copyright 1996, Society of Petroleum Engineers, Inc. 36633-MS.

Joshi, K. and Lee, W. 2013. Comparison of Various Deterministic Forecasting Techniques in Shale Gas Reservoirs. Paper presented at the 2013 SPE Hydraulic 
Fracturing Technology Conference, The Woodlands, Texas, USA. Society of Petroleum Engineers SPE-163870-MS. DOI: 10.2118/163870-ms.

Lee, W.J. and Sidle, R. 2010. Gas-Reserves Estimation in Resource Plays. SPE

Economics \& Management 2: 86-91. DOI: 10.2118/130102-pa.

Mattar, L. 2008. Production Analysis and Forecasting of Shale Gas Reservoirs: Case History-Based Approach. Paper presented at the SPE Shale Gas Production Conference, Fort Worth, Texas, USA. SPE 119897-ms. DOI: 10.2118/119897ms.

McCain, W. 2009. Reservoir Engineering. Lecture notes on five types of reservoir fluid. Petroleum engineering department at Texas A\&M University. College Station, Texas.

McKinney, P.D., Rushing, J.A., and Sanders, L.A. 2002. Applied Reservoir Characterization for Maximizing Reserve Growth and Profitability in Tight Gas Sands: A Paradigm Shift in Development Strategies for Low-Permeability Gas Reservoirs. Paper presented at the SPE Gas Technology Symposium, Calgary, Alberta, Canada. Copyright 2002, Society of Petroleum Engineers Inc. 00075708. DOI: 10.2118/75708-ms.

Petroleum Experts. 2013. PROSPER, IPM suite version 8.0, http://www.petex.com/ Pope, C.D., Palisch, T., and Saldungaray, P. 2012. Improving Completion and Stimulation Effectiveness in Unconventional Reservoirs- Field Results in the Eagle Ford Shale of North America. Paper presented at the SPE/EAGE European 
Unconventional Resources Conference and Exhibition, Vienna, Austria. Society of Petroleum Engineers SPE-152839-MS. DOI: 10.2118/152839-ms.

Railroad Commission of Texas. 2013. Eagle Ford Information.

https://www.rrc.state.tx.us/eagleford/

SEC. 2009. Modernization of Oil and Gas Reporting.

http://www.sec.gov/rules/final/2008/33-8995.pdf

SPE, AAPG, WPC et al. 2007. Petroleum Resources Management System.

http://www.spe.org/industry/docs/Petroleum_Resources_Management_System_2

007.pdf

Tian, Y., Ayers, W., and McCain, W. 2013. The Eagle Ford Shale Play, South Texas:

Regional Variations in Fluid Types, Hydrocarbon Production and Reservoir

Properties. Paper presented at the 6th International Petroleum Technology

Conference, Beijing, China. 2013, International Petroleum Technology

Conference IPTC-16808-MS. DOI: 10.2523/16808-ms.

Valko, P.P. and Lee, W.J. 2010. A Better Way to Forecast Production from

Unconventional Gas Wells. Paper presented at the SPE Annual Technical

Conference and Exhibition, Florence, Italy. Society of Petroleum Engineers

134231. DOI: $10.2118 / 134231-\mathrm{ms}$. 